\title{
Early integrated palliative care in the acute care setting
}

Citation for published version (APA):

Fliedner, M. C. (2021). Early integrated palliative care in the acute care setting: impact on patients and nurses' roles and responsibilities. [Doctoral Thesis, Maastricht University]. Ridderprint. https://doi.org/10.26481/dis.20211122mf

Document status and date:

Published: 01/01/2021

DOI:

10.26481/dis.20211122mf

Document Version:

Publisher's PDF, also known as Version of record

\section{Please check the document version of this publication:}

- A submitted manuscript is the version of the article upon submission and before peer-review. There can be important differences between the submitted version and the official published version of record.

People interested in the research are advised to contact the author for the final version of the publication, or visit the DOI to the publisher's website.

- The final author version and the galley proof are versions of the publication after peer review.

- The final published version features the final layout of the paper including the volume, issue and page numbers.

Link to publication

\footnotetext{
General rights rights.

- You may freely distribute the URL identifying the publication in the public portal. please follow below link for the End User Agreement:

www.umlib.nl/taverne-license

Take down policy

If you believe that this document breaches copyright please contact us at:

repository@maastrichtuniversity.nl

providing details and we will investigate your claim.
}

Copyright and moral rights for the publications made accessible in the public portal are retained by the authors and/or other copyright owners and it is a condition of accessing publications that users recognise and abide by the legal requirements associated with these

- Users may download and print one copy of any publication from the public portal for the purpose of private study or research.

- You may not further distribute the material or use it for any profit-making activity or commercial gain

If the publication is distributed under the terms of Article $25 \mathrm{fa}$ of the Dutch Copyright Act, indicated by the "Taverne" license above, 


\section{EARLY INTEGRATED PALLIATIVE CARE IN THE ACUTE CARESETTING IMPACT ON PATIENTS AND NURSES' ROLES AND RESPONSIBILITIES}
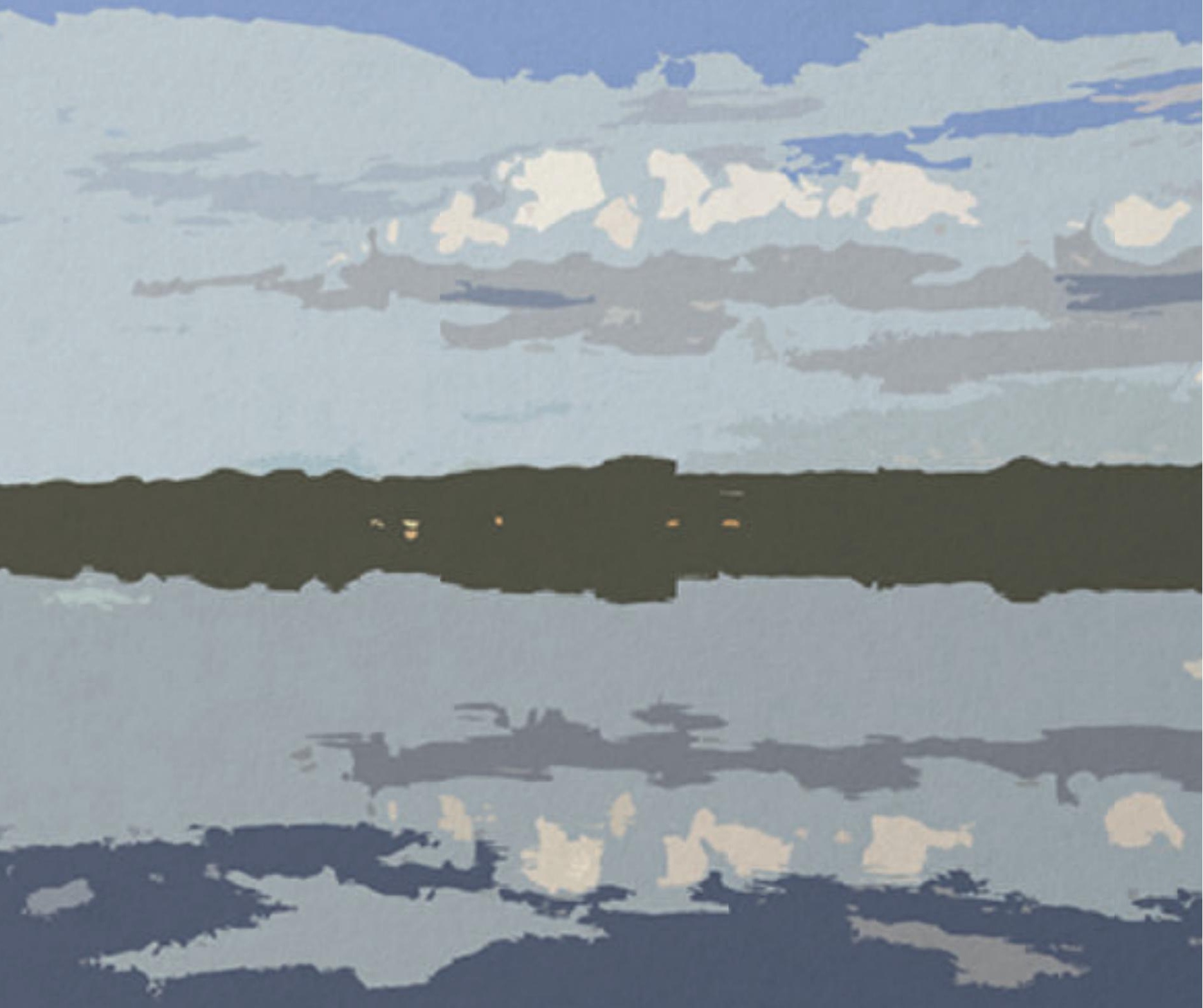

Monika C. Fliedner 



\section{Early Integrated Palliative Care in the Acute Care Setting}

- Impact on Patients and Nurses' Roles and Responsibilities

Monika Caroline Fliedner

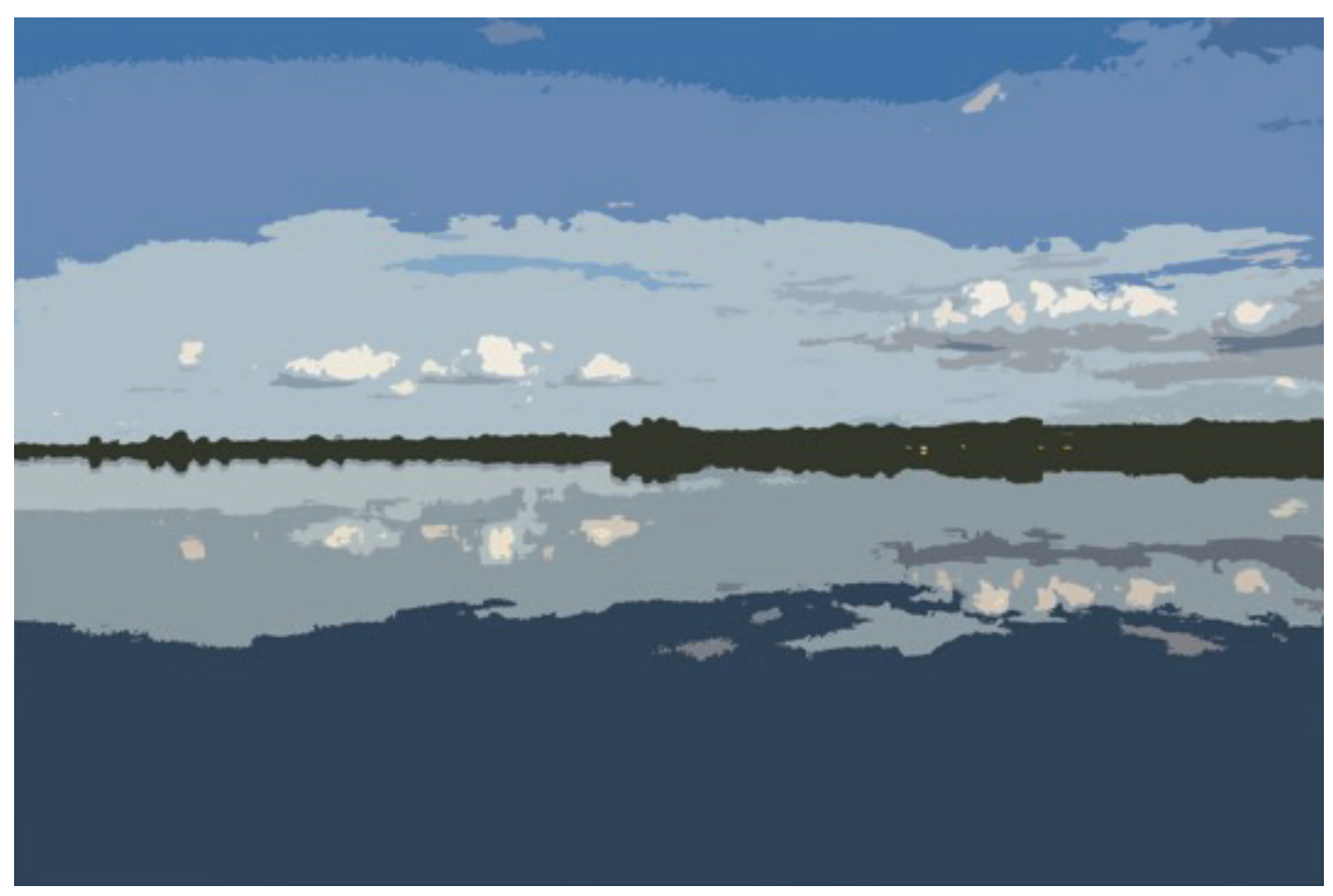

Chobe River, Botswana 2010 M.Fliedner $\odot$ 
The research presented in this thesis was conducted at Care and Public Health Research Institute (CAPHRI), Department of Health Services Research (HSR) of Maastricht University in collaboration with the University Hospital Bern, Inselspital.

The study in chapter 4 of this thesis was financially supported by the Swiss National Funds within the NFP 67 project. The funders did not have any influence on the data collection, data analysis, or data interpretation (Grant/ Award Number: “145088 (NRP 67)”)

Copyright @ Monika C. Fliedner, Maastricht, 2021

All rights reserved. No part of this thesis may be reproduced or transmitted in any form or by any means, electronic or mechanical, including photocopying, recoding on any information storage or retrieval system without permission from the author, or when appropriate, from the publisher of the publications.

ISBN:

978-94-6416-417-6

Cover image:

Chobe River, Botswana 2010 by M.Fliedner

Cover design \& lay-out:

Publiss | www.publiss.nl

Printing:

Ridderprint | www.ridderprint.nl 


\title{
Early integrated Palliative Care in the Acute Care Setting - Impact on Patients and Nurses' Roles and Responsibilities
}

\author{
DISSERTATION \\ to obtain the degree of Doctor at Maastricht University, \\ on the authority of the Rector Magnificus, Prof. Dr. Rianne M. Letschert \\ in accordance with the decision of the Board of Deans, \\ to be defended in public \\ on Monday $22^{\text {nd }}$ of November 2021, at 13.00 hours \\ by
}

Monika Caroline Fliedner 


\section{Supervisors}

Prof. Dr. J.M.G.A. Schols

Prof. Dr. S. Eychmüller (University of Bern)

Prof. Dr. C. Lohrmann (Medical University of Graz)

\section{Co-Supervisor}

Dr. R.J.G. Halfens

\section{Assessment committee}

Prof. Dr. S. Zwakhalen (chair)

Dr. J.M.M. Meijers

Prof. Dr. M.H.J. van den Beuken - van Everdingen

Prof. Dr. N.J.A. van den Noortgate (University Hospital Gent)

Prof. Dr. P. Larkin (University of Lausanne) 


\section{Contents}

Chapter 1 General Introduction 7

Chapter 2 Development and Use of the 'SENS'-Structure to Proactively Identify Care Needs in Early Palliative Care - An Innovative Approach

Chapter 3 The impact of early palliative care on the quality of care during the last days of life: what does the evidence say?

Chapter 4 An early palliative care intervention can be 75 confronting but reassuring: A qualitative study on the experiences of patients with advanced cancer

Chapter 5 Roles and responsibilities of nurses in advance care planning in palliative care in the acute care setting a scoping review

Chapter 6 Does Time for (in)Direct Nursing Care Activities at the End of Life for Patients With or Without Specialized Palliative Care in a University Hospital Differ? A Retrospective Analysis

Chapter 7 Case study: Concurrent palliative care based on 151 SENS- structure for patients with advanced prostate cancer

Chapter 8 General Discussion

Chapter 9 Impact

Summary 205

$\begin{array}{ll}\text { Samenvatting } & 215\end{array}$

$\begin{array}{ll}\text { Acknowledgements } & 227\end{array}$

About the author $\quad 235$

Publications 


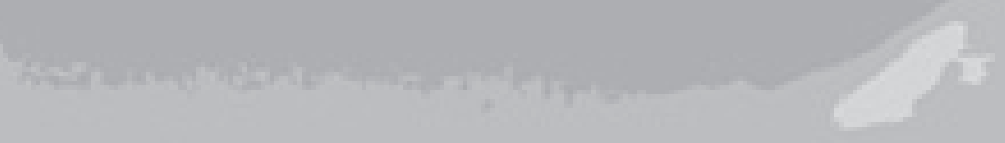

\section{Chas}
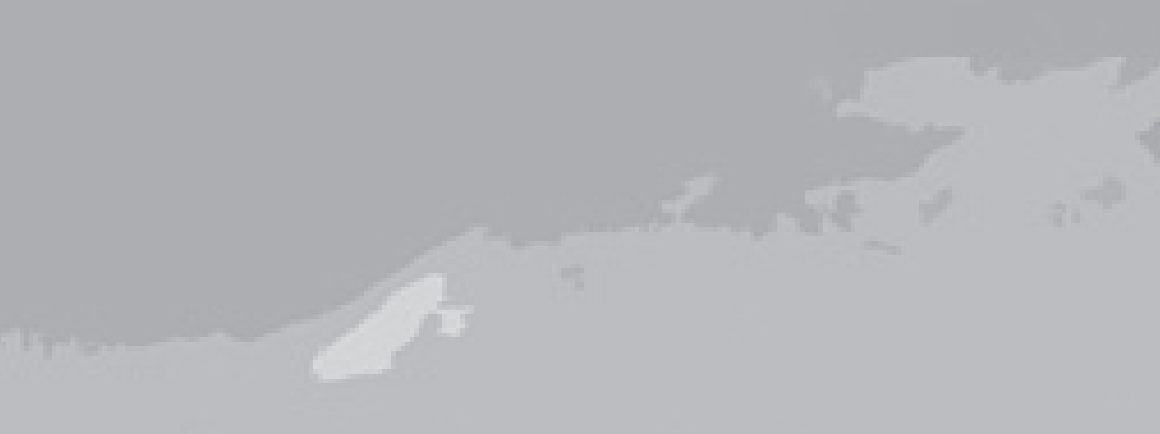

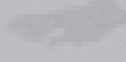

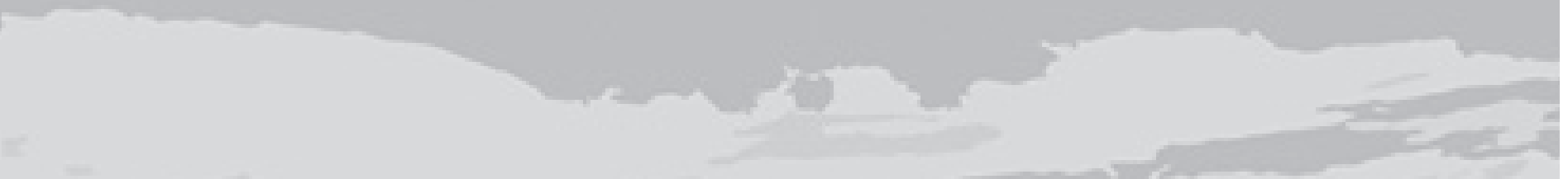

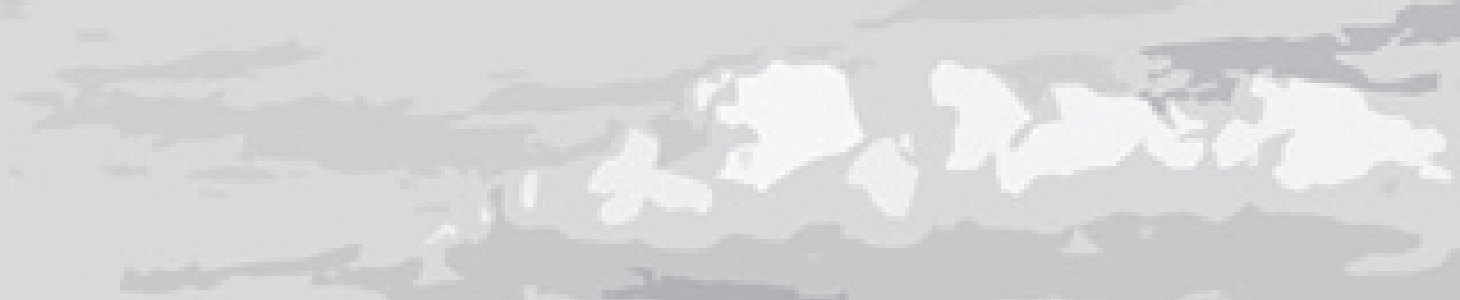

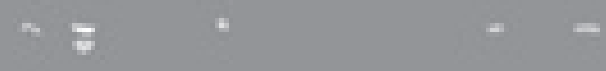

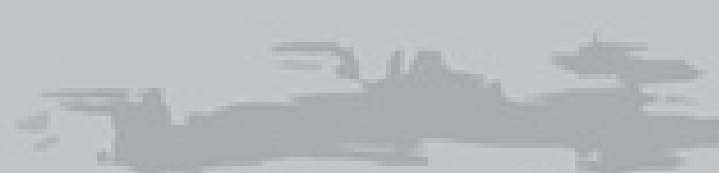

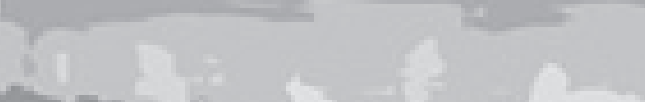

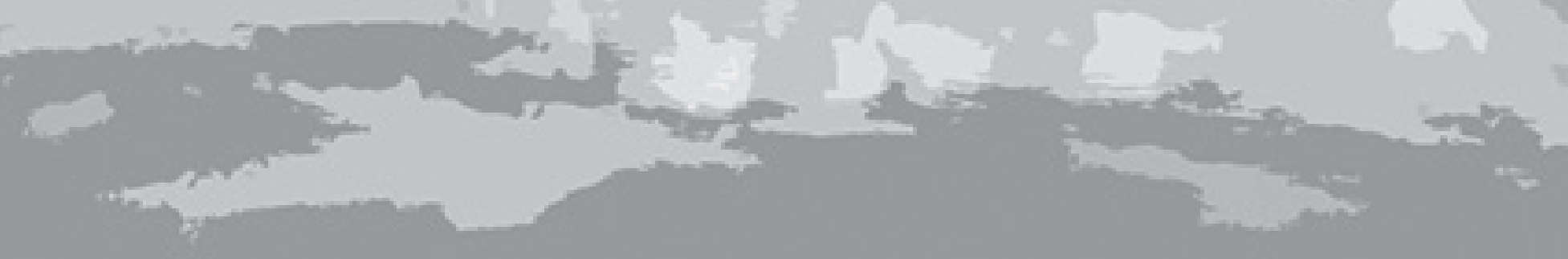


Chapter 1

General Introduction 


\section{Mr. T - An exemplary Clinical Case Report}

The following is a fictitious case study. It is used as an example of clinical nursing practice in the acute care setting of a hospital, in which staff nurses realized the concerns of a patient with advanced cancer. Despite these concerns he was not offered palliative care, including an advance care planning conversation, early in the trajectory of his life-limiting disease nor was specialized palliative care involved when the situation became more complex towards end of life.

Mr. T, aged 64, was diagnosed with prostate cancer in 1997, for which he underwent a prostatectomy. In 2018, he developed lymphogenic, hepatic and lung metastases. For the latter, he received radio-surgery and chemotherapy. Six months later he was hospitalized for a pathological fracture due to bone metastases, which were treated with radiotherapy. Mr. T was married and had no children. He wanted to live as long as possible at home. His wife was overwhelmed with everything that needed to be discussed, decided and organized prior to discharge, besides her fulltime job.

Up to now, the focus was mainly on treating Mr. T's tumor. None of his personal uncertainties and concerns (e.g. work and social life, and spiritual concerns) or his fear of dying were addressed in depth by healthcare professionals. The interprofessional team had not yet discussed, whether the involvement of palliative care (PC) early in his disease trajectory would make any difference for his last phase of life, which is why the specialized PC team was not involved in this early phase. Despite his hope for the best, Mr. T was worried that he would suffer from pain, fatigue and social isolation. Mr. T was hesitant to discuss decisions such as resuscitation with his wife and healthcare professionals. He did not know how his wife would be able to cope with his deterioration and decisions.

Based on their general knowledge about PC, staff nurses (RN, undergraduate level) realized the presence of Mr. T's personal worries as well as his concerns about the future, but a clear structure to identify his PC needs was lacking. Staff nurses were not sure whether it was their responsibility to raise issues around the question "what shall we do in case of...". They believed that they did not have adequate training to raise the issue of proactively starting a conversation with Mr. T about his wishes and concerns. In addition, staff nurses did not know, which topics they should discuss with Mr. T and his wife. They discussed, if a nurse on advanced practice nurse level (APRN, graduate level) with specialized 
PC knowledge and expertise would be more appropriate and qualified to have these conversations. Furthermore, they wondered what it would mean in terms of their workload (positively or negatively) if the specialized PC team became involved to support the treating team along Mr. T.'s disease trajectory.

Although Mr. T's cancer stage was no longer amenable to curative treatments, the oncologist felt that it was too early to discuss end-of-life questions with the patient. Moreover, the oncologist was not familiar with a pragmatic structure for PC needs assessment such as "SENS" (Symptoms, End-of-life decisions, Network, Support for the carers) to discuss future care and treatment options. On the other hand, staff nurses believed they did not have enough experience to estimate how Mr. T would perceive a conversation about end-of-life issues and how to deal with his and his wife's' reaction.

Mr. T was discharged as soon as he was physically stable, without being in contact with the specialized PC team. The couple managed the situation for about four weeks, when Mr. T's physical condition deteriorated. Mr. T visited the emergency unit again for severe bone pain. His situation quickly became more complex and unstable: he was suffering from severe pain, immobility, fatigue, dyspnea, loss of appetite, and other symptoms that were leading to the impression that Mr. T's death was approaching. Staff nurses felt that if the specialized PC team became involved in situations like this, Mr. T and his wife could very well benefit from their expertise.

Ideally, integration of a specialized PC team early in the course of a lifelimiting disease would allow nurses to achieve a high level of care without feeling overwhelmed by tasks that may not reflect their daily clinical focus. For Mr. T and his wife, such an approach would probably have meant a better quality of care combined with adequate disease modifying treatment and a patient-centered care approach with the best possible quality of life until the end and beyond for Mr. T's wife during bereavement. The specialized PC team could support the interprofessional team and specifically the nurses by leading difficult conversations, including talking about inevitable death, managing challenging symptoms and coordinating complex care not only for the patient, but also for the family/loved ones. 


\subsection{Introduction and issues derived from the case report}

In the course of an advanced, refractory or progressive disease, the medical intention of cure eventually shifts to a palliative care (PC) approach. Palliative care is offered: a) when treatment will not change the course of the disease, b) to relieve and manage symptoms, and c) to deal with personal situations that may interfere with the individuals' quality of life. ${ }^{1}$ Palliative care is a person-centered holistic approach, which assesses and manages physical, psychological, social and spiritual well-being and aims to decrease suffering, maintain autonomy and dignity, and increase quality of life of patients and their families including the bereavement phase..$^{2,3}$

Patients with a life-limiting disease in the acute care setting often show signs of a serious, sometimes complex and unstable, medical condition, in which individually tailored care is necessary. The case report demonstrates that patients with a life-limiting disease such as cancer are frequently uncertain about their future but hesitate to ask healthcare professionals for advice because it might be too difficult to cope with the finiteness of life. This makes patients in the last months of life vulnerable ${ }^{4}$, especially in moments of significant changes and/or progression of their disease status, or serious alterations to their cultural (e.g. within their community) or social (e.g. family) relationships. ${ }^{5}$

Palliative care is preferably provided by an interprofessional team of healthcare professionals usually from a variety of medical disciplines. ${ }^{6,7}$ The American Society of Clinical Oncology (ASCO) ${ }^{6}$ recommends that all patients “... with advanced cancer should receive dedicated PC services, [started] early in the disease course, concurrent with active treatment" (p. 96). In the context of a cancer disease, early integration of PC means that PC services commence at a time, such as within 8 weeks of diagnosis of disease progression, or when the disease is defined as no longer amenable to curative treatment. Depending on the disease trajectory and its symptoms, studies suggest that PC services should be included when life expectancy ranges between 3 to 24 months. 8 .9 Palliative care includes the comprehensive discussion of future treatment and care issues which is often referred to as advance care planning (ACP) $)^{10-12}$ or discussion of goals of care. ${ }^{13}$

A focus of PC and end-of-life research in the past decade has been on the impact of the early integration of PC (EPC) on the quality of life (QOL) of patients with a life-limiting disease. Trials found evidence to show that 
patients receiving early integrated PC experienced a better quality of life, ${ }^{14-18}$ improved management of symptoms, and a better psychosocial support. ${ }^{15,16}$ Early integrated PC optimizes timing of treatment, eases potential transition to hospice services ${ }^{19}$ and reduces health care costs. ${ }^{20-22}$ How this early integration of PC affects other outcomes, such as the dying phase of patients, requires further research and understanding.

The case report shows that staff nurses as part of the interprofessional team can be uncertain about their role in conversations with patients in the early phase of PC and discussing patients' concerns and worries. Nurses believe that they do not know which topics should be discussed in more detail with the patient nor do they have a clear structure for these conversations. This is supported by the literature, which found that staff nurses often feel that they do not have enough confidence, competences and knowledge to raise these issues. ${ }^{23,24}$ Moreover, research in PC as an area of general competencies, and the awareness about the specific role and contribution of nurses in this field, is still scarce. Therefore, this thesis focuses specifically on the nursing profession in the acute care setting of a hospital.

A major challenge, also demonstrated in the case report, is to find a structure for PC needs assessment and conversations of goals, as well as discussions about an agreed upon care plan between healthcare professionals and patients, including their families, without overburdening them. ${ }^{25}$ Several structures in PC practice are currently used to assess the needs and help to focus on patients' goals and wishes. These structures include, but are not limited to: a) the physical, psychological, social and spiritual suffering as defined by the World Health Organization $\left.(\mathrm{WHO})^{2}, \mathrm{~b}\right)$ the listing of $\mathrm{PC}$ needs in the National Comprehensive Cancer Network (NCCN) Guidelines ${ }^{26}$ and c) the "PEPSI-COLA"- structure within the National Gold Standards Framework (GCF). ${ }^{27,28}$ All these structures aim at differentiating the often complex needs of patients into smaller manageable parts. It is largely unknown how these structures were developed and whether they were based on clinical experiences involving patients or rather on research projects exploring the PC needs of patients.

This thesis will address and evaluate various aspects that often do not go well in regards to early integrated palliative care, as demonstrated in the fictitious case report of a cancer patient as an example, and will identify ways how these could and should be handled better. This introductory chapter discusses relevant definitions and underlying concepts, after which the various aspects covered in this thesis will be outlined. 


\subsection{Definitions and concepts in palliative care}

\subsubsection{Early integrated Palliative Care in relation to End-of-life Care}

As illustrated in the case report, in which the patient with cancer did not receive early integrated PC, a lack of clarity emerged about his wishes related to treatment and care at the end of his life. In addition, Advance Care Planning as part of early integrated PC was not discussed. If PC is integrated early in the acute care trajectory of patients with a life-limiting disease, healthcare professionals need to understand the impact it will have on patients' end-of-life care.

Palliative care includes care for the person nearing death and should be integrated early at diagnosis of a life-limiting disease until the end-of-life phase. ${ }^{29}$ It includes the support of the family throughout patients' disease trajectory and extends to the bereavement phase. This approach is suitable and mostly accepted for adult patients with any life-limiting disease in the acute care setting such as patients with advanced cancer ${ }^{15,16,30-32}$, patients with advanced chronic kidney disease contemplating dialysis ${ }^{33}$, patients on hemodialysis with severe co-morbidities ${ }^{34}$, patients with amyotrophic lateral sclerosis ${ }^{35,36}$, as well as patients with advanced / chronic lung or heart diseases ${ }^{8,37}$ including COPD ${ }^{38-40}$, or patients with dementia ${ }^{41}$. Palliative care involves a close collaboration between all medical specialties (e.g. oncology, nephrology, cardiology, geriatrics, anesthesia) and professions (e.g. physicians, nurses, social workers, psychologists, physiotherapists, dieticians) involved in the care of the person in question. ${ }^{42,43}$

In the context of this thesis, the timeframe of early integrated palliative care (EPC) is defined as offering PC as early as possible in the course of any life-limiting disease. ${ }^{44}$ Different terms and concepts are used to describe what EPC parallel to any disease modifying treatment approach such as "concurrent care" $^{\text {"45-47 }}$ or "early integrated Palliative Care" $30,48,49$ entails. EPC can or should be applied concurrently to diagnosis-modifying treatments. ${ }^{8,47,50-53}$ Its onset is usually based on disease-related triggers such as the underlying disease (e.g. advanced cancer no longer amenable to curative treatment approach).

Integrating PC early in the disease trajectory may include the following: a) building a trusting relationship with the patient; b) assessing potential or current 
symptoms; c) discussing lifestyle and coping strategies including spirituality; d) promoting a realistic understanding of patients' disease and related expectations; e) discussing and deciding treatment options; f) discussing end of life concerns and wishes of care; and g) involving and supporting patients' family in the process. ${ }^{9,54}$ Therefore, in addition to clinical patient care, it includes, but is not limited to, a proactive advance care planning (ACP) (chapter 1.2.2).

Despite efforts to address PC early in the trajectory of a life-limiting disease in the acute care setting, it is still not routinely integrated ${ }^{55-57}$ and some medical specialists scarcely transfer this responsibility explicitly to other professions such as nurses. ${ }^{58}$ This may be due to the complex nature or unpredictability of a life-limiting disease ${ }^{59,60}$, as well as specialists misconception that PC is only about end-of-life ${ }^{61}$ and therefore an uncertainty about when (and how) to commence PC. As a quality indicator and to prolong cancer patients' survival, the American National Comprehensive Cancer Network (NCCN) provides advice to consult, integrate and/or collaborate early with a specialized PC team. ${ }^{62}$

Although it has changed over the years, hesitations to integrate PC early in the disease trajectory might still be contributed to the fact that PC is often considered by healthcare professionals as care provided primarily at the end of life. ${ }^{63-65}$ Patients might associate PC with end-of-life care and a system of reduced care, in which many treatment modalities are no longer an option. ${ }^{66}$ Being an important part of PC, end-of-life care is usually referred to as the care provided to patients in the last or terminal phase of life until death. It is also referred to as hospice care. There is no consensus-based definition for how long this care could last, but it can encompass up to the last 6 months ${ }^{29}$ before death, when the disease is progressive and patients' overall situation is deteriorating and he is nearing death. The last phase of life is often characterized by an increasing symptom load and care dependency, which could develop into a complete inability to perform self-care activities of daily living. ${ }^{67-69}$ Therefore, care activities mainly intend to provide comfort and relieve suffering, while avoiding futile and invasive diagnostics or interventions that prevent a peaceful death. ${ }^{70}$ The focus during this phase is therefore on minimizing distress and dying with dignity. ${ }^{29,69}$ 


\subsubsection{Advance Care Planning as one part of Early integrated Palliative Care}

In relation to the case report, although the stage of Mr. T's cancer was no longer amenable to curative treatment, and the patient raised concerns about his future, the oncologist felt that it was too early for the patient to get involved in questions around treatment and care decisions including ACP conversations. The question "what shall we do in case of..." was not thoroughly discussed by the oncologist.

Early integrated PC into chronic life-limiting disease trajectories necessitates the timely definition of a treatment and care plan. An essential part of EPC is engaging early in the ACP discussions taking into consideration a holistic assessment about patients' physical, psychological, social, and spiritual well-being. ${ }^{71}$ Advance Care Planning can be defined as a process that helps to make sure that patients "... receive medical care that is consistent with their values, goals and preferences during serious and chronic illness."12(p.826) There still exists ambiguity about the terms that are used for the ongoing process of planning and decision making for future treatment and care between patients and healthcare professionals as one part of EPC. The literature uses both terms "goals of care" (GOC) or "advance care planning" (ACP) to cover what is meant by discussing what is most important for patients with a life-limiting disease towards healthcare decision making. This interrelation between the two terms can often be found in the literature on tools for and outcomes of decisive discussion with patients about the question "what to do if...". ${ }^{72}$ Conversations about GOC are often regarded as discussing and aligning treatment and care decisions in an actual clinical situation. ${ }^{73}$ The discussion should be based on patients' values and beliefs that might impact the decision towards future treatment and care ${ }^{74}$ and may be revisited as the patient's health and care situation changes. ${ }^{12,75}$

In this thesis the author refers to the process of ACP that supports and enables patients at any age or stage of health in understanding and sharing their personal values, life goals, and preferences regarding well-considered future treatment and care wishes. ${ }^{12,76,77}$ Clinically, ACP is designated to anticipate potential complications and to agree on individually adapted therapeutic actions including but not limited to withdrawal of resuscitation, medication/ interventions independent on the state of consciousness. The conversation on these issues can be decisive for patients, family carers and 
health care professionals. Thus, the outcome of an ACP conversation can be a) an advance directive, Physician Order for Life-Sustaining Treatment (POLST) or Medical Orders for Life-Sustaining Treatment (MOLST) ${ }^{78}$ which can be useful for surrogates and healthcare professionals in case the patient loses his/her decision-making capacity ${ }^{12,79}$ and b) an anticipatory care plan including what to do in emergency situations. Advance care planning can therefore be summarized as a process of structuring complex treatment and care decisions and situations into components that can be worked on one by one and offering pragmatic support to the patient along the way.

\subsubsection{Palliative Care in the Acute Care Setting}

Patients may receive PC in all settings: hospitals, home care, long term care facilities and / or assisted living facilities (e.g., nursing homes, facilities for handicapped individuals), hospices or other settings. ${ }^{80}$ Patients with a chronic life-limiting disease may move for short or long periods of time between the hospital and their home to receive acute care. This may require at certain times hospital-based treatment and care. In the acute care setting, effectiveness largely depends on time-sensitive and, frequently, rapid interventions.

Based on the WHO definition of acute care ${ }^{81}$, this thesis focuses on hospitalbased PC as the acute care setting, where acute general and specialized PC services are offered at any given time throughout the trajectory of a life-limiting disease. The primary purpose of hospital-based PC is to stabilize complex situations, improve symptoms and provide the best possible quality of care for patients. ${ }^{80}$

\subsubsection{Person-Centered Care in Palliative Care}

In the past decades, the focus of nursing has moved from being task-oriented towards a person-centered care approach. ${ }^{82-84}$ Person-centered care - especially with patients with multiple morbidities or a chronic disease - has become an essential pillar of PC. ${ }^{85,86}$ Next to the awareness of the physical, psychological, social and spiritual well-being of patients, the priority of respecting their choices, desires, and needs has become central to nursing care on undergraduate (staff or RN) and advanced level (APRN). This also includes the awareness of the cultural background of the patient. ${ }^{87}$ As part of person-centered care, RNs and APRNs have learned how to be present with the patient and the family by actively listening to their wishes and concerns. 
Person-centered care can be used to structure PC conversations taking into consideration patients' values, beliefs, personal characteristics, resources and inner feelings towards relevant decisions in regard to palliative and end-of-life care. ${ }^{88}$ This approach also involves the harmonization of care and treatment activities with the continuously changing situation while respecting patients' autonomy and dignity. ${ }^{82,89}$ Person-centered care has been used in several studies in connection with early integrated PC. 14,86,90,91

\subsubsection{General and Specialized Palliative Care}

Overall, general and specialized PC are approaches, which aim at achieving a better quality of life for patients within the physical, psychological, social and spiritual domains when cure is no longer an option. ${ }^{92}$ They require a problemsolving and typically interprofessional approach, focusing on supporting the patient and his/her family ${ }^{92}$ in coping with the situation.

Not all patients with a life-limiting disease need specialized PC., ${ }^{2,93}$ Core concepts of general PC, as previously described and defined by the World Health Organization (WHO) and the European Association of Palliative Care (EACP), should be an integral part of care for patients with a life-limiting disease provided by all healthcare professionals with basic PC knowledge. ${ }^{94-97}$ It includes, but is not limited to, decision-making conversations with patients and suitable pharmacological and non-pharmacological interventions to control symptoms. ${ }^{97}$

In complex and unstable situations, such as a high or uncontrolled symptom burden often needing clinical attention, multimorbidity, or multifaceted psychological and/or social issues, specialized PC is provided by a specifically trained interprofessional PC team with appropriate resources.93,97 This team focuses on supporting the primary team, including completing an often complex assessment of symptoms (e.g., unrelenting or total pain, persistent nausea and vomiting, the wish to die or existential distress), managing symptoms insufficiently controlled by previous interventions, or assisting with difficulties in communication about therapeutic or care decisions. ${ }^{97-99}$ This thesis focuses on general as well as specialized PC. 


\subsection{Guiding Structures for Assessment, Planning and Management in Palliative Care including Advance Care Planning}

The case report suggests that a supporting or guiding structure could facilitate conversations in clinical practice to comprehensively assess complex situations, define priorities and plan appropriate treatment and care interventions. In the case report the team was not sure how to assess the needs and concerns of Mr. $T$, which structure could be useful in the conversation and how this could be clinically used in a pragmatic way. To better understand one specific structure, the SENS-structure, its background and how to facilitate implementation into clinical practice need to be explained in more detail.

Several structures can offer a basis for conversations as part of PC services to assess patients' wishes and resources for future care. Structures used in the acute care setting include but are not limited to: a) Five Wishes (agingwithdignity. $\operatorname{org})^{100,101}$, b) Respecting Choices ${ }^{\circledR}$ (respectingchoices.org) $77,101,102$, c) the Chronic Care Model which is used also in the acute care setting within the care continuum ${ }^{103-105}$, d) components for early integrated PC consultations ${ }^{106}$, e) Clinical Practice Guidelines for Quality Palliative Care in oncology ${ }^{62}$ which includes a guidance regarding anticipated disease trajectory and prognosis, f) concurrent or simultaneous care, ${ }^{14,45,107,108}$ and g) the "SENS-structure" (which stands for Symptoms, Expectations and end-of-life decisions, Network and Support of the network). ${ }^{109,110}$ These structures support the decision making process by anticipating future treatment and care options (ACP), and communicating these through e.g. an advance directive. ${ }^{111}$

Reports of how these structures were developed are still scarce. ${ }^{112-115}$ This thesis describes how the SENS-structure was developed and tested in the Swiss context. The SENS-structure can be considered as a complex intervention ${ }^{116,117}$ because a) its outcomes are based on the individual issues, needs, wishes and concerns of the patient, b) it necessitates a certain flexibility by the healthcare professional in assessing and tailoring interventions and c) it usually requires the interprofessional team to be able to manage issues in all areas of PC. 


\subsection{Perceptions of Patients receiving Palliative Care Integrated Early in the Disease Trajectory}

In relation to situations like in the case report, healthcare professionals need to understand specifically how patients perceive PC conversations and interventions based on a structure like SENS, when applied early in their disease trajectory, in which the cancer is no longer amenable to curative treatment. Additionally, it is essential to know whether patients feel that professionals start conversations about these topics too early or whether it is timewise appropriate.

If an EPC approach is recommended for and applied in clinical practice, such as in the care for patients with advanced cancer ${ }^{52}$, healthcare professionals need to understand how patients experience PC and ACP conversations to be able to anticipate any levels of distress. Healthcare professionals should understand whether the structured approach meets patients' needs and what impact it might have on their well-being.

So far, only a few studies explored patients' perception of and experience with an EPC intervention. ${ }^{118-120}$ Maloney et al ${ }^{118}$ found that patients with cancer benefited from a multicomponent telephone-based conversational intervention which enhanced their problem-solving abilities and feeling of empowerment to engage actively in their healthcare. They also felt supported and reassured by the intervention. Hannon et $\mathrm{al}^{119}$ showed that, as a result of palliative care, cancer patients felt strengthened and assisted without an increased level of distress. But still, when patients are referred to PC, they often associate the term with dying, death and cessation of active diagnosis-related treatments and is often initially a shock. $^{121}$

Despite these few early studies, little is still known about the experience of patients with advanced cancer with an EPC intervention using a structured approach. Moreover, it is essential to learn from patients, if such an approach based on the SENS-structure causes additional burden or has potential side effects, such as distress, sorrow, or anger. To improve patients' quality of care, healthcare professionals have to gain insight in the topics that are most relevant to patients. This will help them to time, prioritize and address specific areas of care in a way that patients and their family caregiver can most benefit from an EPC approach. 


\subsection{Role of Nurses as Members of the inter- professional Palliative Care Team}

As demonstrated in the case report, RNs often identify problems, concerns and needs of patients during this vulnerable phase of life. However, the appropriate role of staff nurses in supporting patients in EPC, is still poorly understood. Furthermore, there is a need to understand, whether certain topics within ACP conversations might be more suitable to be covered by nurses trained on an advanced level (APRNs), who have more experience and specialized palliative care expertise than RNs.

A close interprofessional and collaborative work relationship is necessary for nurses (RN and APRN) in PC to provide best care by identifying patients' needs and wishes and to holistically work together to support the patients and their families in physical, psychological, social and spiritual areas. ${ }^{122}$ As members of the interprofessional team, nurses play a pivotal role in taking care of patients and navigating them through difficult times both in general PC and specialized PC. ${ }^{123-125}$

Caring is an essential part of the profession of nursing on all levels - from staff to advanced practice level. A compassionate attitude guides all nursing activities in all settings and moments of care. ${ }^{126}$ Nursing care is grounded in person-centeredness, while applying knowledge and skills and being respectful toward patients as individuals. ${ }^{127-129}$ Next to providing direct physical, emotional and psychological patient care and communicating with patients, nurses are engaged in indirect care activities such as advocating for patients' wishes, organizing and coordinating care together with different healthcare professionals as well as patients and their family. ${ }^{130}$

In recent years it was suggested that nurses should or could be involved in facilitating or leading ACP conversations. Most of these ACP conversations focus on values and goals as well as non-medical and medical aspects of care and treatment options suggested and/or approved by the physician. ${ }^{79}$ Currently there is little knowledge about the specific role nurses (RNs with basic PC knowledge or APRNs with specific PC knowledge and expertise) as part of the interprofessional teamshould play, what educational background nurses should have, which topics they should discuss with patients and how this varies between countries and even differs throughout institutions. 


\subsection{Impact of Specialized compared to General Palliative Care on the Workload of Nurses providing End-of-Life Care}

In the acute care setting, when patients are in complex end-of-life situations, nurses (RNs) might be supported by a specialized PC team. As indicated in the case report, it is important to understand how much of RNs' work time is devoted to direct and indirect care activities for patients at the end of life compared to patients, who need specialized PC in a complex end-of-life situation. Thus, the authors wanted to understand the effect of a structured intervention ("SENS structure") delivered by a specialized PC team on RNs' indirect or direct work time in the acute care setting while caring for dying patients.

Nurses work time, while caring for dying patients, focuses on all areas of wellbeing by providing direct and indirect care activities. ${ }^{125,131-134}$ Direct care activities include a considerable amount of time for communication with patients and their family, assessing symptoms, and performing care procedures and appropriate symptom relief. Nursing care also necessitates indirect care activities such as dedicated work time for communication with other healthcare professionals. Among others, these activities can involve preparing care interventions and coordinating care with healthcare professionals across healthcare settings.

As illustrated in the clinical case report, the situation of a severely-ill patient can be very challenging for the primary team offering general PC. Often communication between the interprofessional team and the patient and family in the end-of-life phase is challenging. Support by a specialized PC team can or should be requested for complex situations including, but not limited to, taking over communication and coordination of care, the management of uncontrollable symptoms and the potential need of palliative sedation, multifaceted family situations with complex cultural issues or how to deal with the wish to hasten death. ${ }^{135-137}$ It is yet unknown, whether and how the support of the specialized PC team influences the direct and indirect work time of nurses providing end-of-life care. 


\subsection{Aims of the Thesis}

The main aim of this thesis is to provide knowledge regarding early integrated PC and the particular role of nurses at undergraduate and graduate level specifically in ACP as part of EPC, and highlight future directions in clinical practice, education and research. The respective aims as defined for each project are

a) to present how the so-called 'SENS'-structure (symptoms, end-of-life decisions, network, and support) was developed, to explore the clinical value and implementation of the 'SENS'-structure and its usefulness for planning, documentation, evaluation, and education in the acute clinical setting from the perspective of professionals. Moreover, its challenges and opportunities are discussed.

b) to critically appraise the existing evidence on 'early [integrated] palliative care' (EPC), discuss its relationship with advance care planning (ACP), and to reflect on the impact of EPC on the quality of care provided during the last days of life.

c) to explore advanced cancer patients' perceptions and experiences of a structured early integrated PC conversational intervention and to determine acceptability and impact on patients' lives including influencing factors.

d) to highlight and identify:

1. specific roles and responsibilities of RNs and/or APRNs involved in the ACP process in the acute care setting

2. themes related to ACP as discussed by RNs and/or APRNs

3. RNs' and/or APRNs' skills and/or educational requirements to be able to engage in or facilitate ACP conversations.

e) to assess the direct and indirect care time of nurses caring for patients who died in a tertiary hospital in Switzerland. Since nurse assistants and vocational trained nurses often work on delegation of registered nurses, the study did not differentiate between educational levels of nurses. Specifically, the aims are

1. to compare the overall time spent for direct and indirect nursing care activities for dying patients who received specialized PC intervention as compared to patients who received usual (general) PC;

2. to find out whether the time spent for direct and indirect care in the group of patients who received specialized PC changes before and after the specialized PC intervention. 
f) to illustrate the impact of the SENS-based PC intervention in which the team discusses with patients/families the management of (potential) symptoms, expectations and end-of-life decisions including ACP, evaluates patients' social network and sources to support them.

\subsection{Outline of the thesis}

To gain knowledge with a focus on patients and nurses as previously identified, this thesis includes five published studies. Figure 1 illustrates the focus of each study. Chapter 2 (development of the SENS-structure) and chapter 7 connects the focus of patients specifically with RNs and APRNs as members of the interprofessional team.

Figure 1: Focus of each chapter of this thesis

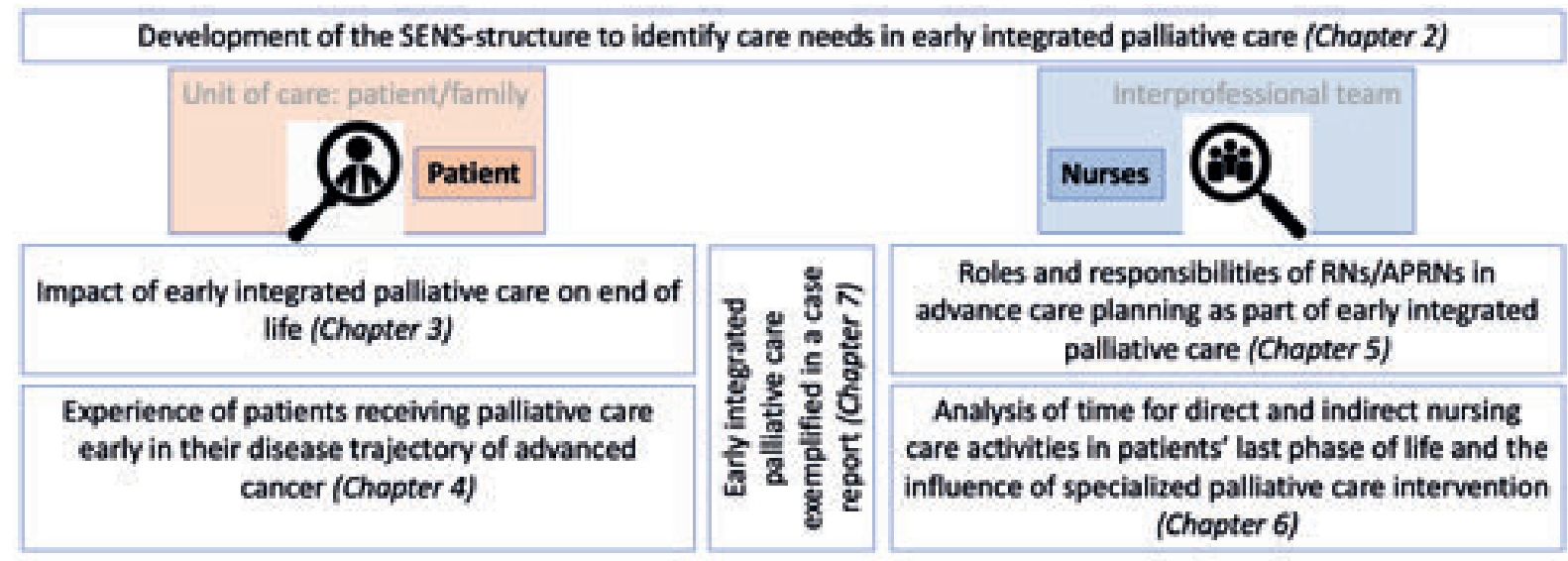

$(\mathrm{RN}=$ Registered or staff nurses; APRNs = Advanced Practice Registered Nurses $)$

The above listed aims will be addressed in the following chapters:

Chapter 2 provides information on how the SENS-structure guiding PC conversations including ACP was developed facilitating PC early in the disease trajectory of a life-limiting disease. ${ }^{88}$

Chapter 3 summarizes the effects or outcomes of EPC on patients' end of life when integrated early in the disease trajectory. ${ }^{138}$

Chapter 4 investigates how the PC intervention based the SENS-structure is perceived by patients using a qualitative content analysis of in-depth, semistructured interviews. ${ }^{139}$ 
Chapter 5 explores the roles, responsibilities and educational requirements of nurses in the early integrated PC phase incorporating advance care planning by using a scoping review approach. ${ }^{140}$

Chapter 6 explores the time that RNs use for direct and indirect nursing care activities in the final phase of life of patients who died in a hospital and how the SENS-structure influences direct and indirect nursing care time. ${ }^{61}$ For this, the electronic controlling system called $\operatorname{tacs}^{\circledR}$ (Task Analysis and Controlling System for staff resources) was used.

Chapter 7 shows the effects of a structured approach based on SENS as exemplified in a clinical case study in which the authors explained how the integration of PC could positively impact the situation of a patient and the role of nurses in this situation.

The studies in chapters 2, 4 and 6 were conducted as part of or based on the larger research project "Active preparation for the end of life with patients with advanced cancer: A way to reduce stress and increase self-determination?", which was funded by the Swiss National Science Foundation (SNF) and completed in 2018. ${ }^{141-143}$ Not considered as part of this thesis, this larger research project also included a randomized controlled trial ${ }^{141}$ as phase 3 of the Medical Research Council's (MRC) 2000 framework looking at its impact on distress and quality of life of patients with advanced cancer. Studies in chapter 3, 5 and 7 were projects in connection with the questions raised in the study funded by the SNF that were completed to find answers to clinically relevant questions on how early integrated PC affects end-of-life care and the role of nurses (RN/APRN) in this process.

Chapter $\mathbf{8}$ is the general discussion, which describes the respective results of this thesis and how they relate to the aims and the case report of the introduction. Interpretations of the findings including their strengths and limitations to generalize the knowledge in clinical practice and education are debated. Moreover, indications for daily practice and future research are given.

\subsection{Ethical considerations}

All studies comprised within this PhD project were conducted according to the Swiss national legal and regulatory requirements including the Federal Act on 
Research involving Human Beings. Studies in chapters 2 and 3 did not require ethical approval because they involved secondary data which were derived from publications.

The Medical Research Council's (MRC) 2000 framework for developing complex interventions was the underlying guide for the study in chapter 2. ${ }^{116}$ For the retrospective chart review in phase 1, ethical approval was not required because it was considered as a quality improvement project. For the survey among professionals (phase 2), the Bernese ethical committee considered this survey as not falling within the scope of the Federal Act on Research involving Human Beings.

Full ethical clearance was granted for the study in chapter 4 (interview study with patients on their perception of early integrated PC) and 6 (retrospective analysis of hospital-based data) from the responsible Swiss cantonal ethics committee. The case report in chapter 7 can be seen as an example of how the SENS-structure can be used in clinical practice and how a patient can benefit from it. It is again a fictitious case report reflecting clinical practice after implementing the SENS-structure and therefore did not need ethical approval. 


\section{References}

1. Morrow A. What Is Palliative Care 2019 [Available from: https://www.verywellhealth. com/what-is-palliative-care-1132354. Accessed 01.10.2020.

2. World Health Organization (WHO). Definition Palliative Care World Health Organization; 2002 [Available from: http://www.who.int/cancer/palliative/definition/ en/. Accessed 16.02.2014.

3. European Association for Palliative Care (EAPC), Radbruch L, Payne S, Board of Directors of the EAPC. White Paper on standards and norms for hospice and palliative care in Europe: part 2 Recommendations from the European Association for Palliative Care. European Journal of Palliative Care. 2010;17(1). doi

4. Stienstra D, Chochinov HM. Palliative care for vulnerable populations. Palliat Support Care. 2012;10(1):37-42. doi 10.1017/S1478951511000563.

5. Stienstra D, D'Aubin A, Derksen J. Heightened vulnerabilities and better care for all: disability and end-of-life care. Palliat Support Care. 2012;10(1):17-26. doi 10.1017/ S147895151100054X.

6. Ferrell BR, Temel JS, Temin S, Alesi ER, Balboni TA, Basch EM, et al. Integration of Palliative Care Into Standard Oncology Care: American Society of Clinical Oncology Clinical Practice Guideline Update. J Clin Oncol. 2017;35(1):96-112. doi 10.1200/ JCO.2016.70.1474.

7. Jones M, Thistlethwaite J. Interprofessional Practice in Palliative Care. In: MacLeod R, Van den Block L, editors. Textbook of Palliative Care. Cham: Springer; 2019.

8. Siouta N, Heylen A, Aertgeerts B, Clement P, Van Cleemput J, Janssens W, et al. Early integrated palliative care in chronic heart failure and chronic obstructive pulmonary disease: protocol of a feasibility before-after intervention study. Pilot Feasibility Stud. 2019;5:31. doi 10.1186/s40814-019-0420-y.

9. Walczak A, Butow PN, Tattersall MH, Davidson PM, Young J, Epstein RM, et al. Encouraging early discussion of life expectancy and end-of-life care: A randomised controlled trial of a nurse-led communication support program for patients and caregivers. Int J Nurs Stud. 2017;67:31-40. doi 10.1016/j.ijnurstu.2016.10.008.

10. ACPEL. The Definition of Advance Care Planning 2015 [Available from: http://www. acpelsociety.com/acpdefinition.php. Accessed 28.09.2015.

11. Rietjens JAC, Sudore RL, Connolly $M$, van Delden J, Drickamer MA, Droger $M$, et al. Definition and recommendations for advance care planning: an international consensus supported by the European Association for Palliative Care. Lancet Oncol. 2017;18(9):e543-e51. doi 10.1016/S1470-2045(17)30582-X.

12. Sudore RL, Lum HD, You JJ, Hanson LC, Meier DE, Pantilat SZ, et al. Defining Advance Care Planning for Adults: A Consensus Definition From a Multidisciplinary Delphi Panel. J Pain Symptom Manage. 2017;53(5):821-32 e1. doi 10.1016/j. jpainsymman.2016.12.331.

13. Bernacki RE, Block SD, American College of Physicians High Value Care Task F. Communication about serious illness care goals: a review and synthesis of best practices. JAMA Intern Med. 2014;174(12):1994-2003. doi 10.1001/ jamainternmed.2014.5271. 
14. Bakitas M, Lyons KD, Hegel MT, Balan S, Brokaw FC, Seville J, et al. Effects of a palliative care intervention on clinical outcomes in patients with advanced cancer: the Project ENABLE II randomized controlled trial. JAMA. 2009;302(7):741-9. doi 10.1001/jama.2009.1198.

15. Zimmermann C, Swami N, Krzyzanowska M, Hannon B, Leighl N, Oza A, et al. Early palliative care for patients with advanced cancer: a cluster-randomised controlled trial. Lancet. 2014;383(9930):1721-30. doi 10.1016/S0140-6736(13)62416-2.

16. Temel JS, Greer JA, Muzikansky A, Gallagher ER, Admane S, Jackson VA, et al. Early palliative care for patients with metastatic non-small-cell lung cancer. $N$ EnglJ Med. 2010;363(8):733-42. doi 10.1056/NEJMoa1000678.

17. Van Mechelen W, Aertgeerts B, De Ceulaer K, Thoonsen B, Vermandere M, Warmenhoven F, et al. Defining the palliative care patient: a systematic review. Palliat Med. 2013;27(3):197-208. doi 10.1177/0269216311435268.

18. Vanbutsele G, Pardon K, Van Belle S, Surmont V, De Laat M, Colman R, et al. Effect of early and systematic integration of palliative care in patients with advanced cancer: a randomised controlled trial. Lancet Oncol. 2018;19(3):394-404. doi 10.1016/S14702045(18)30060-3.

19. Amano K, Morita T, Tatara R, Katayama H, Uno T, Takagi I. Association between early palliative care referrals, inpatient hospice utilization, and aggressiveness of care at the end of life. J Palliat Med. 2015;18(3):270-3. doi 10.1089/jpm.2014.0132.

20. Zhang B, Wright AA, Huskamp HA, Nilsson ME, Maciejewski ML, Earle CC, et al. Health care costs in the last week of life: associations with end-of-life conversations. Archives of internal medicine. 2009;169(5):480-8. doi 10.1001/archinternmed.2008.587.

21. May P, Normand C, Morrison RS. Economic impact of hospital inpatient palliative care consultation: review of current evidence and directions for future research. $J$ Palliat Med. 2014;17(9):1054-63. doi 10.1089/jpm.2013.0594.

22. May P, Garrido MM, Cassel JB, Kelley AS, Meier DE, Normand C, et al. Prospective Cohort Study of Hospital Palliative Care Teams for Inpatients With Advanced Cancer: Earlier Consultation Is Associated With Larger Cost-Saving Effect. Journal of Clinical Oncology. 2015. doi 10.1200/jco.2014.60.2334.

23. Coffey A, McCarthy G, Weathers E, Friedman MI, Gallo K, Ehrenfeld M, et al. Nurses' knowledge of advance directives and perceived confidence in end-of-life care: a cross-sectional study in five countries. Int J Nurs Pract. 2016;22(3):247-57. doi 10.1111/ijn.12417.

24. Mcllfatrick S, Mawhinney A, Gilmour F. Assessing the educational needs of palliative care link nurses. Int J Palliat Nurs. 2010;16(11):555-9. doi 10.12968/ ijpn.2010.16.11.80198.

25. Biondo PD, Lee LD, Davison SN, Simon JE, Advance Care Planning Collaborative Research Innovation Opportunities Program (ACP CRIO). How healthcare systems evaluate their advance care planning initiatives: Results from a systematic review. Palliat Med. 2016;30(8):720-9. doi 10.1177/0269216316630883.

26. Levy M, Smith T, Alvarez-Perez A, Back A, Baker JN, Beck AC, et al. Palliative Care Version 1.2016. J Natl Compr Canc Netw. 2016;14(1):82-113. doi

27. National Gold Standards Framework Centre. National Gold Standards Framework 2014 [Available from: http://www.goldstandardsframework.org.uk/advance-careplanning. Accessed 16.02.2014. 
28. Shaw KL, Clifford C, Thomas K, Meehan H. Review: improving end-of-life care: a critical review of the gold standards framework in primary care. Palliat Med. 2010;24(3):317-29. doi 10.1177/0269216310362005.

29. Krau SD. The Difference Between Palliative Care and End of Life Care: More than Semantics. Nurs Clin North Am. 2016;51(3):ix-x. doi 10.1016/j.cnur.2016.07.002.

30. Temel JS, Greer JA, El-Jawahri A, Pirl WF, Park ER, Jackson VA, et al. Effects of Early Integrated Palliative Care in Patients With Lung and Gl Cancer: A Randomized Clinical Trial. J Clin Oncol. 2017;35(8):834-41. doi 10.1200/JCO.2016.70.5046.

31. Zimmermann C, Ryan S, Hannon B, Saltman A, Rodin G, Mak E, et al. Team-based outpatient early palliative care: a complex cancer intervention. BMJ Support Palliat Care. 2019. doi 10.1136/bmjspcare-2019-001903.

32. Vanbutsele G, Van Belle S, Surmont V, De Laat M, Colman R, Eecloo K, et al. The effect of early and systematic integration of palliative care in oncology on quality of life and health care use near the end of life: A randomised controlled trial. Eur J Cancer. 2020;124:186-93. doi 10.1016/j.ejca.2019.11.009.

33. Luckett T, Sellars M, Tieman J, Pollock CA, Silvester W, Butow PN, et al. Advance care planning for adults with CKD: a systematic integrative review. Am J Kidney Dis. 2014;63(5):761-70. doi 10.1053/j.ajkd.2013.12.007.

34. Weisbord SD, Carmody SS, Bruns FJ, Rotondi AJ, Cohen LM, Zeidel ML, et al. Symptom burden, quality of life, advance care planning and the potential value of palliative care in severely ill haemodialysis patients. Nephrol Dial Transplant. 2003;18(7):134552. doi

35. Karam CY, Paganoni S, Joyce N, Carter GT, Bedlack R. Palliative Care Issues in Amyotrophic Lateral Sclerosis: An Evidenced-Based Review. Am J Hosp Palliat Care. 2016;33(1):84-92. doi 10.1177/1049909114548719.

36. Sukockiene E, lancu Ferfoglia R, Boegli M, Lefranc Barranco C, Truffert A, Heritier Barras AC, et al. Early advance care planning in amyotrophic lateral sclerosis patients: results of a systematic intervention by a palliative care team in a multidisciplinary management programme - a 4-year cohort study. Swiss Med Wkly. 2021;151:w20484. doi 10.4414/smw.2021.20484.

37. Greutmann M, Tobler D, Colman JM, Greutmann-Yantiri M, Librach SL, Kovacs $\mathrm{AH}$. Facilitators of and barriers to advance care planning in adult congenital heart disease. Congenit Heart Dis. 2013;8(4):281-8. doi 10.1111/chd.12025.

38. 38. Duenk RG, Verhagen C, Bronkhorst EM, van Mierlo P, Broeders M, Collard SM, et al. Proactive palliative care for patients with COPD (PROLONG): a pragmatic cluster controlled trial. Int J Chron Obstruct Pulmon Dis. 2017;12:2795-806. doi 10.2147/ COPD.S141974.

39. Earp M, Cai P, Fong A, Blacklaws K, Pham TM, Shack L, et al. Hospital-based acute care in the last 30 days of life among patients with chronic disease that received early, late or no specialist palliative care: a retrospective cohort study of eight chronic disease groups. BMJ Open. 2021;11(3):e044196. doi 10.1136/bmjopen-2020-044196.

40. Scheerens C, Pype P, Van Cauwenberg J, Vanbutsele G, Eecloo K, Derom E, et al. Early Integrated Palliative Home Care and Standard Care for End-Stage COPD (EPIC): A Phase II Pilot RCT Testing Feasibility, Acceptability, and Effectiveness.J Pain Symptom Manage. 2020;59(2):206-24 e7. doi 10.1016/j.jpainsymman.2019.09.012.

41. Van den Block $L$. The need for integrating palliative care in ageing and dementia policies. Eur J Public Health. 2014;24(5):705-6. doi 10.1093/eurpub/cku084. 
42. Junger S, Payne S, Brearley S, Ploenes V, Radbruch L. Consensus building in palliative care: a Europe-wide delphi study on common understandings and conceptual differences. J Pain Symptom Manage. 2012;44(2):192-205. doi 10.1016/j. jpainsymman.2011.09.009.

43. LibGuides C. Medicine \& Public Health in Credo: Health Professions and Disciplines 2020 [Available from: https://credoreference.libguides.com/c. php?g=139793\&p=915300. Accessed 24.09.2020.

44. Sepulveda C, Marlin A, Yoshida T, Ullrich A. Palliative Care: the World Health Organization's global perspective. J Pain Symptom Manage. 2002;24(2):91-6. doi

45. Smith CB, Phillips T, Smith TJ. Using the New ASCO Clinical Practice Guideline for Palliative Care Concurrent With Oncology Care Using the TEAM Approach. Am Soc Clin Oncol Educ Book. 2017;37:714-23. doi 10.14694/EDBK_175474.

46. LeBlanc TW. Addressing End-of-Life Quality Gaps in Hematologic Cancers: The Importance of Early Concurrent Palliative Care. JAMA Intern Med. 2016;176(2):265-6. doi 10.1001/jamainternmed.2015.6994.

47. Bakitas MA, Tosteson TD, Li Z, Lyons KD, Hull JG, Li Z, et al. Early Versus Delayed Initiation of Concurrent Palliative Oncology Care: Patient Outcomes in the ENABLE III Randomized Controlled Trial. J Clin Oncol. 2015;33(13):1438-45. doi 10.1200/ JCO.2014.58.6362.

48. Thomas TH, Jackson VA, Carlson H, Rinaldi S, Sousa A, Hansen A, et al. Communication Differences between Oncologists and Palliative Care Clinicians: A Qualitative Analysis of Early, Integrated Palliative Care in Patients with Advanced Cancer. J Palliat Med. 2019;22(1):41-9. doi 10.1089/jpm.2018.0092.

49. Barth C, Colombet I, Montheil V, Huillard O, Boudou-Rouquette P, Tlemsani C, et al. First referral to an integrated onco-palliative care program: a retrospective analysis of its timing. BMC Palliat Care. 2020;19(1):31. doi 10.1186/s12904-020-0539-x.

50. Lindley LC. Health Care Reform and Concurrent Curative Care for Terminally III Children: A Policy Analysis. J Hosp Palliat Nurs. 2011;13(2):81-8. doi 10.1097/ NJH.0b013e318202e308.

51. Advisory Board. Concurrent care: The buzzword in hospice services 2015 [Available from: https://www.advisory.com/research/care-transformation-center/ care-transformation-center-blog/2015/09/hospice-concurrent-care-opportunityassessment-2. Accessed 01.09.2020.

52. Ferrell BR, Twaddle ML, Melnick A, Meier DE. National Consensus Project Clinical Practice Guidelines for Quality Palliative Care Guidelines, 4th Edition. J Palliat Med. 2018. doi 10.1089/jpm.2018.0431.

53. Iyer AS, Dionne-Odom JN, Ford SM, Crump Tims SL, Sockwell ED, Ivankova NV, et al. A Formative Evaluation of Patient and Family Caregiver Perspectives on Early Palliative Care in Chronic Obstructive Pulmonary Disease across Disease Severity. Ann Am Thorac Soc. 2019;16(8):1024-33. doi 10.1513/AnnalsATS.201902-1120C.

54. Yoong J, Park ER, Greer JA, Jackson VA, Gallagher ER, Pirl WF, et al. Early palliative care in advanced lung cancer: a qualitative study. JAMA Intern Med. 2013;173(4):28390. doi 10.1001/jamainternmed.2013.1874.

55. Ledoux M, Rhondali W, Lafumas V, Berthiller J, Teissere M, Piegay C, et al. Palliative care referral and associated outcomes among patients with cancer in the last 2 weeks of life. BMJ Support Palliat Care. 2019;9(1):e16. doi 10.1136/bmjspcare-2014-000791. 
56. Sedhom R, Gupta A, MacNabb L, Smith TJ. The Impact of Palliative Care Dose Intensity on Outcomes for Patients with Cancer. Oncologist. 2020. doi 10.1634/ theoncologist.2020-0551.

57. Sedhom R, Barile D. Palliative care referrals and related outcomes among advanced cancer patients: A study revealing our institutional shortcomings. Journal of Clinical Oncology. 2017;35(15_suppl):e21506-e. doi 10.1200/JCO.2017.35.15_suppl.e21506.

58. Ho A, Jameson K, Pavlish C. An exploratory study of interprofessional collaboration in end-of-life decision-making beyond palliative care settings. J Interprof Care. 2016;30(6):795-803. doi 10.1080/13561820.2016.1203765.

59. May CR, Cummings A, Myall M, Harvey J, Pope C, Griffiths P, et al. Experiences of long-term life-limiting conditions among patients and carers: what can we learn from a meta-review of systematic reviews of qualitative studies of chronic heart failure, chronic obstructive pulmonary disease and chronic kidney disease? BMJ Open. 2016;6(10):e011694. doi 10.1136/bmjopen-2016-011694.

60. Etkind SN, Koffman J. Approaches to managing uncertainty in people with lifelimiting conditions: role of communication and palliative care. Postgrad Med J. 2016;92(1089):412-7. doi 10.1136/postgradmedj-2015-133371.

61. Fliedner MC, Hagemann M, Eychmuller S, King C, Lohrmann C, Halfens RJG, et al. Does Time for (in)Direct Nursing Care Activities at the End of Life for Patients With or Without Specialized Palliative Care in a University Hospital Differ? A Retrospective Analysis. Am J Hosp Palliat Care. 2020;37(10):844-52. doi 10.1177/1049909120905779.

62. National Comprehensive Cancer Network (NCCN). NCCN Clinical Practice Guidelines in Oncology (NCCN Guidelines $®$ ) Palliative Care Version 1.2020. 2020. https://www. nccn.org/professionals/physician_gls/pdf/palliative.pdf28.09.2020.

63. Siouta N, Clement P, Aertgeerts B, Van Beek K, Menten J. Professionals' perceptions and current practices of integrated palliative care in chronic heart failure and chronic obstructive pulmonary disease: a qualitative study in Belgium. BMC Palliat Care. 2018;17(1):103. doi 10.1186/s12904-018-0356-7.

64. Romano M. Barriers to Early Utilization of Palliative Care in Heart Failure: A Narrative Review. Healthcare (Basel). 2020;8(1). doi 10.3390/healthcare8010036.

65. Salins N, Ghoshal A, Hughes S, Preston N. How views of oncologists and haematologists impacts palliative care referral: a systematic review. BMC Palliat Care. 2020;19(1):175. doi 10.1186/s12904-020-00671-5.

66. Collins A, McLachlan S-A, Philip J. Initial perceptions of palliative care: An exploratory qualitative study of patients with advanced cancer and their family caregivers. Palliative Medicine. 2017;31(9):825-32. doi 10.1177/0269216317696420.

67. Frohnhofen $\mathrm{H}$, Hagen $\mathrm{O}$, Heuer HC, Falkenhahn C, Willschrei P, Nehen HG. The terminal phase of life as a team-based clinical global judgment: prevalence and associations in an acute geriatric unit. Z Gerontol Geriatr. 2011;44(5):329-35. doi 10.1007/s00391-011-0180-7.

68. Georges JJ, Onwuteaka-Philipsen BD, van der Heide A, van der Wal G, van der Maas PJ. Symptoms, treatment and "dying peacefully" in terminally ill cancer patients: a prospective study. Support Care Cancer. 2005;13(3):160-8. doi 10.1007/s00520-0040688-0. 
69. Oechsle K, Wais MC, Vehling S, Bokemeyer C, Mehnert A. Relationship between symptom burden, distress, and sense of dignity in terminally ill cancer patients. J Pain Symptom Manage. 2014;48(3):313-21. doi 10.1016/j.jpainsymman.2013.10.022.

70. Kennedy C, Brooks-Young P, Brunton Gray C, Larkin P, Connolly M, Wilde-Larsson $B$, et al. Diagnosing dying: an integrative literature review. BMJ Support Palliat Care. 2014;4(3):263-70. doi 10.1136/bmjspcare-2013-000621.

71. Institute of Medicine (IOM). Dying in America: Improving Quality and Honoring Individual Preferences Near the End of Life. Washington, D.C., USA: The National Academies Press; 2015.

72. Jimenez G, Tan WS, Virk AK, Low CK, Car J, Ho AHY. Overview of Systematic Reviews of Advance Care Planning: Summary of Evidence and Global Lessons.J Pain Symptom Manage. 2018;56(3):436-59 e25. doi 10.1016/j.jpainsymman.2018.05.016.

73. Secunda K, Wirpsa MJ, Neely KJ, Szmuilowicz E, Wood GJ, Panozzo E, et al. Use and Meaning of "Goals of Care" in the Healthcare Literature: a Systematic Review and Qualitative Discourse Analysis. J Gen Intern Med. 2020;35(5):1559-66. doi 10.1007/ s11606-019-05446-0.

74. Myers J, Cosby R, Gzik D, Harle I, Harrold D, Incardona N, et al. Provider Tools for Advance Care Planning and Goals of Care Discussions: A Systematic Review. Am J Hosp Palliat Care. 2018;35(8):1123-32. doi 10.1177/1049909118760303.

75. Bundesamt für Gesundheit (BAG), palliative ch. Gesundheitliche Vorausplanung mit Schwerpunkt «Advance Care Planning». Nationales Rahmenkonzept für die Schweiz. Bern, Switzerland: Eidgenössisches Departement des Innern EDI, Bundesamt für Gesundheit BAG, Direktionsbereich Gesundheitspolitik; 2018.

76. Agarwal R, Shuk E, Romano D, Genoff M, Li Y, O'Reilly EM, et al. A mixed methods analysis of patients' advance care planning values in outpatient oncology: Person-Centered Oncologic Care and Choices (P-COCC). Support Care Cancer. 2020;28(3):1109-19. doi 10.1007/s00520-019-04910-1.

77. Rietjens JA, Korfage IJ, Dunleavy L, Preston NJ, Jabbarian LJ, Christensen CA, et al. Advance care planning - a multi-centre cluster randomised clinical trial: the research protocol of the ACTION study. BMC Cancer. 2016;16(1):264. doi 10.1186/s12885-0162298-x.

78. Saiki C, Ferrell B, Longo-Schoeberlein D, Chung V, Smith TJ. Goals-of-care discussions. J Community Support Oncol. 2017;15(4):e190-e4. doi 10.12788/jcso.0355.

79. Hospice and Palliative Nurses Association (HPNA). HPNA Position Statement Advance Care Planning. Journal of Hospice \& Palliative Nursing. 2018;20(5):E1-E3. doi

80. Bundesamt für Gesundheit (BAG), palliative ch. Versorgungsstrukturen für spezialisierte Palliative Care in der Schweiz. Bern, Switzerland: Eidgenössisches Departement des Innern EDI, Bundesamt für Gesundheit BAG, Direktionsbereich Gesundheitspolitik; 2012.

81. Hirshon JM, Risko N, Calvello EJ, Stewart de Ramirez S, Narayan M, Theodosis C, et al. Health systems and services: the role of acute care. Bull World Health Organ. 2013;91(5):386-8. doi 10.2471/BLT.12.112664.

82. Lavoie $M$, Blondeau D, Martineau I. The integration of a person-centered approach in palliative care. Palliat Support Care. 2013;11(6):453-64. doi 10.1017/ S1478951512000855. 
83. Watson R. Commentary on McCance T, Slater P \& McCormack B (2009) Using the caring dimensions inventory as an indicator of person-centred nursing. Journal of Clinical Nursing, 18, 409-417. J Clin Nurs. 2009;18(3):475. doi 10.1111/j.13652702.2008.02624.x.

84. Yu F. Era of person-centered care for people with chronic illnesses. Nurs Health Sci. 2014;16(4):413-4. doi 10.1111/nhs.12172.

85. Johnston B, Pringle J, Gaffney M, Narayanasamy M, McGuire M, Buchanan D. The dignified approach to care: a pilot study using the patient dignity question as an intervention to enhance dignity and person-centred care for people with palliative care needs in the acute hospital setting. BMC Palliat Care. 2015;14:9. doi 10.1186/ s12904-015-0013-3.

86. Kmetec S, Stiglic G, Lorber M, Mikkonen I, McCormack B, Pajnkihar M, et al. Nurses' perceptions of early person-centred palliative care: a cross-sectional descriptive study. Scand J Caring Sci. 2020;34(1):157-66. doi 10.1111/scs.12717.

87. Grassi L. Communicating anticancer treatment cessation and transition to palliative care: The need for a comprehensive and culturally relevant, person-centered approach. Cancer. 2015;121(23):4104-7. doi 10.1002/cncr.29638.

88. Fliedner MC, Mitchell G, Bueche D, Mettler M, Schols JMGA, Eychmueller S. Development and use of the 'SENS'-structure to proactively identify care needs in early palliative care - an innovative approach. Healthcare. 2019;7(32):1-12. doi 10.3390/healthcare7010032.

89. Pringle J, Johnston B, Buchanan D. Dignity and patient-centred care for people with palliative care needs in the acute hospital setting: A systematic review. Palliat Med. 2015;29(8):675-94. doi 10.1177/0269216315575681.

90. Schellinger SE, Anderson EW, Frazer MS, Cain CL. Patient Self-Defined Goals: Essentials of Person-Centered Care for Serious Illness. Am J Hosp Palliat Care. 2018;35(1):159-65. doi 10.1177/1049909117699600.

91. van Vliet LM, de Veer AJE, Raijmakers NJH, Francke A. Is Information Provision about Benefits and Risks of Treatment Options Associated with Receiving Person-Centered Care?: A Survey among Incurably III Cancer Patients. J Palliat Med. 2019;22(7):797803. doi 10.1089/jpm.2018.0591.

92. Hui D, De La Cruz M, Mori M, Parsons HA, Kwon JH, Torres-Vigil I, et al. Concepts and definitions for "supportive care," "best supportive care," "palliative care," and "hospice care" in the published literature, dictionaries, and textbooks. Support Care Cancer. 2013;21(3):659-85. doi 10.1007/s00520-012-1564-y.

93. Bundesamt für Gesundheit (BAG), Schweizerische Konferenz der kantonalen Gesundheitsdirektorinnen und -direktoren (GDK), palliative ch. Rahmenkonzept Palliative Care Schweiz. Eine definitorische Grundlage für die Umsetzung der «Nationalen Strategie Palliative Care». Bern2014.

94. Gidwani R, Nevedal A, Patel M, Blayney DW, Timko C, Ramchandran K, et al. The Appropriate Provision of Primary versus Specialist Palliative Care to Cancer Patients: Oncologists' Perspectives. J Palliat Med. 2017;20(4):395-403. doi 10.1089/ jpm.2016.0399.

95. Quill TE, Abernethy AP. Generalist plus specialist palliative care--creating a more sustainable model. N Eng/J Med. 2013;368(13):1173-5. doi 10.1056/NEJMp1215620. 
96. Veigh CM, Reid J, Larkin P, Porter S, Hudson P. The provision of generalist and specialist palliative care for patients with non-malignant respiratory disease in the North and Republic of Ireland: a qualitative study. BMC Palliat Care. 2017;17(1):6. doi 10.1186/s12904-017-0220-1.

97. European Association for Palliative Care (EAPC), Radbruch L, Payne S, Board of Directors of the EAPC. White Paper on standards and norms for hospice and palliative care in Europe: part 1. Recommendations from the European Association for Palliative Care. European Journal of Palliative Care. 2009;16(6):278-89. doi

98. Teike Luthi F, Bernard M, Beauverd M, Gamondi C, Ramelet AS, Borasio GD. IDentification of patients in need of general and specialised PALLiative care (IDPALL(c)): item generation, content and face validity of a new interprofessional screening instrument. BMC Palliat Care. 2020;19(1):19. doi 10.1186/s12904-0200522-6.

99. Ostgathe C, Wendt KN, Heckel M, Kurkowski S, Klein C, Krause SW, et al. Identifying the need for specialized palliative care in adult cancer patients - development and validation of a screening procedure based on proxy assessment by physicians and filter questions. BMC Cancer. 2019;19(1):646. doi 10.1186/s12885-019-5809-8.

100. Dyar S, Lesperance M, Shannon R, Sloan J, Colon-Otero G. A nurse practitioner directed intervention improves the quality of life of patients with metastatic cancer: results of a randomized pilot study. J Palliat Med. 2012;15(8):890-5. doi 10.1089/ jpm.2012.0014.

101. Horne G, Seymour J, Shepherd K. Advance care planning for patients with inoperable lung cancer. Int J Palliat Nurs. 2006;12(4):172-8. doi 10.12968/ijpn.2006.12.4.21014.

102. Sinclair C, Auret KA, Evans SF, Williamson F, Dormer S, Wilkinson A, et al. Advance care planning uptake among patients with severe lung disease: a randomised patient preference trial of a nurse-led, facilitated advance care planning intervention. $B M J$ Open. 2017;7(2):e013415. doi 10.1136/bmjopen-2016-013415.

103. De Regge M, De Pourcq K, Meijboom B, Trybou J, Mortier E, Eeckloo K. The role of hospitals in bridging the care continuum: a systematic review of coordination of care and follow-up for adults with chronic conditions. BMC Health Serv Res. 2017;17(1):550. doi 10.1186/s12913-017-2500-0.

104. Gomez-Batiste X, Martinez-Munoz M, Blay C, Espinosa J, Contel JC, Ledesma A. Identifying needs and improving palliative care of chronically ill patients: a community-oriented, population-based, public-health approach. Curr Opin Support Palliat Care. 2012;6(3):371-8. doi 10.1097/SPC.0b013e328356aaed.

105. Siu AL, Spragens LH, Inouye SK, Morrison RS, Leff B. The ironic business case for chronic care in the acute care setting. Health Aff (Millwood). 2009;28(1):113-25. doi 10.1377/hlthaff.28.1.113.

106. Jacobsen J, Jackson V, Dahlin C, Greer J, Perez-Cruz P, Billings JA, et al. Components of early outpatient palliative care consultation in patients with metastatic nonsmall cell lung cancer. J Palliat Med. 2011;14(4):459-64. doi 10.1089/jpm.2010.0382.

107. Bakitas M, Lyons KD, Hegel MT, Balan S, Barnett KN, Brokaw FC, et al. The project ENABLE II randomized controlled trial to improve palliative care for rural patients with advanced cancer: baseline findings, methodological challenges, and solutions. Palliat Support Care. 2009;7(1):75-86. doi 10.1017/S1478951509000108. 
108. Bakitas M, Lyons KD, Hegel MT, Ahles T. Oncologists' perspectives on concurrent palliative care in a National Cancer Institute-designated comprehensive cancer center. Palliat Support Care. 2013;11(5):415-23. doi 10.1017/S1478951512000673.

109. Eychmueller S. [SENS is making sense - on the way to an innovative approach to structure Palliative Care problems]. Ther Umsch. 2012;69(2):87-90. doi 10.1024/00405930/a000256.

110. Eychmueller S. A Structured Early Palliative Care Intervention for Patients With Advanced Cancer - a Randomized Controlled Trial With a Nested Qualitative Study (SENS Trial): ClinicalTrials.gov; 2013 [Available from: https://clinicaltrials.gov/ct2/ show/NCT01983956?term=SENS\&rank=1. Accessed 01.12.2014.

111. Butler M, Ratner E, McCreedy E, Shippee N, Kane RL. Decision aids for advance care planning: an overview of the state of the science. Ann Intern Med. 2014;161(6):40818. doi 10.7326/M14-0644.

112. Song MK, Happ MB, Sandelowski M. Development of a tool to assess fidelity to a psycho-educational intervention. J Adv Nurs. 2010;66(3):673-82. doi 10.1111/j.13652648.2009.05216.x.

113. Bakitas M, Stevens M, Ahles T, Kirn M, Skalla K, Kane N, et al. Project ENABLE: a palliative care demonstration project for advanced cancer patients in three settings. J Palliat Med. 2004;7(2):363-72. doi 10.1089/109662104773709530.

114. Rummans TA, Clark MM, Sloan JA, Frost MH, BostwickJM, Atherton PJ, et al. Impacting quality of life for patients with advanced cancer with a structured multidisciplinary intervention: a randomized controlled trial. J Clin Oncol. 2006;24(4):635-42. doi 10.1200/JCO.2006.06.209.

115. Duncan E, O'Cathain A, Rousseau N, Croot L, Sworn K, Turner KM, et al. Guidance for reporting intervention development studies in health research (GUIDED): an evidence-based consensus study. BMJ Open. 2020;10(4):e033516. doi 10.1136/ bmjopen-2019-033516.

116. Medical Research Council (MRC). A Framework For Development and Evaluation of RCTs For Complex Interventions to Improve Health. London, UK2000.

117. Craig P, Dieppe P, Macintyre S, Michie S, Nazareth I, Petticrew M, et al. Developing and evaluating complex interventions: the new Medical Research Council guidance. BMJ. 2008;337:a1655. doi 10.1136/bmj.a1655.

118. Maloney C, Lyons KD, Li Z, Hegel M, Ahles TA, Bakitas M. Patient perspectives on participation in the ENABLE II randomized controlled trial of a concurrent oncology palliative care intervention: benefits and burdens. Palliat Med. 2013;27(4):375-83. doi 10.1177/0269216312445188.

119. Hannon B, Swami N, Rodin G, Pope A, Zimmermann C. Experiences of patients and caregivers with early palliative care: A qualitative study. Palliat Med. 2017;31(1):7281. doi 10.1177/0269216316649126.

120. Zimmermann C, Swami N, Krzyzanowska M, Leighl N, Rydall A, Rodin G, et al. Perceptions of palliative care among patients with advanced cancer and their caregivers. CMAJ. 2016;188(10):E217-E27. doi 10.1503/cmaj.151171.

121. Collins A, McLachlan SA, Philip J. Communication about palliative care: A phenomenological study exploring patient views and responses to its discussion. Palliat Med. 2018;32(1):133-42. doi 10.1177/0269216317735247. 
122. Mcllfatrick S. Interprofessional collaboration in palliative care: rhetoric or reality? Int J Palliat Nurs. 2013;19(9):419. doi 10.12968/ijpn.2013.19.9.419.

123. Bilodeau K, Dubois S, Pepin J. Interprofessional patient-centred practice in oncology teams: utopia or reality? J Interprof Care. 2015;29(2):106-12. doi 10.3109/13561820.2014.942838.

124. Fliedner MC, Eychmueller S. Ansprüche an die interprofessionelle Zusammenarbeit - Die anderen und ich. Der Onkologe. 2016;22:631-7. doi 10.1007/s00761-016-00700.

125. Fitch Ml, Fliedner MC, O'Connor M. Nursing perspectives on palliative care 2015. Ann Palliat Med. 2015;4(3):150-5. doi 10.3978/j.issn.2224-5820.2015.07.04.

126. Baum U. Caring: Kernelement der professionellen Pflege. Pflegezeitschrift. 2017;70(6):53-6. doi 10.1007/s41906-017-0102-4.

127. Wu Y, Larrabee JH, Putman HP. Caring Behaviors Inventory: a reduction of the 42item instrument. Nurs Res. 2006;55(1):18-25. doi 10.1097/00006199-20060100000003.

128. Bartz CC. International Council of Nurses and person-centered care. Int J Integr Care. 2010;10 Suppl:e010. doi 10.5334/ijic.480.

129. Byrne AL, Baldwin A, Harvey C. Whose centre is it anyway? Defining person-centred care in nursing: An integrative review. PLoS One. 2020;15(3):e0229923. doi 10.1371/ journal.pone.0229923.

130. Goodman A. Palliative Care and the Role of Nurses. The Oncology Nurse. 2015;8(4). doi

131. Butcher $H$, Bulechek G, Dochterman JM, Wagner C. Nursing Interventions Classification (NIC). 7th ed. St Louis (USA): Mosby (Elsevier - Health Sciences Division); 2018.

132. Dobbins EH. Improving end-of-life care: Recommendations from the IOM. Nurse Pract. 2016;41(9):26-34. doi 10.1097/01.NPR.0000490388.58851.e0.

133. Raymond A, Lee SF, Bloomer MJ. Understanding the bereavement care roles of nurses within acute care: a systematic review. J Clin Nurs. 2017;26(13-14):1787-800. doi 10.1111/jocn.13503.

134. Wittenberg-Lyles E, Goldsmith J, Ragan S. The shift to early palliative care: a typology of illness journeys and the role of nursing. Clin J Oncol Nurs. 2011;15(3):304-10. doi 10.1188/11.CJON.304-310.

135. Glare P, Plakovic K, Schloms A, Egan B, Epstein AS, Kelsen D, et al. Study using the NCCN guidelines for palliative care to screen patients for palliative care needs and referral to palliative care specialists. J Natl Compr Canc Netw. 2013;11(9):1087-96. doi 10.6004/jncen.2013.0130.

136. Federal Office of Public Health (FOPH), Swiss Conference of the Cantonal Ministers of Public Health $(\mathrm{CMH})$, palliative ch. Framework Concept for Palliative Care in Switzerland. A basis for defining palliative care for the implementation of the «National Strategy for Palliative Care». Bern; 2014 15th July 2014. www.bag.admin. ch/palliativecare.

137. Swiss Academy of Medical Sciences (SAMS). Management of dying and death. Bern: Swiss Academy of Medical Sciences (SAMS); 2018. www.sams.ch/ guidelines10.10.2020. 
138. Zambrano SC, Fliedner MC, Eychmuller S. The impact of early palliative care on the quality of care during the last days of life: what does the evidence say? Curr Opin Support Palliat Care. 2016;10(4):310-5. doi 10.1097/SPC.0000000000000240.

139. Fliedner M, Zambrano S, Schols JM, Bakitas M, Lohrmann C, Halfens RJ, et al. An early palliative care intervention can be confronting but reassuring: A qualitative study on the experiences of patients with advanced cancer. Palliat Med. 2019:269216319847884. doi 10.1177/0269216319847884.

140. Fliedner M, Halfens RJG, King CR, Eychmueller S, Lohrmann C, Schols JMGA. Roles and Responsibilities of Nurses in Advance Care Planning in Palliative Care in the Acute Care Setting: A Scoping Review. J Hosp Palliat Nurs. 2021;23(1):59-68. doi 10.1097/NJH.0000000000000715.

141. Eychmuller S, Zwahlen S, Fliedner MC, Juni P, Aebersold DM, Aujesky D, et al. Single early palliative care intervention added to usual oncology care for patients with advanced cancer: A randomized controlled trial (SENS Trial). Palliat Med. 2021;35(6):1108-17. doi 10.1177/02692163211005340.

142. Hagemann M, Zambrano SC, Butikofer L, Bergmann A, Voigt K, Eychmuller S. Which Cost Components Influence the Cost of Palliative Care in the Last Hospitalization? A Retrospective Analysis of Palliative Care Versus Usual Care at a Swiss University Hospital. J Pain Symptom Manage. 2020;59(1):20-9 e9. doi 10.1016/j. jpainsymman.2019.08.026.

143. Swiss National Science Foundation (SNF). Synthesis Report NRP 67 - End Of Life. 2017. http://www.nfp67.ch/SiteCollectionDocuments/nfp67-synthesebericht-en. pdf2020-10-04. 


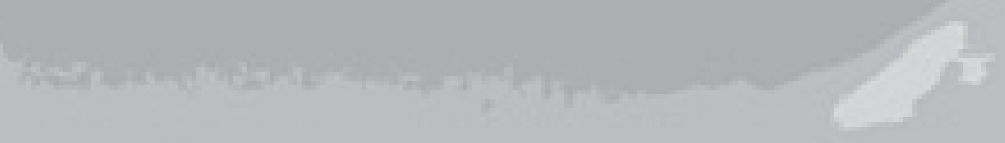

\section{Chas}
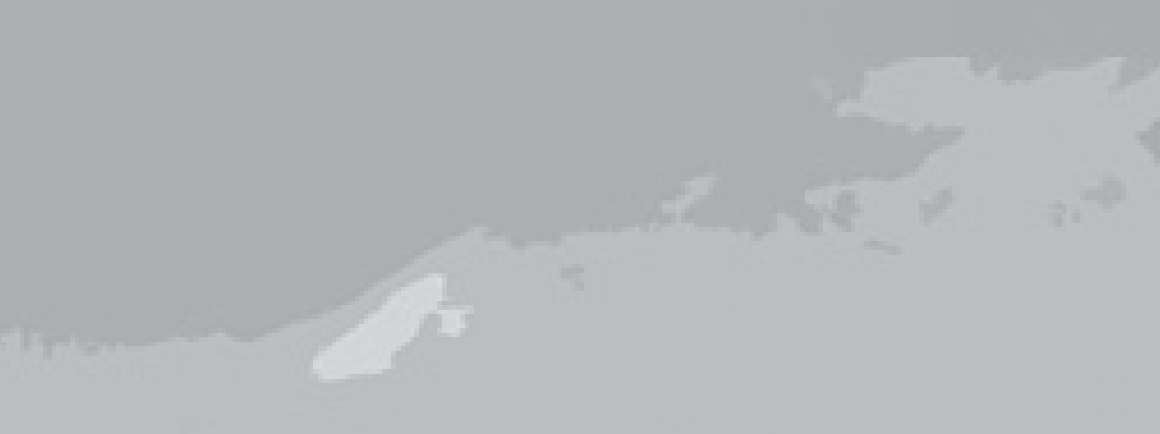

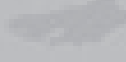

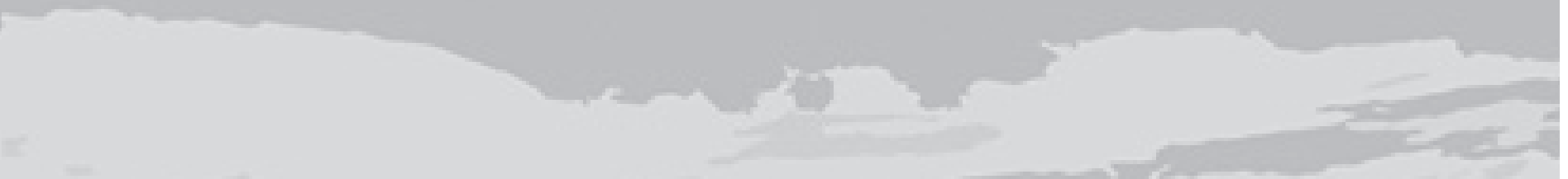

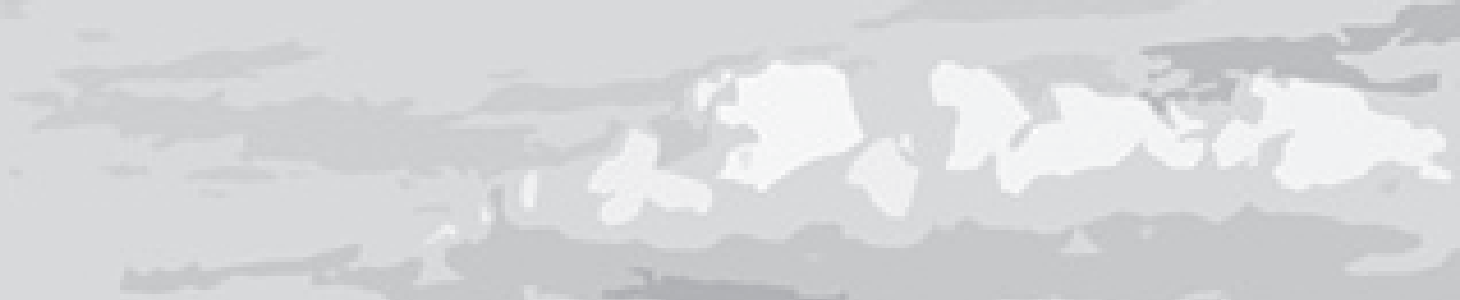

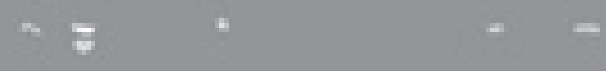

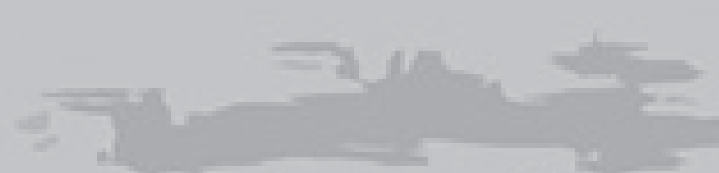

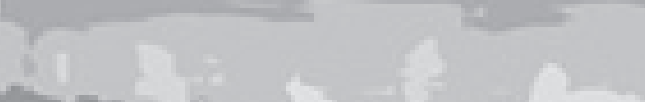

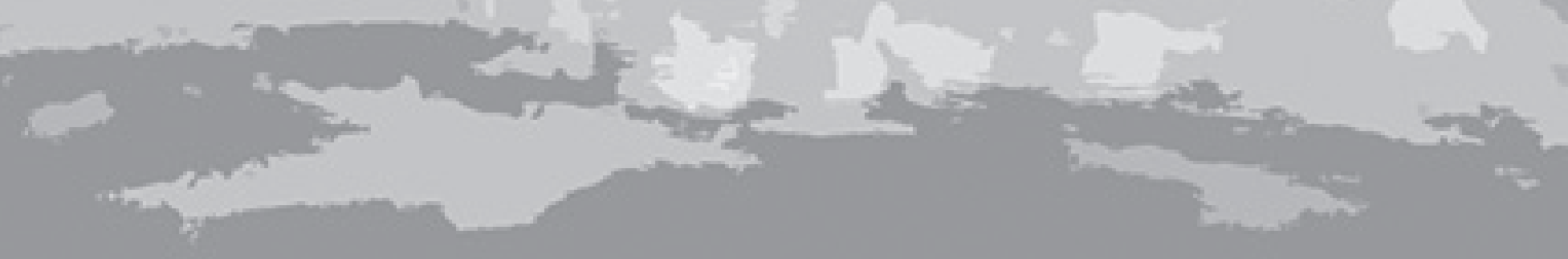




\section{Chapter 2}

\section{Development and Use of the 'SENS'- Structure to Proactively Identify Care Needs in Early Palliative Care - An Innovative Approach}

This chapter was published as: Fliedner MC, Mitchell G, Bueche D, Mettler M, Schols JMGA, Eychmueller S. Development and use of the 'SENS'-structure to proactively identify care needs in early palliative care - an innovative approach. Healthcare. 2019;7(32):1-12. doi 10.3390/healthcare7010032 


\section{Abstract}

Anticipatory planning for end of life requires a common language for discussion among patients, families, and professionals. Studies show that early Palliative Care (PC) interventions based on a problem-oriented approach can improve quality of life, support decision-making, and optimize the timing of medical treatment and transition to hospice services. The aim of this quality-improvement project was to develop a pragmatic structure meeting all clinical settings and populations needs. Based on the Medical Research Council (MRC) framework, a literature review identifying approaches commonly used in PC was performed. In addition, more than 500 hospital-based interprofessional consultations were analyzed. Identified themes were structured and compared to published approaches. We evaluated the clinical usefulness of this structure with an online survey among professionals. The emerged 'SENS'-structure stands for: Symptoms patients suffer from; End-of-life decisions; Network around the patient delivering care; and Support for the carer. Evaluation among professionals has confirmed that the 'SENS'-structure covers all relevant areas for anticipatory planning in PC. 'SENS' is useful in guiding patient-centered PC conversations and pragmatic anticipatory planning, alongside the regular diagnosis-triggered approach in various settings. Following this approach, 'SENS' may facilitate systematic integration of PC in clinical practice. Depending on clearly defined outcomes, this needs to be confirmed by future randomized controlled studies.

\section{Keywords}

chronic life-limiting condition; palliative care; patient-centered care; early palliative care intervention; advance care planning; needs assessment 


\section{Introduction}

Anticipatory planning for the end of life, including Advance Care Planning (ACP) as a component of Palliative Care (PC), has become a core element in western healthcare systems to improve the care for people with advanced life-limiting illnesses ${ }^{1}$. Early integration of PC into the illness trajectory means initiating a conversation on future treatment and care wishes, taking into consideration patients' values and personal circumstances, as well as their social surroundings. In addition, clinicians can plan for anticipated clinical complications that may not be present now but may occur in the future. Finally, the physical, social and emotional needs of the informal carers of patients also need to be considered ${ }^{2,3}$. Such anticipatory planning seems to improve quality of life ${ }^{4}$, optimize the timing of treatment and transition to hospice services, and may reduce health care costs 5,6 . Early PC (ePC) is best incorporated into care pathways of chronic life-limiting diseases in need of a PC approach alongside the traditional diagnosis-focused approach by initiating a conversation on future treatment and care wishes ${ }^{7}$. This approach is suitable for patients with any chronic lifelimiting disease, such as patients with advanced cancer 8,9 or advanced chronic kidney disease contemplating haemodialysis ${ }^{10}$, as well as patients already on haemodialysis with severe co-morbidities or those considering withdrawing from dialysis ${ }^{11}$ or suffering from Amyotrophic Lateral Sclerosis ${ }^{12}$ or advanced heart disease ${ }^{13}$. A major challenge is finding a common language for discussions on future care and ACP among patients, families, and health care professionals ${ }^{14}$.

However, the most effective but still easy to use thematic structure in an ePC intervention to identify and prioritize areas used in an ePC intervention ${ }^{15}$ and how to prioritize care needs without overburdening patients and carers is still unknown. For clinical purposes, our team of Swiss PC professionals identified the need for an easy-to-use structure, which could support active participation of patients and their families in conversations with professionals to prioritize care and anticipate care planning. The aforementioned professionals, working in a hospital-based specialized PC-consultation service in St.Gallen and Bern, consisted of two physicians and two nurses, all trained in PC at the specialist level. In addition, a sociologist worked during the time of the development of the structure on her Ph.D. in PC, including communication and interaction with people at the end of life. The structure should help patients to become more self-efficient by subdividing the current or future challenges into "manageable 
proportions"16. It might also assist patients to make carefully considered decisions in various domains, including future medical care.

We present how our team developed the so-called 'SENS'-structure (symptoms, end-of-life decisions, network, and support)-a thematic structure for anticipatory planning as the essence of ePC interventions. The purpose of our PC hospital-wide, quality-enhancing project was to develop a pragmatic and, by the interprofessional team, concise assessment structure to identify patients' major concerns and priorities, as well as their main resources. The structure should (a) be easy to use, (b) support a mutual agreed multidimensional care plan to facilitate self-efficacy in medically challenging situations, (c) facilitate the evaluation of interventions toward defined goals of care, and (d) ease the information flow between general and specialized PC. Furthermore, it should eventually serve as an educational structure for patients and health professionals, as well as support financial reimbursement for PC interventions.

We explore the clinical value and implementation of the 'SENS'-structure and its usefulness for planning, documentation, evaluation, and education primarily in the acute clinical setting from the perspective of professionals. We are going to discuss its uptake, challenges, and opportunities. Its validity and effects in the interaction with patients will be the subject of future articles.

\section{Materials and Methods}

For the development of the 'SENS'-structure (Figure 1), we used the Medical Research Council's (MRC) 2000 framework for developing complex interventions ${ }^{17}$, which we followed in five distinct phases: a preclinical phase, a modeling and piloting phase, which was followed by an explorative phase. To show all developmental phases of the intervention, the subsequent research phases will only briefly be mentioned.

As part of the hospital quality improvement project in St.Gallen and Bern ${ }^{18}$, we followed a cyclic and reflective action-research approach, primarily including feedback from professional users for the pre-clinical phase, as well as phases 1 and 2. For the retrospective chart review in phase 1, ethical approval was not required. For the survey among professionals (phase 2), ethical approval was obtained from the local ethical committee. 
Figure 1. Phases of development of the 'SENS'-structure based on the Medical Research Council (MRC) framework (2000).

\begin{tabular}{|c|c|c|c|c|c|c|}
\hline \multicolumn{5}{|c|}{ Developmental and explorative phase } & \multicolumn{2}{|c|}{ Patient centered research } \\
\hline $\begin{array}{l}\text { Pre-clinical } \\
\text { phase } \\
2068-2010\end{array}$ & \multicolumn{3}{|c|}{$\begin{array}{l}\text { Phase 1: } \\
\text { Modelling and piloting } \\
2010-2012\end{array}$} & $\begin{array}{c}\text { Phase 2: } \\
\text { Exploratory phase } \\
2012 \text { - } 2018\end{array}$ & $\begin{array}{c}\text { Phase } 3: \\
\text { Detinitive RCT } \\
2014-2018\end{array}$ & \begin{tabular}{c|} 
Phase \\
$2019+$ \\
\end{tabular} \\
\hline $\begin{array}{c}\text { Review of } \\
\text { edsting } \\
\text { approaches for } \\
\text { Palliative Care } \\
\text { conversation }\end{array}$ & $\begin{array}{c}\text { Analysis of } \\
\text { so0+ inpotient } \\
\text { Palliative Care } \\
\text { consultation } \\
\text { reports } \\
\end{array}$ & $\begin{array}{l}\text { Definition of } \\
\text { repetitive main } \\
\text { components } \\
\text { (duaster) }\end{array}$ & \begin{tabular}{|l|} 
Development of \\
'SENS' \\
Symptoens \\
End-of-life decisions \\
Nutwork \\
Support
\end{tabular} & \multirow{2}{*}{ 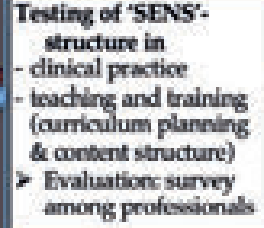 } & \multirow[t]{2}{*}{$\begin{array}{l}\text { The 'SENS } \\
\text { Study": } \\
\text { RCC to test the } \\
\text { effects of SENS on } \\
\text { putients distress } \\
\text { level (main } \\
\text { octcome) }\end{array}$} & \multirow[t]{2}{*}{ 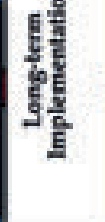 } \\
\hline Goals & 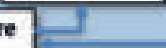 & & & & & \\
\hline \multicolumn{5}{|c|}{ Hospital quality improvement project } & & \\
\hline
\end{tabular}

Pre-clinical phase (2008-2010): Based on an exploration of the literature, we tried to identify clinical approaches that were commonly used to structure care-planning conversations thematically. We used the search terms "palliative care", "needs assessment", "assessment of health care needs", "guideline health planning", and "advance care planning" using the Boolean operators "and/or", respectively. Our interprofessional team of PC experts critically evaluated these approaches for their clinical application and practicability. Derived common goals of PC as defined within the Swiss national PC strategy ${ }^{19}$ served as a first structure.

Phase 1: During the modeling phase (2010-2012), we tested the feasibility and acceptability of the first structure in daily clinical practice. For that, we systematically reviewed, retrospectively, more than 500 records of documented inpatient PC consultations, performed by our interprofessional PC team with patients disregarding their disease and their families. We compared and ordered clusters of common themes into the goals of $\mathrm{PC}^{20}$ and discussed any discrepancies among our team until we reached consensus. Through this process, we developed the 'SENS'-structure.

Phase 2: During the exploratory phase (2012-2018), we clinically tested the usefulness of the 'SENS'-structure for initial PC assessment, organization of the interprofessional care plan, documentation, and evaluation of patient preferences and priorities. Over a two-year period, and as part of the PC national audit process ${ }^{21}$, professionals from other settings who also used the 'SENS'-structure in their clinical practice after its publication ${ }^{20}$ provided us with feedback, which we considered in the final refinement of the 'SENS'-structure. In this period, we observed how 'SENS' was used and implemented in different 
clinical settings, as well as by educational and political organizations.

In addition, in October/November 2018, we performed an online survey among clinical users of the 'SENS'-structure in the German speaking part of Switzerland in various settings (hospital, home care, long-term care) to collect formal and anonymized feedback from professionals. The local ethical committee of Bern considered this survey as being outside their sphere of responsibility. Participants (collaborating professionals, such as general practitioners, PC physicians, and nurses from hospitals and former students of the specialized PC training) were identified and approached by our two major PC centers (University Hospital in Bern and at the Cantonal Hospital St.Gallen), providing a link by email to the respective survey. Their anonymous participation was considered as consent to participate in the survey.

In phase 3, we performed a randomized controlled 'SENS'-study 22 (20142017) in patients with advanced cancer, including an integrated qualitative study exploring patients' experience with a 'SENS'-based intervention and reflecting upon the 'SENS'-themes for their consistency and completeness.

In phase 4, we are going to study the long-term implementation of the 'SENS'-structure in outpatient care through a cluster randomized controlled trial (RCT). Within this article, we focused only on the developmental and explorative phases and will discuss the findings of Phase 3 and 4 in later publications.

\section{Results}

\subsection{Pre-Clinical Phase}

As major thematic structures for anticipatory planning in PC, we identified the definition of the World Health Organization (WHO) on PC23,24, the listing of PC needs from the National Comprehensive Cancer Network (NCCN) Guidelines on PC ${ }^{25,26}$, and the "PEPSI-COLA" structure within the National Gold Standards Framework (GSF) ${ }^{27-29}$. All structures had certain goals of care in common which were identified and clustered alongside the four goals of the Swiss national PC strategy: (a) Improving self-efficacy and self-help capacity, (b) promoting self-determination by supporting a certain sense of coherence in decisionmaking, (c) ensuring safety in sometimes life-threatening situations, and (d) assuring support of the encumbered carer including the bereavement phase. Subsequently, the topics covered by these guidelines were assigned to the identified goals of PC (Table 1). 
Table 1. Overview of themes discussed in Palliative Care (PC) conversations.

\begin{tabular}{|c|c|c|c|c|c|}
\hline $\begin{array}{c}\text { Common } \\
\text { Goals of PC } \\
\text { (Switzerland, } \\
\text { 2014) } \\
\end{array}$ & $\begin{array}{l}\text { WHO }{ }^{1} \\
\text { Definition } \\
\text { of PC } \\
(2002) \\
\end{array}$ & $\begin{array}{c}\text { NCCN }^{2} \\
\text { Guideline } \\
\text { for PC } \\
(2009 / 2016) \\
\end{array}$ & $\begin{array}{c}\text { GSF }^{3} \\
(2014)\end{array}$ & Theme & $\begin{array}{c}\text { 'SENS'-Structure } \\
\text { Theme } \\
\text { (Eychmueller, } \\
\text { 2012) } \\
\end{array}$ \\
\hline \multirow[t]{7}{*}{$\begin{array}{l}\text { Improving Self- } \\
\text { help capacities }\end{array}$} & & & & $\begin{array}{l}\text { Self- } \\
\text { effectiveness }\end{array}$ & Symptoms \\
\hline & $x$ & $x$ & $x$ & Physical & \\
\hline & & $x$ & $x$ & $\begin{array}{l}\text { Educational and } \\
\text { informational } \\
\text { needs }\end{array}$ & \\
\hline & $x$ & & $x$ & Spiritual & \\
\hline & $x$ & & $x$ & Quality of life & \\
\hline & & & $x$ & $\begin{array}{l}\text { Personal (e.g., } \\
\text { inner journey) }\end{array}$ & \\
\hline & & & $x$ & $\begin{array}{l}\text { Late (e.g., death } \\
\text { rattle, agitation) }\end{array}$ & \\
\hline \multirow[t]{4}{*}{$\begin{array}{l}\text { Promoting Self- } \\
\text { determination }\end{array}$} & & $x$ & $x$ & $\begin{array}{l}\text { Self } \\
\text { determination }\end{array}$ & End-of-life decisions \\
\hline & & $x$ & & $\begin{array}{l}\text { Benefits } \\
\text { and risks of } \\
\text { (anticancer) } \\
\text { treatment }\end{array}$ & \\
\hline & & & $x$ & $\begin{array}{l}\text { Emotional } \\
\text { (e.g., fears, } \\
\text { relationships) }\end{array}$ & \\
\hline & $x$ & & & Dying issues & \\
\hline \multirow{4}{*}{$\begin{array}{l}\text { Ensuring } \\
\text { Safety in } \\
\text { sometimes life- } \\
\text { threatening } \\
\text { situations }\end{array}$} & & & $x$ & $\begin{array}{l}\text { Out of hours- } \\
\text { emergency }\end{array}$ & Network \\
\hline & & & & Safety & \\
\hline & $x$ & $x$ & & Psychosocial & \\
\hline & & $x$ & & $\begin{array}{l}\text { Cultural factors } \\
\text { affecting life }\end{array}$ & \\
\hline \multirow{2}{*}{$\begin{array}{l}\text { Assuring } \\
\text { Support for the } \\
\text { encumbered } \\
\text { family }\end{array}$} & $x$ & & $x$ & $\begin{array}{l}\text { Support of } \\
\text { family }\end{array}$ & Support of the carer \\
\hline & & & $x$ & $\begin{array}{l}\text { Afterwards } \\
\text { (bereavement } \\
\text { period) }\end{array}$ & \\
\hline
\end{tabular}

Abbreviations: 'WHO: World Health Organization; ${ }^{2} \mathrm{NCCN}$ : National Comprehensive Cancer Network; ${ }^{3}$ GSF: Gold Standards Framework ${ }^{\circledR}$.

\subsection{Phase 1: Piloting and Modeling Phase}

By analysis of the content of consultations, we identified four main clusters of themes that we regrouped to form the 'SENS'-structure. The acronym 'SENS' represents the following themes (Tables 1 and 2): 
- Symptoms patients suffer from or worries they may have, including selfsupport strategies in case of a crisis, as well as carer empowerment in symptom crises;

- End-of-life decisions in regard to the future, including individual care and treatment preferences, potentially formulated as an advance directive;

- Network organization (private and professional), including assessment of current living circumstances and organization of support in case of an emergency not manageable at home/nursing home;

- Support for the carers to cope with the situation and to prevent overburdening.

Table 2. Patient prompt sheet: 'SENS'-structure with themes and potential assessment questions.

\begin{tabular}{|c|c|}
\hline $\begin{array}{l}\text { 'SENS'-Theme and } \\
\text { Definition }\end{array}$ & $\begin{array}{l}\text { Potential Assessment Questions: To Identify Patients' and } \\
\text { Their Family's Priorities It is Essential to Ask Questions that } \\
\text { will Help the Patient to Focus }\end{array}$ \\
\hline $\begin{array}{l}\text { Symptom } \\
\text { management: } \\
\text { The best possible } \\
\text { way to treat the } \\
\text { symptoms and to } \\
\text { self-empower the } \\
\text { patient for self-help } \\
\text { in dealing with the } \\
\text { symptom. }\end{array}$ & $\begin{array}{l}\text { Which problems, themes, or symptoms are you the most worried } \\
\text { about at the moment, and which concerns are you the most } \\
\text { worried about for the future? Concerning the topics below, which } \\
\text { make you feel anxious? } \\
\text { o Physical, e.g., pain, nausea, dyspnea, fatigue; } \\
\text { o Psychological, e.g., limitations in thinking, grief, anger, anxiety, } \\
\text { depression; } \\
\text { o spiritual, e.g., faith/religion, question of meaning, hope and } \\
\text { despair; } \\
\text { o socio-cultural, e.g., own role (family/profession), tradition/ } \\
\text { rituals, relationships. } \\
\text { - In which areas did you have good experiences so far? What } \\
\text { helped or supported you in these situations? What resources } \\
\text { helped you to deal with symptoms, problems, challenges? }\end{array}$ \\
\hline
\end{tabular}




\section{‘SENS'-Theme and Potential Assessment Questions: To Identify Patients' and Definition Their Family's Priorities It is Essential to Ask Questions that will Help the Patient to Focus}

- How have you made important decisions so far in your life (e.g., alone, support people)? Or, did you mainly rely on the advice of others? Or, did you let others decide for you?

- What is very important to you? What do you want to urgently

End-of-life

decisions and expectations: Stepby-step and selfregulated decisionmaking, definition of personal preferences, and preventive planning for potential complications. experience or resolve? Which goals would you like to achieve (with medical measures)?

- Which questions regarding your disease are still unanswered? What (and how much) do you want to know?

- Regarding your dying-what needs to be clarified and managed related to your plans for death? What would you like to determine in advance (e.g., in an advance directive)? What is your attitude toward life-prolonging measures, i.e., Cardiopulmonary Resuscitation-measures in case of a circulatory arrest? What should be done with your body after you die (autopsy, organ donation)?

- Do you have any special wishes or ideas that should be done for you when you cannot decide anymore for yourself (including care, rituals, funeral)?

- Is there any unfinished business that you want to deal with or arrange?

- If your health situation does not improve substantially-where would you like to stay? What is your home environment like (e.g., stairs, access to the bathroom)?

- Who of your family members/friends can support you when you

Networkbecome weaker and you lose your strength? Who of your family organization: Professional (including out-ofhours support) and private care network. or friends could you involve in your care? Which professionals (e.g., social services, spiritual care, community nursing, general practitioner, volunteers) are available?

- If any complication occurs or if there is an emergency: What can you do? What should your family do? Who should be involved in your chain-of-rescue?

- What are your alternatives for any future care (e.g., nursing homes)? Do you need to consider and maybe already plan ahead in case the care at the location of your choice (e.g., being as long as possible at home) is not possible?

\section{Support of the} carers: support system for family members, including in the bereavement phase, and for the involved professional carers.
- Who of your main family members or friends will most likely need support? Who is already available for support? Which professionals, family members, or friends can offer support? Who will provide support after your death to your family and friends?

- Does your family need additional specific support (e.g., in financial or legal matters)? 
We compared the goals of care identified in the preclinical phase with the 'SENS'structure and saw that 'SENS' seems to covers all relevant themes. Subsequently, we used 'SENS' to design a patient prompt sheet with concrete questions to assist patients and families in preparing for ePC conversations with health professionals.

\subsection{Phase 2: Exploratory Phase}

Together with other Swiss healthcare facilities, we evaluated the usefulness of 'SENS' in the acutehospital and outpatient PC setting.

A formal evaluation among professionals revealed important feedback. The majority (49.1\%) of the respondents had a nursing background (Table 3), working either in a specialized hospital-based or home care service, with a considerable amount of PC experience.

Table 3. Demographics.

\begin{tabular}{llll}
\hline Variables & & \multicolumn{2}{l}{ Number Percentage } \\
\hline Gender $(N=55)$ & Male & 18 & $31.6 \%$ \\
& Female & 37 & $64.9 \%$ \\
& Unknown & 2 & $3.5 \%$ \\
\hline Years in profession $(N=56)$ & Professional years in general & 19.4 & \\
& (mean) & \multicolumn{2}{l}{} \\
& Years working in PC (mean) & 7.6 & \\
\hline Profession $(N=57)$ & Physician & 26 & $45.6 \%$ \\
& Nurse & 28 & $49.1 \%$ \\
& Pastoral carer & 2 & $3.5 \%$ \\
& Psycho(onco)logist & 1 & $1.8 \%$ \\
\hline Main place of work $(N=57)$ & Hospital-based general PC service & 7 & $13.0 \%$ \\
& Hospital-based special PC service & 21 & $38.9 \%$ \\
& General practitioner & 9 & $16.7 \%$ \\
& Home care & 12 & $22.2 \%$ \\
& Nursing home & 6 & $11.1 \%$ \\
& Hospice & 2 & $3.7 \%$ \\
\hline
\end{tabular}

Overall, 'SENS' was used by the respondents both in the early PC phase and in the dying phase, respectively (72.2\%). Respondents used 'SENS' mainly within the interprofessional team context, and was rated most helpful for providing an overview of current problems and individual expectations, as well as for interprofessional collaboration and coordination. The vast majority of the 
respondents (81.5\%) felt that the active participation of patients and family carers in defining a common care plan was well supported by the 'SENS'structure. Although professionals need certain training to lead the conversation with the patient according to the 'SENS'-structure, most participants (87\%) had good experience with the use of 'SENS'. Specifically, when patients do not want to address the issue of dying and death, some professionals felt that it was challenging to use 'SENS' with all its components.

Feedback from professionals (nurses and physicians) and patients as part of annual medical quality assurance audits, as well as responses from the survey, revealed benefits in the following four main areas:

Firstly, the 'SENS'-structured initial assessment seemed to help patients and families to gain a systematic overview of future challenges. 'SENS' encouraged them to talk about these-often very personal-worries. Often, a medical diagnosis-driven approach was in the foreground; therefore, some patients seemed challenged by focusing early on non-medical topics and analyzing their situation systematically.

We found that all four areas of 'SENS' were equally relevant. 'SENS' provided an initial overview which could then be assessed in greater detail using validated assessment tools for specific symptoms whenever appropriate. The structure seemed to be evenly helpful in ePC, in more advanced and complex palliative situations and the dying phase. The distinction between managing symptoms and discussing end-of-life decisions was obvious to clinicians. In some documented conversations, the difference between the " $\mathrm{N}$ " = network (who belongs to the social network and which professional systems do the patients and families have in place) and the second " $\mathrm{S}$ " = support for the carers was not always clear. We concluded that "support" as term alone may be misinterpreted and added "for the carers" to specifically focus on the assessment of carer or family burden.

These findings were supported by the results of the online survey, in which the majority of the participants felt that all four areas covered always or almost always the situation of patients. This was particularly clear in the themes 'Symptom management' (94.6\%), 'End-of-life decisions (89.3\%), and 'Networkorganization' (78.6\%). Probably the theme 'Support for the carer' still needs more refinement since $50.9 \%$ of the survey participants felt that it covered the support for patients but not the support needs for the burdened carers. It offered a needs-based approach for multifaceted situations driven by concrete problems of daily life, while utilizing resources of patients. 
From the perspective of health care professionals, 'SENS' has been independently used and proven to be helpful in clinical practice ${ }^{30}$ for structuring the assessment of the main concerns. It appeared to be helpful as a "short and simple" enough assessment structure for general and specialist PC settings ${ }^{19,31}$, such as hospitals (inpatient PC, consultancy services), nursing homes, or primary care settings.

Secondly, from clinical practice, we know that 'SENS' was often used in interprofessional rounds. It showed that 'SENS' served as a useful structure to develop a care plan together with patients, guiding the setting of goals of care, expectations, prioritization, responsibility, planning, and allocation of resources and financial reimbursement. It also supported the collaboration within the interprofessional team (Table 4).

Table 4. Interprofessional team working together with the patient and family based on 'SENS'.

\begin{tabular}{ll}
\hline 'SENS'-Themes & Involved Professionals (Examples) \\
\hline Symptoms & $\begin{array}{l}\text { Physician, nurse, physiotherapist, psychologist, pastoral care } \\
\text { worker, dietician, music or art therapist. }\end{array}$ \\
\hline End-of-life decisions & Physician, nurse, pastoral care worker, psychologist. \\
\hline Network-organization & Nurse, social worker, general practitioner, volunteer service. \\
\hline Support of the carer & $\begin{array}{l}\text { Physician, nurse, psychologist, spiritual counselor, social } \\
\text { worker. }\end{array}$ \\
\hline
\end{tabular}

Clear distribution of tasks and responsibilities within the interprofessional team, including timelines and changes of priorities, could be outlined from the beginning of the PC intervention based on 'SENS'. As an example: if physical symptoms were initially in the foreground, close cooperation between the medical and nursing staff was necessary. The focus could later shift to discussing the future place of care, including network organization and emergency planning, for which the social worker and mobile PC teams may have taken the lead.

Thirdly, 'SENS' structured the evaluation of care, which allowed a better judgment of the complexity within a particular area. Based on a common language, 'SENS' offered an effective way to prepare and document a problemoriented family conference in which the interprofessional team members each had their specific tasks. In addition, 'SENS' helped to thematically structure case discussions and critical review. 
Fourthly, 'SENS' has lately been officially recommended as a structure for professional education and reimbursement. The areas of 'SENS' can be weighted depending on the target of professional education (physicians, nurses, social workers, etc.), as shown in postgraduate basic and specialist PC training programs in Switzerland ${ }^{32}$. At the same time, it can ensure that all essential topics are equally covered. Since 2015, the 'SENS' structure was officially implemented in Swiss medical schools by the publication of Eychmueller et al..$^{33}$ as recommended teaching material. In addition, 'SENS' was adopted as a basic assessment-structure triggering the comprehensive diagnosis related groups (DRG)-codes for complex PC treatment within the SWISS Health Care System ${ }^{34}$.

\subsection{Phases 3 and 4: Patient-Centered Research and Implementation}

In phases 3 and 4, we are currently investigating the impact of a 'SENS'structured conversation on patients' distress and trust through two RCT. In a prospective RCT including an embedded qualitative study with ePC cancer patients (ClinicalTrials.gov Identifier NCT01983956)22, we investigated whether 'SENS' is helpful to increase patient self-efficacy and reduce distress and costs, as suggested in other studies. These results are in submission or under review for publication, respectively ${ }^{35,36}$. To create additional evidence for the usefulness of 'SENS' in the primary care setting, a cluster RCT ${ }^{37}$ is underway.

\section{Discussion}

The 'SENS'-structure was developed using a stepwise approach for complex interventions, as recommended by the $\mathrm{MRC}^{17}$. Most of the existing guidelines did not seem designed for clinical use ${ }^{24}$ or were highly complex ${ }^{26}$ or needed further refinement for the use in hospitals and across care settings ${ }^{38}$. In contrast, 'SENS' seemed to meet the expectations of professionals for assessment, planning, evaluation, education, documentation, and communication in various settings across the care continuum. Other structures ${ }^{39}$ or frameworks were either not designed for assessing care needs or considered rather complex in non-specialist PC settings and were, therefore, not taken into consideration. As part of the Swiss national PC strategy, the 'SENS'-structure was rapidly adopted for clinical and educational purposes because of its simplicity and comprehensiveness. 


\subsection{Impact of the Use of the 'SENS'-Structure on Clinical Practice}

In terms of completeness compared to other assessment structures in PC, from the health care professionals' perspective, 'SENS' seemed to cover all relevant themes. Clinical audits showed that 'SENS' seemed to support patients and carers to be an active part in generating anticipatory planning and to feel empowered for future challenges. In addition, it seemed to enable interprofessional teams to prioritize and focus, together with patients and families, on what is important and manageable in individual situations.

Despite complex medical situations, 'SENS' seemed to help patients to regain control over personal areas of life and to shift the focus to patients' strengths and resilience, facilitating their self-efficacy. More research on this effect has been undertaken. Thus, 'SENS' is more likely to contribute to a flexible and equally comprehensive concept of biopsychosocial and spiritual care, alongside diagnosis-based medical reasoning and disease-specific approaches, as recently proposed through the term "concurrent care" by the American Society for Clinical Oncology (ASCO) ${ }^{40,41}$. Concurrent care with 'SENS' as the patient-centered assessment structure may foster the integration of PC in other vulnerable populations, such as people with dementia ${ }^{42,43}$ or other chronic life-limiting diseases, which is in line with the World Health Assembly's call for action $^{44}$.

\subsection{Effects of the Initiation of a 'SENS'-Based Conversation}

During the different phases of developing and piloting 'SENS', we encountered clinical acceptance by professionals when 'SENS' was administered alongside medical reasoning.

No harmful effects of the 'SENS'-structure have been mentioned in any feedback from professionals, but more detailed evaluation is under way. Some professionals would expect that patients could experience the systematic analysis of 'SENS' themes as challenging, perhaps because patients might not be prepared to deal with the life-limiting nature of their disease or to discuss $P C$ issues early on in their disease trajectory. This could especially be true in a health system with a clear focus on "cure", with healthcare providers being less likely to actively and early address PC needs. 'SENS' may help to structure communication on anticipatory planning complementary to medical reasoning. Health professionals may finally feel better prepared and trained for end-of- 
life conversations. Such conversation has earlier been entitled 'the multimillion dollar conversation' because of its ability to save money through the redirection of hope and trust from potential toxic medical intervention to individual goals of care ${ }^{6}$.

\subsection{Impact of 'SENS' on Financial Reimbursement of PC Interventions}

The current Swiss healthcare system is a strongly diagnosis-oriented system (DRG), while PC is a problem-based approach. Defining specific activities for PC, therefore, is paramount to obtain sufficient financial reimbursement. The 'SENS'structure has recently been officially acknowledged as the basic assessmentstructure triggering the comprehensive DRG-codes for complex palliative treatment. Introducing a problem-based structure like other ePC interventions the 'SENS'-structure could have a positive impact on overall health care costs in the last months of life, with more emphasis on problem-solving than expensive diagnosis-driven interventions.

\subsection{Impact of 'SENS' on PC Education and Research}

The 'SENS'-structure has been integrated into professional PC curricula at undergraduate and postgraduate levels in our country ${ }^{33}$. The four themes of 'SENS' seemed to cover what PC is actually offering and doing in clinical practice, providing an overview which is easy to understand-for professionals, as well as for the broad public. Of course, conversations based on 'SENS' need to be trained, especially in the ways how to speak about certain sensitive topics at the right time to not overburden the patient.

Although qualitative and health service research is getting more attention, areas such as decision-making, health care services/network, and areas of burden and resources of the family are less frequently a subject of interprofessional research. 'SENS' may also allow for a more comprehensive view on palliative research topics and on their weighting.

Further development and refinement of the 'SENS'-structure and testing in clinical and educational settings through research is needed. Whether 'SENS' truly covers all aspects of assessment and care planning in PC for specific populations, such as pediatric, elderly, and patients with dementia, remains to be determined by systematic research. 


\section{Conclusions}

Since the medical field is mostly aligned with a diagnosis-focused approach, a problem and resources-oriented approach is rather unusual. 'Concurrent care' has recently become a promising model of care to bring these two approaches together. The 'SENS'-structure was developed to foster a strong patient-needsbased and participatory approach in such a model.

The starting point of our search for a meaningful person-centered interprofessional PC approach led us toward a structure that is easy to use in clinical practice in and across all settings, but also in PC research and professional education. Support from a specialized PC team might encourage and facilitate the implementation of the 'SENS'-structure into care pathways for patients with a life-limiting disease.

The 'SENS'-structure seemed to covers all themes and complexity as proposed by other structures, such as the GSF or the NCCN guidelines for PC. Providing guidance for $\mathrm{ePC}$ conversations, including $\mathrm{ACP}$, it focuses particularly on patient perspectives. Practice experience so far shows that 'SENS' helped patients and their families facing complex PC situations to plan proactively and to be prepared for future challenges, including death and dying. In addition, professionals reported its usefulness to prioritize and focus on what is important and manageable in the individual situation and to define task distributions within a common care plan through direct cooperation and mutual respect. Further research to confirm the usefulness of the 'SENS'-structure as experienced by patients and clinicians is required in phases 3 and 4 of the MRC framework.

In the German-speaking part of Switzerland, the 'SENS'-structure has been implemented in clinical practice in hospitals, as well as in primary care over the past six years and has been recommended by the Swiss federal office of health. We anticipate that the 'SENS'-structure may play a significant role in further development of 'concurrent' treatment, combining disease-modifying treatment and a person-centered care plan, making sense for patients' family, and carers, as well as for professionals. 
Author Contributions: S.E., D.B., and M.M. developed the idea, performed the analysis of the ePC conversations, and drafted the 'SENS'-structure. M.C.F. participated in the discussion and further refinement of the 'SENS'-structure and its clinical testing and drafted the article. G.M. and J.M.G.A.S. supported the discussion of the usefulness of 'SENS' in other settings than hospitals and advised in the preparation of the manuscript. All authors read, critically revised and approved the article before publication, and ensured that questions related to the accuracy or integrity of the work were appropriately looked into.

Funding: This project received no external funding.

Acknowledgments: The authors wish to thank patients and families for their openness in ePC conversations, which enabled us to develop the 'SENS'structure. Also, we would like to thank all clinicians for their valuable feedback in the development process. A special thanks to Sofia Zambrano and Nora Lüthi who helped us by editing the article.

Conflicts of Interest: The authors declare no conflict of interest. 


\section{References}

1. Dixon J, Matosevic T, Knapp M. The economic evidence for advance care planning: Systematic review of evidence. Palliat Med. 2015, 29, 869-884. doi 10.1177/0269216315586659.

2. Mitchell GK. The role of general practice in cancer care. Aust Fam Physician 2008, 37, 698-702.

3. Rubin G, Berendsen A, Crawford SM, Dommett R, Earle C, Emery J, Fahey T, Grassi L, Grunfeld E, Gupta S, et al. The expanding role of primary care in cancer control. Lancet Oncol. 2015, 16, 1231-1272. doi 10.1016/S1470-2045(15)00205-3.

4. Brinkman-Stoppelenburg A, Rietjens JA, van der Heide, A. The effects of advance care planning on end-of-life care: A systematic review. Palliat Med. 2014, 28, 1000-1025. doi 10.1177/0269216314526272.

5. Bond WF, Kim M, Franciskovich CM, Weinberg JE, Svendsen JD, Fehr LS, Funk A, Sawicki R, Asche CV. Advance care planning in an accountable care organization is associated with increased advanced directive documentation and decreased costs. J Palliat Med. 2018, 21, 489-502. doi 10.1089/jpm.2017.0566.

6. Zhang B, Wright AA, Huskamp HA, Nilsson ME, Maciejewski ML, Earle CC, Block SD, Maciejewski PK, Prigerson HG. Health care costs in the last week of life: Associations with end-of-life conversations. Arch Intern Med. 2009, 169, 480-488. doi 10.1001/ archinternmed.2008.587.

7. Gomez-Batiste X, Martinez-Munoz M, Blay C, Espinosa J, Contel JC, Ledesma A. Identifying needs and improving palliative care of chronically ill patients: A community-oriented, population-based, public-health approach. Curr Opin Support Palliat Care. 2012, 6, 371-378. doi 10.1097/SPC.0b013e328356aaed.

8. Temel JS, Greer JA, Muzikansky A, Gallagher ER, Admane S, Jackson VA, Dahlin CM, Blinderman CD, Jacobsen J, Pirl WF, et al. Early palliative care for patients with metastatic non-small-cell lung cancer. N Engl J Med. 2010, 363, 733-742. doi 10.1056/ NEJMoa1000678.

9. Zimmermann C, Swami N, Krzyzanowska M, Hannon B, Leighl N, Oza A, Moore M, Rydall A, Rodin G, Tannock I. et al. Early palliative care for patients with advanced cancer: A cluster-randomised controlled trial. Lancet. 2014, 383, 1721-1730. doi 10.1016/S0140-6736(13)62416-2.

10. Luckett T, Phillips J, Agar M, Virdun C, Green A, Davidson PM. Elements of effective palliative care models: A rapid review. BMC Health Serv Res. 2014, 14, 136. doi 10.1186/1472-6963-14-136.

11. Weisbord SD, Carmody SS, Bruns FJ, Rotondi AJ, Cohen LM, Zeidel ML, Arnold RM. Symptom burden, quality of life, advance care planning and the potential value of palliative care in severely ill haemodialysis patients. Nephrol Dial Transplant. 2003, 18, 1345-1352. doi 10.1093/ndt/gfg105.

12. Karam CY, Paganoni S, Joyce N, Carter GT, Bedlack R. Palliative care issues in amyotrophic lateral sclerosis: An evidenced-based review. Am J Hosp Palliat Care. 2016, 33, 84-92. doi 10.1177/1049909114548719.

13. Greutmann M, Tobler D, Colman JM, Greutmann-Yantiri M, Librach SL, Kovacs $\mathrm{AH}$. Facilitators of and barriers to advance care planning in adult congenital heart disease. Congenit Heart Dis. 2013, 8, 281-288. doi 10.1111/chd.12025. 
14. Biondo PD, Lee LD, Davison SN, Simon JE. Advance Care Planning Collaborative Research; Innovation Opportunities Program. How healthcare systems evaluate their advance care planning initiatives: Results from a systematic review. Palliat Med. 2016, 30, 720-729. doi 10.1177/0269216316630883.

15. Block SD, Billings JA. A need for scalable outpatient palliative care interventions. Lancet 2014, 383, 1699-1700. doi 10.1016/S0140-6736(13)62676-8.

16. Saunders $C$. The treatment of intractable pain in terminal cancer. Proc $R$ Soc Med. 1963, 56, 195-197.

17. Medical Research Council (MRC). A Framework for Development and Evaluation of RCTs for Complex Interventions to Improve Health. 2000. Available online: https:// mrc.ukri.org/documents/pdf/rcts-for-complex-interventions-to-improve-health/ (accessed on 20 May 2008).

18. Stiftung SanaCERT Suisse. Standard 25: [Palliative Care]. Available online: http://www. sanacert.ch/qualitaetsstandards/akutbereich/ (accessed on 21 November 2008).

19. Federal Office of Public Health (FOPH). Framework concept for palliative care in switzerland. A basis for defining palliative care for the implementation of the «National Strategy for Palliative Care». In Proceedings of the Swiss Conference of the Cantonal Ministers of Public Health (CMH) and palliative ch (2014), Bern, Switzerland, 15 July 2014.

20. Eychmueller S. SENS is making sense-On the way to an innovative approach to structure Palliative Care problems. Ther Umsch. 2012, 69, 87-90. doi 10.1024/00405930/a000256.

21. Qualitépalliative [Association for Quality in Palliative Care]. Available online: https:// www. qualitepalliative.ch/das-label/?L=0 (accessed on 1 November 2018).

22. Eychmueller S, Fliedner M. Active Preparation for the End of Life with Patients with Advanced Cancer: A Way to Reduce Stress and Increase Self-Determination? Available online: http://www.nfp67.ch/de/ projekte/modul-1-sterbeverlaeufe-undversorgung/projekt-eychmueller (accessed on 1 October 2014).

23. Sepulveda C, Marlin A, Yoshida T, Ullrich A. Palliative Care: The World Health Organization's global perspective. J Pain Symptom Manage. 2002, 24, 91-96. doi 10.1016/s0885-3924(02)00440-2.

24. World Health Organization (WHO). National Cancer Control Programmes: Policies and Managerial Guidelines, 2nd ed.; World Health Organization (WHO): Geneva, Switzerland, 2002.

25. Levy M, Smith T, Alvarez-Perez A, Back A, Baker JN, Beck AC, Block S, Dalal S, Dans M, Fitch TR. et al. Palliative Care Version 1.2016. J. Natl. Compr. Can. Netw. 2016, 14, 82-113.

26. Levy MH, Back A, Benedetti C, Billings JA, Block S, Boston B, Bruera E, Dy S, Eberle C, Foley KM. et al. NCCN clinical practice guidelines in oncology: Palliative care. J Natl Compr Canc Netw. 2009, 7, 436-473. doi 10.6004/jnccn.2016.0009.

27. National Gold Standards Framework Centre. National Gold Standards Framework. Available online: http://www.goldstandardsframework.org.uk/advance-careplanning (accessed on 16 February 2014).

28. Shaw KL, Clifford C, Thomas K, Meehan H. Review: Improving end-of-life care: A critical review of the gold standards framework in primary care. Palliat Med. 2010, 24, 317-329. doi 10.1177/0269216310362005. 
29. Thomas K, Noble B. Improving the delivery of palliative care in general practice: An evaluation of the first phase of the Gold Standards Framework. Palliat Med. 2007, 21, 49-53. doi 10.1177/0269216306072501.

30. Popescu G, Tschanz Cooke K, Leemann H, Zimmermann J, Popescu R. SENS und Sensibility-Ambulante und stationäre Palliative Care in der Hirslanden Klinik Aarau (HKA) [SENS and Sensibility-outpatient and inpatient Palliative Care in the Hirslanden Hospital Aarau]. In Proceedings of the Nationaler Palliative Care Kongress, Biel, Switzerland, 26-27 November 2014; p. 29.

31. Federal Office of Public Health (FOPH) and palliative.ch. Palliative Care: Quality of Life until the End-An Information Sheet for General Practitioners. 2014. Available online: http://www.palliative.ch/ fileadmin/user_upload/palliative/fachwelt/ informationsblatt/palliative_care_hausaerzte.pdf (accessed on 20 December 2019).

32. Palliative Ostschweiz. Palliative Care-Professional Competencies Level A-C Based on, SENS; Palliative Ostschweiz: St. Gallen, Switzerland, 2015.

33. Eychmueller S, Abbühl LS, Bock F, Bueche D, Christen S, Gudat H, Marti M, Neuenschwander $\mathrm{H}$, Obrist $\mathrm{S}$, Pautex $\mathrm{S}$, et al. Palliative Medicine EssentialsFundamentals of Palliative Care; Verlag Hans Huber: Bern, Switzerland, 2015.

34. Federal Statistical Office (BFS). Circular for Coders: 2018/Nr. 1. 2017, p. 11. Available online: https://www.bfs.admin.ch/bfs/de/home/aktuell/neue-veroeffentlichungen. assetdetail.4202459.html (accessed on 21 November 2018).

35. Zwahlen S, Trelle S, Fliedner MC, Juni P, Aebersold D, Aujesky D, Fey M, Eychmueller S. A single early Palliative Care intervention-A randomized controlled trial. 2019; under submission.

36. Fliedner MC, Zambrano S, Schols JMGA, Bakitas M, Lohrmann C, Halfens RJG, Eychmueller S. A structured early palliative care intervention based on "SENS" can be confronting but reassuring: A qualitative study on the experiences of patients with advanced cancer. 2019; under review.

37. Eychmueller S, Egger M, Streit S, Gross C, Kläui H, Gerber A, Trelle S, Cina C, Mitchell G. The Bern Primary Palliative Care Trial (Bern-PPCT): A Cluster Trial of Palliative Needs Assessment and Care in General Practice. Available online: http://www.nfp74. ch/de/projekte/sektor-uebergreifende-versorgung/ projekt-eychmueller (accessed on 17 July 2018).

38. Walshe C, Caress A, Chew-Graham C, Todd C. Implementation and impact of the Gold Standards Framework in community palliative care: A qualitative study of three primary care trusts. Palliat Med. 2008, 22, 736-743. Doi 10.1177/0269216308094103.

39. Maas EA, Murray SA, Engels Y, Campbell C. What tools are available to identify patients with palliative care needs in primary care: A systematic literature review and survey of European practice. BMJ Suppor. Palliat Care. 2013, 3, 444-451. doi 10.1136/ bmjspcare-2013-000527.

40. Smith CB, Phillips T, Smith TJ. Using the New ASCO Clinical Practice Guideline for Palliative Care Concurrent With Oncology Care Using the TEAM Approach. Am Soc Clin Oncol Educ Book 2017, 37, 714-723. doi 10.14694/EDBK_175474.

41. Ferrell BR, Temel JS, Temin S, Alesi ER, Balboni TA, Basch EM, Firn JI, Paice JA, Peppercorn JM, Phillips T. et al. Integration of Palliative Care into Standard Oncology Care: American Society of Clinical Oncology Clinical Practice Guideline Update. J. Clin. Oncol. 2017, 35, 96-112. doi 10.1200/JCO.2016.70.1474. 
42. Van den Block $L$. The need for integrating palliative care in ageing and dementia policies. EurJ Public Health. 2014, 24, 705-706. doi 10.1093/eurpub/cku084.

43. Mehta Z, Giorgini K, Ellison N, Roth ME. Integrating palliative medicine with dementia care. Agging Well 2012, 5, 18.

44. World Health Organization (WHO). Strengthening of Palliative Care as a Component of Comprehensive Care throughout the Life Course; World Health Assembly: Geneva, Switzerland, 2014.

45. Greer JA, Tramontano AC, McMahon PM, Pirl WF, Jackson VA, El-Jawahri A, Parikh RB, Muzikansky A, Gallagher ER, Temel JS. Cost analysis of a randomized trial of early palliative care in patients with metastatic nonsmall-cell lung cancer. J Palliat Med. 2016, 19(8) 842-8. Doi 10.1089/jpm.2015.0476.

46. Smith S, Brick A, O'Hara S, Normand C. Evidence on the cost and cost-effectiveness of palliative care: A literature review. Palliat Med. 2014, 28, 130-150. doi 10.1177/0269216313493466.

(c) 2019 by the authors. Licensee MDPI, Basel, Switzerland. This article is an open access article distributed under the terms and conditions of the Creative Commons Attribution (CC BY) license (http://creativecommons.org/licenses/by/4.0/). 


\section{Chapter 3}

\section{The impact of early palliative care on the quality of care during the last days of life: what does the evidence say?}

This chapter was published as: Zambrano, S.C., M.C. Fliedner, and S. Eychmuller, The impact of early palliative care on the quality of care during the last days of life: what does the evidence say? Curr Opin Support Palliat Care, 2016. 10(4): p. 310-315. doi 10.1097/SPC.0000000000000240 


\section{Purpose of review}

The aim of this review is to critically appraise the existing evidence on 'early palliative care' (EPC), discuss its relationship with advance care planning, and to reflect on the impact of EPC on the quality of care provided during the last days of life.

\section{Recent findings}

There are indicators that EPC may help to avoid aggressive treatment, shorten hospital stay, improve overall quality of life, and to see more frequently dying and death at the preferred place of care.

\section{Summary}

The evidence from randomized controlled trials supports the integration of palliative care early in the disease trajectory. However, in terms of outcomes and quality indicators for care in the last days of life, evidence is still lacking. Predominantly, when it comes to the outcomes which may be more difficult to assess, such as spiritual aspects, or the social network, for which more comprehensive information is needed. These outcomes should not be neglected in palliative care studies, particularly when they can provide meaningful information about patient and family adjustment, and focus on psychosocial aspects rather than physical symptom control.

\section{Keywords}

advance care planning, early palliative care, last days of life, palliative care

\section{Key Points}

- The observed effects of EPC cannot be extrapolated directly to benefits during the last days of life.

- The similarities and differences between EPC and ACP need to be further explored.

- EPC should be 'concurrent' in certain disease pathways, but its initiation should be considered according to the individual needs of the patient. 


\section{Introduction}

Despite a relatively rapid expansion, the provision and implementation of palliative care into clinical care has been hindered by cultural barriers, medical reasoning with an emphasis on 'cure', and societal attitudes towards death and dying. In particular, there exists a general misconception that palliative care is reserved for the last days or weeks of life, a view which is at odds with the emphasis on early integration advocated by the WHO since $1990^{1}$.

The aim of this review is to critically appraise the existing evidence on 'early palliative care' (EPC), discuss its relationship with advance care planning (ACP), and to reflect on the impact of EPC on the quality of care provided during the last days of life.

\section{What is early palliative care?}

There is no accepted definition of EPC applicable to all contexts and clinical situations. EPC or 'early integration of palliative care', in the context of cancer care, is often defined as the 'introduction of specialized palliative care early in the disease trajectory ${ }^{\prime 2,3}$. However, the notion of providing early specialist palliative care has been challenged by emphasizing the shortage of palliative care specialists, and the need for EPC to be delivered by oncologists ${ }^{42}$, geriatricians ${ }^{5}$, and general practitioners ${ }^{5}$, among many other medical specialists.

Difficulties in understanding and defining EPC are further encountered when determining what 'early' refers to. In a systematic review of peer-reviewed articles about early integration of palliative care in oncology, only 18 out of 101 articles provided a time frame for the delivery of EPC6\&\&. Some studies, including the most recent American Society of Clinical Oncology (ASCO) recommendations, suggest the introduction of EPC at diagnosis of a life-limiting illness ${ }^{7-9}$. Others are more specific and suggest its initiation at diagnosis of advanced illness, or focus on life expectancy, the patient's performance status, or symptom burden ${ }^{6 \& \&, 10}$. The studies suggesting life expectancy propose a wide range of times: from 24 to 12 months or from 6 to 3 months before assumed death ${ }^{118,12,13}$. Other authors establish 3 months before expected death as the minimum time frame for palliative care to be considered 'early'14.

Identifying the appropriate moment in which to address palliative care needs remains a challenge. Not only are illness trajectories often unpredictable, but as mentioned above, most studies implement 'early' at very different 
moments ${ }^{15}$. An agreement seems to be that palliative care should be integrated before patients experience burdening symptoms for the first time. Therefore, given the prevalence of symptoms and the lack of significant differences in many studies, Gaertner et al. ${ }^{10}$ question whether what is considered 'early' could already be too late, if patients are being referred to palliative care when their symptoms are uncontrolled. Bruera et al. describe EPC as an 'integrated care model' in which the oncologist focuses on disease management, while palliative care teams focus on ACP as well as on physical, spiritual, and psychosocial concerns ${ }^{10,16,17}$.

\section{Provided by whom?}

The majority of the studies which have implemented EPC approaches have done so through specialist palliative care services. Considering that specialist palliative care services are scarce, general palliative care approaches are needed to incorporate palliative care into the care of the majority of patients with life-limiting illnesses ${ }^{18 z \&}$. Therefore, there is an emphasis on teaching general skills during medical and nursing school and during postgraduate training in the disciplines in which this type of care is needed the most, such as oncology, geriatrics, and general practice, cardiology, and nephrology ${ }^{18 z}$. This is particularly relevant because trained specialists can implement an integrated model of palliative care in which they provide basic palliative care on their own but are able to ascertain when they require the support and intervention of specialist palliative care teams ${ }^{5}$. Without this training and experience, it is possible that current practices of late palliative care referrals continue to occur.

\section{Differences and similarities between early palliative care and advance care planning}

The primary purpose of ACP is to ensure that the care provided to patients meets their preferences by respecting their decisions and autonomy ${ }^{19 \&}$. Although ACP can be regarded as a long-lasting process and involves more comprehensive interventions than just defining advance directives, EPC seems to have a wider approach focused on minimizing or dealing with the illness and the effects of its treatment. Yoong et al. ${ }^{20}$ proposed seven key elements of EPC in cancer care: rapport building, symptom management, addressing coping strategies, establishing illness understanding, discussing treatments, end-of-life planning, and engaging family members. These key aspects cannot easily be differentiated 
from those of complex ACP approaches ${ }^{21}$ and therefore, even though they are generally described as different entities, it is still difficult to differentiate the concepts of ACP and EPC.

\section{What aspects and from whose perspective?}

Palliative care clinicians establish a relationship first and determine patient needs and preferences for information before initiating the discussion of endof-life planning, when the health status of the patient has changed ${ }^{20}$. However, there seems to be a lack of clarity on the content and 'effective component' of EPC interventions ${ }^{22}$. From the patients' perspective, the literature defines certain topics and domains that need to be addressed in a comprehensive early assessment and planning. For example, symptom management, preparation for death, achieving a sense of completion, decisions about treatment preferences, and being treated as a 'whole person' are generally regarded by stakeholders as goals of treatment ${ }^{23}$. However, goals which are important for healthcare professionals may not be as meaningful to patients: A study found that patients gave more relevance than physicians to being mentally aware, having funeral arrangements planned, not being a burden, helping others, and coming to peace with $\mathrm{God}^{23}$.

\section{Impact on the last days of life}

A landmark randomized controlled trial (RCT) about the impact of EPC found that patients experienced improved quality of life, received less aggressive care, were more likely to establish advance directives, and lived longer ${ }^{9}$. Other studies identified improvements in symptoms ${ }^{3,24}$, depression ${ }^{24,25}$, distress ${ }^{26}$, quality of life ${ }^{3,24,27}$, and satisfaction with care and communication ${ }^{3,28,29}$. Family members reported emotional and spiritual growth and were more satisfied with care feeling that the needs of their relative were addressed appropriately ${ }^{30,31}$. Palliative care interventions also influence health service utilization: Patients are less likely to be admitted to the hospital, ICU, or emergency department ${ }^{29,32}$, and have an increased likelihood of dying in their preferred place ${ }^{29,33}$. Despite highlighting that some result discrepancies between RCTs may be related to differences in the nature and type of interventions, the timing of initiation or EPC, as well as defined outcomes, several systematic reviews of EPC further confirm its positive effects ${ }^{6 \& \&, 15,34 \&, 35 \& \&}$. Most importantly, the observed effects cannot be extrapolated directly to benefits during the last days of life, because the majority 
of the studies do not measure the outcomes which are more relevant to the last days of life, except when measuring place of death and certain measures of healthcare utilization.

The OPCARE 9 collaboration sought consensus about quality indicators, including care outcomes relevant to the last days of life ${ }^{36,37}$. Among the highest ranking parameters were managing physical symptoms such as pain, nausea/ vomiting, dyspnea, and other aspects of care such as anxiety, and timely communication about approaching death ${ }^{36}$. In the proposed list of topics by Raijmakers et al..$^{37}$ were the availability of a family room, a home visit after the patient's death, preferred place of death, less patients receiving chemotherapy, limited need for pain control, fewer gastrointestinal symptoms, and adequate communication between professionals and the patient and families, as well as the use of care plans, pathways or guidelines.

The evidence from RCTs supports the integration of palliative care early in the disease trajectory. However, in terms of the proposed outcomes and quality indicators for care in the last days of life, evidence is still lacking. Predominantly, when it comes to the outcomes which may be more difficult to assess, such as spiritual aspects, or for which more comprehensive information is needed, such as the social network. These outcomes should not be neglected in palliative care studies, particularly when they can provide meaningful information about patient and family adjustment and focus on psychosocial aspects rather than physical symptom control ${ }^{382 \&, 39}$.

More specific aspects which can be considered as part of better care during the last days of life can be more easily identified in ACP studies than in EPC studies, in which matched preferences for place of death with actual place of death tend to be found after most interventions, as well as less use of resuscitation and life-sustaining equipment ${ }^{21}$. This may be the case because ACP studies include these end-of-life outcomes, whereas the majority of EPC studies focus on more general health care and economic outcomes.

Cost-saving studies of palliative care, in which invasive and expensive treatments are reduced, can provide some evidence that patients receive less aggressive treatments at the end-of-life ${ }^{40,41}$. Studies on personal costs such as out of pocket costs for family members of patients in palliative care are still scarce $^{42}$.

Of the many studies identified, only one assessed the effects of EPC on the treatment during the last week of life. Zhang et al. ${ }^{43}$ found that patients who 
had discussions about the end-of-life about 6 months before death, including discussions about treatment preferences, were more likely to choose more conservative treatments and to be more realistic about their prognosis. In their study, an end-of-life conversation was associated with a good quality of life in the last week of life in terms of being less likely to die in the ICU, to be resuscitated, having less physical distress, and it was also associated with $35.7 \%$ less hospital costs during the last week of life. They did not find differences in psychological distress or survival time. Further analyses showed that higher medical costs were associated with more distress and worse overall quality of death from the caregiver's perspective ${ }^{43,44}$.

\section{Clinical and research implications}

Reviewing the effect of 'EPC' on the quality of death and dying has led us to reflect on three main aspects: what are the differences between EPC and ACP?, which are the essential factors that may contribute to a 'good death'?, and what are the meaningful outcomes of this relatively new approach called 'EPC'? The answers to these questions encompass a more profound discussion on 'what is the effective component of palliative care?', and even further, on 'what is palliative care', 'EPC', and 'ACP'?

In good clinical practice, early and comprehensive assessment and management of potential stressful situations in deteriorating health conditions for patients, family carers but also for health professionals is warranted. In this context, timing ('right time for the right patient') might be an important issue.

\section{What are the differences between early palliative care and advance care planning?}

'Early' in the clinical setting is a poorly defined term. From our perspective, 'concurrent' may be a better, and less bothersome term. As Bruera and Hui ${ }^{16}$ pointed out palliative care or EPC is not a matter of timing but of content. Patients may fear 'early' palliative care, as may do specialists and health insurance companies (see reimbursement policy in the United States for hospice care). In its implementation, 'palliative care' has created despair and new fears (e.g. ${ }^{45 \& \&, 46}$ ), and even after decades of routine implementation in many countries and settings, palliative care is still often associated with dying and death ${ }^{47 \& \& 48}$. Based on the literature, a new 'branding' of what we do and offer is important: 'EPC' is in 
other words 'concurrent ACP' in chronic progressive conditions including the last months, weeks, and days of life, and explicitly addressing fears in terms of 'dying and death'. By following this interpretation, EPC would add pragmatic planning driven by the patients' and families' agenda and consequently, would structure the questions (patient-related meaningful outcomes) that should be addressed, offering a clear process based on a high level of compassionate communication.

\section{Which are the essential factors that may contribute to a 'good death'?}

As mentioned above beyond the question of 'when', the 'what' is crucial: evidence shows that palliative care adds a problem-based, patient-centred, interprofessional approach to assessment and care planning, which complements the pure medical diagnosis-based reasoning prevailing in the medical context.

End-of-life discussions and evaluating the goals early enough to avoid emergency situations and crisis decisions are specifically helpful to improve quality of care, quality of life, and the appropriateness of medical interventions (e.g., ${ }^{3,43,49}$ ). In addition, certain barriers need to be overcome to facilitate working hand-in-hand between specialists, the palliative care team and/or primary care clinicians ${ }^{50,51}$.

There is no research directly connecting EPC interventions and quality of death in an experimental design. There are indicators that EPC may help to avoid aggressive treatment, shorten hospital stay, improve overall quality of life, and possibly to see more frequently dying and death at the preferred place of care. However, taking into account the character of mixed and complex interventions with various potentially confounding factors, and the heterogeneity of involved populations and health systems (which may influence endpoints such as place of care), it is still unknown whether there is any causality between EPC interventions and 'a good dying and death'.

\section{What are the meaningful outcomes of early palliative care?}

Questions regarding patient priorities as to which outcomes of care are more relevant in the last days of life remain unexplored ${ }^{52}$. How can services best identify and meet patients' individual needs, and how can they effectively measure them? Research with a more narrow focus on the late stage of life is required ${ }^{53}$. During the last days of life, the symptoms of dying as well as the 
illness itself and the awareness of dying may affect the patient at a level in which it had not before, and many areas of patient and family need could be neglected, or given less importance based on current outcome standards ${ }^{39}$.

There is no agreed upon core outcome set for best care for the dying or indicators of a 'good death'. Much more work is needed to better understand common and individual outcomes from the perspective of patients (if possible to be captured) and family caregivers. Partnership research projects bringing together all stakeholders, including health professionals, patients, and families, may provide such information in the future.

\section{Conclusion}

The issue of identifying an appropriate time for 'early' palliative care requires a reconsideration of the characteristics of the specific setting, considering that although some patients may have a longer life expectancy as in breast cancer or congestive heart failure, in other diagnoses the model of EPC delivery should include specialized palliative care teams in addition to the basic palliative care provided by superficially trained professionals ${ }^{17}$.

EPC and ACP are interrelated concepts which need to be more clearly defined. We suggest that complex ACP interventions provide comprehensive palliative care irrespective of a disease time frame, whereas EPC focuses on the clinical effects of disease early on. The components of what makes a difference for the patients and families via EPC or ACP need to be incorporated into routine clinical care for patients with a life-limiting illness.

\section{Acknowledgements}

None.

\section{Financial support and sponsorship}

In the writing of the manuscript the authors received no financial support and/or sponsorship.

\section{Conflicts of interest}

There are no conflicts of interest. 


\section{References and recommended reading}

Papers of particular interest, published within the annual period of review, have been highlighted as:

\& of special interest

$\& \&$ of outstanding interest

1. World Health Organisation. Cancer pain relief and palliative care. WHO expert committee on cancer pain relief and active supportive care. Geneva: World Health Organisation; 1990.

2. Gaertner J, Weingartner V, Wolf J, Voltz R. Early palliative care for patients with advanced cancer: how to make it work? Curr Opin Oncol. 2013;25(4):342-52. doi 10.1097/CCO.0b013e3283622c5e.

3. Zimmermann C, Swami N, Krzyzanowska M, Hannon B, Leighl N, Oza A, et al. Early palliative care for patients with advanced cancer: a cluster-randomised controlled trial. Lancet. 2014;383(9930):1721-30. doi 10.1016/S0140-6736(13)62416-2.

\& 4. Hui D, Finlay E, Buss MK, Prommer EE, Bruera E. Palliative Oncologists: Specialists in the Science and Art of Patient Care. J Clin Oncol. 2015;33(20):2314-7. doi 10.1200/ JCO.2014.60.3274.

Interesting piece highlighting what palliative oncology is and the role of palliative oncologists in bridging oncology and specialist palliative care.

5. Quill TE, Abernethy AP. Generalist plus specialist palliative care--creating a more sustainable model. N Eng/J Med. 2013;368(13):1173-5. doi 10.1056/NEJMp1215620.

\&\& 6. Hui D, Kim YJ, Park JC, Zhang Y, Strasser F, Cherny N, et al. Integration of oncology and palliative care: a systematic review. Oncologist. 2015;20(1):77-83. doi 10.1634/ theoncologist.2014-0312.

This systematic review identified 101 articles which point to different aspects (clinical, administrative, educational and research) of early integration of palliative care into oncology.

7. Ferris FD, Bruera E, Cherny N, Cummings C, Currow D, Dudgeon D, et al. Palliative cancer care a decade later: accomplishments, the need, next steps -- from the American Society of Clinical Oncology. J Clin Oncol. 2009;27(18):3052-8. doi 10.1200/ JCO.2008.20.1558.

8. Smith TJ, Temin S, Alesi ER, Abernethy AP, Balboni TA, Basch EM, et al. American Society of Clinical Oncology provisional clinical opinion: the integration of palliative care into standard oncology care. Journal of Clinical Oncology. 2012;30(8):880-7. doi 10.1200/JCO.2011.38.5161.

9. Temel JS, Greer JA, Muzikansky A, Gallagher ER, Admane S, Jackson VA, et al. Early palliative care for patients with metastatic non-small-cell lung cancer. N Engl J Med. 2010;363(8):733-42. doi 10.1056/NEJMoa1000678.

10. Gaertner J, Wolf J, Frechen S, Klein U, Scheicht D, Hellmich M, et al. Recommending early integration of palliative care - does it work? Support Care Cancer. 2012;20(3):50713. doi 10.1007/s00520-011-1111-2. 
\& 11. Amano K, Morita T, Tatara R, Katayama H, Uno T, Takagi I. Association between early palliative care referrals, inpatient hospice utilization, and aggressiveness of care at the end of life. J Palliat Med. 2015;18(3):270-3. doi 10.1089/jpm.2014.0132.

This retrospective study of 266 cancer decedents in Japan found that early palliative care referrals facilitated hospice admission and less aggressive end of life care.

12. Nieder C, Tollali T, Haukland E, Reigstad A, Flatoy LR, Engljahringer K. Impact of early palliative interventions on the outcomes of care for patients with non-small cell lung cancer. Support Care Cancer. [Epub ahead of print]

13. Hui D, Kim SH, Roquemore J, Dev R, Chisholm G, Bruera E. Impact of timing and setting of palliative care referral on quality of end-of-life care in cancer patients. Cancer. 2014;120(11):1743-9. doi 10.1002/cncr.28628.

14. Davis MP, Carrino C. Promoting further use of palliative care in cancer care centers. Expert Review of Quality of Life in Cancer Care. 2016;1(3):213-20. doi 10.1080/23809000.2016.1181976.

15. Dalgaard KM, Bergenholtz $\mathrm{H}$, Nielsen ME, Timm H. Early integration of palliative care in hospitals: A systematic review on methods, barriers, and outcome. Palliat Support Care. 2014;12(6):495-513. doi 10.1017/S1478951513001338.

16. Bruera E, Hui D. Integrating supportive and palliative care in the trajectory of cancer: establishing goals and models of care. J Clin Oncol. 2010;28(25):4013-7. doi 10.1200/ JCO.2010.29.5618.

17. Greer JA, Jackson VA, Meier DE, Temel JS. Early integration of palliative care services with standard oncology care for patients with advanced cancer. CA Cancer J Clin. 2013;63(5):349-63. doi 10.3322/caac.21192.

\&\&18. Gaertner J, Maier BO, Radbruch L. Resource allocation issues concerning early palliative care. Ann Palliat Med. 2015;4(3):156-61. doi 10.3978/j.issn.22245820.2015.07.02.

This review article discusses early palliative care provided through general and specialist approaches and concludes that both approaches must coexist as a joint effort.

\& 19. Rietjens J, Korfage I, van der Heide A. Advance care planning: Not a panacea. Palliat Med. 2016;30(5):421-2. doi 10.1177/0269216316642963.

This editorial discusses the advantages, challenges, dilemmas and pitfalls of engaging patients in advance care planning (ACP) and suggests a way forward for research studies to provide more meaningful evidence on the usefulness of ACP.

20. Yoong J, Park ER, Greer JA, Jackson VA, Gallagher ER, Pirl WF, et al. Early palliative care in advanced lung cancer: a qualitative study.JAMA Intern Med. 2013;173(4):283-90. doi 10.1001/jamainternmed.2013.1874.

21. Brinkman-Stoppelenburg A, Rietjens JA, van der Heide A. The effects of advance care planning on end-of-life care: a systematic review. Palliat Med. 2014;28(8):1000-25. doi 10.1177/0269216314526272.

22. Block SD, Billings JA. A need for scalable outpatient palliative care interventions. Lancet. 2014;383(9930):1699-700. doi 10.1016/S0140-6736(13)62676-8.

23. Steinhauser KE, Christakis NA, Clipp EC, McNeilly M, Mclntyre L, Tulsky JA. Factors considered important at the end of life by patients, family, physicians, and other care providers. JAMA. 2000;284(19):2476-82. doi 10.1001/jama.284.19.2476. 
24. Bakitas M, Lyons KD, Hegel MT, Balan S, Brokaw FC, Seville J, et al. Effects of a palliative care intervention on clinical outcomes in patients with advanced cancer: the Project ENABLE II randomized controlled trial. JAMA. 2009;302(7):741-9. doi 10.1001/jama.2009.1198.

25. Pirl WF, Greer JA, Traeger L, Jackson V, Lennes IT, Gallagher ER, et al. Depression and survival in metastatic non-small-cell lung cancer: effects of early palliative care. J Clin Oncol. 2012;30(12):1310-5. doi 10.1200/JCO.2011.38.3166.

26. Aiken LS, Butner J, Lockhart CA, Volk-Craft BE, Hamilton G, Williams FG. Outcome evaluation of a randomized trial of the PhoenixCare intervention: program of case management and coordinated care for the seriously chronically ill. J Palliat Med. 2006;9(1):111-26. doi 10.1089/jpm.2006.9.111.

27. Clark MM, Rummans TA, Sloan JA, Jensen A, Atherton PJ, Frost MH, et al. Quality of life of caregivers of patients with advanced-stage cancer. Am J Hosp Palliat Care. 2006;23(3):185-91. doi 10.1177/1049909106289074.

28. Engelhardt JB, McClive-Reed KP, Toseland RW, Smith TL, Larson DG, Tobin DR. Effects of a program for coordinated care of advanced illness on patients, surrogates, and healthcare costs: a randomized trial. Am J Manag Care. 2006;12(2):93-100.

29. Brumley R, Enguidanos S, Jamison P, Seitz R, Morgenstern N, Saito S, et al. Increased satisfaction with care and lower costs: results of a randomized trial of in-home palliative care. J Am Geriatr Soc. 2007;55(7):993-1000. doi 10.1111/j.15325415.2007.01234.x.

30. Roza KA, Lee EJ, Meier DE, Goldstein NE. A survey of bereaved family members to assess quality of care on a palliative care unit. J Palliat Med. 2015;18(4):358-65. doi 10.1089/jpm.2014.0172.

31. Hales S, Chiu A, Husain A, Braun M, Rydall A, Gagliese L, et al. The quality of dying and death in cancer and its relationship to palliative care and place of death. J Pain Symptom Manage. 2014;48(5):839-51. doi 10.1016/j.jpainsymman.2013.12.240.

32. Khandelwal N, Benkeser DC, Coe NB, Curtis JR. Potential Influence of Advance Care Planning and Palliative Care Consultation on ICU Costs for Patients With Chronic and Serious Illness. Crit Care Med. 2016;44(8):1474-81. doi 10.1097/ CCM.0000000000001675.

33. Abel J, Pring A, Rich A, Malik T, Verne J. The impact of advance care planning of place of death, a hospice retrospective cohort study. BMJ Support Palliat Care. 2013;3(2):16873. doi 10.1136/bmjspcare-2012-000327.

\& 34. Tassinari D, Drudi F, Monterubbianesi MC, Stocchi L, Ferioli I, Marzaloni A, et al. Early Palliative Care in Advanced Oncologic and Non-Oncologic Chronic Diseases: A Systematic Review of Literature. Rev Recent Clin Trials. 2016;11(1):63-71. doi 10.2174/ 1574887110666151014141650.

This is the most recent systematic review that combines evidence for early palliative care (EPC) in malignant and nonmalignant illnesses.

\&\& 35. Davis MP, Temel JS, Balboni T, Glare P. A review of the trials which examine early integration of outpatient and home palliative care for patients with serious illnesses. Ann Palliat Med. 2015;4(3):99-121. doi 10.3978/j.issn.2224-5820.2015.04.04.

While identifying evidence in favour of EPC in the outpatient setting, the authors provide critical arguments on why better research is needed in this area and how it can be improved. 
36. Eychmueller S, Grossenbacher-Gschwend B, Montag T, Voltz R. What we should achieve: core outcome sets for care in the dying phase. In: Ninth world research congress of the European Association for Palliative Care; June 9-11, 2016, Dublin: Palliative Medicine; 2016.NP1-NP401.

37. Raijmakers N, Galushko M, Domeisen F, Beccaro M, Lundh Hagelin C, Lindqvist O, et al. Quality indicators for care of cancer patients in their last days of life: literature update and experts' evaluation. J Palliat Med. 2012;15(3):308-16. doi 10.1089/ jpm.2011.0393.

\&\& 38. Michael N, O'Callaghan C, Brooker JE, Walker H, Hiscock R, Phillips D. Introducing a model incorporating early integration of specialist palliative care: A qualitative research study of staff's perspectives. Palliat Med. 2016;30(3):303-12. doi 10.1177/0269216315598069.

This qualitative study explored staff perceptions of the challenges associated with providing EPC and discuss its implications for services implementing new models of palliative care delivery.

39. Currow DC. The PRISMA Symposium 3: lessons from beyond Europe. why invest in research and service development in palliative care? An Australian perspective. J Pain Symptom Manage. 2011;42(4):505-10. doi 10.1016/j.jpainsymman.2011.06.007.

40. Smith S, Brick A, O'Hara S, Normand C. Evidence on the cost and cost-effectiveness of palliative care: a literature review. Palliat Med. 2014;28(2):130-50. doi $10.1177 / 0269216313493466$.

41. Gade G, Venohr I, Conner D, McGrady K, Beane J, Richardson RH, et al. Impact of an inpatient palliative care team: a randomized control trial.J Palliat Med. 2008;11(2):18090. doi 10.1089/jpm.2007.0055.

42. Penders YW, Rietjens J, Albers G, Croezen S, Van den Block L. Differences in outof-pocket costs of healthcare in the last year of life of older people in 13 European countries. Palliat Med. 2016. [Epub ahead of print]

43. Zhang B, Wright AA, Huskamp HA, Nilsson ME, Maciejewski ML, Earle CC, et al. Health care costs in the last week of life: associations with end-of-life conversations. Archives of internal medicine. 2009;169(5):480-8. doi 10.1001/archinternmed.2008.587.

44. Zhang B, Nilsson ME, Prigerson HG. Factors important to patients' quality of life at the end of life. Archives of internal medicine. 2012;172(15):1133-42. doi 10.1001/ archinternmed.2012.2364.

\&\& 45. Zimmermann C, Swami N, Krzyzanowska M, et al. Perceptions of palliative care among patients with advanced cancer and their caregivers. Can Med Assoc J 2016; 188:E217 - E227. [Epub ahead of print]

This qualitative follow-up study investigated patients' and caregivers' perceptions of palliative care after participating in a randomized controlled trial of EPC. The authors found that both groups (intervention and nonintervention) had similar negative perceptions of palliative care. After completion of the study, those in the intervention group had a wider definition of palliative care but still held a negative perception of the term.

46. Maciasz RM, Arnold RM, Chu E, Park SY, White DB, Vater LB, et al. Does it matter what you call it? A randomized trial of language used to describe palliative care services. Support Care Cancer. 2013;21(12):3411-9. doi 10.1007/s00520-013-1919-z. 
\&\& 47. Weil J, Weiland TJ, Lane $\mathrm{H}$, et al. What's in a name? A qualitative exploration of what is understood by 'palliative care' in the emergency department. Palliat Med 2015; 29:293 - 301. [Epub ahead of print]

Staff perceptions of palliative care were investigated in this qualitative study. The authors highlight several contradictions in staff's understanding of palliative care and discuss its implications on palliative care referrals.

48. Gott M, Seymour J, Ingleton C, Gardiner C, Bellamy G. 'That's part of everybody's job': the perspectives of health care staff in England and New Zealand on the meaning and remit of palliative care. Palliat Med. 2012;26(3):232-41. doi $10.1177 / 0269216311408993$.

49. Holmes HM, Hayley DC, Alexander GC, Sachs GA. Reconsidering medication appropriateness for patients late in life. Archives of internal medicine. 2006;166(6):6059. doi 10.1001/archinte.166.6.605.

50. Kelley AS, Meier DE. Palliative Care - A Shifting Paradigm. New England Journal of Medicine. 2010;363(8):781-2. doi doi:10.1056/NEJMe1004139.

51. Alesi ER, Fletcher DS. Integrating palliative care into oncology care: confronting the barriers. Oncology (Williston Park). 2013;27(1).

52. Chan R, Webster J. End-of-life care pathways for improving outcomes in caring for the dying. Cochrane Database Syst Rev. 2010(1):CD008006. doi 10.1002/14651858. CD008006.pub2.

53. Costantini M, Lunder U. OPCARE9 - A European perspective on the last days of life. European Journal of Palliative Care. 2012;19(4):175-7. 


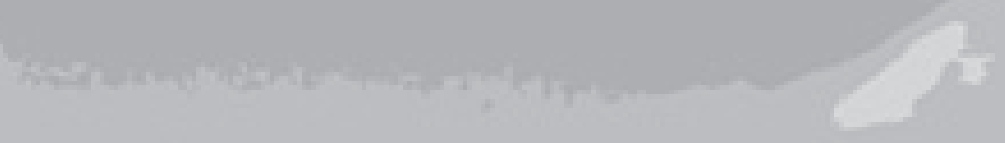

\section{Chas}
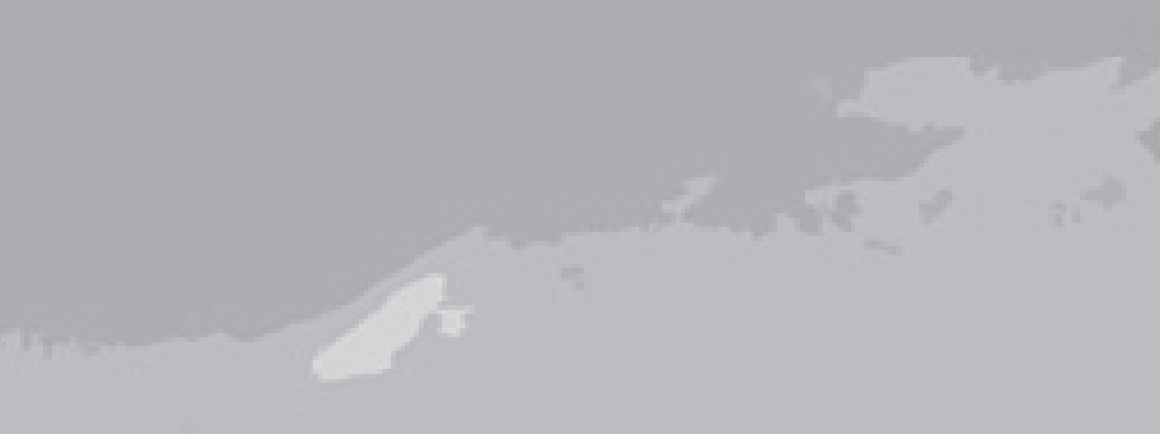

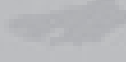

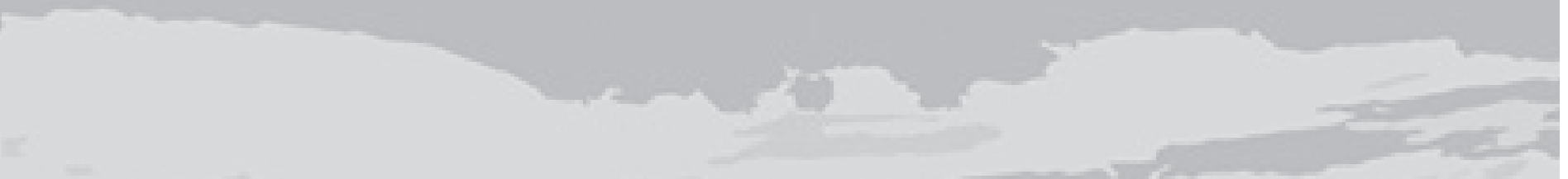

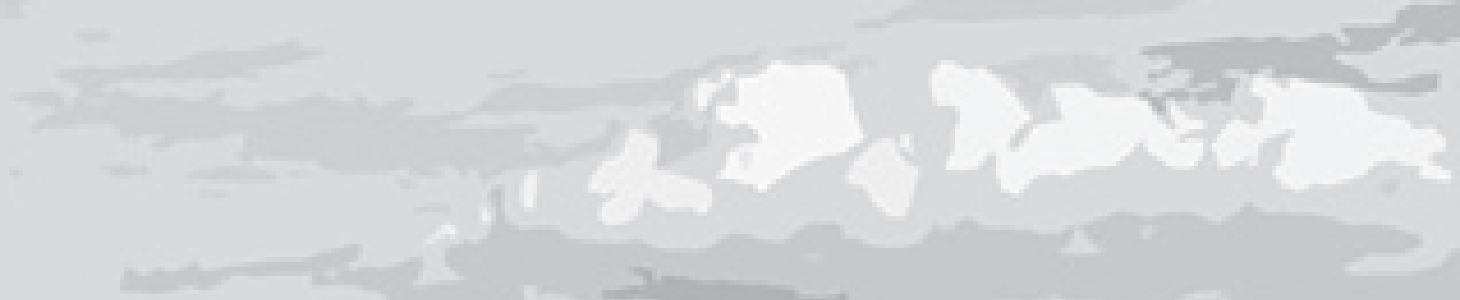

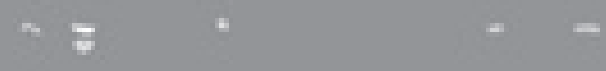

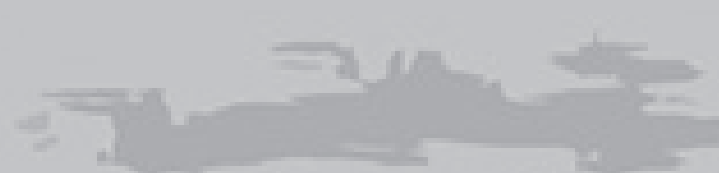

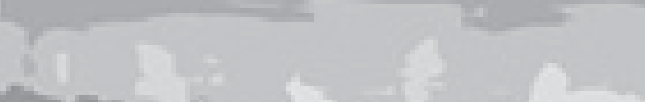

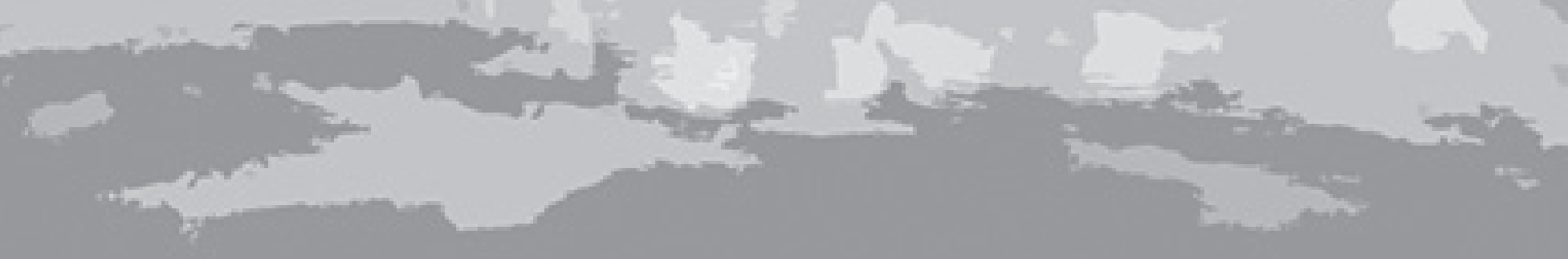




\section{Chapter 4}

\section{An early palliative care intervention can be confronting but reassuring: A qualitative study on the experiences of patients with advanced cancer}

This chapter was published as:

Fliedner, M., Zambrano, S., Schols, J. M., Bakitas, M., Lohrmann, C., Halfens, R. J., \& Eychmuller, S. (2019). An early palliative care intervention can be confronting but reassuring: A qualitative study on the experiences of patients with advanced cancer. Palliat Med, 33(7), 783-792. doi $10.1177 / 0269216319847884$ 


\section{Abstract}

Background: Intervention trials confirm that patients with advanced cancer receiving early palliative care experience a better quality of life and show improved knowledge about and use of palliative care services. To involve patients in future healthcare decisions, health professionals should understand patients' perspectives. However, little is known about how patients experience such interventions.

Aim: To explore advanced cancer patients' experiences with a structured early palliative care intervention, its acceptability and impact on the patients' life including influencing factors.

Design: Qualitative content analysis of in-depth, semi-structured interviews.

Setting/participants: Patients with various advanced cancer diagnoses were enrolled in a multicenter randomized controlled trial (NCT01983956), which investigated the impact of "Symptoms, End-of-life decisions, Network, Support," a structured early palliative care intervention, on distress. Of these, 20 patients who underwent the intervention participated in this study.

Results: Participants received the intervention well and gained a better understanding of their personal situation. Patients reported that the intervention can feel "confronting" but with the right timing it can be confirming and facilitate family conversations. Patients' personal background and the intervention timing within their personal disease trajectory influenced their emotional and cognitive experiences; it also impacted their understanding of palliative care and triggered actions toward future care planning.

Conclusion: Early palliative care interventions like "Symptoms, End-of-life decisions, Network, Support" may provoke emotions and feel "confrontational" often because this is the first time when issues about one's end of life are openly discussed; yet, advanced cancer patients found it beneficial and felt it should be incorporated into routine care.

\section{Keywords}

(Early) palliative care, neoplasms, qualitative research, advance care planning 


\section{What is already known about the topic?}

- Early palliative care interventions for patients with advanced cancer lead to improved quality of life and less burdening symptoms and depression compared to usual cancer care.

\section{What this paper adds?}

- The "SENS" intervention structure, a conversational intervention about Symptoms, End-of-life decisions, Network and Support, was designed to meet relevant domains of patient needs and enhances self-guided anticipatory planning.

- Patients perceive the SENS-intervention as emotional and confronting but at the same time find that it provides safety, support and affirmation. The timing of the intervention should be individualized.

- Patients' experiences with the intervention affect their understanding of what palliative care entails and the concrete actions that were triggered by the SENS-intervention (e.g., anticipatory planning).

\section{Implications for practice, theory or policy}

- SENS is helpful to structure early palliative care conversations using a participatory approach and helps unravel complex issues.

- Palliative care conversations should be initiated by a trusted healthcare professional, early in the trajectory of a life limiting disease and concurrent with disease modifying treatment.

- Practical information about self-management when a disease is progressive can stimulate patients to reflect on their wishes toward future care.

- Health professionals need specialized skills to sensitively support patients to address future worries and fears and to establish a trusting patient-health care professional relationship.

- Supporting and empowering patients to engage in early conversations with their social network about future health care needs prepares them to face more vulnerable times. 


\section{Introduction}

Multiple organizations ${ }^{1-4}$ emphasize that palliative care interventions should be initiated early in the disease trajectory and support advance care planning (ACP) ${ }^{5}$ for patients with serious, life-limiting illnesses alongside disease modifying treatment. ${ }^{3,6}$ Early palliative care, including ACP, involves complex interventions ${ }^{7}$ in which professionals discuss symptom management, support end-of-life decision-making and coordinate care.

Intervention trials ${ }^{6,8-19}$ confirm that patients with advanced cancer who receive early palliative care experience improved quality of life, ${ }^{6,19-21}$ symptoms, ${ }^{6,19}$ and mood, ${ }^{6}$ are more likely to document end-of-life care decisions, ${ }^{19}$ and be knowledgeable about palliative and hospice care. ${ }^{20}$ To provide person-centered care $^{22}$ and to involve patients in medical and future care decisions, health professionals need to understand the patient and family perspectives about their values and the impact on their care.

Few studies have explored patients' perspectives on early palliative care. ${ }^{14,23}$ Maloney et al. ${ }^{14}$ found that cancer patients participating in an early palliative care intervention reported enhanced problem-solving abilities and felt empowered to engage actively in their healthcare. Similarly, Hannon et al. ${ }^{23}$ found that cancer patients felt strengthened rather than distressed by palliative care. However, these studies were conducted in North America and it is unclear how experiences may vary between cultures. ${ }^{2}$ Therefore, our aim was to explore advanced cancer patients' perceptions and experiences of a structured early palliative care conversational intervention to determine acceptability and impact on patients' lives including influencing factors.

\section{Methods}

\section{Design}

We undertook a qualitative study nested within a multicenter randomized controlled trial (hereafter called the SENS-Trial,24 NCT01983956) in three Swiss German tertiary oncology centers (Bern, St. Gallen and Lucerne). The SENSTrial investigated the impact of a single conversational intervention using the 'SENS'-structure, on distress of patients newly diagnosed with locally advanced or metastatic cancer not amenable to curative treatment. "SENS" stands for Symptoms, End-of-life decisions, Network, and Support for the carers (Table 1). ${ }^{25,26}$ 
Table 1: SENS-structure Intervention description based on TIDieR ${ }^{26}$

- BRIEF NAME: SENS

- WHY25

As part of the hospital quality improvement project following the Medical Research Council's framework (2000) for developing complex interventions, we developed a structure for conversations with patients to identify and prioritize care needs and anticipate care planning. Based on a review of the literature, clinical approaches that were commonly used to structure conversations thematically were identified:

- World Health Organizations' definition of palliative care (2002)

- listing of palliative care needs from the National Comprehensive Cancer Network Guidelines (2009/2016)

- "PEPSI- COLA"- structure within the National Gold Standards Framework (2014).

Cluster of common themes served as a first structure which was tested in clinical practice. Through a cyclic and reflective process, the SENS-structure was developed.

- WHAT

- SENS-structure and definitions used during the conversations

- Symptoms and their management: the best possible way to treat the symptoms and to empower the patient for self-help in dealing with the symptom

- End-of-life Decisions: step-by-step and self-regulated decision-making, definition of own preferences and preventive planning for potential complications

- Network: structuring of a support net using a consolidation of out-patient (care at home) and in-patient structures as well as professionals and family / friends as support structure

- Support of the carers: constitution of a support system for family members also after the death of the patient as well as a support system for the involved professionals to prevent overburdening

To enhance patient involvement a written prompt-sheet with questions following the acronym 'SENS' was provided before, during or after the 50-minute structured intervention.

- WHO PROVIDED: Local palliative care physician and advanced practice nurse for palliative care

- HOW: Individual face-to-face conversation with participants

- WHERE: In the outpatient setting

- WHEN and HOW MUCH: One interventional conversation within 16 weeks after randomization

- TAILORING: SENS structure guided strictly the conversation and during the intervention, themes were deepened depending on the needs of the participant

- MODIFICATIONS: None

- HOW WELL: A protocol was written by the providers during the intervention to document the adherence to the intervention.

SENS: Symptoms, End-of-life decisions, Network, Support; TIDieR: template for intervention description and replication.

To enhance patient involvement a prompt-sheet with questions following the acronym "SENS" was provided before, during or after the 50-minute structured intervention, which was facilitated by a local palliative care physician and nurse in the outpatient clinic. In this qualitative study, we employed semi-structured, 
open-ended, face-to-face interviews. The interview guide was based on guides from prior studies, ${ }^{14,27}$ and translated to German (Table 2). The first author (M.F.) tested the guide with two patients with advanced cancer not participating in the SENS-Trial. Due to organizational reasons, this study took place in Bern and St. Gallen. The relevant ethics committees approved the study (KEK-Nr. 102/13).

Table 2: Sample questions of the interview

\section{Experience / perception of the SENS-intervention}

- How did you feel / what did you think when you were approached for participation in the SENS study?

- You had the conversation with a physician and the Advanced Practice Nurse from the Palliative Care team - what can you remember from this?

- Can you tell me your experiences, thoughts and/or feelings about this conversation?

\section{Impact of the SENS-intervention on the patient}

- Were any problem-solving strategies discussed and were you able to realize any of these?

- Did the discussed themes within the SENS structure have any impact on you, your work situation, your family or practical concerns?

\section{Data collection}

Based on the main SENS-Trial eligibility criteria (Table 3), we invited consecutive intervention participants, to participate in the interview. We initially interviewed and preliminary analyzed data from 10 participants but continued sampling until we reached data saturation $(N=20)$ whereby no new categories were identified.

Table 3: Eligibility criteria for the SENS-Trial

\begin{tabular}{|c|c|}
\hline Inclusion criteria & Exclusion criteria \\
\hline $\begin{array}{ll}\text { - } & \text { Age }>18 \text { years } \\
\text { Eastern Cooperative } \\
\text { Oncology Group (ECOG) }{ }^{28} \\
\text { Physical performance } \\
\text { status } \leq 2 \\
\text { Metastatic or locally } \\
\text { advanced cancer, not } \\
\text { amenable to curative } \\
\text { treatment within } 16 \\
\text { weeks after diagnosis }\end{array}$ & $\begin{array}{l}\text { - Unable to provide informed consent due to the } \\
\text { presence of delirium or dementia or any other } \\
\text { reason } \\
\text { - } \quad \text { Inability to communicate adequately in German } \\
\text { Patient's lack of accountability, inability to } \\
\text { appreciate the nature, meaning and consequences } \\
\text { of the study and to formulate his/her own wishes } \\
\text { correspondingly } \\
\text { Patients who already received or are receiving care } \\
\text { by an inpatient palliative care service }\end{array}$ \\
\hline
\end{tabular}


Between December 2014 and July 2017 during the SENS-Trial followup phase, a male ethicist experienced in handling interviews in sensitive life situations, a female communication expert, and M.F., a female Advanced Practice Nurse trained in communication of sensitive topics, conducted and digitally recorded the interviews.

\section{Data analysis}

A study nurse transcribed the interviews using a guideline and the F5software (V3.2.2). M.F. checked and corrected all transcriptions to corroborate translations. For data analysis, we employed the German transcriptions but did all coding in English, employing MAXQDA Analytics Pro 12/18. Field notes on patients' background and interview circumstances informed the analysis and helped to ensure reflexivity.

Influenced by a positivist coding approach, we performed qualitative content analysis (Mayring), ${ }^{29}$ using a deductive lens for category development based on the SENS-structure. Through reflection, we ultimately followed an inductive coding approach with the intent of identifying what was important to participants from their own perspective, rather than using a pre-specified structure. M.F. (an Advanced Practice Nurse in a doctoral program with experience in content analysis) performed the main analyses. M.F. and the second author (S.Z.; a senior psychologist experienced in qualitative research) coded and analyzed independently four interviews to later compare the coding approach and make sure that the coding was intersubjectively comprehensible. After all interviews were coded, M.F. and S.Z. through repeated intensive discussions adapted and consolidated the final categories and subcategories.

\section{Results}

\section{Participants}

On average, patients $(\mathrm{N}=20)$ were 66 years old, and more men participated. All participants were in good physical condition. Detailed characteristics appear in Table 4. The time between the intervention and the interview (58 days average) varied widely. Two interviews took place in the presence of a spouse. Since all participants were still attending the outpatient oncology clinic, interviews took place with scheduled hospital visits $(n=19)$ or on request at their home $(n=1)$. 
Table 4: Characteristics of participants and interview data $(\mathrm{N}=20)$

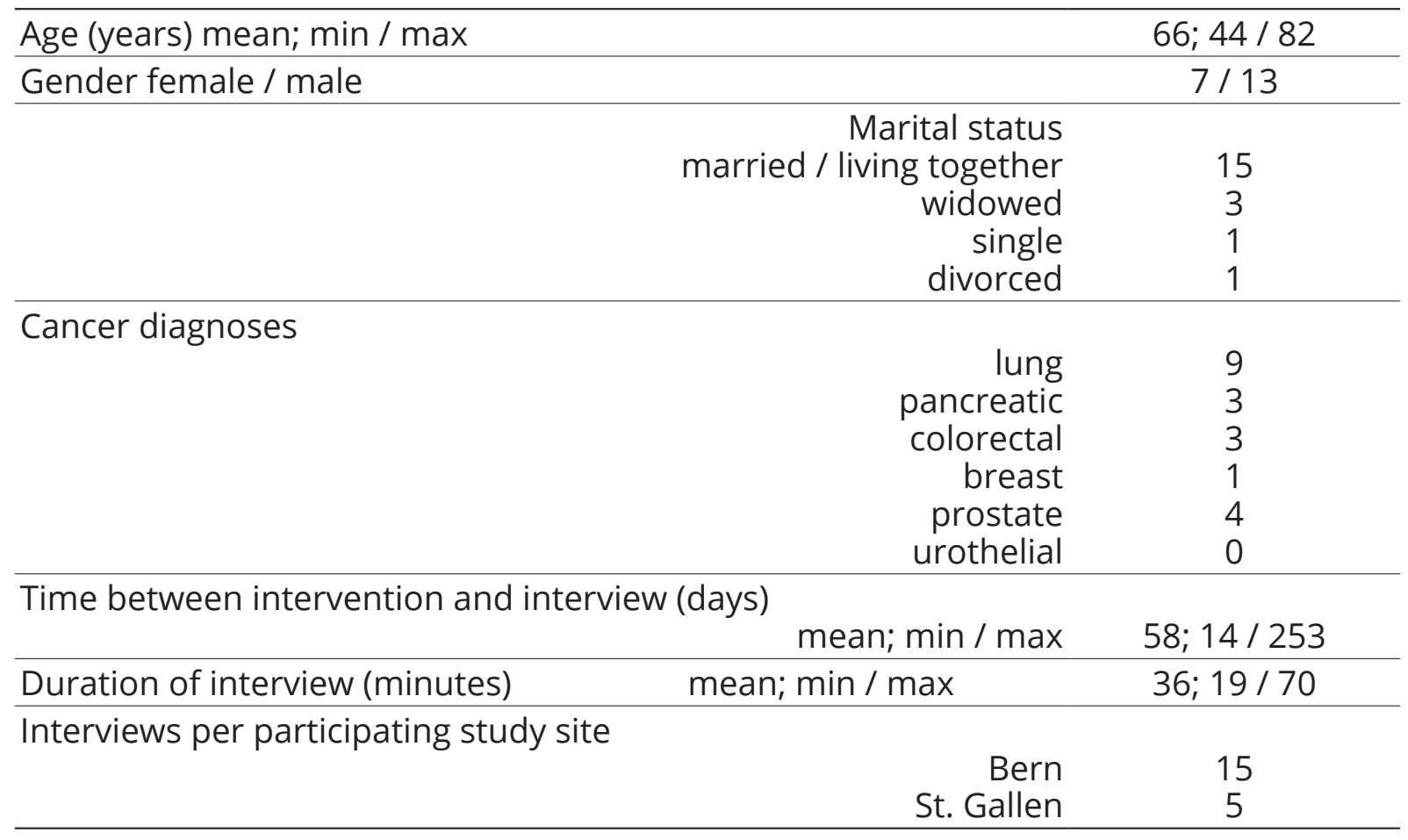

\section{Content analysis}

Participants' experiences and perceptions of the SENS-intervention could be understood in four primary categories with multiple subcategories: (1) emotional experiences, (2) cognitive experiences, (3) intervention impact on changing the understanding of what palliative care entails and (4) triggering concrete actions. The personal background such as previous knowledge about palliative care and the timing of the intervention seemed to also influence participants' experiences and perceptions of the intervention, as well as its impact (see Figure 1). 
Figure 1: Experiences with and perception of the SENS intervention and its influence on the impact which is affected by the personal background and timing of the intervention

\begin{tabular}{|c|c|c|}
\hline & \multicolumn{2}{|c|}{ Experience with / perception of SENS intervention } \\
\hline 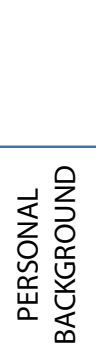 & $\begin{array}{l}\text { Emotional experience } \\
\text { - Conversation based on trust \& } \\
\text { attentiveness } \\
\text { - No necessity to be too pessimistic } \\
\text { - Normal but emotional conversation } \\
\text { - Challenge talking honestly about death } \\
\text { \& dying and bemoaning difficult topics }\end{array}$ & $\begin{array}{l}\text { Cognitive experience } \\
\text { - SENS makes sense } \\
\text { - SENS provides safety, support } \\
\text { and affirmation } \\
\text { - Incorporation of PC into } \\
\text { standard care } \\
\text { - Factual conversation }\end{array}$ \\
\hline \multirow{2}{*}{ 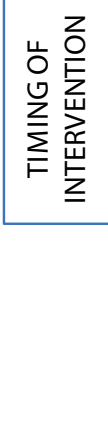 } & Impact fron & n SENS \\
\hline & $\begin{array}{l}\text { Change of understanding of PC } \\
\text { - PC also for family } \\
\text { - Food for thoughts } \\
\text { - Encouraging impulse to reflect on } \\
\text { future } \\
\text { - Knowing where to turn to } \\
\text { - Associations with end-of-life }\end{array}$ & $\begin{array}{l}\text { Actions triggered by SENS } \\
\text { - Involving social network } \\
\text { - Actively planning future health } \\
\text { care issues } \\
\text { - Self-determination of practical } \\
\text { matters }\end{array}$ \\
\hline
\end{tabular}

\section{Emotional and cognitive experiences with and perception of the SENS-intervention}

\section{Category 1. Emotional experience with the SENS-intervention}

Conversation based on trust and attentiveness. Participation in the trial made a strong emotional impression on some of the participants. It touched deeply their inner feelings and confronted them with their finiteness at different levels. For most participants, it was clear that an early palliative care intervention can only be based on mutual trust and attentiveness: "... and this conversation gave me in that sense a lot of trust. Trust that despite the situation there are contact persons within the health care system who listen" (Participant (P) 1, female (f)).

No need to be too pessimistic about the future. The experience of the SENSintervention was very personal and most participants were very open about how they felt. Some participants appreciated the reflection on their future but had the feeling that it was not necessary to be too pessimistic, and that the tone of the discussions could be more positive: "for me everything was a bit in a somber atmosphere-rather negative, ... and I think more positively-I take it from the good 
side and that somehow disturbed me-it was like a gravedigger-atmosphere" (P20, $\mathrm{m}$ ). For them, it was too early to actively plan their future care: “... (talking about moving) ... - because of the stairs and we live too high ... and there I need to say, yes, well-for me it is not yet really a topic to discuss" $(\mathrm{P} 6, \mathrm{~m})$.

An emotional experience though a normal conversation. Most participants mentioned that they received arealistic picture of how the future might look that allowed them to plan ahead. They felt the conversation was emotional but not burdensome:

...and it was a conversation that was not burdensome. It wasn't so (pause), yes it was a normal conversation. There was nothing in it of which I would say now that is too much for me ... and otherwise it was a conversation which was not cumbersome ... (P12, m)

Although some participants mentioned that this intervention touched their feelings, they nevertheless thought it did them well: "... so it [the intervention] was quite emotional but I cannot say-well, it also was good for me" (P14, f). The conversation helped to speak with a professional openly about their thoughts and concerns. They struggled with the anticipation that the situation might deteriorate and they should prepare for future care: "... we talked intensively about my final phase of life and that was deeply emotional for $m e^{\prime \prime}(\mathrm{P} 17, \mathrm{~m})$.

Challenging, but appreciated honest communication. Most participants expressed that it was a challenge and sometimes even shocking for them to talk openly about death and dying while discussing the future: "... It wasn't somehow negative or so. Just, it just showed how the future could look ... one first had to digest that" (P11, m). Or as another participant said,

...so what shocked me a bit was how doctor X explained to me how it could develop, that it could go for some time well and then "Boom!" and that is the end. To be honest that somehow shocked me. $(\mathrm{P} 15, \mathrm{f})$

Participants described how they coped with the honest conversation in which their situation was discussed in a language that they were able to understand. They felt relieved to reflect realistically on certain sensitive topics. Others bemoaned these discussions: "... it frightened me that, on the Palliative Care Unit patients can stay only for two to three weeks and then you are basically kicked out" 
(P11, m). Some participants felt the doctor really listened:

"[referring to the SENS doctor] ... I had for the first time the feeling that there is someone who actually realizes what is going on, who realizes what is happening, who senses my feelings ..." (P8, m).

\section{Category 2. Cognitive experience of the SENS-intervention}

At a cognitive level, participants found the SENS-intervention helpful in that the topics were structured and helped them to prioritize their future care.

SENS makes sense. The SENS-intervention and topics within the structure were perceived as helpful because new topics that had not yet been discussed with their treating physician were finally addressed. For most participants, the structure made sense especially when they were able to prepare for the content of the conversation with a prompt sheet: "... I specifically appreciated it that I received a questionnaire [prompt sheet] in advance ... there are topics that one thought about prior to the conversation but had never talked about" (P12, m).

SENS provides safety and support and topics should be incorporated into usual care. For participants who already had started their future planning, the SENSintervention topics, such as ACP, provided a sense of safety, support and affirmation of what they already had prepared for their future: "... on the other hand I received confirmation that basically I had already done everything about these future issues" (P17, m). Therefore, these participants suggested that these SENS topics should be incorporated into standard oncological care conversations: "... well-yes I would say it [the topics of the SENS intervention] should be rather intertwined [into normal care]" (P14, f).

Factual conversation with worthwhile information. Most participants experienced SENS as a factual conversation with their doctor which they would recommend for others because it did not cause them any harm: "... but otherwise it was in general a conversation as we talk right now-about the circumstances, the family and such things" (P10, m). For them, it was good to get written and oral information, but they thought that they probably would not need it in the very near future. Participant $4(\mathrm{~m})$ mentioned, "... somehow the facts are now on the table and ... therefore it is extremely good, that this institution exists." When reflecting on the conversation, participants expressed to be strengthened in doing as much by themselves as possible: "... exactly - they told me that I should look after myself and 
do what does me well' (P18, f) or to seek support and take back control and not be steered only by a particular medical treatment.

\section{Impact of the SENS-intervention}

Participation in the SENS-Trial had an active impact in terms of actions triggered by the intervention, as well as a more passive impact on the participant in terms of a changed understanding of palliative care (categories 3 and 4). The majority of the participants appreciated being strengthened to actively deal with issues concerning a pragmatic planning of future healthcare and to finish matters such as making decisions toward their final phase of life. In addition, their understanding of what palliative care covers and how one can profit from an early palliative care approach put patients into a contemplative mood.

\section{Category 3. A change in the understanding of palliative care and their own future}

Beyond specific actions and decisions, participation in the SENS-intervention generated a change in participants' perceptions of palliative care and changed their understanding of their own future. Most participants learned that palliative care is not only associated with death and dying but has many facets "... I got a bit of information and realized-it impressed me-how many subjects are covered [by palliative care]" (P8, m). It astonished them that palliative care aims to also support the family: "...- yes, we talked about all these things and also what kind of support one can get for the family, not only for oneself' (P20, m). On the other hand, the conversation put some participants into a contemplative mood:

... yes, it gave me an impulse, yes. But also-exactly, I wasn't able to do it, the résumé [to write the story of my life to be read at the funeral] of my life and these things-these I still need to do ... it is still on my mind. $(\mathrm{P} 13, \mathrm{f})$

The intervention encouraged most participants to reflect on their future, which they did not yet feel ready to act upon "... [I] was probably also invited to reflect on problem areas which I need to address. The financial, or for example an advance directive. These practical things" (P1, f). Based on the information they received during the conversation, they knew where to turn when their health deteriorates: "... yes-simply that (pause) actually, if it, if it is really time to (pause) that I will-also when it is not possible at home any more, that I would come here [to the palliative care center] or somewhere else" (P6, m). 
Despite the changes of understanding of what palliative care entails and how it could impact their pragmatic planning, some participants still associated palliative care with end-of-life and a place where they will receive support and can turn to for the dying phase "... but it then it appeared to me that the next step is dying" (P17, m). All patients who associated palliative care with death and dying also mentioned that-although difficult —it did not frighten them but were relieved to be able to talk the fear off their heart.

\section{Category 4. Actions triggered by SENS}

Some participants described how they had started involving their social network into their decisions "... I also told my wife that there are two things for me-when I suddenly cannot steer myself any more, and then we talked (pause). Now she knows what to do and when ..." (P17, m). An anticipatory planning for future health care in which they documented their wishes by filling in, for example, an advance directive was triggered: "... and (pause) yes-in the meantime we have made an advance directive" (P9, f). The intervention based on SENS stimulated participants to actively discuss their situation and specific future care wishes within the family and supported their self-determination on practical things:

... we went so far-an example: so far I did all the things in my family-the bank, ah bank transfers-all that I did for the family. Step by step I transferred it to my wife. These are small things but they also belong to that. (P17, m)

As one participant mentioned, "... Yes, it was good ... One doesn't do it only for oneself. That way I also talked with my partner about some of the topics" (P12, m).

\section{Personal background, knowledge of and attitude toward palliative care}

Prior and during the interviews, participants mentioned having had indirect exposure to palliative care through family members or the media and not in the context of their own disease. Some participants were outspoken about their self-determination and wanted to stay in control for as long as possible or had a positive attitude despite being aware of the life-limiting nature of their disease. This background affected how they perceived and experienced the SENS-intervention. 
Some participants explained how they had already prepared for their future care in light of the life-limiting disease such as writing an advance directive, deciding legal issues or future places of care when circumstances deteriorate: "Oh yes, we have done that [advance directive], we really did that. We haven't finished it at that time but we were discussing it ... and we are registered in a nursing home" (P9, f). Other participants had already been confronted with palliative care in the past or were previously informed about what palliative care offers: "Yes, [what Palliative Care offers] was explained to me often enough. ... I informed myself about the whole thing, also from the Internet ..." (P20, m). Others reported that one of their family members was even trained in the care for seriously ill or dying people: "My wife has then-for a few years she-she took courses in Care for the Dying and so on ..." (P10, m). Based on these experiences, some participants related palliative care to death and dying '... but when I heard 'Palliative Care' I thought that I would die' (P8, m) but were still open for the intervention.

Most of the male participants experienced the intervention as very emotional and connected palliative care mainly with the last phase of life: "... [it need to be communicated empathetically] ... and not just boom-from now on you have only three months to live. And then it is three or four months and then the time is over anyways, right? This cannot be dealt with so easily ..." (P16, m). Females, on the other hand, recognized the practical side and the SENS structure as a guideline to plan the future: "... now I need to plan ahead if I want to plan the funeral, whom they would have to inform-now I will have to do that ..." (P13, f).

\section{Intervention timing}

Some participants were surprised to be asked to participate in a palliative care study and felt overwhelmed by facts of the life-limiting disease. When approached early on for such a conversation, participants expected high levels of empathy from their treating physician. Participants reflected openly about the timing of an early palliative care conversation. It became clear that it should be initiated based on patients' individual needs and on a close relationship between health care provider and the patient. It should be seen as a process: "... and to approach someone-I think that is individual-it is difficult to say either right at diagnosis or wait-I have the feeling that this differs really between the patients" (P20, m).

For some participants, the timing of the intervention came too early, especially if they were in a phase when they still needed to cope with the diagnosis: 
... the conversation would ... not have been necessary, at least not at this timepoint. You know when someone of course is still a bit ... unstable and ... then such a conversation is too early-I can imagine that then it pulls you down. $(\mathrm{P} 6, \mathrm{~m})$

or "... and in a phase when diagnosis is still doubtful and just then the conversation is a bit too early" (P17, m). Others suggested that such a conversation should be initiated as early as possible in the disease trajectory especially when a person is devastated by the diagnosis: "... and here [when a patient is paralyzed by the diagnosis] such a conversation with your institution could be very helpful" (P17, $m)$. These reflections on whether and how the intervention was initiated at the right time for the participant influenced their experience and impact of the intervention.

\section{Discussion}

We aimed to explore advanced cancer patients' perceptions and experiences of a structured early palliative care intervention, its acceptability as well as influencing factors. Overall, participants welcomed the SENS-intervention and gained a better understanding of their personal situation. We found that such an intervention can be confronting but also confirming, and that it can facilitate conversations within the family, which may translate into the acceptability of these interventions. Patients' personal background influenced their emotional or cognitive experience of the intervention, which had an impact on their understanding of palliative care and triggered actions toward their future.

This study did not support health professionals' concerns that ACP conversations might be too threatening for patients with advanced cancer. ${ }^{30-33}$ Although participants found the honest discussions as challenging, many felt that the way in which the intervention was delivered and the SENS-structure itself provided them with support, a feeling of safety, and affirmation. Possibly leading to lesser distress, which is comparable to findings from other studies. 23,34

Although being confronted with palliative care themes provoked emotions, most participants felt this was manageable. This emotional confrontation of early palliative care has been reported. ${ }^{14}$

In our study, male participants in particular were more emotionally touched by the conversation, while females appreciated more the practical side of the intervention. This is unlike the gender differences explained by Saeed et al. ${ }^{35}$ 
in which more females preferred the expression of emotions when in contact with palliative care and males more often preferred aggressive therapy and less contact with palliative care. Whether the SENS-intervention in general led to less aggressive therapy in males needs to be determined in the quantitative part of the SENS-Trial.

Participants stated that the areas discussed were helpful and even more dynamic if they had received the prompt sheet prior to the intervention. As in the study by Arthur et al. ${ }^{36}$ such a prompt sheet does not increase distress but rather gives the person the opportunity to prioritize relevant topics.

When being approached for the study, some participants connected palliative care with death, further confirming the perception that palliative care is reserved for the dying phase. ${ }^{37,38}$ This may influence patients' hesitation to engage with palliative care. The SENS-intervention broadened patients' understanding of what palliative care entails. Hence, providing palliative care services early on may contribute to change public perceptions.

The intervention often led participants to act and make decisions about future care, including communication with their family. This is comparable to a study ${ }^{14}$ in which cancer patients undergoing a similar intervention felt more empowered to communicate with others.

Participants in our study addressed the issue of "the right time"2 for an early palliative care intervention. For some participants, it was timely because they were eager to receive additional information about palliative care. This is specifically noticeable because the intervention was offered early on in their disease trajectory in which patients usually have a low symptom burden but may be fearful of future symptoms. Similar to other studies, ${ }^{34}$ other patients felt it was too early because they were unprepared to be confronted with their finiteness. Participants supported that the timing needs to be chosen on a personal basis and alongside or even integrated into standard oncological care. 2,9,39,40 For participants, the "how" and "by whom" was more important than the "when."

\section{Study strengths and limitations}

Several quantitative studies have underlined significant positive effects on patients exposed to early palliative care interventions. However, qualitative studies are better able to answer questions about the mechanisms that generate 
these outcomes. Ours is one of a few studies in which researchers give voice to participants undergoing an early palliative care intervention, providing insights not available from structured questionnaires.

Notable limitations are that we cannot determine the extent to which prior palliative care experiences influenced the experiences of patients in our sample and their reaction to it. Also, our results should be viewed in the context of patients with similar diagnoses and the Swiss German culture, but may be extrapolated to similar contexts.

\section{Conclusion}

Overall, patients with advanced cancer experienced a structured interprofessional early palliative care intervention as positive and beneficial. However, the direct approach provoked emotional reactions that were initially perceived as confrontational. SENS provided safety, support and affirmation and triggered structured actions, such as involving their social network, which could lead to a care more consistent with their values. While the palliative care teams' approach during SENS encouraged trust, an important finding was that patients wanted a focus on not only deterioration but also on what was still possible.

The timing of early palliative care interventions continues to be debated and our study confirms that there is still much need to introduce this approach in a tailored and empathetic way based on individual circumstances. The timing of these sensitive conversations is probably not only a matter of "when" but rather of "what" and "how" these topics are addressed.

\section{Acknowledgements}

The authors would like to thank all participants for their willingness to share their experiences with and views on the early palliative conversational intervention. Also the authors would like to acknowledge the work of the research team in St.Gallen for their support, and to the interviewers Rouven Porz and Sibylle Felber.

\section{Authors' contributions}

S.E., M.F., S.Z. and M.B. made a substantial contribution to the concept or design of the work and analysis or interpretation of data; M.F. and S.Z. performed the 
analysis of the early palliative conversations and were supported by M.B. C.L., R.H., and J.S. supported the analysis and discussion of the results and advised in the preparation of the manuscript. All authors read, critically revised and approved the article before submission and ensured that questions related to the accuracy or integrity of the work are appropriately looked into.

\section{Availability of the data}

All data can be made available on request to the corresponding author as long as the request complies with the ethical regulations of the corresponding ethical committee and an application is approved for this end.

\section{Declaration of conflicting interests}

The author(s) declared no potential conflicts of interest with respect to the research, authorship, and/or publication of this article.

\section{Ethical approval and consent for publication}

The SENS-Trial was approved by the ethical committee of the Swiss Canton of Bern as primary committee and subsequently by the ethical committees of the Cantons Lucerne and St. Gallen. All participants provided written informed consent.

\section{Funding}

The study was funded by the Swiss National Funds within the NFP 67 project. The funders did not have any influence on the data collection, data analysis, or data interpretation. Schweizerischer Nationalfonds zur Förderung der Wissenschaftlichen Forschung, (Grant/Award Number: "145088 (NRP 67)") 


\section{References}

1. Dans $M$, Smith $T$, Back $A$, et al. NCCN guidelines insights: palliative care, version 2.2017. J Natl Compr Canc Netw 2017; 15(8): 989-997.

2. Ferrell BR, Temel JS, Temin S, et al. Integration of pallia- tive care into standard oncology care: American Society of Clinical Oncology clinical practice guideline update. J Clin Oncol 2017; 35(1): 96-112.

3. Institute of Medicine (IOM). Dying in America: improving quality and honoring individual preferences near the end of life. Washington, DC: The National Academies Press, 2015.

4. Smith TJ, Temin S, Alesi ER, et al. American Society of Clinical Oncology provisional clinical opinion: the integration of palliative care into standard oncology care. J Clin Oncol 2012; 30(8): 880-887.

5. Mattes MD, Tung K, Baum R, et al. Understanding the views of those who care for patients with cancer on advance care planning and end-of-life care. Am J Hosp Palliat Care 2015; 32(8): 802-809.

6. TemelJS, Greer JA, Muzikansky A, et al. Early palliative care for patients with metastatic non-small-cell lung cancer. N Engl J Med 2010; 363(8): 733-742.

7. Zambrano SC, Fliedner MC and Eychmuller S. The impact of early palliative care on the quality of care during the last days of life: what does the evidence say. Curr Opin Support Palliat Care 2016; 10(4): 310-315.

8. Bakitas MA, Tosteson TD, Li Z, et al. Early versus delayed initiation of concurrent palliative oncology care: patient outcomes in the ENABLE III randomized controlled trial. J Clin Oncol 2015; 33(13): 1438-1445.

9. Beernaert K, Deliens L, Vleminck A, et al. Is there a need for early palliative care in patients with life-limiting illnesses? Interview study with patients about experienced care needs from diagnosis onward. Am J Hosp Palliat Care 2015; 33(5): 489-497.

10. Greer JA, Pirl WF, Jackson VA, et al. Effect of early palliative care on chemotherapy use and end-of-life care in patients with metastatic non-small-cell lung cancer. J Clin Oncol 2012; 30(4): 394-400.

11. Hannon B, Swami N, Pope A, et al. The oncology palliative care clinic at the Princess Margaret Cancer Centre: an early intervention model for patients with advanced cancer. Support Care Cancer 2015; 23(4): 1073-1080.

12. Harden KL. Early intervention with transplantation recipients to improve access to and knowledge of palliative care. Clin J Oncol Nurs 2016; 20(4): E88-E92.

13. Le $B H$, Mileshkin L, Doan $K$, et al. Acceptability of early integration of palliative care in patients with incurable lung cancer. J Palliat Med 2014; 17(5): 553-558.

14. Maloney C, Lyons KD, Li Z, et al. Patient perspectives on participation in the ENABLE II randomized controlled trial of a concurrent oncology palliative care intervention: benefits and burdens. Palliat Med 2013; 27(4): 375-383.

15. McDonald J, Swami N, Hannon B, et al. Impact of early palliative care on caregivers of patients with advanced cancer: cluster randomised trial. Ann Oncol 2016; 28(1): 163-168.

16. Meeussen $K$, Van den Block $L$, Echteld $M$, et al. Advance care planning in Belgium and The Netherlands: a nationwide ret- rospective study via sentinel networks of general practitioners. J Pain Symptom Manage 2011; 42(4): 565-577. 
17. Rietjens JA, Korfage IJ, Dunleavy L, et al. Advance care planning-a multi-centre cluster randomised clinical trial: the research protocol of the ACTION study. BMC Cancer 2016; 16: 264.

18. Vanbutsele $G$, Van Belle $S$, De Laat $M$, et al. The systematic early integration of palliative care into multidisciplinary oncology care in the hospital setting (IPAC), a randomized controlled trial: the study protocol. BMC Health Serv Res 2015; 15: 554.

19. Zimmermann C, Swami N, Krzyzanowska M, et al. Early palliative care for patients with advanced cancer: a cluster-randomised controlled trial. Lancet 2014; 383(9930): 1721-1730.

20. Dyar S, Lesperance $M$, Shannon $R$, et al. A nurse practitioner directed intervention improves the quality of life of patients with metastatic cancer: results of a randomized pilot study. J Palliat Med 2012; 15(8): 890-895.

21. Bakitas M, Lyons KD, Hegel MT, et al. Effects of a palliative care intervention on clinical outcomes in patients with advanced cancer: the Project ENABLE II randomized controlled trial. JAMA 2009; 302(7): 741-749.

22. Mead $\mathrm{N}$ and Bower P. Patient-centredness: a conceptual framework and review of the empirical literature. Soc Sci Med 2000; 51(7): 1087-1110.

23. Hannon B, Swami N, Rodin G, et al. Experiences of patients and caregivers with early palliative care: a qualitative study. Palliat Med 2017; 31(1): 72-81. doi: 10.1177/02692 16316649126

24. Eychmueller $S$ and Fliedner $M$. A structured early palliative care intervention for patients with advanced cancer-a randomized controlled trial with a nested qualitative study. Swiss National Science Foundation, http://www.nfp67.ch/ en/ projects/module-1-dying-processes-provision-care/ project-eychmueller (2013, accessed 10 July 2018).

25. Fliedner MC, Mitchell G, Bueche D, et al. Development and use of the 'SENS'structure to proactively identify care needs in early palliative care-an innovative approach. Healthcare 2019; 7(1): 32.

26. Hoffmann TC, Glasziou PP, Boutron I, et al. Better reporting of interventions: template for intervention description and rep- lication (TIDieR) checklist and guide. BMJ 2014; 348: g1687.

27. Bakitas $M$, Stevens $M$, Ahles $T$, et al. Project ENABLE: a palliative care demonstration project for advanced cancer patients in three settings. J Palliat Med 2004; 7(2): 363372.

28. Oken MM, Creech $\mathrm{RH}$, Tormey DC, et al. Toxicity and response criteria of the Eastern Cooperative Oncology Group. Am J Clin Oncol 1982; 5(6): 649-655.

29. Mayring P. Qualitative Inhaltsanalyse: Grundlagen und Techniken, 12th ed. Weinheim: Beltz, 2014.

30. Ethier JL, Paramsothy T, You JJ, et al. Perceived barriers to goals of care discussions with patients with advanced cancer and their families in the ambulatory setting: $a$ multicenter survey of oncologists. J Palliat Care 2018: 33(3): 125-142.

31. Von Roenn JH, Voltz R and Serrie A. Barriers and approaches to the successful integration of palliative care and oncology practice. J Natl Compr Canc Netw 2013; 11(Suppl. 1): S11-S16.

32. Zhi WI and Smith TJ. Early integration of palliative care into oncology: evidence, challenges and barriers. Ann Palliat Med 2015; 4(3): 122-131. 
33. Horlait $\mathrm{M}$, Chambaere $\mathrm{K}$, Pardon $\mathrm{K}$, et al. What are the barriers faced by medical oncologists in initiating discussion of palliative care? A qualitative study in Flanders, Belgium. Support Care Cancer 2016; 24(9): 3873-3881.

34. Yoo SH, Kim M, Yun YH, et al. Attitudes toward early palliative care in cancer patients and caregivers: a Korean nationwide survey. Cancer Med 2018; 7(5): 1784-1793.

35. Saeed $F$, Hoerger $M$, Norton $S A$, et al. Preference for palliative care in cancer patients: are men and women alike. J Pain Symptom Manage 2018; 56(1): 1-6.e1.

36. Arthur J, Yennu S, Zapata KP, et al. Perception of helpful- ness of a question prompt sheet among cancer patients attending outpatient palliative care. J Pain Symptom Manage 2017; 53(1): 124-130.e1.

37. Mcllfatrick S, Noble H, McCorry NK, et al. Exploring public awareness and perceptions of palliative care: a qualitative study. Palliat Med 2014; 28(3): 273-280.

38. Westerlund $C$, Tishelman $C$, Benkel I, et al. Public aware- ness of palliative care in Sweden. Scand J Public Health 2018; 46(4): 478-487.

39. Von Roenn JH. Optimal cancer care: concurrent oncology and palliative care. J Natl Compr Canc Netw 2013; 11(Suppl. 1): S1-S2.

40. Nakajima N and Abe Y. Concurrent specialized palliative care upon initiation of firstline chemotherapy for cancer progression: is it early enough. Am J Hosp Palliat Care 2016; 33(4): 340-345. 


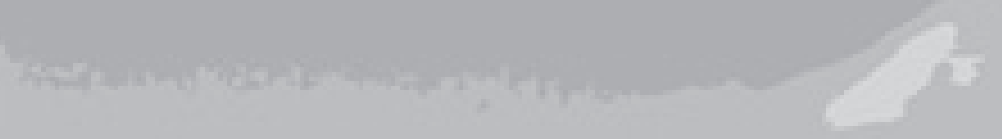

\section{4he and}
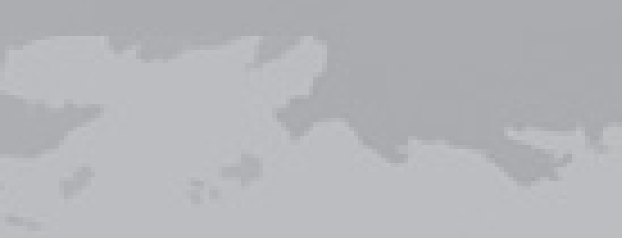

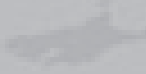

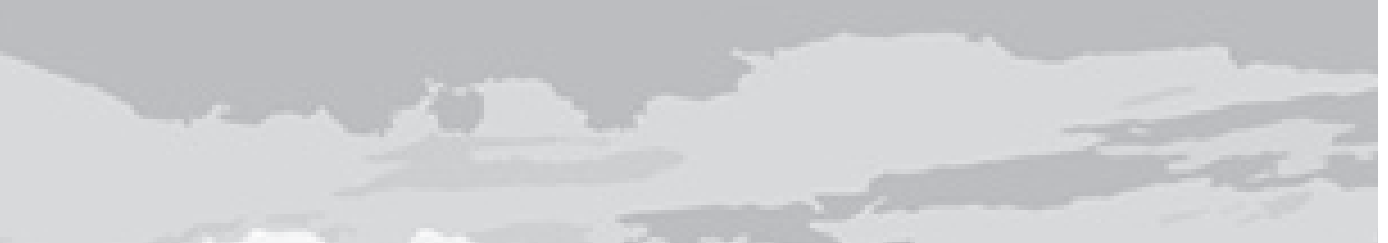

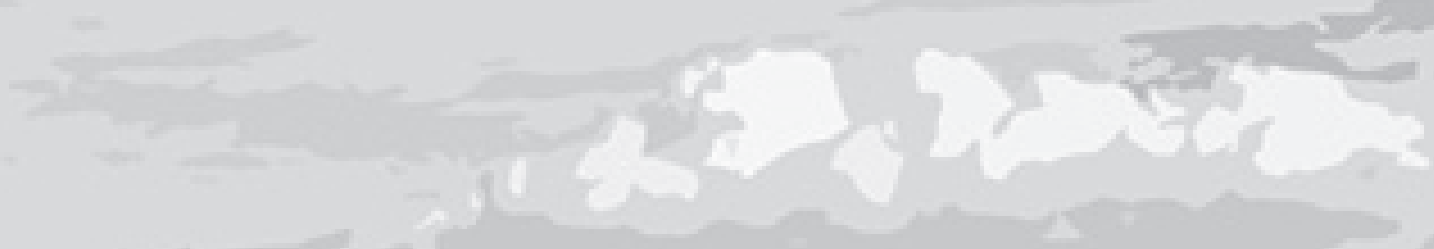
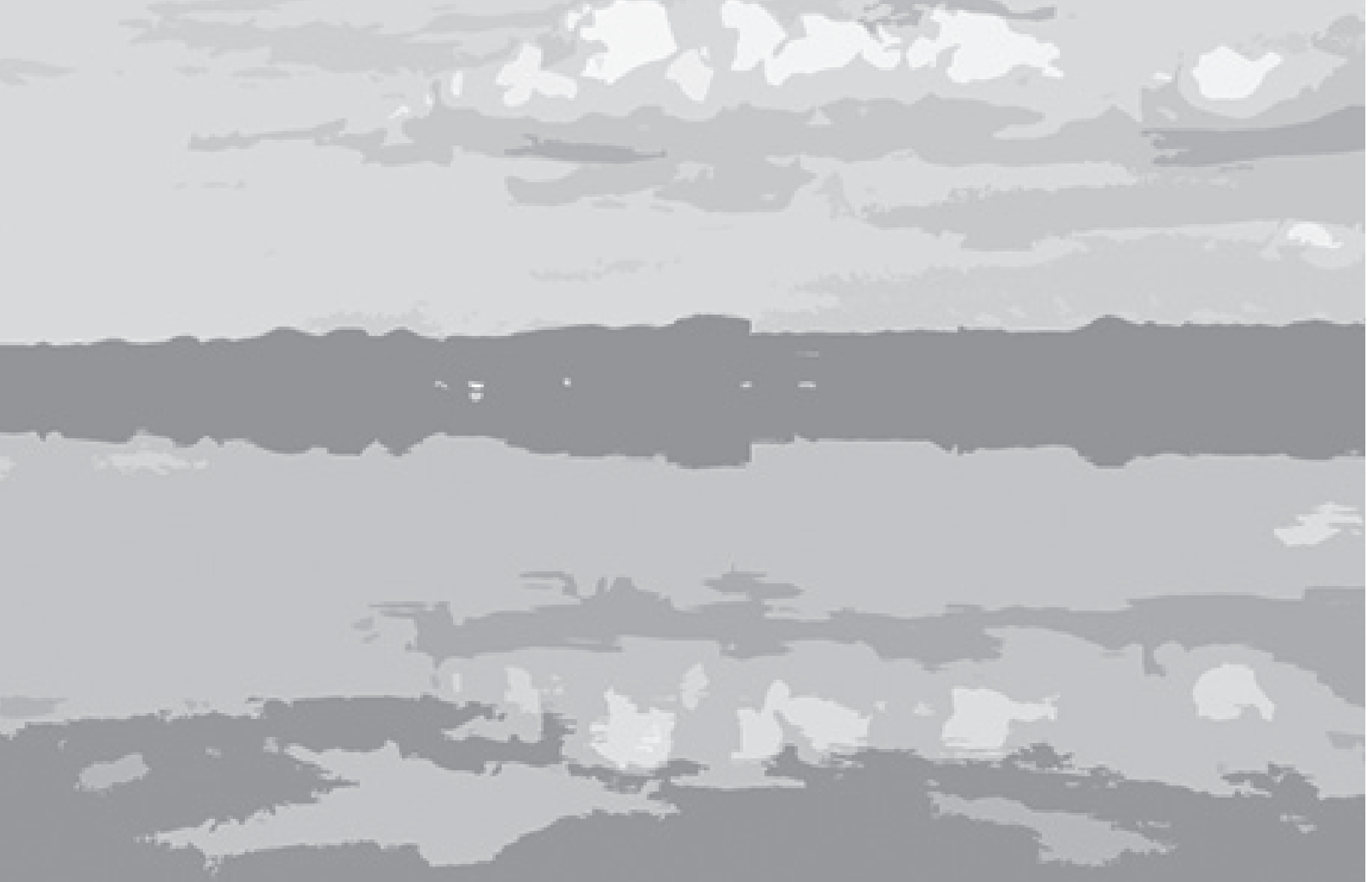


\section{Chapter 5}

\section{Roles and responsibilities of nurses in advance care planning in palliative care in the acute care setting - a scoping review}

This chapter was published as:

Fliedner, M. C., Halfens, R. J. G., King, C. R., Eychmueller, S., Lohrmann, C., \& Schols, J. M. G. A. Roles and responsibilities of nurses in advance care planning in palliative care in the acute care setting - a scoping review. J Hosp Palliat Nurs. 2021;23(1):59-68. doi 10.1097/NJH.0000000000000715. 


\section{Abstract}

Palliative care focuses on symptom management, discussion of treatment and care decisions, network organization, and support of the family. As part of the advance care planning (ACP) process, staff nurses in the acute care setting are often involved in all of the above areas. It is yet unclear what nurses' roles and responsibilities are and what skills are needed in the ACP process. The themes that staff nurses and advanced practice registered nurses (APRNs) discuss in relationship to ACP are manifold. This scoping review demonstrates that staff nurses' core role is advocating for the wishes and values of patients with any lifelimiting disease. Staff nurses also serve as facilitators, educators, and advocates to help start ACP conversations and ease patients' transitions between settings based on well-discussed decisions. To be able to engage in ACP discussions, APRNs must have excellent communication skills. Continuous training to improve these skills is mandatory. In the future, clarifying the contribution of staff nurses and APRNs in the ACP process in relation to other members of the interprofessional team can lay the groundwork for improved interprofessional collaboration.

\section{Key words}

acute care setting, advance care planning, advanced practice registered nurses (APRNs), palliative care, roles and responsibilities, staff nurses 


\section{Background}

Palliative care $(P C)$ is a holistic, person-centered interprofessional approach aimed at improving quality rather than quantity of the remaining lifespan for patients with a life-limiting disease. ${ }^{1-5}$ Integrating PC as early as possible and preferably within weeks after diagnosis of a life-limiting disease and starting a conversation about patients' hopes and fears contribute to improved patientreported outcomes such as better symptom management. ${ }^{6-9}$

Palliative care services in the acute care setting are offered to improve symptoms, prevent suffering, and improve quality of life. The effectiveness of improvement largely depends on time-sensitive and, frequently, rapid intervention. Palliative care focuses on physical, psychosocial, and spiritual needs as well as the support of patients in the decision-making process and expectations for future treatment and care. Moreover, PC focuses on the interprofessional team and the network of support for the patients and their families. ${ }^{1,10}$ This article concentrates specifically on conversations with patients about PC-related decisions and expectations via the advance care planning (ACP) process.

Conversations about future health care decisions should be proactively commenced by health care professionals concurrent to diagnosis-related treatment approaches before patients lose their decision-making capacity. 7,11 This is recommended as the standard for all patients with a life-limiting disease. ${ }^{12,13}$ These active conversations are suitable when patients with a lifelimiting disease are informed about treatment options and begin to consider decisions such as life-prolonging therapies or future hospitalizations. ${ }^{14}$ These proactive and decisive conversations between patients and professionals based on patients' expressed needs, wishes, and values are referred to as ACP. ${ }^{15}$

Advance care planning is defined as the ability to enable individuals to (a) proactively define goals and preferences for impending treatment and care, (b) engage in discussions about these goals and preferences with family and health care professionals, and (c) document and review these preferences whenever necessary. ${ }^{16,17}$ Therefore, throughout this article, ACP is the term used to engage patients with a life-limiting disease as early as possible in shared decisionmaking about future treatment and care. ${ }^{14}$ Although sometimes emotional, patients value the conversation about having a meaningful life until death. ${ }^{18-21}$ They might experience ACP conversations as challenging but reassuring, which does not negatively affect their hope or anxiety. ${ }^{21-23}$ 
As part of the interprofessional team in the acute care setting, staff nurses (registered nurses [RNs]) and advanced practice RNs (APRNs) providing palliative and end-of-life care are recognized as significant partners. ${ }^{24-27}$ In this review, we specifically refer to RN and APRNs working in an acute care setting, which is considered to be a hospital.

Staff nurses and APRNs play an essential role in educating patients on how to engage in the ACP process ${ }^{11,28}$ and participate in ACP conversations..$^{29-31}$ Staff nurses and APRNs advise patients with life-limiting diseases throughout their illness trajectory including supporting their decisions related to future health care. ${ }^{32}$ During ACP conversations, patients with a life-limiting disease and their family rely on the support given by nurses based on mutual trust and a continuous relationship. ${ }^{33-35}$ Thus, nurses enable the ACP process by honoring patients' values and ensuring patients' wishes are followed, as well as supporting patients with respect to their choices. ${ }^{36,37}$ For these tasks, RNs and APRNs are qualified because of their expanded competencies and skills. ${ }^{38}$ The ACP conversations can contribute to (a) higher quality of end-of-life discussions between patients and their physician, ${ }^{39}$ (b) improved coordination of future care, ${ }^{35}$ (c) superior documentation of decisions, ${ }^{40}$ (d) less unwanted aggressive treatment at the end of life, and (e) potential reduction of symptoms..$^{41,42}$

Initially, studies on the role of health care professionals in the ACP process focused primarily on physicians. ${ }^{43}$ However, recently, there is more evidence regarding the contribution of RNs and APRNs to ACP. ${ }^{39,40,43}$ However, little attention has been given to specific RNs' and APRNs' responsibilities, as well as the educational requirements to engage in the ACP process. The purpose of this review of literature is to focus on essential aspects of the nursing role related to ACP conversations with patients receiving PC in acute care settings, as well as themes covered by nurses, and skills needed by nurses to be involved in ACP conversations.

\section{Methods}

\section{Aims}

By reviewing relevant literature, the aim was to identify

(1) specific roles and responsibilities of RNs and/or APRNs involved in the ACP process in the acute care setting; 
(2) themes related to ACP as discussed by RNs and/or APRNs; and

(3) RNs' and/or APRNs' skills and/or educational requirements to be able to engage in or facilitate ACP conversations.

Overall, this scoping review is conducted to highlight the roles of RNs and APRNs related to ACP in the acute care setting, which might have implications for clinical practice. Because this deals specifically with RNs and APRNs providing PC in the remainder of this article, the authors will refer only to RNs and APRNs.

\section{Design}

The methodology for a scoping literature review as proposed by Arksey and O'Malley ${ }^{44}$ guides this review. In contrast to a systematic review, which is often used to develop clinical guidelines, this review approach allows a broad overview of current knowledge on a specific topic and the inclusion of studies with diverse methodologies. ${ }^{45-47}$ It comprises studies and other document types that address the topic and clarifies concepts relevant to our aims. ${ }^{47,48}$ The following steps were taken:

(1) Search for a variety of literature databases to identify possible relevant studies that were comprehensive in regard to the aims.

(2) Use of designated inclusion and exclusion criteria to assist in selecting relevant studies and eliminate inappropriate studies (first and third authors participated in this step).

(3) Evaluation and analysis of data including the appraisal of the quality of the documents were completed by the first author.

(4) Identification of (a) responsibilities of RNs and APRNs in ACP, (b) themes discussed by nurses, and (c) skills and educational requirements of nurses (completed by the first and third authors).

(5) Discussion of implications for practice and education (primarily the first author with dialogue among all the authors).

\section{Search Methods}

The search was conducted between June 2019 and January 2020 in the following databases: (a) PubMed, (b) CINAHL, and (c) gray literature via OpenAIRE searching for relevant literature published over the previous decade. 


\section{Search Terms}

The following search terms were used to focus specifically on nursing roles and responsibilities in ACP and were combined with additional terms such as (a) palliative care (MeSH), (b) acute care setting, (c) advance care planning [MeSH], (d) nurse's role [MeSH], (e) professional education (MeSH), and (f) professional responsibility. To avoid missing important articles, references of significant articles were also perused for relevant literature that was missed during the initial search.

\section{Inclusion - Exclusion Criteria}

Literature referring to RNs or APRNs caring for adult patients in the acute care setting was included because ACP has been a well-known concept in PC literature for the past decade. Searches were limited to the English, Dutch, and German language (the languages the authors comprehend). All types of articles and documents that were relevant to the aims were included. Documents referring to any non-acute care settings (e.g., long-term care and rehabilitation) were excluded. Articles related to legal, financial, or regulatory issues were excluded.

\section{Data Extraction}

Initially, records were identified in the previously mentioned databases and then screened for their relevance to the aims (first author). Abstracts were imported into the database Covidence (www.covidence.org/home), which deleted duplicates $(n=29)$. After the screening of abstracts, noneligible records were excluded. Of the eligible articles, the full text was assessed for relevance (first and third authors). Finally, pertinent articles were assessed for background information and definitions of the terminology used to identify the underlying concepts related to ACP and the aims. The following information was collected: (a) study design, (b) sampling procedures, (c) sample/setting, (d) instrumentation and measures, (e) results, and (f) practical implications. Subsequently, data were extracted and organized by the first and third authors into themes and categories based on the 3 aims. 


\section{Synthesis}

The data were continuously discussed and decided upon between the first and third author. The components of nursing roles, responsibilities, and educational requirements were compared for their similarities and discrepancies. The first author classified the topics that were discussed by nurses during the ACP conversations. Next, the third author reviewed the topics. Lastly, the first and third authors discussed and revised the topics until agreement was reached and themes evolved.

\section{Quality Appraisal}

Each article included was graded and appraised by the first and third authors independently. ${ }^{49}$ The critical appraisal framework as defined by Caldwell and colleagues ${ }^{50}$ was used because it gave the opportunity to assess quantitative and qualitative research with one list of questions. It allowed for the evaluation of relevant studies, synthesizing the findings and drawing conclusions. Characteristics of each study including ethical/practical considerations and the main findings were compiled. Inclusion or exclusion discrepancies were discussed until agreement between the first and third author was reached.

\section{Results}

After reviewing titles and abstracts and deleting duplicates, 146 records were evaluated by the first and third author and eventually 21 articles were included in the review. The Figure illustrates the number of articles initially identified, eventually included or excluded, and the reasons for exclusion and report of the findings based on the PRISMA (Preferred Reporting Items for Systematic Reviews and Meta-analyses) checklist.51,52 When reviewing the studies, essential aspects of the RNs' and/or APRNs' role as well as the responsibilities and competencies in the ACP process in an acute care setting were located. Additionally, themes that were discussed by RNs and/or APRNs in ACP conversations were found. 
Figure. Flowchart of included/excluded documents based on PRISMA (Preferred Reporting Items for Systematic Reviews and Meta-analyses) ScR. ${ }^{51}$

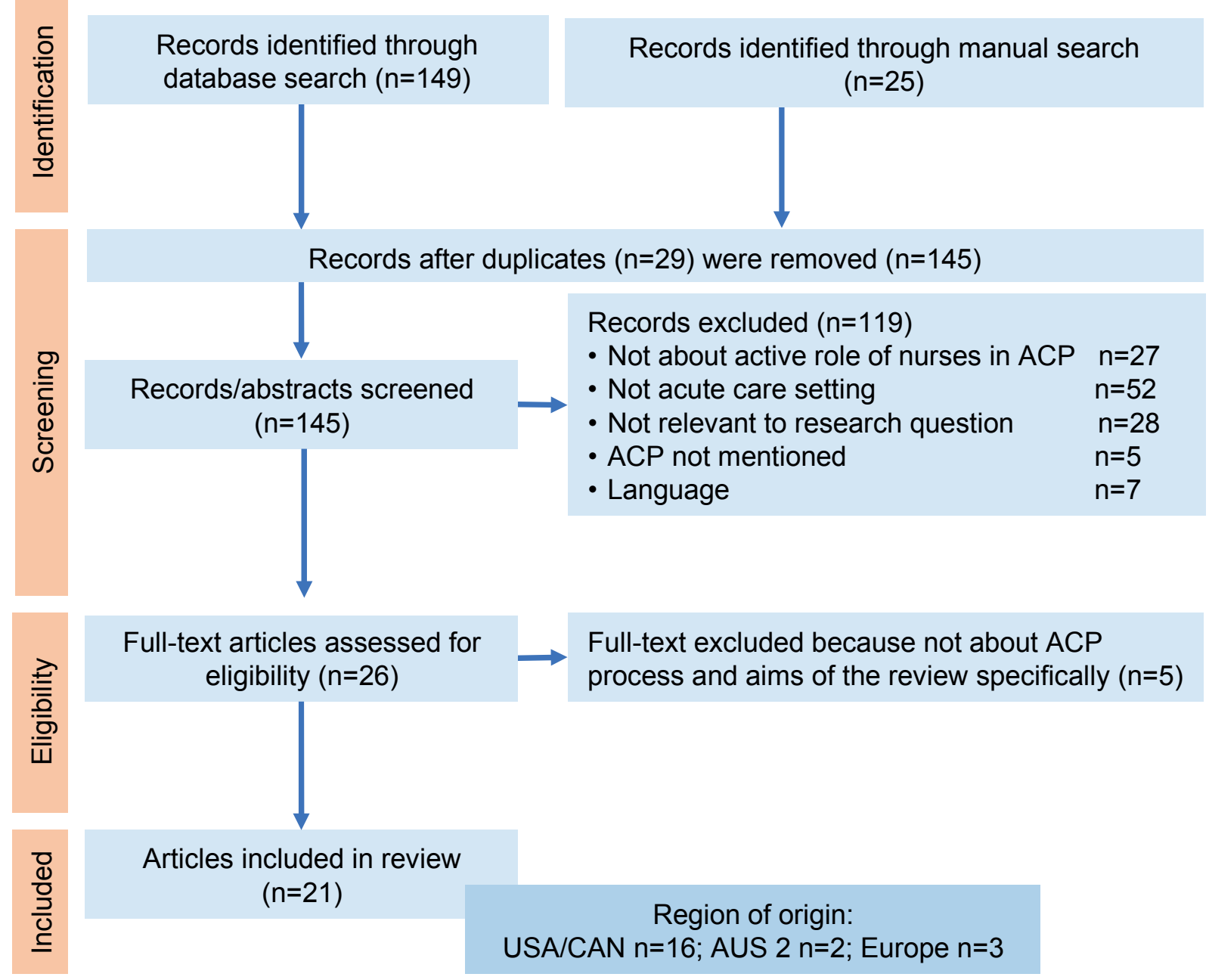

\section{Aim 1: Roles and/or Responsibilities of RNs and/or APRNs in the ACP Process}

As summarized in the Table, 15 articles provide details about the roles and responsibilities of RNs and/or APRNs related to ACP conversations. These roles and responsibilities include facilitating ACP conversations, providing education, and counseling related to medical information. Furthermore, they involve advocating for patients/families, documenting aspects related to ACP conversations, and teaching health care professionals and the general public on ACP.

Adams and colleagues ${ }^{55}$ summarize the roles of RNs. These roles encompass (a) facilitating conversations between patients/families and health care 
providers, (b) providing information to and between health care professionals and patients/families, (c) supporting patients and families by showing empathy and understanding of the situation, and (d) advocating for patients' wishes in their relationship with family members and health care professionals.

Two articles point at the responsibility of specialized RNs to facilitate and encourage ACP conversations with patients/families. ${ }^{39,61}$ Fischer and colleagues ${ }^{57}$ discuss the importance of RNs taking into consideration the language, cultural, and religious backgrounds of patients when conducting ACP conversations in the acute care setting. Moreover, the authors describe how RNs assist patients to navigate through the health care system. A myriad of articles explain the roles of RNs and/or APRNs in facilitating ACP conversations and emphasizing the need for patients to make health care decisions. ${ }^{33,39,40,53,55-58,60,61,63}$ It is recommended that conversations about ACP take place before patients are hospitalized for acute situations. The ACP process appears to minimize stress related to the admission to an acute care setting and clarifies decisions such as resuscitation. ${ }^{57}$

Various articles summarize the importance of patients receiving education and counseling about medical information related to their specific disease state. ${ }^{40,55-57,59,60,63}$ This medical information may include symptom management. ${ }^{60}$ During the ACP conversations, RNs and/or APRNs serve as advocates for patients encouraging them to discuss their wishes and perceptions of quality of life. While serving in this advocacy role, nurses at any level protect patients' wishes not honored during treatment. ${ }^{55}$

Four articles mention that documentation of details of the conversation including the reaction of the patients and families is crucial after RNs and/or APRNs have ACP conversations with patients/families so that this information is available to the interprofessional team. ${ }^{40,57,61,63}$ Authors emphasize that based on $\mathrm{RNs}^{\prime}$ and/or APRNs' knowledge and expertise in PC, RNs and/or APRNs engage in teaching, coaching, and mentoring of the general public to engage in ACP conversations. ${ }^{33,62}$

Improving nurses' professional knowledge and teaching skills regarding ACP conversations in the acute care setting is viewed as a critical role in the literature. O'Connor and colleagues ${ }^{60}$ highlight the importance of providing formal clinical education sessions, personal mentoring, and joint client visits of acute care APRNs with community or home care nurses to support the ACP conversations with patients and provide continuity of care. 


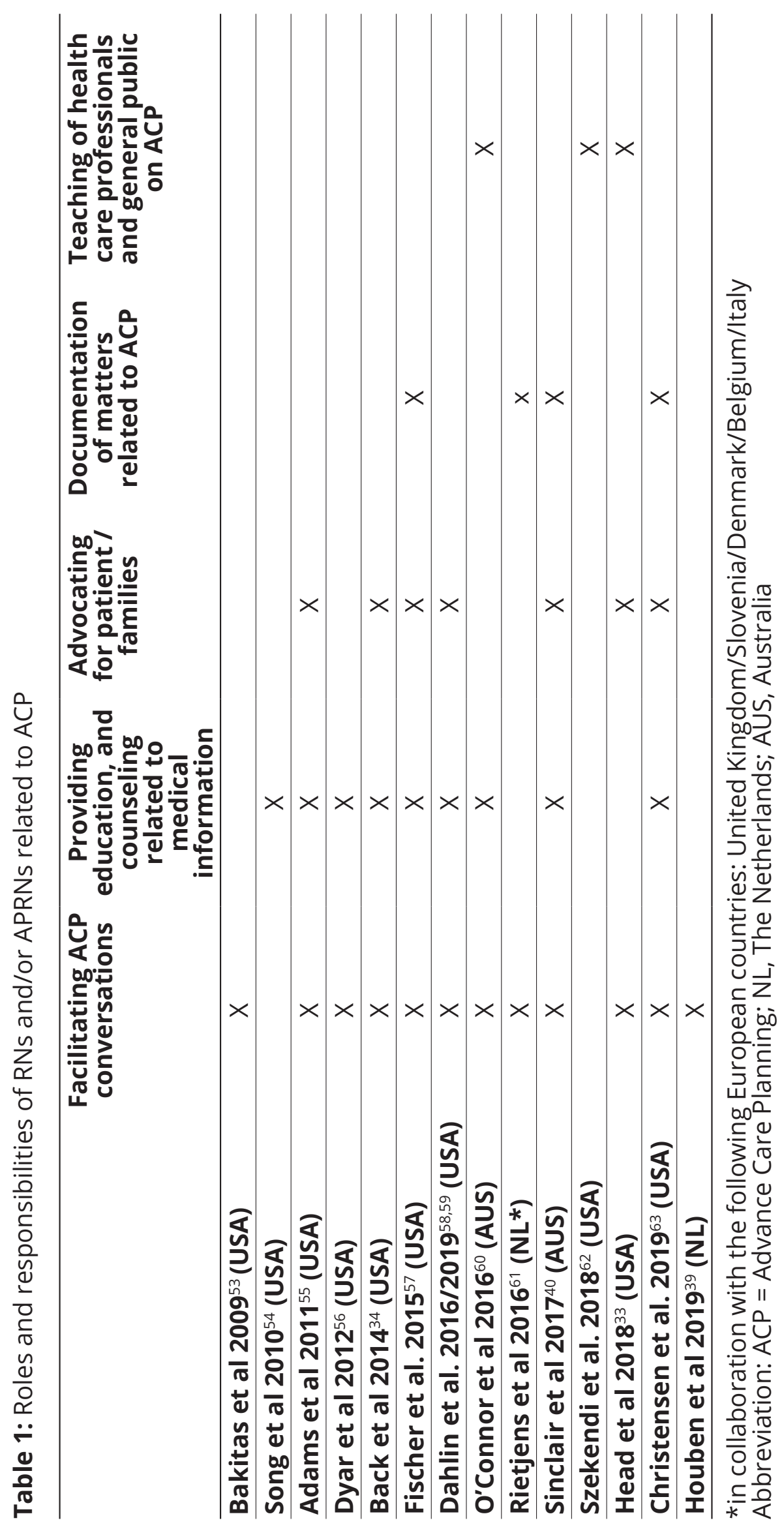




\section{Aim 2: Themes Discussed by RNs and/or ARPNs in ACP Conversations}

A variety of themes were discovered that were discussed by RNs or APRNs throughout the ACP conversations (see Supplemental Digital Content 1, http:// links.Iww.com/ JHPN/A50). Themes discussed include (a) medical information about disease, treatment options, and symptoms, as well as explanations of prognostic estimates; (b) care and treatment questions based on patients'/ families' view of life; (c) future treatment options and decisions based on values, wishes, and goals of care; (d) future potential places of care and end-of-life care; (e) communication with what has been discussed and decided. Several underlying concepts or frameworks such as "Five Wishes" (agingwithdignity. org) ${ }^{56}$ or "Respecting Choices" (respectingchoices.org) ${ }^{40,61}$ serve as the basis for nurses' ACP discussions. All mentioned concepts and frameworks are commonly used in PC in the acute care setting. Staff nurses or APRNs may have conversation about difficult topics such as the patients' personal view of life and preferences related to end-of-life care. ${ }^{34,54}$ Specifically, end-of-life treatment decisions based on patients' (assumed) wishes and values (e.g., life-sustaining measures or aggressive treatment at the end of life) are discussed by several authors. ${ }^{39,40,43,54-56,61,62,64}$

Bakitas and colleagues ${ }^{53}$ include themes such as a description of what PC entails, effective problem-solving strategies to assist patients in future crisis, and self-care management of symptoms. In this study, the authors add strategies for the patient on how to communicate about ACP topics with family and health care professionals, as well as the options related to a timely referral to PC and hospice resources.

\section{Aim 3: Skills and Educational Prerequisites of RNs and/or APRNs in Relation to ACP}

To be able to successfully execute the nursing role related to ACP conversations, RNs and/or APRNs need a theoretical foundation of general PC and end-oflife care. In addition, nurses need specific problem-solving competencies and skills for professionally communicating with patients in ACP conversations. Supplemental Digital Content 2 (http://links.Iww.com/JHPN/A51) summarizes skills and educational requirements in relation to RNs'/APRNs' ACP roles and responsibilities. Cohen and Nirenberg ${ }^{43}$ show a lack of proper training about 
ACP in nursing curricula. Many nurses (mostly RNs) had minimal knowledge about ACP conversations. But nurses want better training to more effectively assist patients/families in ACP. ${ }^{63}$ In their undergraduate and graduate curricula, staff nurses need to be specifically trained in the competencies to engage in ACP conversations..$^{33}$ This education should also include legal issues related to the nursing role in ACP conversations. ${ }^{33,65}$

A thorough educational background is necessary to understand patients' situations, provide care in accordance with patients' wishes and gain practical experience, ${ }^{54,66}$ and increase learning with a PC team. ${ }^{57}$ Clinical knowledge needed by nurses includes, but is not limited to, pain assessment, misconceptions about or barriers to pain management, and basics of hospice care. ${ }^{57,66,67}$ Dahlin and Coyne ${ }^{59}$ distinguish between general PC nursing at level of the RN versus level of the APRN. Staff nurses with a foundation in PC have basic communication skills to introduce ACP conversations. Palliative APRNs are experts in communication skills and discussing goals of care, as well as leading family meetings. Dahlin and colleagues ${ }^{58}$ use a 1-week training for APRNs to intensify PC knowledge and skills for more complex palliative situations. The program contributes to extended knowledge and improved skills for APRNs. ${ }^{66}$

Most publications describe further education for RNs and APRNs related to (a) improving communication skills, (b) increasing problem-solving strategies, (c) expanding leadership skills, and (d) refining decision-making skills.33,39,40,66-68 Staff nurses need to be able to discuss end-of-life topics in a person-centered way that takes into consideration patients' cultural background and beliefs. ${ }^{63}$ These discussions may also include techniques such as taking a history based on patients' beliefs, values, needs, and desires ${ }^{43,69}$ and the identification of the social circumstances in which patients live with their life-limiting condition. ${ }^{67}$ Several publications describe how knowledge about local, regional, or national laws and regulations, as well as specific legal documents, is vital to guide the ACP process. ${ }^{33,63,67}$

Ultimately, nurses' competencies and skills should be transformed into institutional standards in order to provide nurses with sufficient structural and organizational support to be able to fulfill their obligations of initiating, documenting, and engaging in ACP conversations with patients. ${ }^{67}$ 


\section{Discussion}

As part of an interprofessional team in the acute care setting, RNs and APRNs with additional education, skills, and clinical experience may play a significant role in educating and empowering patients and families in the ACP process. Talking about the topics in ACP conversations supports better coordinated care in times when patients strive for autonomy and informed decision-making at the end of life. The ACP process can assist patients to remain in their preferred place of care as long as possible and feel confident about their situation. ${ }^{60}$

\section{Aim 1: Roles and Responsibilities of RNs and/or APRN in the ACP Process}

Based on the increase of publications in the past years, this review shows that RNs and APRNs are more actively involved in the ACP process and should be encouraged to engage and collaborate with interprofessional team members in ACP conversations. ${ }^{70}$ Several studies confirm that $\mathrm{RNs}^{55,71}$ and $\mathrm{APRNs}^{72}$ with a diversity of clinical experiences and additional communication skills are in the perfect position for engaging patients in ACP conversations because of their trusting relationship with patients.

Even in the intensive care unit, RNs play a vital role by screening patients for PC needs and enhancing access to PC services. ${ }^{73}$ Other studies offer PC and ACP to patients early in the acute care setting, but the authors did not specify the role of RNs or APRNs in the process. ${ }^{74,75}$ During the COVID-19 pandemic, the role of APRNs in ACP conversations has become more crucial. ${ }^{76}$ Because PC involves a team approach, specific responsibilities of RNs and APRNs in an early and continued ACP process related to members of the interprofessional team could be further clarified. A close partnership to other team members may help expand the role and responsibilities of RNs and APRNs in ACP conversations. ${ }^{63,77}$ This could eventually lead to dedicated staff facilitating ACP conversations. ${ }^{78}$

\section{Aim 2: Themes Related to ACP as Discussed by RNs and/or APRNs}

In conducting this literature review, it became clear which themes RNs or APRNs discuss with patients during the ACP process. In the acute care setting, RNs and APRNs discuss a variety of themes in relation to ACP, and there was no single 
specific theme that was exclusive to nursing. Staff nurses and APRNs inform patients about disease status, treatment options, and potential symptoms, as well as consequences of their decisions for their social network.

This is similar to what Back and colleagues $^{34}$ showed regarding interprofessional teammembers, including APRNs, helping patients understand their illness, as well as assisting them to make well-informed ACP decisions. Staff nurses and APRNs as members of the interprofessional team can support patients in communicating their needs, values, and wishes in relation to ACP conversations. Although RNs and APRNs engage in ACP conversations, several studies do not mention the effects of early involvement of PC services and specifically the role of $\mathrm{RNs}^{79}$ or APRNs ${ }^{42}$ in the ACP process. Despite the awareness for cultural sensitivity to the patient's situation when engaging in ACP conversations, ${ }^{63}$ this issue is not mentioned in any article in this review.

\section{Aim 3: RNs' and APRNs' Skills and Educational Requirements Related to ACP}

The literature review reveals that nurses (whether RNs or APRNs) who have the appropriate education and skills are able to engage effectively in the ACP process. Nurses need to be prepared to perform the specific roles and responsibilities in ACP conversations. As members of the interprofessional team, RNs and APRNs may need additional training to be successful in the ACP process. ${ }^{63,80}$

Authors mention requirements for nurses such as communication skills and a broad clinical knowledge of patients' cultural and health situations, as well as ethical and legal principles. Often these requirements mean that $A P R N s^{67}$ or RNs have had special courses addressing these essential skills and competencies. ${ }^{37,65}$ Certain authors specifically discuss the role of APRNs in the ACP process in the acute care setting. ${ }^{72,81}$ Because APRNs already have a strong foundation to engage in the ACP process, Heale and colleagues ${ }^{67}$ find it important to outline and disseminate these skills and competencies to members of the interprofessional team in order to be integrated in the process. Then, ultimately, they may be able to evaluate outcomes of the ACP process.

During their graduate programs and in clinical practice, ${ }^{82}$ nurses need to continuously (a) increase their knowledge about the ACP process, (b) improve their communication skills, and (c) execute a range of responsibilities on an APRN level to give patients a secure feeling within the acute care setting. ${ }^{60}$ 
Family meetings in which RNs participate as advocates are a forum for conversations with patients/families about future care. ${ }^{83}$ Although these forums provide opportunities to engage in the ACP process, it is still not common for RNs without additional communication training to be included in or even lead these meetings. ${ }^{55}$ Publications discuss the importance that RNs continue to learn and improve communication skills and strategies to be able to engage in and potentially lead ACP conversations. ${ }^{80,83,84}$

\section{Limitations/Strengths}

Because this review covers the broad topic of the role of RNs and/or APRNs in early PC and their responsibility in the ACP process, it has its limitations but also strengths. Despite searching for publications in 3 languages, the authors found mostly literature from Anglo-Saxon countries, which limits the applicability of RNs' or APRNs' roles and responsibilities in the ACP process in acute care settings in other countries with potentially different nursing educational or clinical requirements.

The strength of this review is the broadness of its scope and the ability to learn from other countries and health care systems. This enhances the understanding of nurses' contributions in the ACP process. This is particularly true related to the educational requirements and themes discussed by RNs and/ or APRNs.

\section{Conclusion and implications}

This review provides a better understanding of the role of RNs and APRNs in the ACP process in the acute care setting and the themes that were discussed related to nurses' responsibilities. It becomes clear that RNs and APRNs are in a good position to be engaged in the ACP process for patients early and throughout their trajectory of any life-limiting disease. One of RNs' and APRNs' core roles is advocating for the wishes and values of patients.

Moreover, knowledge and skills provided to RNs/APRNs prior to engagement early in the ACP process in the acute care setting may assist in finding solutions with patients and families. Staff nurses and APRNs have the responsibility to cover specific themes during ACP conversations such as explanations of prognostic estimates and goals of care. 
The roles of nurses as facilitator, educator, and advocate advance the continuity of care for patients between settings. The contributions of RNs and APRNs for patients in PC in the acute care setting need to be clarified within the nursing profession and ultimately within the interprofessional team. A clearer differentiation of the roles and responsibilities of RNs and APRNs in the ACP process can lay the groundwork for improved team collaboration. Once the roles and responsibilities are defined and resources are dedicated, RNs and APRNs can provide increased support in the ACP process. ${ }^{37}$ How to measure the specifics of the ACP conversations as well as the aspects of RNs'/APRNs' involvement that patients find effective will need attention in the future. 


\section{References}

1. Hui D, De La Cruz M, Mori M, et al. Concepts and definitions for "supportive care," "best supportive care," "palliative care," and "hospice care" in the published literature, dictionaries, and textbooks. Support Care Cancer. 2013;21(3):659-685. doi:10.1007/ s00520-012-1564-y.

2. Van Mechelen W, Aertgeerts B, De Ceulaer K, et al. Defining the palliative care patient: a systematic review. Palliat Med. 2013; 27(3):197-208. doi:10.1177/0269216311435268.

3. World Health Organization (WHO). WHO definition of palliative care. https://www. who.int/cancer/palliative/definition/en/. Accessed August 27, 2020.

4. National Institute on Aging. Understanding palliative care. https://www.nia.nih.gov/ health/what-are-palliative-care-and-hospicecare\#palliative. Accessed August 27, 2020.

5. Canadian Hospice Palliative Care Association. Defining hospice palliative care. https://www.chpca.ca/about-hpc/. Accessed August 27, 2020.

6. Back AL, Arnold RM, Quill TE. Hope for the best, and prepare for the worst. Ann Intern Med. 2003;138(5):439-443. doi:10.7326/0003-4819-138-5-200303040-00028.

7. Ferrell BR, Temel JS, Temin S, et al. Integration of palliative care into standard oncology care: American Society of Clinical Oncology clinical practice guideline update. J Clin Oncol. 2017; 35(1):96-112. doi:10.1200/JCO.2016.70.1474.

8. LeBlanc TW, Roeland EJ, El-Jawahri A. Early palliative care for patients with hematologic malignancies: is it really so difficult to achieve? Curr Hematol Malig Rep. 2017;12(4):300-308. doi:10.1007/s11899-017-0392-z.

9. Nakagawa S, Garan AR. Hospice use and palliative care for patients with heart failure: never say never in medicine, but it is never too early to start the conversation. JAMA Cardiol. 2018; 3(10):926-928. doi:10.1001/jamacardio.2018.2750.

10. Fliedner MC, Mitchell G, Bueche D, Mettler M, Schols J, Eychmueller S. Development and use of the 'SENS'-structure to proactively identify care needs in early palliative care-an innovative approach. Healthcare (Basel). 2019;7(1). doi:10.3390/ healthcare7010032.

11. Izumi S. Advance care planning: the nurse's role. Am J Nurs. 2017; 117(6):56-61. doi:10.1097/01.NAJ.0000520255.65083.35.

12. Kernick LA, Hogg KJ, Millerick Y, Murtagh FEM, Djahit A, Johnson M. Does advance care planning in addition to usual care reduce hospitalisation for patients with advanced heart failure: a systematic review and narrative synthesis. Palliat Med. 2018;32(10):1539-1551. doi:10.1177/0269216318801162.

13. Smith CB, Phillips T, Smith TJ. Using the New ASCO clinical practice guideline for palliative care concurrent with oncology care using the TEAM approach. Am Soc Clin Oncol Educ Book. 2017;37:714-723. doi:10.14694/EDBK_175474.

14. Bally K, Cina C. Hope for the best, and prepare for the worst. Prim Hosp Care Allg Inn Med. 2018;18(4):70-72.

15. ACPEL. The definition of advance care planning. http://www.acpelsociety.com/ acpdefinition.php. Accessed September 28, 2015.

16. Sudore RL, LumHD, You JJ, et al. Defining advance care planning for adults: a consensus definition from a multidisciplinary Delphi panel. J Pain Symptom Manage. 2017; 
17. Rietjens JAC, Sudore RL, Connolly $M$, et al. Definition and recommendations for advance care planning: an international consensus supported by the European Association for Palliative Care. Lancet Oncol. 2017;18(9):e543-e551. doi:10.1016/ S1470-2045(17)30582-X.

18. Michael N, O'Callaghan C, Baird A, Hiscock N, Clayton J. Cancer caregivers advocate a patient- and family-centered approach to advance care planning. J Pain Symptom Manage. 2014;47(6): 1064-1077. doi:10.1016/j.jpainsymman.2013.07.009.

19. Slomka J, Prince-Paul M, Webel A, Daly BJ. Palliative care, hospice, and advance care planning: views of people living with HIV and other chronic conditions. J Assoc Nurses AIDS Care. 2016;27(4):476-484. doi:10.1016/j.jana.2016.02.003.

20. Hutchison LA, Raffin-Bouchal DS, Syme CA, Biondo PD, Simon JE. Readiness to participate $\{$ Head, 2018 \#3754\}in advance care planning: a qualitative study of renal failure patients, families and healthcare providers. Chronic IIIn. 2017;13(3):171-187. doi:10.1177/1742395316675023.

21. Waldrop DP, Meeker MA. Communication and advanced care planning in palliative and end-of-life care. Nurs Outlook. 2012; 60(6):365-369. doi:10.1016/j. outlook.2012.08.012.

22. Green MJ, Schubart JR, Whitehead MM, Farace E, Lehman E, Levi BH. Advance care planning does not adversely affect Hope or anxiety among patients with advanced cancer. J Pain Symptom Manage. 2015;49(6):1088-1096. doi:10.1016/j. jpainsymman.2014.11.293.

23. Fliedner M, Zambrano S, Schols JM, et al. An early palliative care intervention can be confronting but reassuring: a qualitative study on the experiences of patients with advanced cancer. Palliat Med. 2019;33(7):783-792. doi:10.1177/0269216319847884.

24. Dobbins EH. Improving end-of-life care: recommendations from the IOM. Nurse Pract. 2016;41(9):26-34. doi:10.1097/01.NPR. 0000490388.58851.e0.

25. Singer AE, Goebel JR, Kim YS, et al. Populations and interventions for palliative and end-of-life care: a systematic review. J Palliat Med. 2016;19(9):995-1008. doi:10.1089/ jpm.2015.0367.

26. Fernando G, Hughes S. Team approaches in palliative care: a review of the literature. Int J Palliat Nurs. 2019;25(9):444-451. doi:10.12968/ijpn.2019.25.9.444.

27. Kirby E, Broom A, Good P. The role and significance of nurses in managing transitions to palliative care: a qualitative study. BMJ Open. 2014;4(9):e006026. doi:10.1136/ bmjopen-2014-006026.

28. You JJ, Downar J, Fowler RA, et al. Barriers to goals of care discussions with seriously ill hospitalized patients and their families: a multicenter survey of clinicians. JAMA Intern Med. 2015;175(4):549-556. doi:10.1001/jamainternmed.2014.7732.

29. Agarwal R, Epstein AS. Advance care planning and end-of-life decision making for patients with cancer. Semin Oncol Nurs. 2018;34(3):316-326. doi:10.1016/j. soncn.2018.06.012.

30. Hilgeman MM, Uphold CR, Collins AN, et al. Enabling advance directive completion: feasibility of a new nurse-supported advance care planning intervention. J Gerontol Nurs. 2018;44(7):31-42. doi:10.3928/00989134-20180614-06.

31. Ora L, Mannix J, Morgan L, Wilkes L. Nurse-led integration of palliative care for chronic obstructive pulmonary disease: an integrative literature review. J Clin Nurs. 2019;28(21-22):3725-3733. doi:10.1111/jocn.15001. 
32. Fitch MI, Fliedner MC, O'Connor M. Nursing perspectives on palliative care 2015. Ann Palliat Med. 2015;4(3):150-155. doi:10.3978/j.issn.2224-5820.2015.07.04.

33. Head BA, Song MK, Wiencek C, Nevidjon B, Fraser D, Mazanec P. Palliative nursing summit: nurses leading change and transforming care: the nurse's role in communication and advance care planning. J Hosp Palliat Nurs. 2018;20(1):23-29. doi:10.1097/NJH.0000000000000406.

34. Back AL, Park ER, Greer JA, et al. Clinician roles in early integrated palliative care for patients with advanced cancer: a qualitative study. J Palliat Med. 2014;17(11):12441248. doi:10.1089/jpm.2014.0146.

35. Sekse RJT, Hunskar I, Ellingsen S. The nurse's role in palliative care: a qualitative metasynthesis. J Clin Nurs. 2018;27(1-2):e21-e38. doi:10.1111/jocn.13912.

36. Hospice and Palliative Nurses Association (HPNA). HPNA position statement advance care planning. J Hosp Palliat Nurs. 2018;20(5):E1-E3.

37. Miller B. Nurses preparation for advanced directives: an integrative review. J Prof Nurs. 2018;34(5):369-377. doi:10.1016/j.profnurs.2018.07.001.

38. Babcock CW, Robinson LE. A novel approach to hospital palliative care: an expanded role for counselors. J Palliat Med. 2011;14(4):491-500. doi:10.1089/jpm.2010.0432.

39. Houben CHM, Spruit MA, Luyten $H$, et al. Cluster-randomised trial of a nurse-led advance care planning session in patients with COPD and their loved ones. Thorax. 2019;74(4):328-336. doi:10.1136/thoraxjnl-2018-211943.

40. Sinclair C, Auret KA, Evans SF, et al. Advance care planning uptake among patients with severe lung disease: a randomized patient preference trial of a nurse-led, facilitated advance care planning intervention. BMJ Open. 2017;7(2):e013415. doi:10.1136/ bmjopen-2016-013415.

41. Skorstengaard $M H$, Brogaard $T$, Jensen $A B$, et al. Advance care planning for patients and their relatives. Int J Palliat Nurs. 2019;25(3):112-127. doi:10.12968/ ijpn.2019.25.3.112.

42. Temel JS, Greer JA, Muzikansky A, et al. Early palliative care for patients with metastatic non-small-cell lung cancer. N Engl J Med. 2010;363(8):733-742. doi:10.1056/ NEJMoa1000678.

43. Cohen A, Nirenberg A. Current practices in advance care planning: implications for oncology nurses. Clin J Oncol Nurs. 2011;15(5): 547-553. doi:10.1188/11.CJON.547553.

44. Arksey H, O'Malley L. Scoping studies: towards a methodological framework. Int J Soc Res Methodol. 2005;8(1):19-32. doi:10.1080/1364557032000119616.

45. Peterson J, Pearce PF, Ferguson LA, Langford CA. Understanding scoping reviews: definition, purpose, and process. J Am Assoc Nurse Pract. 2017;29(1):12-16. doi:10.1002/2327-6924.12380.

46. Pham MT, Rajic A, Greig JD, Sargeant JM, Papadopoulos A, McEwen SA. A scoping review of scoping reviews: advancing the approach and enhancing the consistency. Res Synth Methods. 2014;5(4):371-385. doi:10.1002/jrsm.1123.

47. Munn Z, Peters MDJ, Stern C, Tufanaru C,McArthur A, Aromataris E. Systematic review or scoping review? Guidance for authors when choosing between a systematic or scoping review approach. BMC Med Res Methodol. 2018;18(1):143. doi:10.1186/ s12874-018-0611-x. 
48. Peters MD, Godfrey CM, Khalil H, Mclnerney P, Parker D, Soares CB. Guidance for conducting systematic scoping reviews. Int J Evid Based Healthc. 2015;13(3):141-146. doi:10.1097/XEB.0000000000000050.

49. Hawker S, Payne S, Kerr C, Hardey M, Powell J. Appraising the evidence: reviewing disparate data systematically. Qual Health Res. 2002;12(9):1284-1299.

50. Caldwell K, Henshaw L, Taylor G. Developing a framework for critiquing health research: an early evaluation. Nurse Educ Today. 2011;31(8):e1-e7. doi:10.1016/j. nedt.2010.11.025.

51. Moher D, Liberati A, Tetzlaff J, Altman DG, Group P. Preferred Reporting Items for Systematic Reviews and Meta-analyses: the PRISMA statement. Open Med. 2009;3(3):e123-e130.

52. Tricco AC, Lillie E, Zarin W, et al. PRISMA Extension for Scoping Reviews (PRISMAScR): checklist and explanation. Ann Intern Med. 2018;169(7):467-473. doi:10.7326/ M18-0850.

53. Bakitas M, Lyons KD, Hegel MT, et al. Effects of a palliative care intervention on clinical outcomes in patients with advanced cancer: the Project ENABLE II randomized controlled trial. JAMA. 2009;302(7):741-749. doi:10.1001/jama.2009.1198.

54. Song MK, Donovan HS, Piraino BM, et al. Effects of an intervention to improve communication about end-of-life care among African Americans with chronic kidney disease. Appl Nurs Res. 2010;23(2):65-72. doi:10.1016/j.apnr.2008.05.002.

55. Adams JA, Bailey DE Jr., Anderson RA, Docherty SL. Nursing roles and strategies in end-of-life decision making in acute care: a systematic review of the literature. Nurs Res Pract. 2011;2011:527834-527815. doi:10.1155/2011/527834.

56. Dyar S, Lesperance M, Shannon R, Sloan J, Colon-Otero G. A nurse practitioner directed intervention improves the quality of life of patients with metastatic cancer: results of a randomized pilot study. J Palliat Med. 2012;15(8):890-895. doi:10.1089/ jpm.2012.0014.

57. Fischer SM, Cervantes L, Fink RM, Kutner JS. Apoyo con Carino: a pilot randomized controlled trial of a patient navigator intervention to improve palliative care outcomes for Latinos with serious illness. J Pain Symptom Manage. 2015;49(4):657665. doi:10.1016/j. jpainsymman.2014.08.011.

58. Dahlin C, Coyne PJ, Cassel JB. The advanced practice registered nurses palliative care externship: a model for primary palliative care education.J Palliat Med. 2016;19(7):753759. doi:10.1089/jpm.2015.0491.

59. Dahlin C, Coyne P. The palliative APRN leader. Ann Palliat Med. 2019;8(Suppl 1):S30-S38. doi:10.21037/apm.2018.06.03.

60. O'Connor M, Palfreyman S, Le B, Lau R. Establishing a nurse practitioner model to enhance continuity between palliative care settings. Int J Palliat Nurs. 2016;22(12):581585. doi:10.12968/ijpn.2016.22.12.581.

61. Rietjens JA, Korfage IJ, Dunleavy L, et al. Advance care planning-a multi-centre cluster randomised clinical trial: the research protocol of the ACTION study. BMC Cancer. 2016;16:264-264. doi:10.1186/s12885-016-2298-x.

62. SzekendiMK, Vaughn J, McLaughlin B, et al. Integrating palliative care to promote earlier conversations and to increase the skill and Comfort of nonpalliative care clinicians: lessons learned from an interventional field trial. Am J Hosp Palliat Care. 2018;35(1):132-137. doi:10.1177/1049909117696027. 
63. Christensen $\mathrm{KL}$, Winters $\mathrm{CA}$, Colclough $\mathrm{Y}$, Oley $\mathrm{E}$, Luparell S. Advance care planning in rural Montana: exploring the nurse's role. J Hosp Palliat Nurs. 2019;21(4):264-271. doi:10.1097/NJH.0000000000000556.

64. Jacobsen J, Jackson V, Dahlin C, et al. Components of early outpatient palliative care consultation in patients with metastatic nonsmall cell lung cancer. Randomized Controlled Trial. J Palliat Med. 2011;14(4):459-464. doi:10.1089/jpm.2010.0382.

65. White KR, McClelland LE, VanDerWielen L, Coyne PJ. Voices from the bedside: palliative nurses' perceptions of current practices and challenges. J Hosp Palliat Nurs. 2013;15(6):360-365. doi:10.1097/NJH.0b013e3182988711.

66. Gentry $\mathrm{JH}$, Dahlin C. The evaluation of a palliative care advanced practice nursing externship. J Hosp Palliat Nurs. 2020;22(3):172-179. doi:10.1097/ NJH.0000000000000637.

67. Heale R, Rietze L, Hill L, Roles S. Development of nurse practitioner competencies for advance care planning. J Hosp Palliat Nurs. 2018;20(2):166-171. doi:10.1097/ $\mathrm{NJH} .0000000000000425$.

68. Bakitas M, Lyons KD, Hegel MT, et al. The project ENABLE II randomized controlled trial to improve palliative care for rural patients with advanced cancer: baseline findings, methodological challenges, and solutions. Palliat Support Care. 2009;7(1):7586. doi:10.1017/S1478951509000108.

69. Kmetec S, Stiglic G, Lorber M, et al. Nurses' perceptions of early person-centred palliative care: a cross-sectional descriptive study. Scand J Caring Sci. 2020;34(1):157166. doi:10.1111/scs.12717.

70. Ho A, Jameson K, Pavlish C. An exploratory study of interprofessional collaboration in end-of-life decision-making beyond palliative care settings. J Interprof Care. 2016;30(6):795-803. doi:10.1080/13561820.2016.1203765.

71. Weber C, Stirnemann J, Herrmann FR, Pautex S, Janssens JP. Can early introduction of specialized palliative care limit intensive care, emergency and hospital admissions in patients with severe and very severe COPD? A randomized study. BMC Palliat Care. 2014;13:47. doi:10.1186/1472-684X-13-47.

72. Zhuang $\mathrm{H}, \mathrm{Ma} \mathrm{Y}$, Wang $\mathrm{L}$, Zhang $\mathrm{H}$. Effect of early palliative care on quality of life in patients with non-small-cell lung cancer. Curr Oncol. 2018;25(1):e54-e58. doi:10.3747/ co.25.3639.

73. McCarroll CM. Increasing access to palliative care services in the intensive care unit. Dimens Crit Care Nurs May/Jun. 2018;37(3):180-192. doi:10.1097/ DCC.0000000000000299.

74. Barnes A, Woodman RJ, Kleinig P, Briffa M, To T, Wigg AJ. Early palliative care referral in patients with end stage liver disease is associated with reduced resource utilisation. J Gastroenterol Hepatol. 2019;35:840-845. doi:10.1111/jgh.14877

75. Yoong J, Park ER, Greer JA, et al. Early palliative care in advanced lung cancer: a qualitative study. JAMA Intern Med. 25 2013; 173(4):283-290. doi:10.1001/ jamainternmed.2013.1874.

76. Rosa WE, Gray TF, Chow K, et al. Recommendations to leverage the palliative nursing role during COVID-19 and future public health crises. J Hosp Palliat Nurs. 2020;22(4):260-269. doi:10.1097/NJH.0000000000000665. 
77. Ferrell BR, Twaddle ML, Melnick A, Meier DE. National Consensus Project Clinical Practice Guidelines for Quality Palliative Care Guidelines, 4th edition. J Palliat Med. 2018;21:1684-1689. doi:10.1089/jpm.2018.0431.

78. Arnett K, Sudore RL, Nowels D, Feng CX, Levy CR, Lum HD. Advance care planning: understanding clinical routines and experiences of Interprofessional team members in diverse health care settings. Am J Hosp Palliat Care. 2017;34(10):946-953. doi:10.1177/1049909116666358.

79. McDonald J, Swami N, Hannon B, et al. Impact of early palliative care on caregivers of patients with advanced cancer: cluster randomised trial. Ann Oncol. 2017;28(1):163168. doi:10.1093/annonc/mdw438.

80. Shepherd J, Waller A, Sanson-Fisher R, Clark K, Ball J. Knowledge of, and participation in, advance care planning: a cross-sectional study of acute and critical care nurses' perceptions. Int J Nurs Stud. 2018;86:74-81. doi:10.1016/j.ijnurstu.2018.06.005.

81. Pirl WF, Greer JA, Traeger $L$, et al. Depression and survival in metastatic non-smallcell lung cancer: effects of early palliative care. J Clin Oncol. 2012;30(12):1310-1315. doi:10.1200/JCO. 2011.38.3166.

82. Coffey A, McCarthy G, Weathers E, et al. Nurses' knowledge of advance directives and perceived confidence in end-of-life care: a cross-sectional study in five countries. Int J Nurs Pract. 2016; 22(3):247-257. doi:10.1111/ijn.12417.

83. Glajchen M, Goehring A. The family meeting in palliative care: role of the oncology nurse. Semin Oncol Nurs. 2017;33(5): 489-497. doi:10.1016/j.soncn.2017.09.007.

84. Wittenberg E, Reb A, Kanter E. Communicating with patients and families around difficult topics in cancer care using the COMFORT communication curriculum. Semin Oncol Nurs. 2018; 34(3):264-273. doi:10.1016/j.soncn.2018.06.007. 


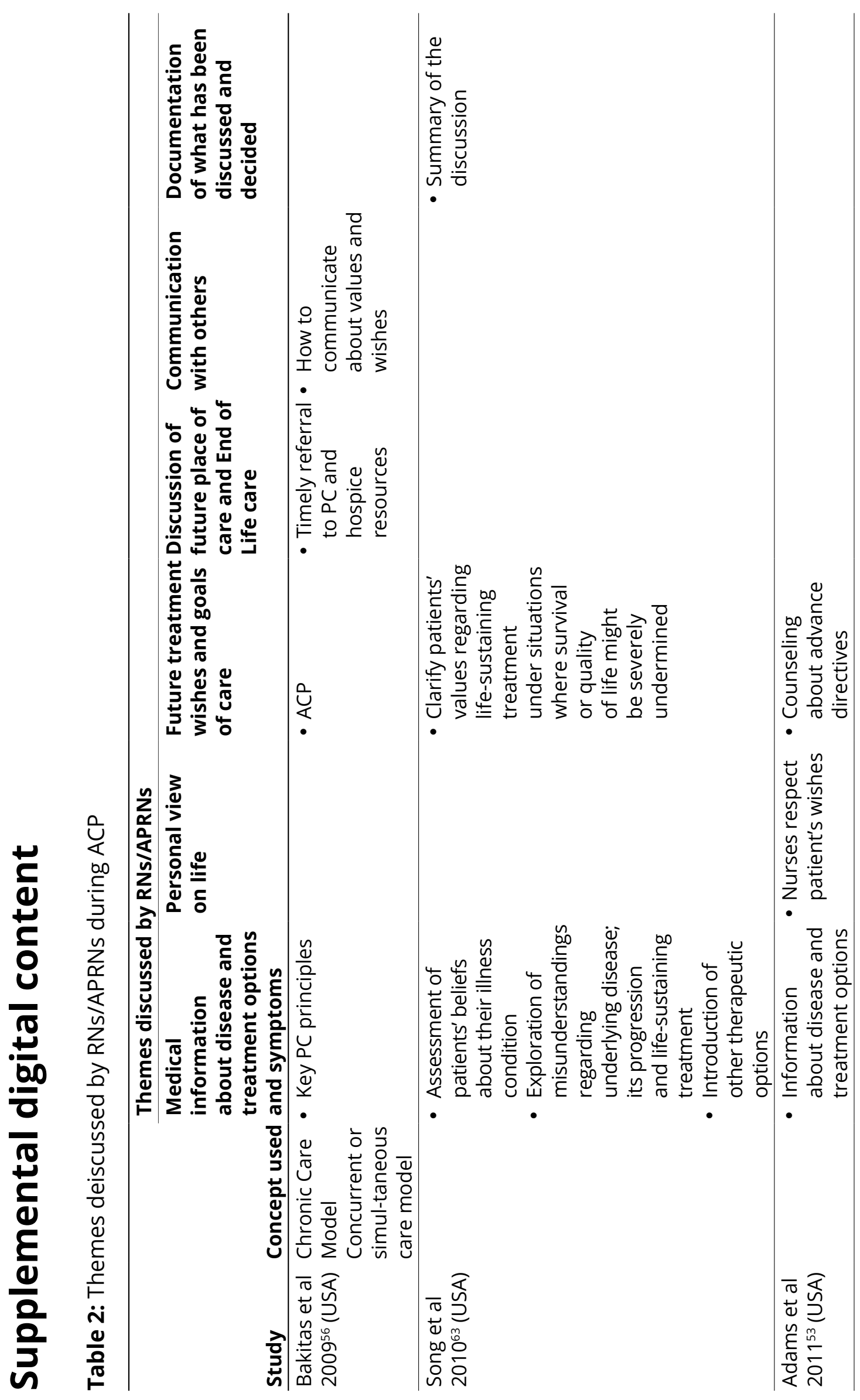




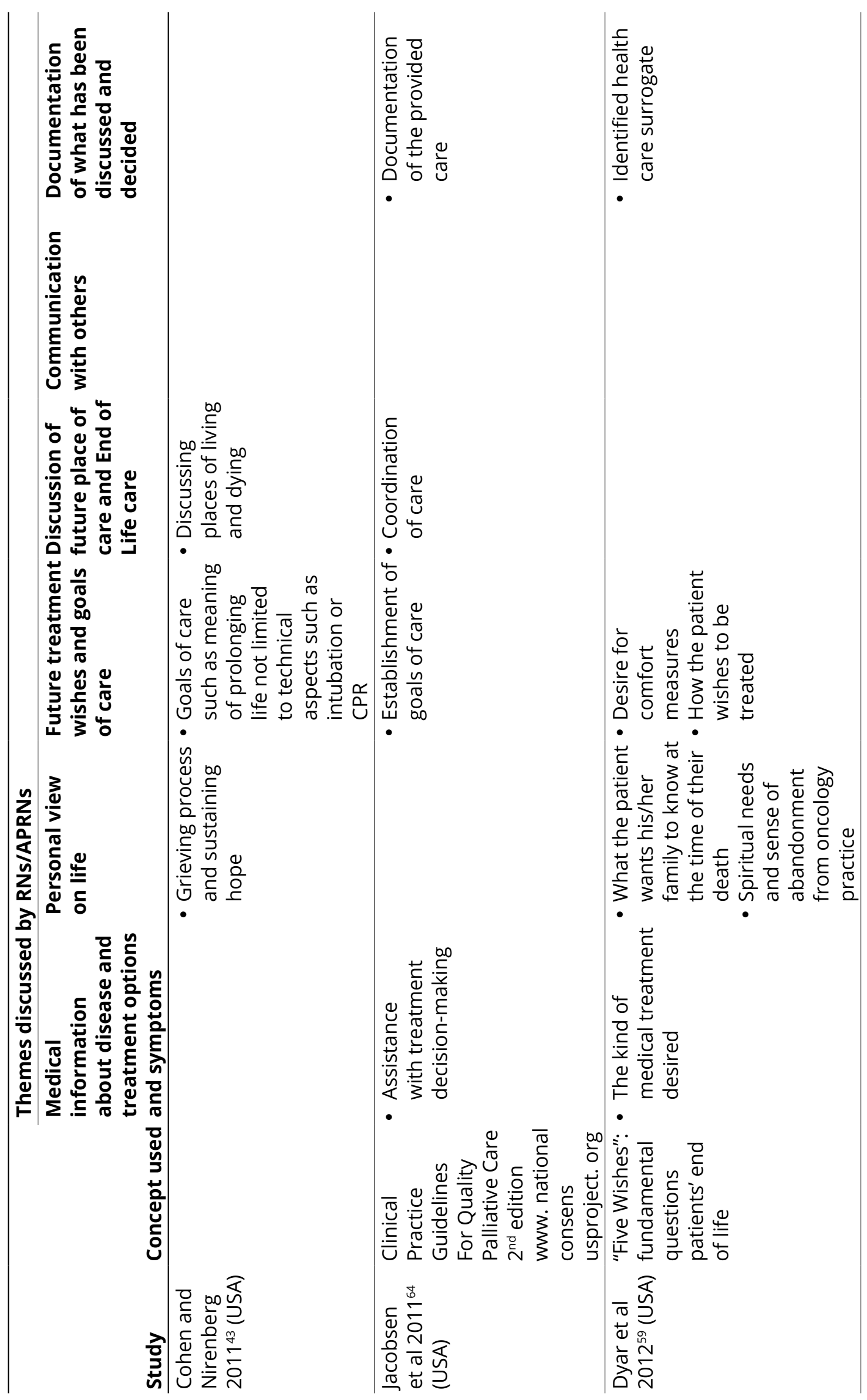




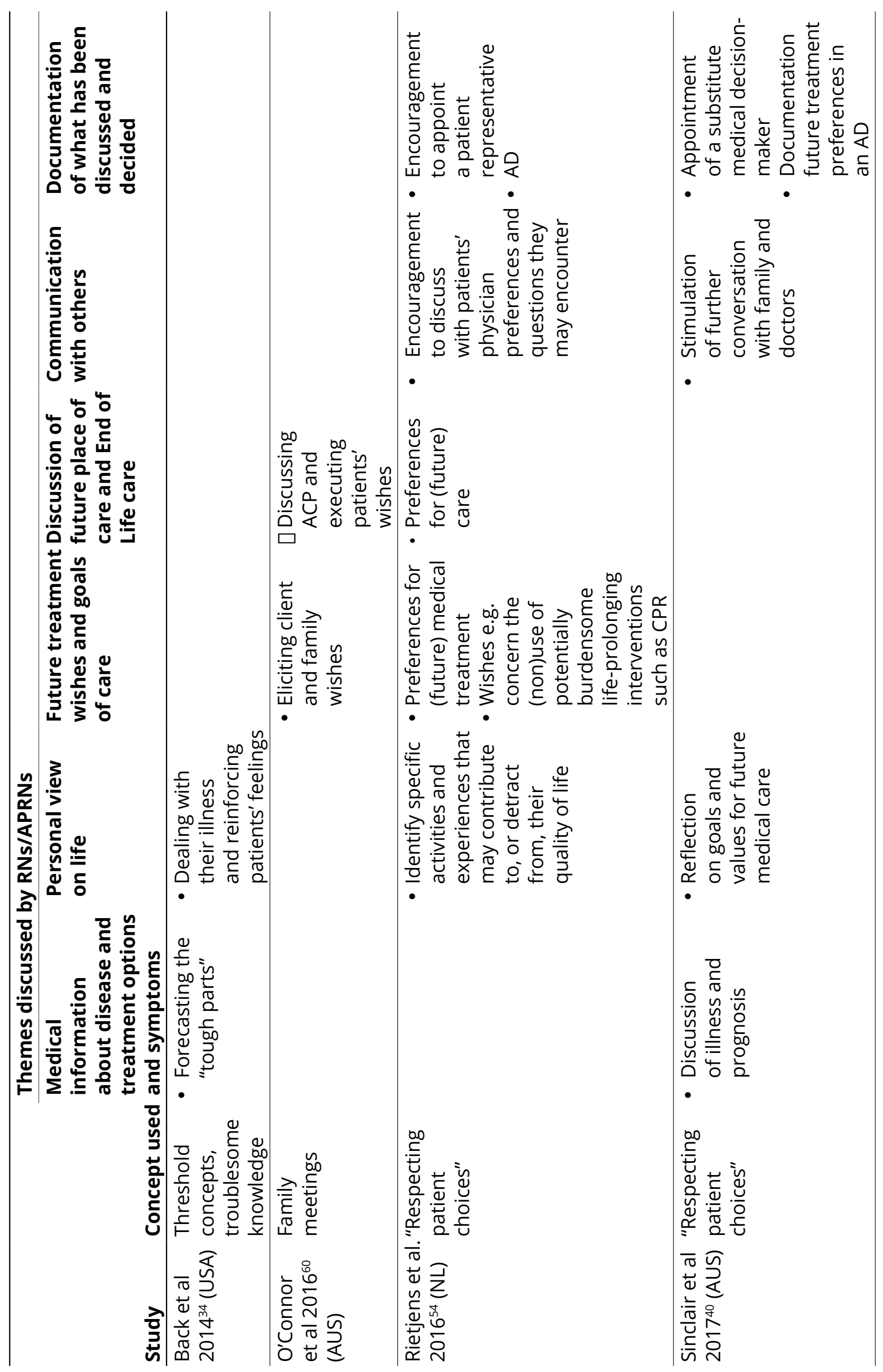




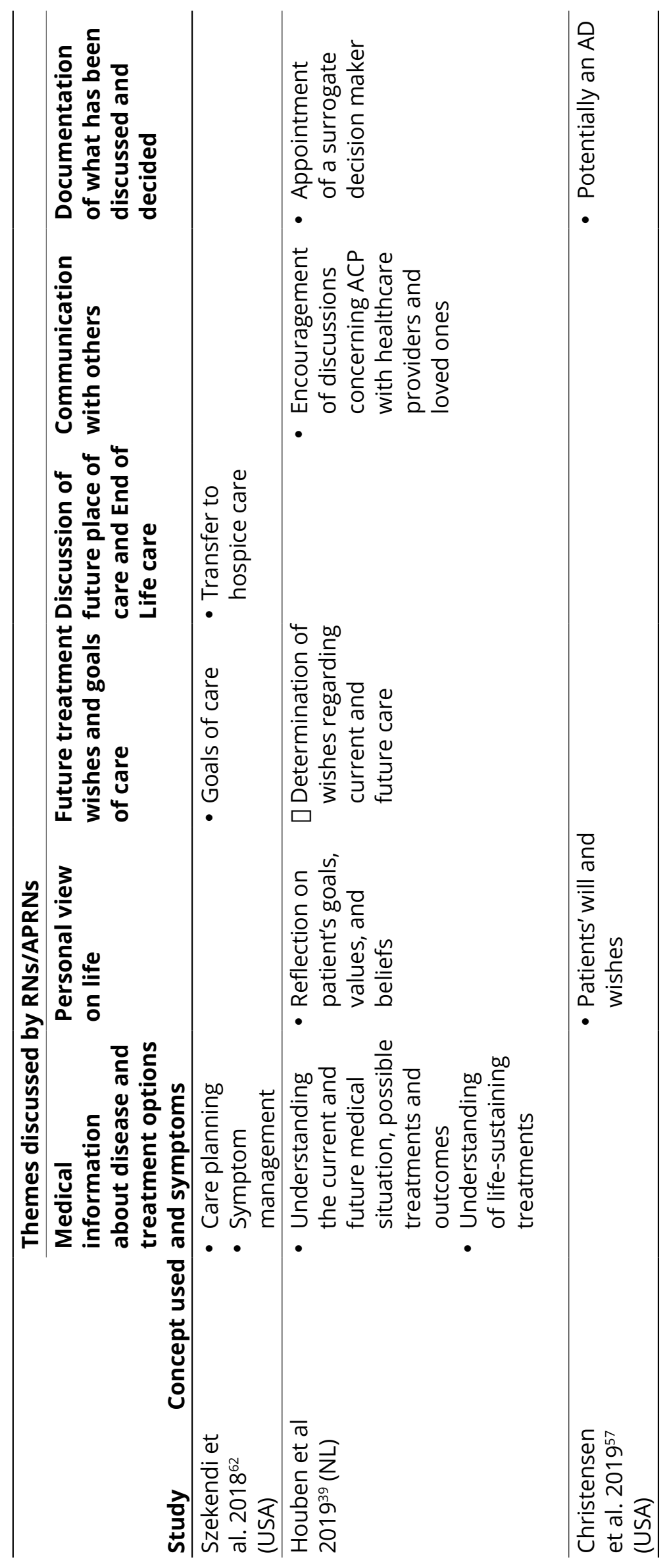




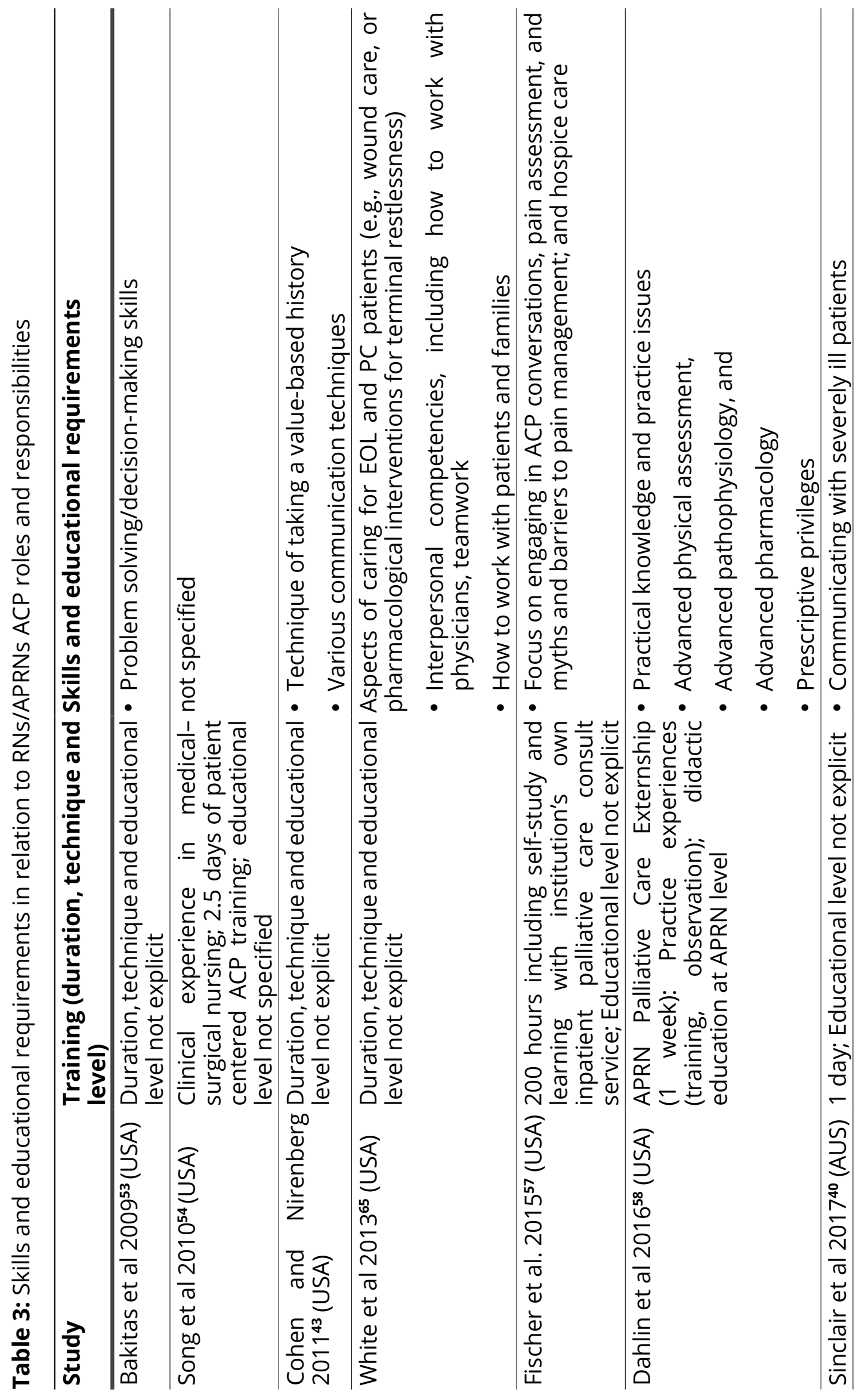




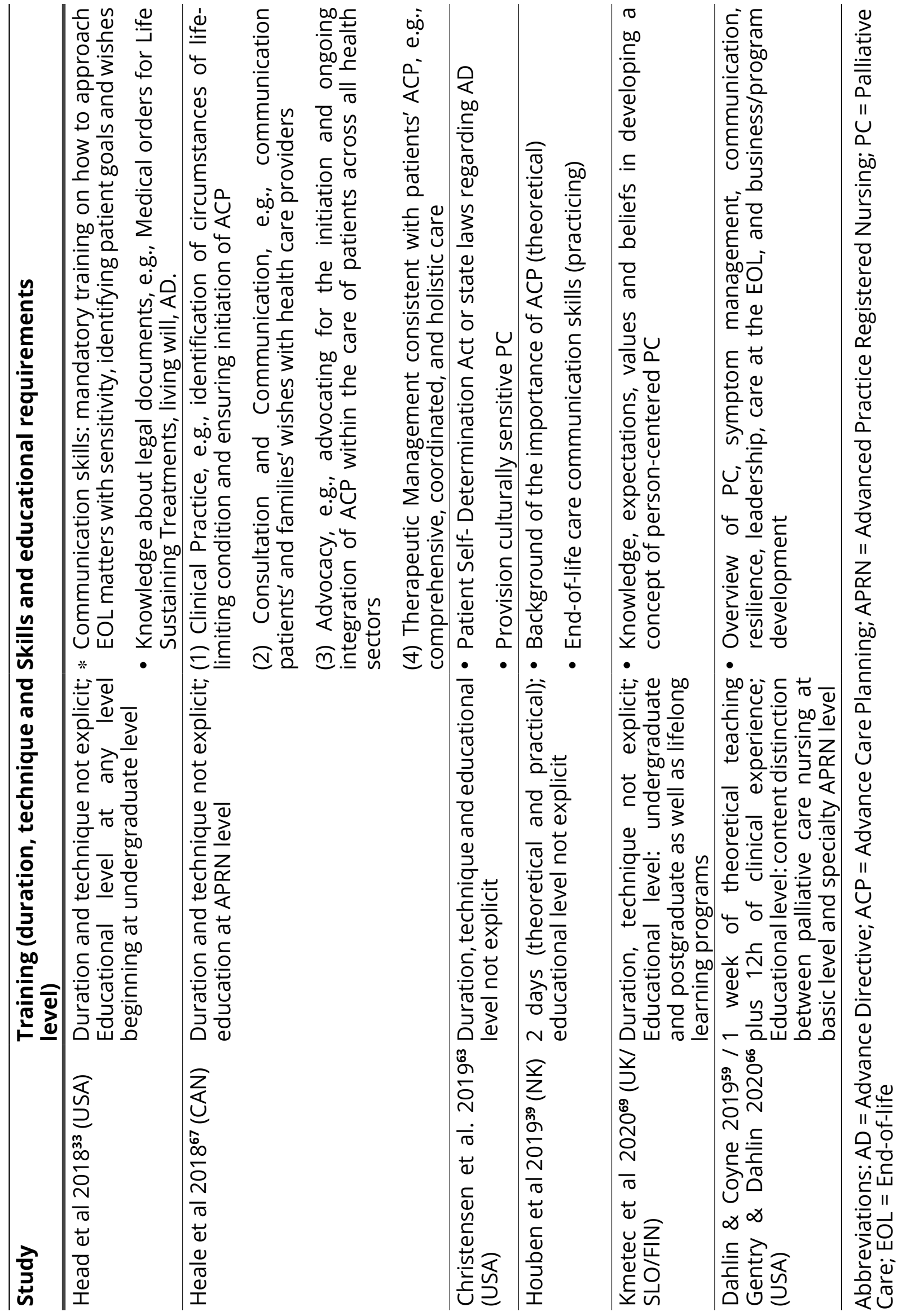




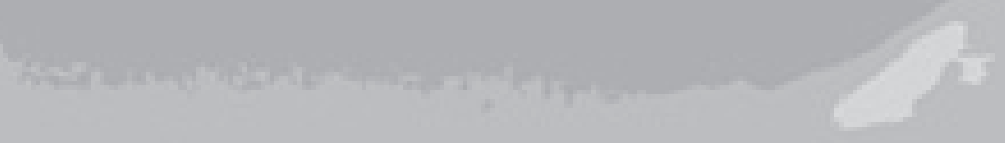

\section{Chas}
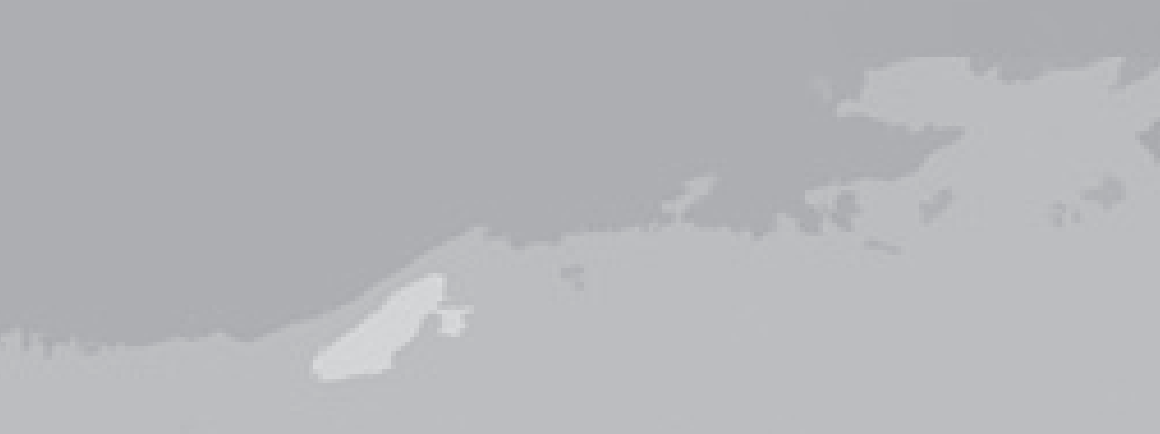

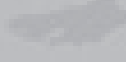

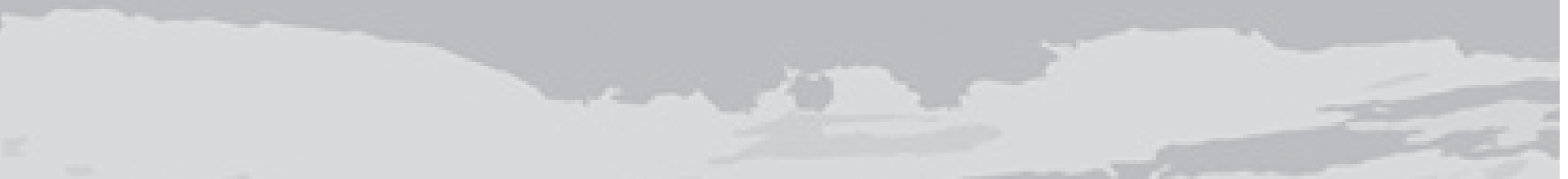

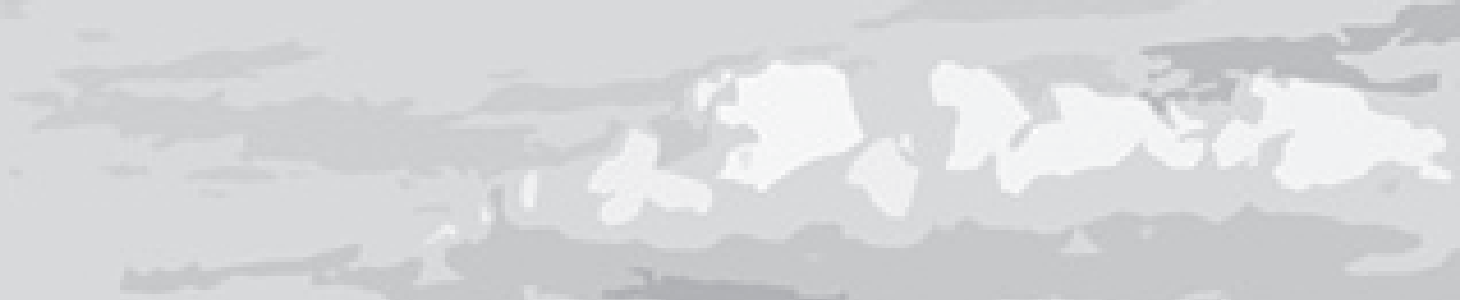

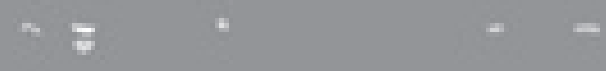

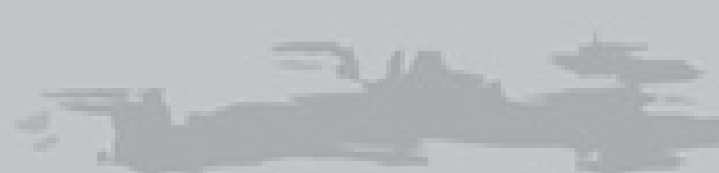

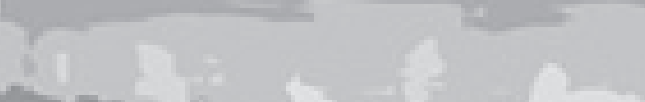

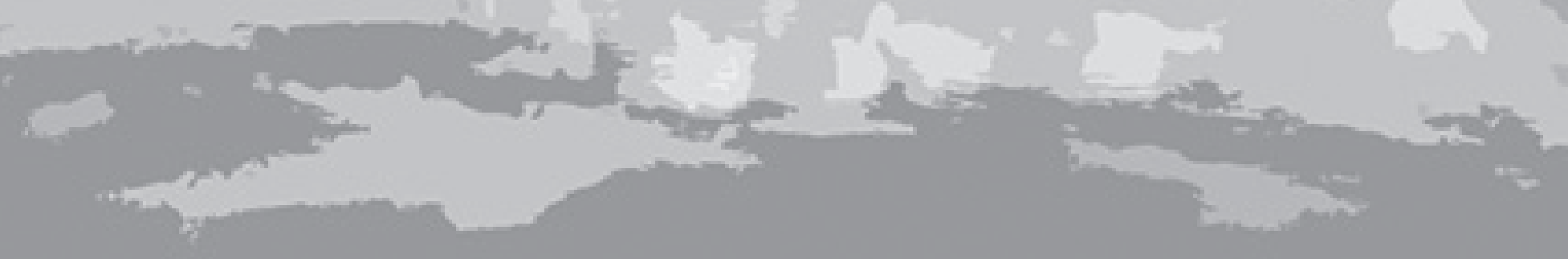




\section{Chapter 6}

\section{Does Time for (in)Direct Nursing Care}

Activities at the End of Life for Patients With or Without Specialized Palliative Care in a University Hospital Differ? A Retrospective Analysis

This chapter was published as:

Fliedner MC, Hagemann M, Eychmuller S, King C, Lohrmann C, Halfens RJG, et al. Does Time for (in)Direct Nursing Care Activities at the End of Life for Patients With or Without Specialized Palliative Care in a University Hospital Differ? A Retrospective Analysis. Am J Hosp Palliat Care. 2020;37(10):844-52. doi 10.1177/1049909120905779. 


\section{Abstract}

Background: Nurses' end of life (EoL) care focuses on direct (eg, physical) and indirect (e.g., coordination) care. Little is known about how much time nurses actually devote to these activities and if activities change due to support by specialized palliative care (SPC) in hospitalized patients. Aims: (1) Comparing care time for EoL patients receiving SPC to usual palliative care (UPC); (2) Comparing time spent for direct/indirect care in the SPC group before and after SPC. Methods: Retrospective observational study; nursing care time for EoL patients based on $\operatorname{tacs}^{\circledR}$ data using nonparametric and parametric tests. The Swiss data method tacs ${ }^{\circledR}$ measures (in)direct nursing care time for monitoring and cost analyses. Results: Analysis of $\operatorname{tacs}^{\circledR}$ data (UPC, $n 1 \frac{1}{4} 642 ;$ SPC, $n 1 / 4$ 104) during hospitalization before death in 2015. Overall, SPC patients had higher $\operatorname{tacs}^{\circledR}$ than UPC patients by 40 direct (95\% confidence interval [Cl]: 5.7-75, P 1/4 $.023)$ and 14 indirect $\operatorname{tacs}^{\circledR}(95 \% \mathrm{Cl}: 6.0-23, \mathrm{P}<.001)$. No difference for tacs ${ }^{\circledR}$ by day, as SPC patients were treated for a longer time (mean number of days 7.2 vs $16, P<.001)$. Subanalysis for SPC patients showed increased direct care time on the day of and after SPC $(P<.001)$, whereas indirect care time increased only on the day of SPC. Conclusions: This study gives insight into nurses' time for (in)direct care activities with/without SPC before death. The higher (in) direct nursing care time in SPC patients compared to UPC may reflect higher complexity. Consensus-based measurements to monitor nurses' care activities may be helpful for benchmarking or reimbursement analysis.

\section{Keywords}

direct nursing care activities, indirect nursing care activities, end-of-life care, usual palliative care intervention, specialized palliative care intervention, health service research, comparative retrospective study 


\section{Background}

When the course of a life-limiting disease changes such that there are no longer curative treatment options, the aim shifts to a palliative approach focusing on patients' quality of life (QOL). Palliative care involves a holistic interprofessional approach and includes identification, prevention, and relief of potential or current suffering. ${ }^{1}$ As part of the palliative approach, when disease-modifying treatments are no longer an option, end-of-life (EoL) care is a core competency ${ }^{2,3}$ of health professionals directed toward patients in the last days or weeks of life. Usual palliative care (UPC) activities aim at supporting patients to die in dignity by managing suffering while taking into consideration the QOL domains of (a) physical, (b) psychosocial, (c) emotional, and (d) spiritual needs. It reaches out to support family members. ${ }^{4-6}$

Nurses play a pivotal role in the provision of palliative care including care for the dying. ${ }^{5,7-9}$ Nurses' focus on EoL care focuses on providing direct patient care activities at the bedside for all QOL domains. ${ }^{10}$ These activities include (a) communication with patients and their family, (b) symptom assessment, and (c) performance of care procedures. ${ }^{11,12}$ It also necessitates devoted time for coordination and communication with healthcare professionals., ${ }^{913-15}$ Indirect care activities cover (a) preparation of care interventions, ${ }^{10}$ (b) coordination of activities, $^{16}$ and (c) coordination of care with healthcare professionals across healthcare settings.

If the treating team agrees that the palliative situation is too complex and unmanageable (e.g., uncontrollable symptoms, multifaceted family situations, wish to hasten death), tertiary care by specialized structured palliative care (SPC) services can be requested for support. ${ }^{17-22}$ In a tertiary hospital, the aim is often focused on curing the patient. However, at a certain time point in the disease trajectory, the treating team, in close cooperation with the patient/family, may decide to shift the goals of care toward a palliative care approach. This decision is often made based on interfering complications and other patientrelated factors. Predetermined screening criteria such as a significant decline in physical status with complex symptoms can help to initiate support by palliative care specialists. These criteria may differ based on the underlying disease ${ }^{23-26}$ or other patient or system-related factors. ${ }^{27}$ Several studies verified the benefit of SPC in complex clinical situations. ${ }^{28-31}$

The SPC intervention by the local specialized team assesses and discusses the focus and goals of care with patients/families and provides 
recommendations to the treating team. In our hospital, the interprofessional SPC intervention is based on the SENS structure. ${ }^{32,33}$ SENS is the acronym for symptoms, EoL decisions, network, and support and includes recommendations about (a) the management of complex symptoms, (b) recommendations about difficult EoL decisions, (c) evaluating patients' social network (e.g., family care options or future place of care) for which the SPC team gives advice on how to best coordinate care, and (d) support for family carers. These recommendations are documented in the chart on the date of the intervention, marking the start of SPC involvement. The treating team takes these recommendations into consideration and is supported by the SPC team in executing them. ${ }^{34}$ Best practice recommends that patients can be admitted to the specialized palliative care unit (SPC-U) for further care if the situation remains unmanageable. ${ }^{35,36}$ Clinical experience shows that carrying out these recommendations of the SPC intervention ${ }^{32}$ often reveals the need for devoted time from the treating team for communication with patients (direct care activities) and coordination of care as well as interactions/discussions within the interprofessional team (indirect care activities).

Little is known about how much worktime nurses actually devote to direct and indirect care activities for EoL patients. To quantify registered nurses' time used for clinical activities and to enable cost analyses based on work time, ${ }^{37}$ several systems or tools have been developed. ${ }^{38}$ In a recent cost analysis, Hagemann et $a^{39}$ confirmed that overall costs for patients receiving SPC were lower compared to UPC. Yet, costs for specific subcomponents such as nursing costs (measured as nurses' care time spent for an individual patient) increased significantly in the SPC population. Based on this study, the researchers were interested in understanding explicitly how SPC influences the time efforts for direct and indirect nursing care activities ${ }^{6,40}$ as compared to patients who received UPC. A closer look at the subpopulation who received SPC and the nursing time efforts for direct and indirect nursing care activities before, during, and after the SPC intervention will help to plan, allocate, and potentially reorganize work forces. ${ }^{7,41}$ This should also benefit nursing care quality and deepen management and leadership knowledge. It will help to understand the effect on nursing care time induced by SPC intervention and potentially support the involvement of an SPC team. ${ }^{42}$ 


\section{Objectives and Aims}

The overall objective of this study was to assess the direct and indirect care time of nurses caring for patients who died in a tertiary hospital in Switzerland. Specifically, the objective was to compare data of nursing care time for patients who received SPC with the patients who received UPC.

The aims of this study were

a. to compare the overall time spent for direct and indirect nursing care activities for dying patients who received SPC intervention as compared to patients who received UPC;

b. to find out whether the time spent for direct and indirect care in the group of patients who received SPC changes before and after the SPC intervention.

\section{Methods}

\section{Study Design}

Based on patient data from the Hagemann study, ${ }^{39}$ a retrospective observational study was performed to assess the direct and indirect nursing care time for patients who died in a Swiss tertiary hospital. With a specific focus on exploring cost components that drive the costs of SPC, including nursing staff costs, Hagemann et al ${ }^{39}$ analyzed the impact of hospital-based SPC on overall hospital costs.

\section{Sample and Setting}

All patients $(\mathrm{N}=976)$ aged 18 years or older who were hospitalized and died between January 1, 2015, and December 31, 2015, in a Swiss tertiary care hospital were included (details of the sampling and setting were published elsewhere ${ }^{39}$ ). Patients who (a) opposed the further use of medical data, (b) died in the emergency department because of accidental causes (e.g., injuries, poisoning), or (c) died on the same day of hospital admission were excluded. This resulted in a total sample of 746 patients who were divided into 2 groups of patients: (1) received UPC, and (2) received the SPC intervention by the SPC team or after being admitted to the SPC-U (Figure 1). 
Figure 1. Flowchart of the sample

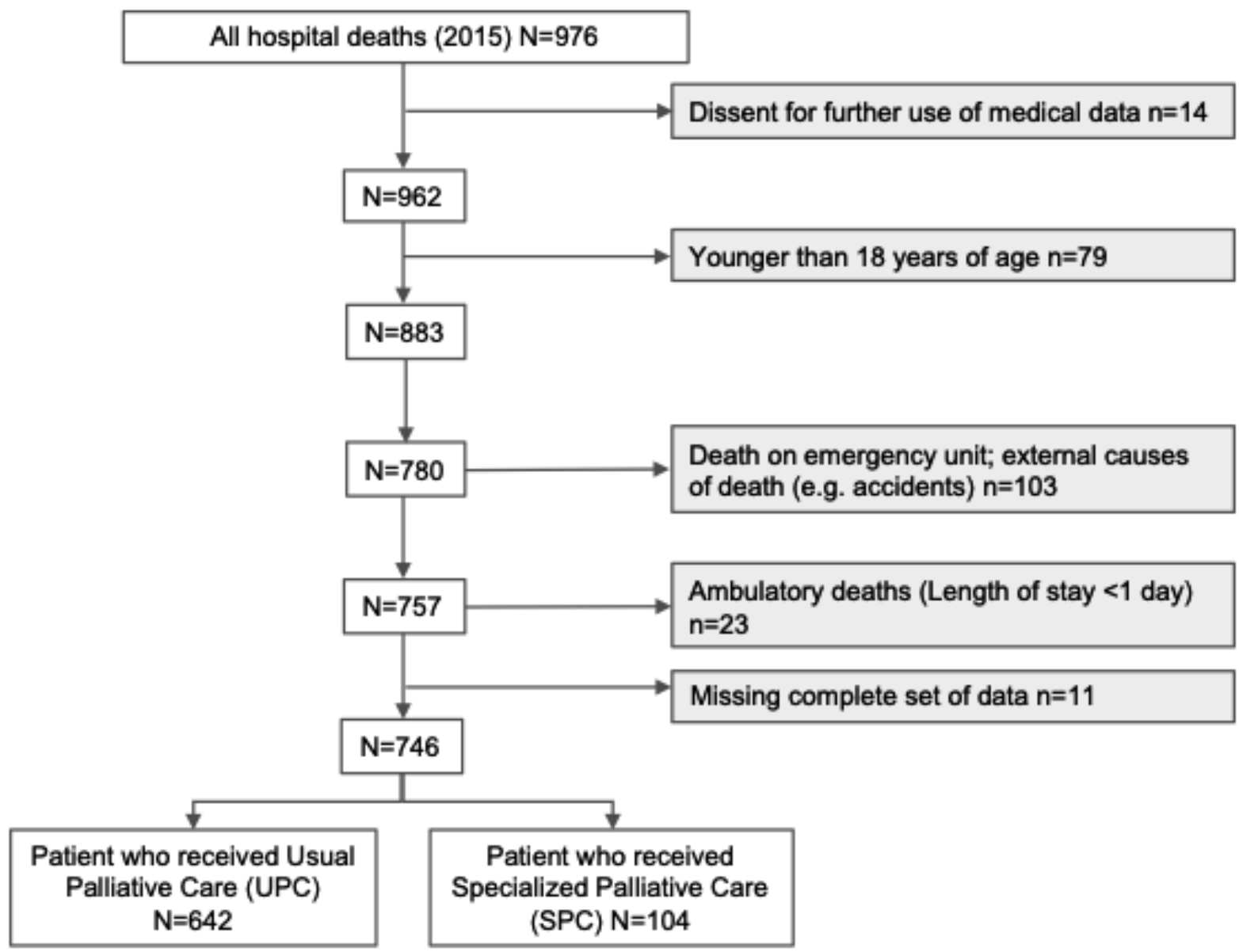

Patients were categorized as SPC patients if they received SPC intervention by the SPC team on demand by the treating team who then considered recommendations from the SPC team and/or after being admitted to the SPC-U.

\section{Data Source and Measure}

Based on the Swiss law on human research and the Cantonal Ethic Commission, ethical approval for this study (Req-2019- 00254) including the obligation to ask for informed consent was waived. To ensure patients' anonymity, only the research team handled the data confidentially. The hospital administration gave permission to access data from medical institutional electronic health records.

The following factors were extracted to identify the sample: (a) patient's characteristics (e.g., age, marital status, primary disease), (b) residency prior to hospitalization, (c) units where patients stayed during the hospitalization prior to death, and (d) the Case Mix Index (CMI). The CMI is an economic surrogate 
marker within the Swiss Diagnosis-Related Group System (Swiss-DRG). It is derived from the hospital-based financial database demonstrating the mix of cost weight of patients' care and allocations of financial hospital resources to patients' treatment. ${ }^{43}$

The nursing administration and controlling department provided data of nursing care activity time from the $\operatorname{tacs}^{\circledR}$ database. In numerous Swiss hospitals, an electronic controlling system called tacs ${ }^{\circledR}$ (Task Analysis and Controlling System for staff resources) is used (www.rodix.ch/referenzen). Based on the balanced scorecard, ${ }^{44} \operatorname{tacs}^{\circledR}$ is a method using local software for generating key figures and key performance indicators such as staffing calculations, which is measured in minutes/hours of working time for care activities. Registered nurses document at the end of their shift their actual care time in minutes for each individual patient covering 24 hours of a workday in a simple computerbased tool.

Table 1: Examples of direct and indirect nursing care activities as defined by the $\operatorname{tacs}^{{ }_{-}}$ system

\begin{tabular}{|c|c|}
\hline & Examples \\
\hline 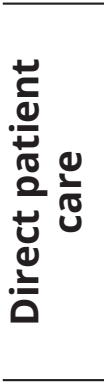 & $\begin{array}{l}\text { - preparation of infusions and administration of (pain) medication } \\
\text { - shift turn over at patients' bedside } \\
\text { - patient and family education } \\
\text { - instruction of patient regarding treatment and examinations } \\
\text { - blood withdrawal } \\
\text { - provision of physical care such as oral care } \\
\text { - conversations with patient during physical care }\end{array}$ \\
\hline 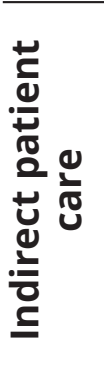 & $\begin{array}{l}\text { - care conversations with interprofessional team } \\
\text { - solve questions about a patient situation by talking to a work colleague } \\
\text { - care coordination with community nurses, home care facilities, nursing homes } \\
\text { - oral rapport to / from following / previous care facility } \\
\text { - case reflection of nursing process and care planning within team } \\
\text { - organization of round table discussion, meetings, transportation of patient } \\
\text { - clarifications with pharmacy about medications }\end{array}$ \\
\hline
\end{tabular}

The method can be adapted to the analytic needs of the institutions. The methodology in this hospital requires nurses to record their efforts in direct and indirect care activities and not to differentiate in detail because the data would not provide sufficient information for hospital-wide analyses. Tacs $^{\circledR}$ data allow the analysis of the overall time across the hospitalization period as well as 
per day for direct and indirect nursing care activities per patient and selected populations ( $1 \operatorname{tacs}^{\circledR}$ point equals 60 minutes of care time). Examples of direct and indirect nursing care activities are listed in Table 1. Higher tacs ${ }^{\circledR}$ data mean more time spent with (direct care) or on behalf of (indirect care) the patient. Tacs $^{\circledR}$ is a useful tool measuring nurses work time specifically within the Swiss performance recording system ${ }^{45}$ and is used as a management tool to allocate nursing workforce and analyze personnel costs within the Swiss-DRG.

\section{Statistical Analysis}

For the statistical analysis, we used the software STATA (Version 15), R (Version 3.5.3), and IBM SPSS Statistics (Version 25).

Patient characteristics were analyzed using descriptive statistics. Continuous variables are presented by mean with standard deviation. Categorical variables are presented by absolute and relative frequencies. The SPC and UPC groups were compared using Wilcoxon-Mann-Whitney and w2 tests for continuous and categorical variables, respectively.

Total nursing care times were analyzed on all hospital days and differentiated between direct and indirect care time as recorded by nurses in tacs ${ }^{\circledR}$ data per patient. These include (a) the sum of direct tacs ${ }^{\circledR}$ over the entire stay, (b) the sum of indirect tacs ${ }^{\circledR}$ over the entire stay, (c) direct tacs ${ }^{\circledR}$ per day, and (d) indirect $\operatorname{tacs}^{\circledR}$ per day.

\section{Aim (a) Comparison of Overall Time Spent for Direct and Indirect Nursing Care Activities for SPC Versus UPC Patients}

The Mann-Whitney-Wilcoxon test with 95\% confidence intervals (Cls) was used for a raw (crude) nonparametric comparison of $\operatorname{tacs}^{\circledR}$ data between SPC and UPC. Although true cause and effect cannot be determined, causal effects were estimated using inverse probability weighting based on propensity scores. ${ }^{46}$ This method uses baseline covariates to adjust for imbalances between the two groups and therefore minimize the impact of bias due to possible nonrandom treatment assignment. ${ }^{47}$ Propensity scores were derived using logistic regression with (a) age, (b) married (yes, no), (c) cancer (yes, no), and (d) location prior to admission with admission from home (yes, no) as covariate. For the inverse probability weighting, we used stabilized weights based on the inverse of the propensity scores ${ }^{48}$ and calculated potential outcome means (POM) and average 
treatment effects (ATE) using weighted linear regression. Since nursing care times were not completely normally distributed, we used bootstrapping with 2000 repetitions (including the calculation of propensity score, POM and ATE) to estimate bias, standard errors, and calculate $95 \% \mathrm{Cls}$. We report bias-corrected point estimate, as well as bias-corrected bootstrap $\mathrm{Cl}^{49}$ and $\mathrm{P}$ values based on bias-corrected point estimate and the bootstrap standard errors with a normal approximation. For comparison, the crude analysis is presented by mean and mean differences with $95 \% \mathrm{Cls}$, the adjusted analysis by potential outcome means and average mean differences with $95 \%$ Cls.

\section{Aim (b) Comparison of Direct and Indirect Nursing Care Time in the SPC Group}

To compare time spent for direct and indirect nursing care (tacs ${ }^{\circledR}$ data) in the SPC group as delivered: (a) prior, (b) on the day of, and (c) after the SPC intervention paired t test was used.

\section{Results}

\section{Patient Characteristics}

Of the 746 patients, 104 received SPC intervention prior to death (Figure 1). The characteristics of SPC compared to UPC patients differed considerably, in particular concerning: (a) age (SPC patients were younger), (b) length of stay (SPC patients were hospitalized longer prior to death than UPC patients), (c) different units where patients were admitted prior to death (UPC were more often admitted to intensive care unit (ICU) and surgery than SPC patient), and (d) more patients in the SPC group were directly admitted from home (Table 2). Patients receiving SPC more often had the primary diagnosis of "cancer" (74.0\% vs $17.0 \%)$ and less often cardiovascular diseases (11.5\% vs 58.7\%). Moreover, SPC patients were more often directly admitted from home or the outpatient setting and less often from another hospital. The higher CMI in the UPC patients showed that more hospital resources were allocated to those patients compared to SPC patients. 
Table 2: Patient characteristics

\begin{tabular}{|c|c|c|c|c|c|c|}
\hline & & $\begin{array}{l}\text { Usual } \\
\text { palliative care } \\
\text { group (UPC) } \\
(n=642)\end{array}$ & $\%$ & $\begin{array}{l}\text { Specialized } \\
\text { Palliative } \\
\text { care group } \\
(\mathrm{SPC})(\mathrm{n}=104)\end{array}$ & $\%$ & $\overline{p-v a l u e}$ \\
\hline Age (years) & Mean (sd) & $70.8(14.0)$ & & 64.7 (14.3) & & $<0.001$ \\
\hline \multirow[t]{2}{*}{ Gender } & Female & 276 & 43.0 & 44 & 42.3 & \multirow{2}{*}{0.896} \\
\hline & Male & 366 & 57.0 & 60 & 57.7 & \\
\hline \multirow{5}{*}{$\begin{array}{l}\text { Marital } \\
\text { status }\end{array}$} & Married & 359 & 55.9 & 65 & 62.5 & \multirow{5}{*}{0.035} \\
\hline & Divorced & 78 & 12.1 & 11 & 10.6 & \\
\hline & Single & 78 & 12.1 & 19 & 18.3 & \\
\hline & Widowed & 108 & 16.8 & 9 & 8.7 & \\
\hline & Unknown & 19 & 3.0 & 0 & 0.0 & \\
\hline \multirow[t]{6}{*}{$\begin{array}{l}\text { Primary } \\
\text { diagnosis }\end{array}$} & $\begin{array}{l}\text { Malignant } \\
\text { neoplasms }\end{array}$ & 108 & 16.8 & 77 & 74.0 & \multirow{6}{*}{$<0.001$} \\
\hline & $\begin{array}{l}\text { Cardiovascular } \\
\text { diseases }\end{array}$ & 377 & 58.7 & 12 & 11.5 & \\
\hline & $\begin{array}{l}\text { Neurological } \\
\text { diseases }\end{array}$ & 23 & 3.6 & 2 & 1.9 & \\
\hline & Infectious diseases & 57 & 8.9 & 5 & 4.8 & \\
\hline & $\begin{array}{l}\text { Gastrointestinal } \\
\text { diseases }\end{array}$ & 43 & 6.7 & 4 & 3.8 & \\
\hline & Other & 34 & 5.3 & 4 & 3.8 & \\
\hline \multirow{6}{*}{$\begin{array}{l}\text { Location } \\
\text { prior to } \\
\text { admission }\end{array}$} & $\begin{array}{l}\text { Home/outpatient } \\
\text { setting }\end{array}$ & 429 & 66.8 & 92 & 88.5 & \multirow{6}{*}{$<0.001$} \\
\hline & Other hospital & 193 & 30.1 & 10 & 9.6 & \\
\hline & Home for elderly & 7 & 1.1 & 1 & 1.0 & \\
\hline & Psychiatric hospital & 2 & 0.3 & 1 & 1.0 & \\
\hline & Penal institution & 1 & 0.2 & 0 & 0.0 & \\
\hline & Other & 10 & 1.6 & 0 & 0.0 & \\
\hline $\begin{array}{l}\text { Length of } \\
\text { Stay (days) }\end{array}$ & Mean (sd) & $7.2(9.5)$ & & $16(12.0)$ & & $<0.001$ \\
\hline \multirow{5}{*}{$\begin{array}{l}\text { Units where } \\
\text { patients } \\
\text { were } \\
\text { admitted } \\
\text { prior to } \\
\text { death }\end{array}$} & $\begin{array}{l}\text { Emergency room } \\
\text { admission }\end{array}$ & 474 & 73.8 & 62 & 59.6 & 0.003 \\
\hline & ICU admission & 420 & 65.4 & 27 & 26.0 & $<0.001$ \\
\hline & Radiology admission & 530 & 82.6 & 91 & 87.5 & 0.210 \\
\hline & $\begin{array}{l}\text { Surgery room } \\
\text { admission }\end{array}$ & 477 & 74.3 & 53 & 51.0 & $<0.001$ \\
\hline & Ward admission & 642 & 100.0 & 104 & 100.0 & - \\
\hline $\begin{array}{l}\text { Casemix- } \\
\text { Index (CMI) }\end{array}$ & Mean (sd) & $2.791(3.515)$ & & $1.991(1.464)$ & & $<0.001$ \\
\hline
\end{tabular}

Abbreviations: CMI, Case Mix Index; ICU, intensive care unit; SD, standard deviation; SPC, specialized palliative care group; UPC, usual palliative care group. 


\section{Aim (a) Comparison of Overall Time Spent for Direct and Indirect Nursing Care Activities for SPC Versus UPC Patients}

The crude nonparametric comparison of overall nursing care time indicated that direct and indirect total $\operatorname{tacs}^{\circledR}$ were significantly higher in the SPC group than in the UPC group. The probability that a random patient treated with SPC had higher $\operatorname{tacs}^{\circledR}$ than a patient treated by UPC was $67 \%$ (95\% Cl: 61\%- 72\%) and 69\% (95\% Cl: 63\%-74\%) for direct and indirect tacs ${ }^{\circledR}$ respectively (Table 3, Total tacs ${ }^{\circledR}$ data). For $\operatorname{tacs}^{\circledR}$ per day (Table 3, $\operatorname{tacs}^{\circledR}$ per day), the opposite was the case. The probability of an SPC patient to have higher $\operatorname{tacs}^{\circledR}$ in minutes per day than an UPC patient was 35\% (95\% Cl: 29\%-40\%) and 37\% (95\% Cl: 31\%-43\%) for direct and indirect tacs ${ }^{\circledR}$ respectively. This apparent discrepancy may be driven by the longer length of stay and therefore more days with any $\operatorname{tacs}^{\circledR}$ data in the SPC group (mean of 16 days in SPC and 7.2 days in UPC, respectively, $\mathrm{P}<.001$ ).

Table 3: Crude analysis of direct and indirect tacs ${ }^{\circledR}$ points (total and per day)

\begin{tabular}{|c|c|c|c|c|c|c|}
\hline \multicolumn{2}{|c|}{ Nursing care time } & Total $(n=746)$ & $\begin{array}{l}\text { UPC group } \\
(n=642)\end{array}$ & $\begin{array}{l}\text { SPC group } \\
(n=104)\end{array}$ & SPC vs UPC ${ }^{a}$ & P-value \\
\hline \multirow{2}{*}{ 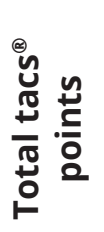 } & $\begin{array}{l}\text { Direct } \operatorname{tacs}^{\circledR} \\
\text { median }(\mathrm{lq}, \mathrm{uq})\end{array}$ & $48(16,114)$ & $40(14,104)$ & $90(46.147)$ & 0.67 (0.61 to 0.72$)$ & $<0.001$ \\
\hline & $\begin{array}{l}\text { Indirect } \operatorname{tacs}^{\circledR} \\
\text { median }(\mathrm{lq}, \mathrm{uq})\end{array}$ & $16(6.3,36)$ & $14(5.3,32)$ & $33(18,52)$ & $0.69(0.63$ to 0.74$)$ & $<0.001$ \\
\hline \multirow{2}{*}{ 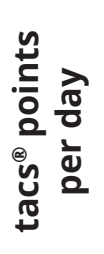 } & $\begin{array}{l}\text { Direct } \quad \operatorname{tacs}^{\circledR} \\
\text { median }(\mathrm{lq}, \mathrm{uq})\end{array}$ & $7.9(5.1,13)$ & $8.5(5.2,14)$ & $5.8(4.8,7.8)$ & $0.35(0.29$ to 0.40$)$ & $<0.001$ \\
\hline & $\begin{array}{l}\text { Indirect } \operatorname{tacs}^{\circledR} \\
\text { median }(\mathrm{lq}, \mathrm{uq})\end{array}$ & $2.6(2.0,3.5)$ & $2.7(2.0,3.7)$ & $2.2(2.0,2.6)$ & 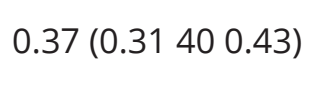 & $<0.001$ \\
\hline
\end{tabular}

Abbreviations: Iq, lower quartile; SPC, specialized palliative care; UPC, usual palliative care; uq, upper quartile ${ }^{a}$ Mann-Whitney statistic (95\% confidence interval), ${ }^{\mathrm{b}} \mathrm{P}$ value from Wilcoxon-Mann-Whitney test.

In the propensity score analysis, we adjusted for age, married yes, no), cancer (yes, no), and being at home before admission (yes, no). Table 4 shows potential outcome means and the average treatment effect for a crude and adjusted analysis for (a) age, (b) marriage status, (c) cancer, and (d) admission from home using inverse probability weighting based on propensity scores. It compares nursing care time in SPC versus UPC patients. Similar to the crude analysis, SPC patients had higher total tacs ${ }^{\circledR}$ by $40(95 \% \mathrm{Cl}: 5.7-75, \mathrm{P}=.023)$ direct 
and 14 (95\% Cl: $6.0-23, \mathrm{P}<.001)$ indirect tacs ${ }^{\circledR}$ data, respectively. For the $\operatorname{tacs}^{\circledR}$ per day, we did not find a clear difference for direct $(-1.6,95 \% \mathrm{Cl}:-3.1$ to 0.7$)$ or indirect tacs ${ }^{\circledR}$ data $(-0.24,95 \% \mathrm{Cl}$ : -0.57 to 0.19$)$.

Table 4: Comparison of nursing care time of specialized palliative care (SPC) versus usual palliative care (UPC) (crude or adjusted for age, marriage status, cancer and admission from home using inverse probability weighting based on propensity scores) ${ }^{a}$

\begin{tabular}{|c|c|c|c|c|c|c|}
\hline & & UPC $(95 \% C 1)$ & $S P C(95 \% C i)$ & Treat:- & t effect $(95 \% \mathrm{Cl})$ & P-value \\
\hline \multirow[t]{2}{*}{ Direct tacse } & crude & es (76 to 96$)$ & $109(95$ to 127$)$ & $25(7,3$ to 44$)$ & $\longrightarrow$ & 0.008 \\
\hline & adussed & 91 (60 to 104) & $131(100$ to 164$)$ & $40(5.71075)$ & $\rightarrow$ & 0.023 \\
\hline \multirow[t]{2}{*}{ Indinect tacto } & crude & $25(23$ to $2 b)$ & $37(39$ to 43$)$ & $12(6.5 \% 18)$ & $\bullet$ & $\infty 001$ \\
\hline & adusted & $27(24$ to 31$)$ & $41(341049)$ & $14(6.010 .23)$ & $\rightarrow$ & 80.001 \\
\hline \multirow[t]{2}{*}{ Diect tacseler 10 days } & crude & 97 (93 to 101) & $67(625073)$ & $-30(-3710-23)$ & 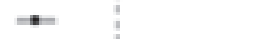 & 60.001 \\
\hline & adpussed & $96(92$ to 100$)$ & $80(65 \$ 102)$ & $-16(-31$ to 7.0$)$ & 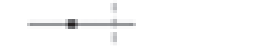 & 0.10 \\
\hline \multirow[t]{2}{*}{ Indinect tacses per 10 days } & crude & $29(28$ to 30$)$ & $23(22$ to 25$)$ & $-5.4(-6.910-3.9)$ & $\boldsymbol{*}$ & $<0,001$ \\
\hline & adpusted & $28(27$ to 29$)$ & $26(23$ t5 30) & $-2.4(.5 .7$ to 1.9$)$ & $\div$ & 0.21 \\
\hline
\end{tabular}

Abbreviations: Cl, confidence interval; SPC, specialized palliative care; UPC, usual palliative care.

aThe crude analysis is presented by mean and mean differences with 95\% confidence intervals $(\mathrm{Cl})$, the adjusted analysis by potential outcome means and average mean differences with 95\% Cls

\section{Aim (b) Comparison of Direct and Indirect Nursing Care Time in the SPC Group}

Results for aim b (Table 5) reveal the differences in time for direct and indirect care time in the group of patients who received SPC. A significant increase in time for direct care on the day of and after the SPC intervention could be observed. In addition, indirect nursing care time increased on the day of the SPC intervention but went back to the same amount of time as before the intervention without any significant difference. 
Table 5: Total $\operatorname{tacs}^{\circledR}$ points prior to, on the day of and after starting specialized palliative care (SPC)

\begin{tabular}{llllllll}
\hline & $\mathbf{n}$ & \multicolumn{1}{l}{ Mean SD } & Comparison of tacs ${ }^{\circledR}$ time $\mathbf{n}$ & \multicolumn{2}{l}{ Comparison } & P-value \\
\hline Pre SPC (Direct) & 80 & 6.18 & 3.58 & Pre (Direct) \& SPC (Direct) & 79 & 0.462 & 0.000 \\
\hline SPC (Direct) & 102 & 6.47 & 3.54 & SPC (Direct) \& Post (Direct) & 98 & 0.512 & 0.000 \\
\hline Post SPC (Direct) & 100 & 6.67 & 3.57 & Pre (Direct) \& Post (Direct) & 77 & 0.257 & 0.024 \\
\hline Pre SPC (Indirect) & 76 & 2.25 & 0.92 & Pre (Indirect) \& SPC (Indirect) 75 & 0.075 & 0.520 \\
\hline SPC (Indirect) & 101 & 2.57 & 0.94 & SPC (Indirect) \& Post (Indirect) 97 & 0.322 & 0.001 \\
\hline Post SPC (Indirect) & 100 & 2.25 & 0.56 & Pre (Indirect) \& Post (Indirect) 73 & 0.185 & 0.117 \\
\hline
\end{tabular}

Abbreviations: pre SPC, prior to SPC intervention; SPC, day of SPC intervention; post SPC, post $S P C$ intervention; $S D$, standard deviation.

\section{Discussion}

This study provides insight into the time differences for direct and indirect nursing care activities for patients at the EoL in a Swiss tertiary hospital after a structured SPC intervention compared to UPC as measured with tacs ${ }^{\circledR}$.

Our comparison indicated that patients with SPC needed overall more time for nursing care activities with significantly higher direct and indirect total tacs ${ }^{\circledR}$ data than those who received UPC. Care activities were spread over more days with any time for nursing activities in the SPC group. Looking at $\operatorname{tacs}^{\circledR}$ data per day, nurses tend to spend less care time for SPC patients than for UPC patients. The length of the stay or the severity of the primary disease could be influencing factors. It needs to be acknowledged that not all patients need SPC at the EoL. ${ }^{18}$

In addition, the analyses showed that the SPC intervention triggers additional coordinative care activities by nurses after which their time for care focuses back toward direct patient care.

\section{Patient Characteristics}

Some significant differences between the UPC and SPC group were disclosed. This study supports the fact that it is more common for patients with cancer than for patients with non-oncological life-limiting diseases to receive SPC. ${ }^{50-52}$ One factor might be the difficult prognostication regarding the EoL in noncancer patients, ${ }^{52}$ although they can have a just as complex symptom burden toward death as patients with advanced cancer. ${ }^{51,53-55}$ In accordance with the literature, ${ }^{56,57}$ younger patients more frequently received SPC than older patients. 
A deeper look into the data revealed that UPC patients had a shorter hospitalization and were admitted to more different units within the hospital (e.g., emergency room, ICU) than patients in the SPC group. Thus, UPC patients may have received more treatment toward EoL than SPC patients, which is comparable to other studies, $39,41,42,58,59$ and therefore, presenting an explanation for an increased CMI.

\section{Aim (a) Comparison of Overall Time Spent for Direct and Indirect Nursing Care Activities for SPC Versus UPC Patients}

In situations where multidimensional care for patients becomes too complex (e.g., unmanageable symptoms) for the treating team, the SPC team offers support. ${ }^{41}$ Based on the propensity score, in which we corrected the imbalance between the two study populations, our data confirmed that patients who needed SPC also required significantly overall more direct and indirect nursing care activities than patients who received UPC. This indicates that SPC patients could be more complex than UPC patients and, therefore, justify a specialist approach. ${ }^{60}$ The SPC care time was spread over a longer period of time which is comparable to the study by De Korte-Verhoef et $a{ }^{59}$ with a longer hospitalization of cancer patients prior to death.

There was a clear influence of having cancer and being in either the UPC or SPC group on the time spent for direct and indirect nursing care activities. The complexity of an advanced cancer disease and its high symptom load could play a role in the nursing care time differences for direct and indirect care as measured with $\operatorname{tacs}^{\circledR}$. This may be due to patients with cancer being admitted directly from home to the hospital and the SPCU at the end of life due to unmanageable symptoms in the home care setting. ${ }^{61,62}$

\section{Aim (b) Comparison of Direct and Indirect Nursing Care Time in the SPC Group}

The analysis of data offered insight into the changes in time for direct and indirect nursing care activities before, on the day of, and after the structured SPC intervention. More time for indirect care activities was required on the day of the initiation of the SPC intervention. This could be due to additional coordinating tasks of nurses including: (a) conferencing with the SPC team, (b) turnover of care to the SPC unit, and (c) conversations with family members about changes of goals of care. 
Tacs $^{\circledR}$ data showed that direct care activities increased after the SPC intervention until death. More time spent by nurses for direct care could be associated with increased patient complexity and the need for more direct care interventions. This might strengthen the justification to involve the SPC team in complex palliative situations. ${ }^{63}$ Also, it could support the allocation of appropriate nursing work force in the dying phase. Other criteria that determine the complexity of the situation might include: (a) a high symptom load in patients, (b) increased distress in the family, or (c) the need for highly qualified medical staff. ${ }^{41}$

\section{Limitations}

Some limitations should be considered because $\operatorname{tacs}^{\circledR}$ data were analyzed retrospectively which meant that relevant patient characteristics were unevenly distributed between the two groups. A direct comparison of SPC patients to UPC patients with similar disease status and significant demographic characteristics was impossible because the calculations with a small number of patients with certain characteristics would not have reached significance. For this reason, the propensity score method was used to balance the two groups and to estimate causal effects and correcting for inequity of the study populations. However, only a limited number of baseline covariates were recorded and some of these had to be simplified for the propensity score model (i.e., the diagnosis); therefore, residual confounding cannot be excluded.

Data were collected in a tertiary hospital. The results might differ in the secondary care sector (e.g., long-term care facilities or outpatient settings) because the complexity of patients' situations might differ.

$\operatorname{Tacs}^{\circledR}$ seems to be sensitive enough to give insight into the time for direct patient-nurse interaction and indirect nursing tasks. This study demonstrates that the main care time provided by nurses is spent at the bedside rather than for documentation or coordination.

However, the content of what direct and indirect activities exactly encompasses could not be differentiated.

\section{Conclusion}

This study adds to an understanding of how the integration of SPC influences time for nursing care activities as measured with $\operatorname{tacs}^{\circledR}$ and its allocated to 
the care of the dying patient in complex situations. End-of-life patients who received SPC needed more direct and indirect nursing care time but also spent a considerably longer time in the hospital prior to death, and therefore, this care time was spread over a longer period of time. With the decision of the treating team to involve the SPC team, coordinative tasks by nurses such as phone calls with family and external healthcare providers were triggered. Whether these changes also triggered changes in the work force allocation to the benefit of the EoL patient with potential disadvantages for other patients need to be explored in future studies.

There is a need for prospective studies evaluating the amount of time for direct and indirect nursing care activities when caring for dying patients. This would help nurses to understand the time that is needed to deliver the best care. To allow benchmarking, further investigation is needed to understand differences in direct and indirect nursing care time. 


\section{Authors' Note}

All authors reviewed the manuscript draft, they approved the final and submitted version of the manuscript.

\section{Acknowledgments}

The authors would like to thank Lukas Büttikofer, statistician at the CTU Berne University, for his endless patience and support in the statistical analysis. The authors also thank Barbara Ammann and Wilko Laan (Directorate of Nursing, Inselspital Bern) for supporting our understanding of the $\operatorname{tacs}^{\circledR}$ data and Rita Jauner, librarian, for her support in providing the underlying literature.

\section{Declaration of Conflicting Interests}

The authors declared no potential conflicts of interest with respect to the research, authorship, and/or publication of this article.

\section{Funding}

The authors received no financial support for the research, authorship, and/or publication of this article.

\section{ORCID iD}

Monica C. Fliedner https://orcid.org/0000-0002-9018-7571 


\section{References}

1. World Health Organization (WHO). Strengthening of palliative care as a component of comprehensive care throughout the life course. World Health Assembly; 2014. http://apps.who.int/medicinedocs/documents/s21454en/s21454en.pdf.

2. Ferris FD, von Gunten CF, Emanuel LL. Competency in end-of-life care: last hours of life. J Palliat Med. 2003;6(4):605-13. doi 10.1089/109662103768253713.

3. Lynch MT. Palliative care at the end of life. Semin Oncol Nurs. 2014;30(4):268-79. doi 10.1016/j.soncn.2014.08.009.

4. Jackson K, Mooney C, Campbell D. The development and implementation of the pathway for improving the care of the dying in general medical wards. Intern Med J. 2009;39(10):695-9. doi 10.1111/j.1445-5994.2009.02002.x.

5. Raymond A, Lee SF, Bloomer MJ. Understanding the bereavement care roles of nurses within acute care: a systematic review. J Clin Nurs. 2017;26(13-14):1787-800. doi 10.1111/jocn.13503.

6. Robinson J, Gott M, Gardiner C, Ingleton C. Specialist palliative care nursing and the philosophy of palliative care: a critical discussion. Int J Palliat Nurs. 2017;23(7):352-8. doi 10.12968/ijpn.2017.23.7.352.

7. Wittenberg-Lyles E, Goldsmith J, Ragan S. The shift to early palliative care: a typology of illness journeys and the role of nursing. Clin J Oncol Nurs. 2011;15(3):304-10. doi 10.1188/11.CJON.304-310.

8. Dobbins EH. Improving end-of-life care: Recommendations from the IOM. Nurse Pract. 2016;41(9):26-34. doi 10.1097/01.NPR.0000490388.58851.e0.

9. Fitch MI, Fliedner MC, O'Connor M. Nursing perspectives on palliative care 2015. Ann Palliat Med. 2015;4(3):150-5. doi 10.3978/j.issn.2224-5820.2015.07.04.

10. Lundgren S, Segesten K. Nurses' use of time in a medical-surgical ward with all-RN staffing. J Nurs Manag. 2001;9(1):13-20. doi 10.1046/j.1365-2834.2001.00192.x.

11. Bulechek G, Butcher $\mathrm{H}$, McCloskey J, Wagner C. Nursing Interventions Classification (NIC). 6th ed. Maryland Heights, MO: Mosby; 2012.

12. Butcher H, Bulechek G, DochtermanJM, Wagner C. Nursing Interventions Classification (NIC). 7th ed. St. Louis,MO:Mosby (Elsevier-Health Sciences Division); 2018.

13. Choi WH, Park IS, Shin HJ, Joo YH, Kim YA, Jung EH, et al. Comparison of direct and indirect nursing-care times between physician order entry system and electronic medical records. Stud Health Technol Inform. 2006;122:288-93.

14. Korst LM, Eusebio-Angeja AC, Chamorro T, Aydin CE, Gregory KD. Nursing documentation time during implementation of an electronic medical record. J Nurs Adm. 2003;33(1):24-30. doi 10.1097/00005110-200301000-00006.

15. Yu P, Song L, Qian S, Yao X, Huang J, Min L, et al. Work pattern of neurology nurses in a Chinese hospital: A time and motion study. J Nurs Manag. 2019;27(2):320-9. doi 10.1111/jonm.12682.

16. Brady AM, Byrne G, Horan P, Griffiths C, MacGregor C, Begley C. Measuring the workload of community nurses in Ireland: a review of workload measurement systems. J Nurs Manag. 2007;15(5):481-9. doi 10.1111/j.1365-2834.2007.00663.x. 
17. Federal Office of Public Health (FOPH), Swiss Conference of the Cantonal Ministers of Public Health $(\mathrm{CMH})$, palliative ch. Framework concept for palliative care in Switzerland. A Basis for Defining Palliative Care for the Implementation of the «national strategy for palliative care»; Bern, Switzerland; July 15, 2014.

18. Bundesamt für Gesundheit (BAG). Schweizerische Konferenz der kantonalen Gesundheitsdirektorinnen und -direktoren (GDK). Indikationskriterien für Spezialisierte Palliative Care (Indication criteria for specialized palliative care). Bern, Switzerland: BAG \& GDK; 2014.

19. Glare P, Plakovic K, Schloms A, Egan B, Epstein AS, Kelsen D, et al. Study using the NCCN guidelines for palliative care to screen patients for palliative care needs and referral to palliative care specialists. J Natl Compr Canc Netw. 2013;11(9):1087-96. doi 10.6004/jnccn.2013.0130.

20. Masso M, Allingham SF, Johnson CE, Pidgeon T, Yates P, Currow D, et al. Palliative Care Problem Severity Score: Reliability and acceptability in a national study. Palliat Med. 2016;30(5):479-85. doi 10.1177/0269216315613904.

21. Brazil K. A Call for Integrated and Coordinated Palliative Care. J Palliat Med. 2018;21(S1):S27-S9. doi 10.1089/.jpm.2017.0430.

22. Arias-Casais N, Garralda E, Rhee JY, et al. EAPC Atlas of Palliative Care in Europe 2019. Vilvoorde, Belgium: EAPC Press; 2019.

23. ational Comprehensive Cancer Network (NCCN). NCCN Clinical Practice Guidelines in Oncology (NCCN Guidelines $\left.{ }^{\circledR}\right)$ Palliative Care Version 2.2019. 2019. https://www. nccn.org/professionals/physician_gls/pdf/palliative.pdf28.07.2019.

24. Kavalieratos D, Gelfman LP, Tycon LE, Riegel B, Bekelman DB, Ikejiani DZ, et al. Palliative Care in Heart Failure: Rationale, Evidence, and Future Priorities. J Am Coll Cardiol. 2017;70(15):1919-30. doi 10.1016/j.jacc.2017.08.036.

25. Chang RS, Poon WS. "Triggers" for referral to neurology palliative care service. Ann Palliat Med. 2018;7(3):289-95. doi 10.21037/apm.2017.08.02.

26. Basedow-Rajwich B, Montag T, Duckert A, Schulz C, Rajwich G, Kleiter I, et al. Mobile Palliative Care Consultation Service (PCCS): Overview of Hospice and Palliative Care Evaluation (HOPE) Data on In-Patients With End-Stage Cancer, Multiple Sclerosis, and Noncancer, Nonneurological Disease From 4 PCCS Centers in Germany in 2013. Palliat Care. 2018;11. doi 10.1177/1178224218785139.

27. Yu JA, Ray KN, Park SY, Barry A, Smith CB, Ellis PG, et al. System-Level Factors Associated With Use of Outpatient Specialty Palliative Care Among Patients With Advanced Cancer. J Oncol Pract. 2019;15(1):e10-e9. doi 10.1200/JOP.18.00234.

28. Rome RB, Luminais $\mathrm{HH}$, Bourgeois DA, Blais CM. The role of palliative care at the end of life. Ochsner J. 2011;11(4):348-52.

29. Ziegler LE, Craigs CL, West RM, Carder P, Hurlow A, Millares-Martin P, et al. Is palliative care support associated with better quality end-of-life care indicators for patients with advanced cancer? A retrospective cohort study. BMJ Open. 2018;8(1):e018284. doi 10.1136/bmjopen-2017-018284.

30. Zhang B, Wright AA, Huskamp HA, Nilsson ME, Maciejewski ML, Earle CC, et al. Health care costs in the last week of life: associations with end-of-life conversations. Archives of internal medicine. 2009;169(5):480-8. doi 10.1001/archinternmed.2008.587. 
31. Brinkman-Stoppelenburg A, Witkamp FE, van Zuylen L, van der Rijt CCD, van der Heide A. Palliative care team consultation and quality of death and dying in a university hospital: A secondary analysis of a prospective study. PLoS One. 2018;13(8):e0201191. doi 10.1371/journal.pone.0201191.

32. Fliedner MC, Mitchell G, Bueche D, Mettler M, Schols JMGA, Eychmueller S. Development and use of the 'SENS'-structure to proactively identify care needs in early palliative care - an innovative approach. Healthcare. 2019;7(32):1-12. doi 10.3390/healthcare7010032..

33. Eychmueller S. [SENS is making sense - on the way to an innovative approach to structure Palliative Care problems]. Ther Umsch. 2012;69(2):87-90. doi 10.1024/00405930/a000256.

34. Palliative Care Australia (PCA). Palliative Care Service Development Guidelines. 2018. www.palliativecare.org.au13.10.2019.

35. European Association for Palliative Care (EAPC), Radbruch L, Payne S, Board of Directors of the EAPC. White Paper on standards and norms for hospice and palliative care in Europe: part 1. Recommendations from the European Association for Palliative Care. European Journal of Palliative Care. 2009;16(6):278-89.

36. European Association for Palliative Care (EAPC), Radbruch L, Payne S, Board of Directors of the EAPC. White Paper on standards and norms for hospice and palliative care in Europe: part 2 Recommendations from the European Association for Palliative Care. European Journal of Palliative Care. 2010;17(1):22-23.

37. van den Oetelaar WF, van Stel HF, van Rhenen W, Stellato RK, Grolman W. Balancing nurses' workload in hospital wards: study protocol of developing a method to manage workload. BMJ Open. 2016;6(11):e012148. doi 10.1136/bmjopen-2016-012148.

38. Lachance J, Douville F, Dallaire C, Padilha KG, Gallani MC. The use of the Nursing Activities Score in clinical settings: an integrative review. Rev Esc Enferm USP. 2015;49 Spec No:147-56. doi 10.1590/S0080-623420150000700021.

39. Hagemann M, Zambrano SC, Butikofer L, Bergmann A, Voigt K, Eychmuller S. Which Cost Components Influence the Cost of Palliative Care in the Last Hospitalization? A Retrospective Analysis of Palliative Care Versus Usual Care at a Swiss University Hospital. J Pain Symptom Manage. 2020;59(1):20-9 e9. doi 10.1016/j. jpainsymman.2019.08.026.

40. Schroeder K, Lorenz K. Nursing and the future of palliative care. Asia Pac J Oncol Nurs. 2017;5:4-8.

41. Pask S, Pinto C, Bristowe K, van Vliet L, Nicholson C, Evans CJ, et al. A framework for complexity in palliative care: A qualitative study with patients, family carers and professionals. Palliat Med. 2018;32(6):1078-90. doi 10.1177/0269216318757622.

42. Penrod JD, Deb P, Dellenbaugh C, Burgess JF, Jr., Zhu CW, Christiansen CL, et al. Hospital-based palliative care consultation: effects on hospital cost. J Palliat Med. 2010;13(8):973-9. doi 10.1089/jpm.2010.0038.

43. Mendez CM, Harrington DW, Christenson P, Spellberg B. Impact of hospital variables on case mix index as a marker of disease severity. Popul Health Manag. 2014;17(1):2834. doi 10.1089/pop.2013.0002.

44. Kaplan RS, Norton DP. The Balanced Scorecard: measures that drive performance. Harvard Business Review. 2010;82:172. 
45. Hansen $T$. [I can remember the first picture of tacs ${ }^{\circledR}$ - a cockpit!] Ich erinnere mich an das erste Bild von tacs ${ }^{\circledR}$ - ein Cockpit! Der rodix tacsameter. Rain, Switzerland: rodix reto odermatt gmbh. 2013;6(Oktober 2013).

46. Guo S, Fraser MW. Propensity Score Analysis-Statistical Methods and Applications. Thousand Oaks, CA: Sage Publications, Inc.; 2010.

47. Halpern EF. Behind the numbers: inverse probability weighting. Radiology. 2014;271(3):625-8. doi 10.1148/radiol.14140035.

48. Cole SR, Hernan MA. Adjusted survival curves with inverse probability weights. Comput Methods Programs Biomed. 2004;75(1):45-9. doi 10.1016/j.cmpb.2003.10.004.

49. Efron B. Better Bootstrap Confidence Intervals. Journal of the American Statistical Association. 1987;82(397):171-85. doi doi:10.2307/2289144.

50. Veigh CM, Reid J, Larkin P, Porter S, Hudson P. The provision of generalist and specialist palliative care for patients with non-malignant respiratory disease in the North and Republic of Ireland: a qualitative study. BMC Palliat Care. 2017;17(1):6. doi 10.1186/s12904-017-0220-1.

51. Chen ML. Inequity of Palliative Care for Non-Cancer Patients. J Nurs Res. 2019;27(2):12. doi 10.1097/JNR.0000000000000324.

52. Gadoud A, Kane E, Macleod U, Ansell P, Oliver S, Johnson M. Palliative care among heart failure patients in primary care: a comparison to cancer patients using English family practice data. PLoS One. 2014;9(11):e113188. doi 10.1371/journal. pone.0113188.

53. Lastrucci V, D'Arienzo S, Collini F, Lorini C, Zuppiroli A, Forni S, et al. Diagnosis-related differences in the quality of end-of-life care: A comparison between cancer and noncancer patients. PLoS One. 2018;13(9):e0204458. doi 10.1371/journal.pone.0204458.

54. Mounsey L, Ferres M, Eastman P. Palliative care for the patient without cancer. Australian Journal for General Practitioners. 2018;47:765-9. doi 10.31128/AJGP-07-184625.

55. Stiel S, Heckel M, Seifert A, Frauendorf T, Hanke RM, Ostgathe C. Comparison of terminally ill cancer- vs. non-cancer patients in specialized palliative home care in Germany - a single service analysis. BMC Palliat Care. 2015;14:34. doi 10.1186/ s12904-015-0033-z.

56. Lloyd A, Kendall M, Carduff E, Cavers D, Kimbell B, Murray SA. Why do older people get less palliative care than younger people? European Journal of Palliative Care. 2016;23(3):132-7.

57. Parr JD, Zhang B, Nilsson ME, Wright A, Balboni T, Duthie E, et al. The influence of age on the likelihood of receiving end-of-life care consistent with patient treatment preferences. J Palliat Med. 2010;13(6):719-26. doi 10.1089/jpm.2009.0337.

58. Wachterman MW, Pilver C, Smith D, Ersek M, Lipsitz SR, Keating NL. Quality of Endof-Life Care Provided to Patients With Different Serious Illnesses. JAMA Intern Med. 2016;176(8):1095-102. doi 10.1001/jamainternmed.2016.1200.

59. De Korte-Verhoef MC, Pasman HR, Schweitzer BP, Francke AL, Onwuteaka-Philipsen BD, Deliens L. Reasons for hospitalisation at the end of life: differences between cancer and non-cancer patients. Support Care Cancer. 2014;22(3):645-52. doi 10.1007/ s00520-013-2019-9. 
60. Quill TE, Abernethy AP. Generalist plus specialist palliative care--creating a more sustainable model. N Engl J Med. 2013;368(13):1173-5. doi 10.1056/NEJMp1215620.

61. Mercadante S, Masedu F, Valenti M, Mercadante A, Aielli F. The characteristics of advanced cancer patients followed at home, but admitted to the hospital for the last days of life. Intern Emerg Med. 2016;11(5):713-8. doi 10.1007/s11739-016-1402-1.

62. Reyniers T, Houttekier D, Cohen J, Pasman HR, Deliens L. What justifies a hospital admission at the end of life? A focus group study on perspectives of family physicians and nurses. Palliat Med. 2014;28(7):941-8. doi 10.1177/0269216314522317.

63. Carduff E, Johnston S, Winstanley C, Morrish J, Murray SA, Spiller J, et al. What does 'complex' mean in palliative care? Triangulating qualitative findings from 3 settings. BMC Palliat Care. 2018;17(1):12. doi 10.1186/s12904-017-0259-z. 


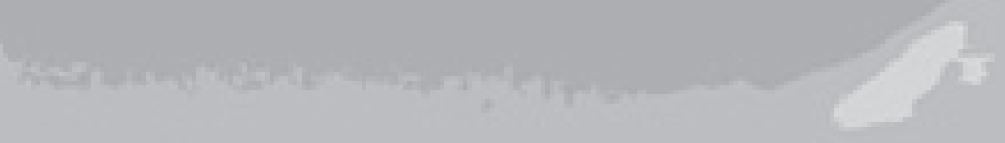

\section{Chas}
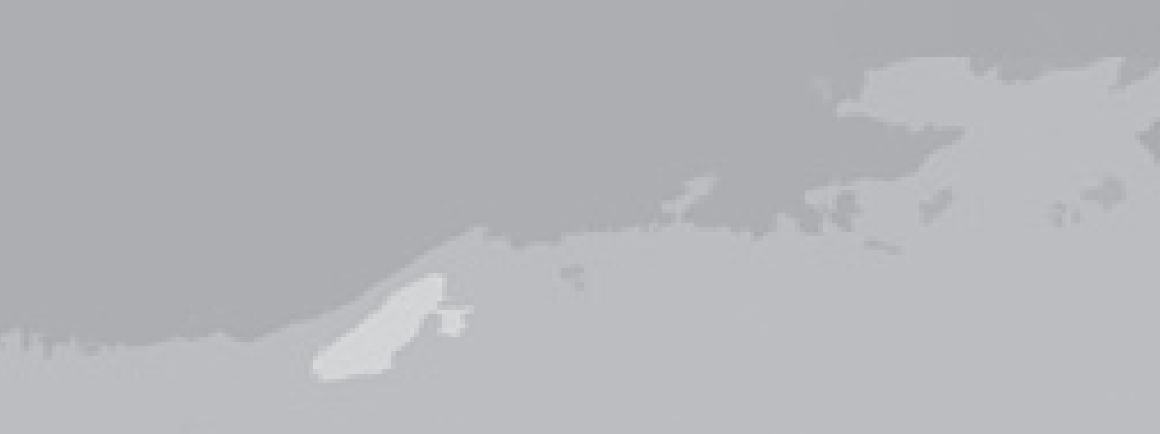

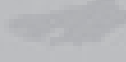

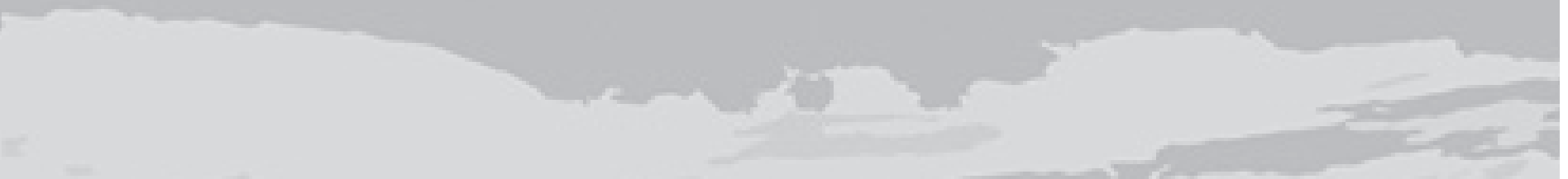

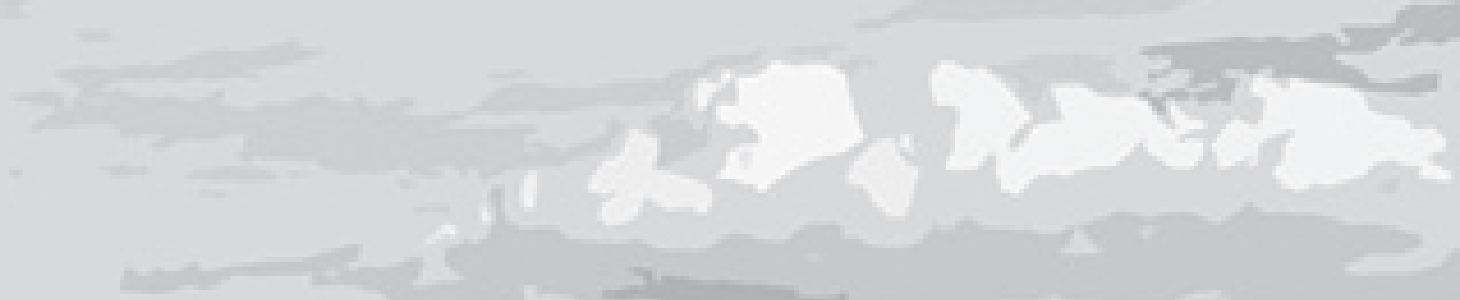

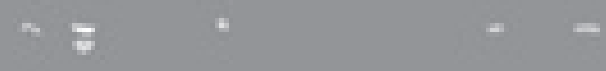

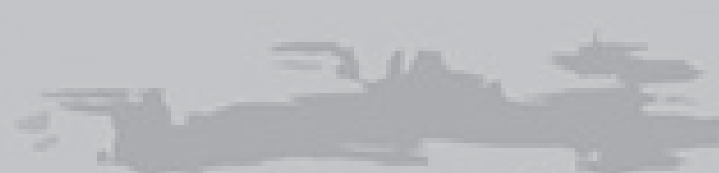

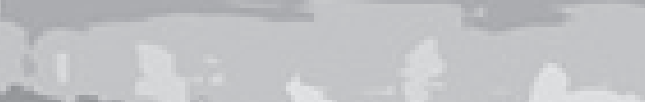

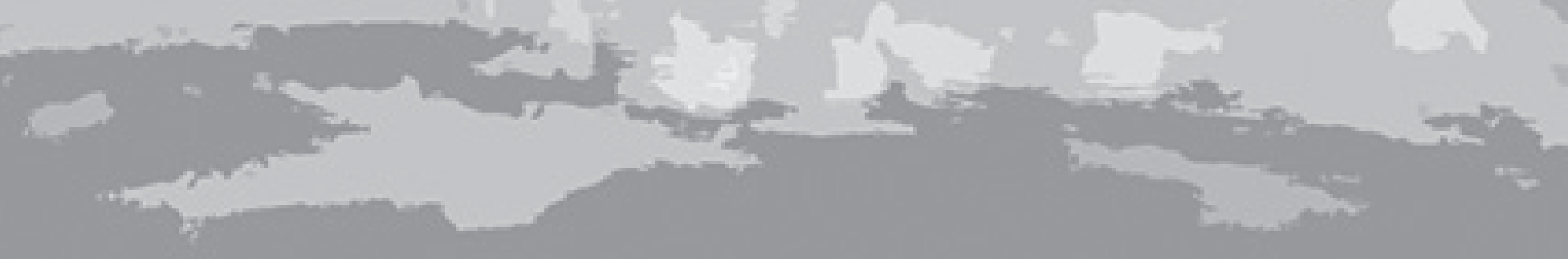




\section{Chapter 7}

\section{Case study: Concurrent palliative care based on SENS-structure for patients with advanced prostate cancer}

This chapter was published as:

Fliedner M, Willener R. A case study: Concurrent palliative care based on SENS-structure for patients with advanced prostate cancer. Int J Urol Nurs. 2020; 1-4. https://doi.org/10.1111/ijun.12232 


\section{Abstract}

On an acute urological ward, it is challenging to meet all needs of patients with lifelimiting progressive cancer disease in complex situations. The focus shifts from curation to the holistic palliative approach aiming at patients' and their families' needs and planning care in advance with an interprofessional attitude. Based on a patient with castration refractory prostate carcinoma with multiple metastasis, the aim of this case study is to describe the palliative care approach, using the established so-called SENS-structure (Symptoms, End-of-life decisions, Network and Support of the carer) in which the bio-, psycho-, social and spiritual needs are addressed. We report on our practice experience using the SENSstructure, in which the team discusses palliative care interventions with patients and their family: management of (potential) symptoms and self-supporting strategies, expectations and end-of-life decisions including advance care planning, evaluation of patients' social and professional network and setting up additional support. The palliative care team provides advice to the treating team on future treatment strategies and care activities. The complex situation of a patient with metastatic prostate cancer and his personal sufferings illustrate the interprofessional use and person-centred focus of the SENS-structure. Important in this phase is-next to the family carers-the involvement of all professions and disciplines to break down the complexity of the situation into manageable proportions. Early involvement of palliative care for patients with advanced cancer is highly recommended. The SENS-structure helps to prioritize and include the personalized approach which is strongly supported by nurses.

\section{Keywords}

advance care planning, advanced prostate cancer, discharge planning, early, interprofessional collaboration, palliative care, SENS-structure 


\section{What is known about this topic}

- Palliative care is a holistic approach and with which the interprofessional team adds quality rather than quantity to patients' life

- Health care professionals often apply the concept of palliative care in a late stage, because they understand it as a concept for end of life only.

\section{What this paper adds}

- Palliative care should be incorporated alongside regular oncological care for patients with advanced cancer, being a person-centred approach next to a disease-related approach

- SENS is a structure that breaks down the many challenges of patients with a life-limiting disease into manageable proportions

- Nurses play an important role in recognizing patients suitable for specialized palliative care and help the palliative care team in identifying challenges of concern 


\section{Introduction}

If in the course of advanced, refractory or progressive cancer, the medical intention of cure shifts to a palliative treatment approach, the focus changes towards facing challenges of the final phase of patients' life by adding quality rather than quantity. Palliative care (PC) is a holistic approach aimed at improving quality of life of patients ${ }^{1-3}$ until death and supporting their family in bereavement. It includes the early identification, prevention and relief of (potential) suffering. ${ }^{4}$ Professionals support patients in their decision on future medical treatment and care including times when they lose their decision-making capacity. This is often referred to as anticipation including advance care planning (ACP). ${ }^{5}$

The PC team is called in by the treating team if the situation becomes multidimensional and unmanageable, complex and instable $e^{6,7}$ and the predictability of the future is challenging. The specialized interprofessional PC team discusses the focus of care with patients, organizes care with a problemrather than diagnosis-driven approach ${ }^{8,9}$ and provides support for families and the treating team. In our university hospital, the concurrent support of the PC team comprises a structured conversational intervention based on SENS, an acronym for Symptoms, Expectations and (End-of-life) decisions, Network and Support (see Figure 1). ${ }^{8}$

Figure 1. SENS-structure

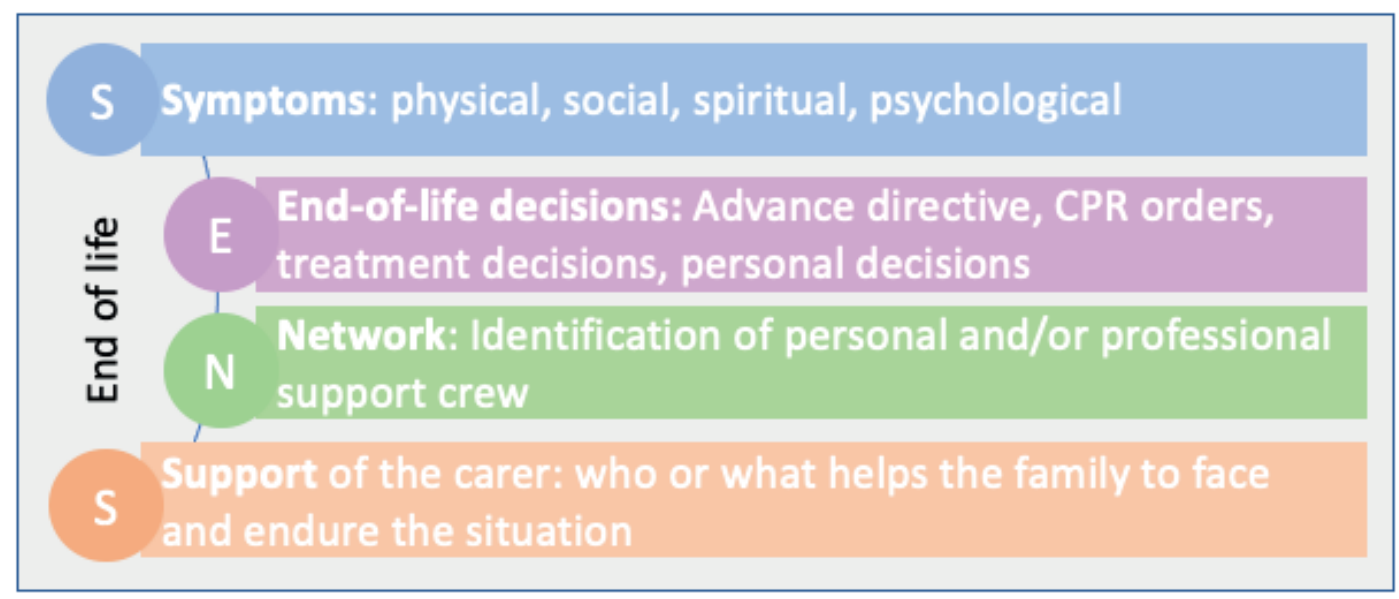

We illustrate the impact of the SENS-based PC intervention in which the team discusses with patients/families the management of (potential) symptoms, expectations and end-of-life decisions including ACP, evaluates patients' social network and sources to support them. The PC team provides advice on future treatment and care activities. 


\subsection{Case}

Mr. T, 64 years of age, married with no children, was diagnosed with castration refractory prostate carcinoma, osseous, lymphogenic and hepatic metastasis in July 2018.

He was admitted to the emergency department in December 2018 for pain exacerbation in the lumbar and right thoracic region and severe dyspnoea with a suspicion of disseminated liver metastasis and progress of diffuse osseous metastasis. In addition, a deep pelvic veins thrombosis was diagnosed. His cognition was adequate. Because of his fatigue, he intended to set only small goals day by day. He still owned a business which he will "have to shut down", but he mentioned that all is on track. He had an advance directive and his lawyer would take over his financial business. Currently, he had no unfinished projects or wishes and expressed no specific spiritual needs.

Up to now, the focus lay mainly on treating his tumour and less on personal challenges that he encountered during the course of the disease. For the PC team, the main concern was the suffering of the patient-looking specifically at his physical, psychological, social and spiritual distress. Based on SENS, we discovered the following areas of focus:

\subsection{Symptoms}

He suffered from tremendous lower back pain and dyspnoea. He feared the symptoms, which decreased after chemotherapy but now regained strength. While resting, he tolerated pain and dyspnoea with Fentanyl transcutaneous 50 $\mu \mathrm{g} / \mathrm{h}$ and Methadon hydrochlorid $5 \mathrm{mg}$ bid. He was afraid to get up because pain and dyspnoea became extremely strong in the upright position. Despite compression, his legs were strongly oedematous which also hindered him to mobilize. However, he believed that without pain he could walk again. Because of a lack of appetite, he currently barely ate but drank cold liquids. He had no bowel movement for the last 5 days. He felt very weak, dozed during the day; he believed that this came from chemo- and radiation therapy. Due to all of these symptoms, he feared that discharge would not be possible.

\subsection{End of life decisions/expectations}

He hoped that pain and dyspnoea would get under control, so that he would regain mobility. With the help of home care nurses, he wished to go home to 
be with his wife and arrange business things. A premise to go home was to be able to walk short distances. He firmly believed that this would be possible when his pain was under control. He considered these ups and downs as a normal process. He hoped that the current radiotherapy would relieve his pain. If this would not occur, then he would reconsider and decide whether to undergo any other anti-tumour therapies. He refused to talk about dying since his wish to go home was very strong. Nonetheless, he stated that he did not want any lifeprolonging therapy such as resuscitation or invasive ventilation.

\subsection{Network-organization}

The couple lived in their own disability adapted flat with a lift to the fifth floor. Being an entrepreneur, he had no financial worries. The couple made all important decisions together. Presently they had only little contact with their friends because he wanted to avoid the necessity of justifying the situation to everyone. The home care nurses came three times a week to support him with personal hygiene. The specialized PC team came once a month to co-ordinate and plan ahead, adjust medications and provide psychological support. The contact to the GP, who made home visits, was good. Although the couples' wish was that he would come home, both realized that this was currently impossible. They agreed to be transferred to the specialized PC unit and if necessary to be transferred later to a hospice.

\subsection{Support for the carers}

He had concerns regarding his wife since she said that she lived only for him. She felt very distressed, was not able to sleep and felt very strained, feared that she would not have the strength to live through what was about to happenmeaning his death. She always wanted to be there for her husband. She was keeping her sorrows for herself and hardly talked to her family or friends about the situation. She asked for sleeping medication. On our advice, she agreed that we contact the psycho-oncologist to support her in this crisis. Although her husband supported this very much, she refused to make use of this offer. 


\subsection{Aims of palliative care}

The following goals where defined with the patient and his wife:

- to preserve patients' autonomy, decision-making and self-management by reducing pain to tolerability

- to enhance mobility to enable discharge

- in a later stage to evaluate options of chemo- and radiotherapy - what does the patient want to achieve with this strenuous treatment

- to well prepare transfer to PC Unit

- to offer psychological support to his wife whenever she is ready for it.

\subsection{Interprofessional care planning}

With their clinical expertise in holistic care and skills in navigating patients and their families through difficult and sometimes complex situations, nurses play a central role within the interprofessional team. ${ }^{10}$ Their interconnectedness across all health care settings is vital for a proactive care planning and improving patients' condition and quality of life while taking the potential burden of the family into consideration.

The urological clinical nurse specialist carried out the SENS assessment with the patient and his wife, suggesting to involve the PC team because the situation was very complex and instable, being indicators for specialized PC support. ${ }^{11}$ She monitored the symptoms, and supported the patient and his wife emotionally and involved the psycho-oncologist. The urology nurses took care of his pain, nausea and bowel management, supported Mr. T. in personal hygiene and mobilization, assisted in sufficient food \& fluid intake offering food supplements based on a nutrition protocol.

The urologist took over the lead for Mr. T. He co-ordinated the various specialist consultations, informed and supported the patient and his wife in making decisions about future therapies. He optimized medication treatment regarding pain, nausea and constipation. The medical- and radio-oncologists evaluated together with the orthopaedist the option of another chemotherapy, radiotherapy and indication for vertebroplasty while the physiotherapist trained and instructed techniques for mobilization. In the meantime, the dietician advised additional supplementary nutrition. The interprofessional PC team organized the admission to the PC unit for stabilization of the situation 
and complex discharge preparations and advised the general practitioner and community nurses in pain therapy and reserve medication.

\section{Discussion}

Concurrent with the regular oncological treatment, ${ }^{12}$ it is necessary to look at the personal concerns of the patient specifically in times when the focus shifts towards adding quality rather than quantity of life. To address these issues the interdisciplinary and interprofessional team requires time to sit down, listen, and discover who the person behind the disease is and to distribute tasks and responsibilities effectively. The SENS-structure proved to be helpful to break down the many concerns of patients into manageable proportions early on in the disease trajectory and to develop a patient centred care plan. This timely person-centred approach supports enhancing the quality of life of the patient and lessens distress of the family. ${ }^{13}$ To reach out with home care professionals such as general practitioners or district nurses is essential for the continuity of care and the preparedness for emergency situations at home. Planning for times when the patient is no longer capable to make decisions and documenting these decisions in an advance care plan or advance directive accessible to all involved helps the family to take off the burden from their shoulders of making hard decisions in difficult times.

\section{Conclusion}

The early involvement of palliative care for patients with advanced cancer is highly recommended by the American Society of Clinical Oncology ${ }^{14}$ in which the holistic approach to patients' life is included and goals of care (ACP) are clarified. SENS provides a useful and comprehensive thematic structure, which helps patients and their family to lay focus on challenges in other areas than simply the diagnosis-driven approach. Planning for times when a patient needs support from family and professionals helps to free time for things that are more important at the end of life. 


\section{Conflict of interest}

The authors declare no conflict of interest.

\section{ORCID}

Monica Fliedner https://orcid.org/0000-0002-9018-7571

Rita Willener https://orcid.org/0000-0003-0592-044X 


\section{References}

1. Hugar LA, Lopa SH, Yabes JG, Yu JA, Turner RM, 2nd, Fam MM, et al. Palliative care use amongst patients with bladder cancer. BJU Int. 2019;123(6):968-75. doi 10.1111/ bju.14708.

2. Mistry NA, Raza SJ, Siddiqui SA. Analysis of Inpatient Palliative Care Consultations for Patients With Metastatic Prostate Cancer. Am J Hosp Palliat Care. 2020;37(2):136-41. doi 10.1177/1049909119864576.

3. Reinke LF, Engelberg RA, Shannon SE, Wenrich MD, Vig EK, Back AL, et al. Transitions regarding palliative and end-of-life care in severe chronic obstructive pulmonary disease or advanced cancer: themes identified by patients, families, and clinicians. J Palliat Med. 2008;11(4):601-9. doi 10.1089/jpm.2007.0236.

4. World Health Organization (WHO). Strengthening of palliative care as a component of comprehensive care throughout the life course. World Health Assembly; 2014. http://apps.who.int/medicinedocs/documents/s21454en/s21454en.pdf.

5. ACPEL. The Definition of Advance Care Planning 2015 [Available from: http://www. acpelsociety.com/acpdefinition.php. Accessed 28.09.2015.

6. Bundesamt für Gesundheit (BAG), Schweizerische Konferenz der kantonalen Gesundheitsdirektorinnen und -direktoren (GDK). Indikationskriterien für spezialisierte Palliative Care (Indication criteria for specialized palliative care). Bern, Switzerland; 2014. https://www.bundespublikationen.admin.ch/cshop_mimes_ bbl/8C/8CDCD4590EE41ED78FF1D2F1B7A1A158.pdf.

7. National Comprehensive Cancer Network (NCCN). NCCN Clinical Practice Guidelines in Oncology (NCCN Guidelines $\left.{ }^{\circledR}\right)$ Palliative Care Version 2.2019. 2019. https://www. nccn.org/professionals/physician_gls/pdf/palliative.pdf28.07.2019.

8. Fliedner MC, Mitchell G, Bueche D, Mettler M, Schols JMGA, Eychmueller S. Development and use of the 'SENS'-structure to proactively identify care needs in early palliative care - an innovative approach. Healthcare. 2019;7(32):1-12. doi 10.3390/healthcare7010032.

9. Eychmueller S. [SENS is making sense - on the way to an innovative approach to structure Palliative Care problems]. Ther Umsch. 2012;69(2):87-90. doi 10.1024/00405930/a000256.

10. Fitch MI, Fliedner MC, O'Connor M. Nursing perspectives on palliative care 2015. Ann Palliat Med. 2015;4(3):150-5. doi 10.3978/j.issn.2224-5820.2015.07.04.

11. Bundesamt für Gesundheit (BAG), Schweizerische Konferenz der kantonalen Gesundheitsdirektorinnen und -direktoren (GDK), palliative ch. Rahmenkonzept Palliative Care Schweiz. Eine definitorische Grundlage für die Umsetzung der «Nationalen Strategie Palliative Care». Bern2014.

12. Huen K, Huang C, Liu H, Kwan L, Pannell S, Laviana A, et al. Outcomes of an Integrated Urology-Palliative Care Clinic for Patients With Advanced Urological Cancers: Maintenance of Quality of Life and Satisfaction and High Rate of Hospice Utilization Through End of Life. Am J Hosp Palliat Care. 2019;36(9):801-6. doi 10.1177/1049909119833663. 
13. Kmetec S, Stiglic G, Lorber M, Mikkonen I, McCormack B, Pajnkihar M, et al. Nurses' perceptions of early person-centred palliative care: a cross-sectional descriptive study. Scand J Caring Sci. 2020;34(1):157-66. doi 10.1111/scs.12717.

14. Ferrell BR, Temel JS, Temin S, Alesi ER, Balboni TA, Basch EM, et al. Integration of Palliative Care Into Standard Oncology Care: American Society of Clinical Oncology Clinical Practice Guideline Update. J Clin Oncol. 2017;35(1):96-112. doi 10.1200/ JCO.2016.70.1474. 


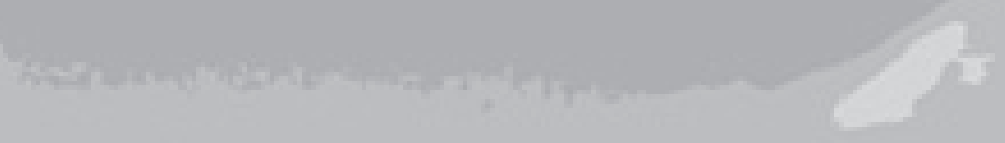

\section{Chas}
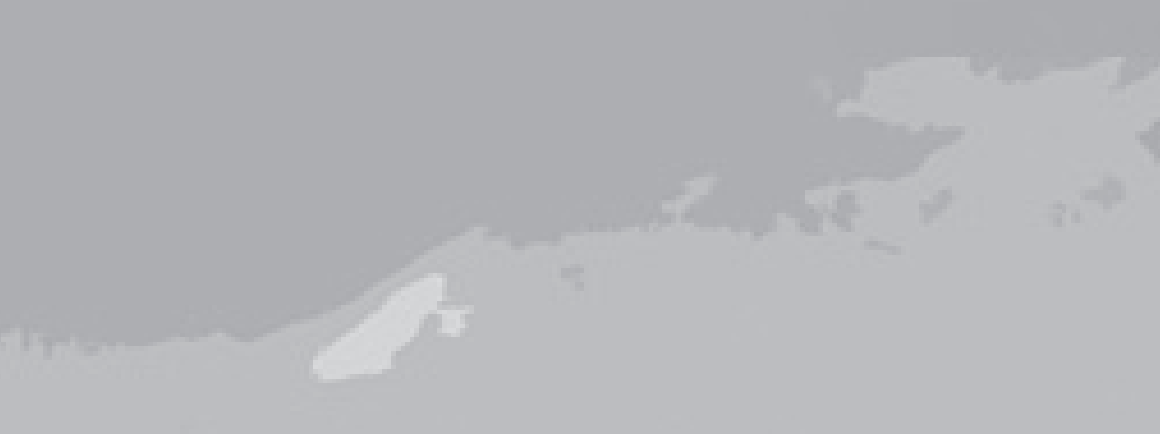

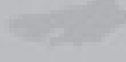

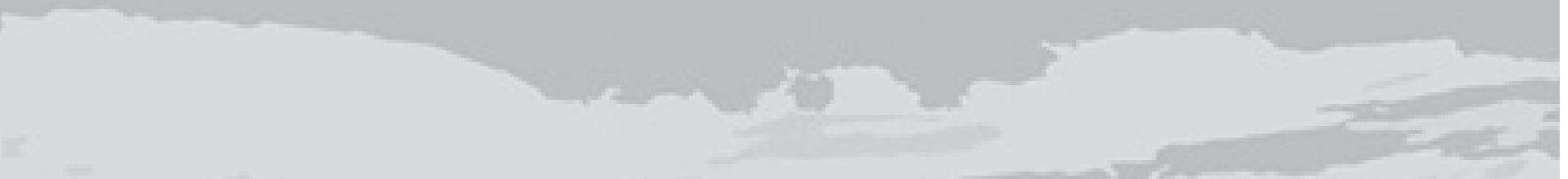

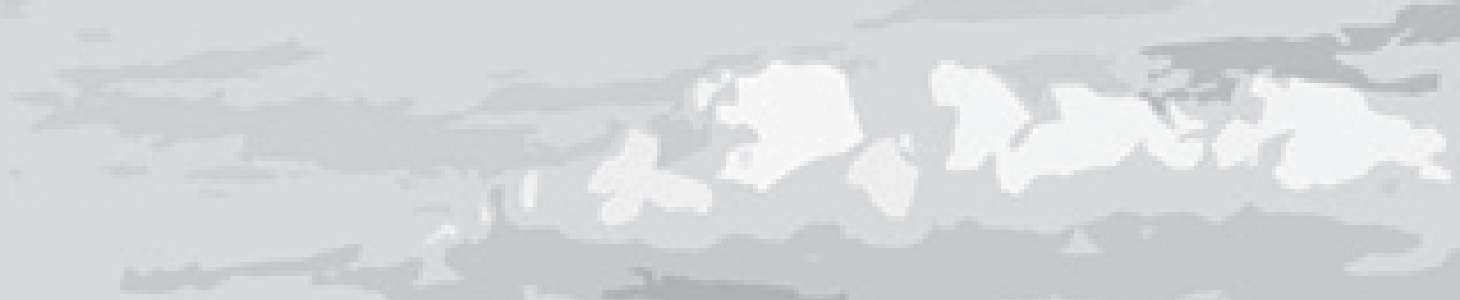

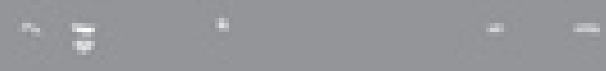

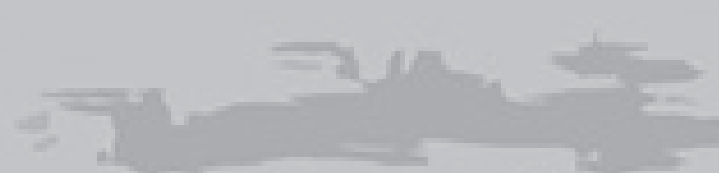

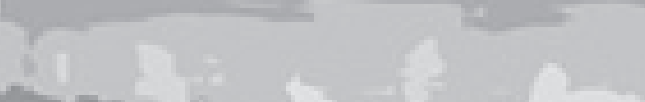

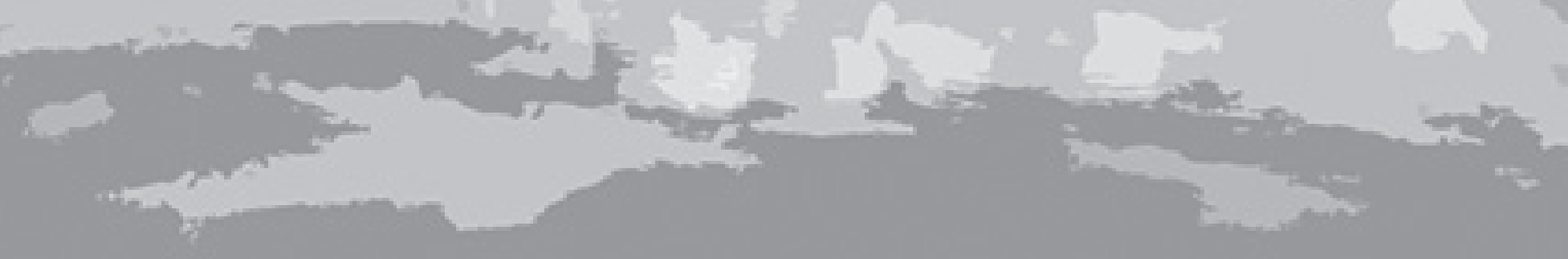


Chapter 8

General Discussion 
This thesis started with a cancer case study about early integrated palliative care (EPC) in the acute care setting which revealed the following issues:

- The interprofessional team needs a thematic structure for conversations with patients: how can a thematic structure be developed which facilitates assessment and management conversations with patients from the perspective of the interprofessional team? The thematic structure that was developed is known by the acronym SENS (Symptoms, End-of-Life decisions which includes Advance Care Planning (ACP), Network and Support of the family and professional caregivers)

- Timing of EPC: when should palliative care $(P C)$ be initiated during a patient's disease trajectory and what would the impact be on end-of-life (EoL) care?

- Patients' perceptions of and experiences with EPC conversations based on the SENS structure: a) Which themes do cancer patients no longer amenable to curative treatment prefer to discuss in ACP conversations as part of EPC? b) To what extent are uncertainty about the future, dealing with finiteness of life and the impact of palliative care (PC) confronting to patients?

- Role of nurses in ACP within EPC: What are the roles and responsibilities of undergraduate (Registered Nurses (RNs)) and postgraduate nurses (Advanced Practice Registered Nurses (APRNs)) specifically in ACP discussions? What educational background is needed to be able to engage in ACP discussions?

- Effects of palliative care (PC) on nurses' worktime in EoL situations as part of PC: What are the effects of specialized PC on worktime for direct/indirect nurses' care activities in EoL care in a hospital?

The overall aim of this thesis was to learn from the experiences of advanced cancer patients receiving PC structured by SENS early in their trajectory as an example of a population in need for PC in the acute care setting. In addition, we wanted to explore the roles of nurses in ACP as a relevant part of EPC and to assess the impact of specialized PC on nurses' worktime for the dying patient in the hospital, not only focusing on oncology. The above-mentioned issues were used to develop several research questions which were explored in 5 studies with a focus on patients as well as nurses (Figure 1). 
Figure 1. Research questions included in this thesis

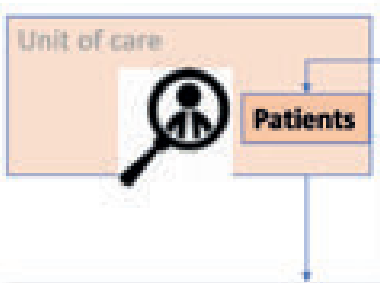

What is the existing evidence on timing of earh integrated palliative care (EPC) and $A C P$ as one part of EPC, and what is the impact on End-ef-Ufe care for patients? (Review, chopter 3 )

How do cancer patients perceive and experience a structured EPC conversational intervention; is the intervention acceptable and what is the impact on patients' lives? (Qualitative study chapter 4)
How was the SENS structure developed to assess and manage patients' major concerns and priorities, as well as their main resources in the acute clinical setting? (Qvality-enhancing aroject repart, chapter 2) $S$ ymptoms

E nd-of-life cecisions including Advance Care Planning (ACP) N etwork (personal, professional)

$S$ upport of the caregivers

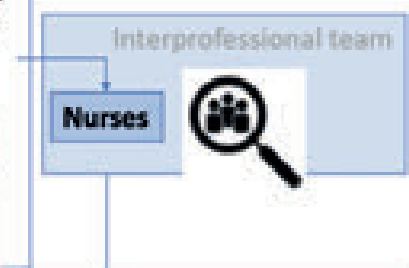

What are the specific roles and responsibilities of RNs and/or APRNs involved in ACP process as one part of EPC in the acute care setting. which themes related to ACP are d scussed and which skills and/or educational requirements are needed to be able to engage in or facilitate ACP conversations? (Scoping review, chopter $S$ )

What is the overall worktime spent for direct / indirect nursing care activities for dying patients who received a specialized PC (SPC) intervention as compared to patients who received usual PC; does the time spent for direct / indirect care in the group of patients who received SPC change before and after the SPC intervention (Retrospective observational study, chopter 6)

\section{Main findings}

The main results of the research projects were the following:

\section{Development of SENS - a thematic structure and its clinical use in EPC}

A thematic structure called SENS to identify and prioritize areas of concern based on patients' goals was developed initially for use in PC in the acute care setting (Chapter 2). ${ }^{1}$ It was designed using a pragmatic interprofessional team approach in which each healthcare professional covers themes based on their expertise and education. Concurrent to the diagnosis-triggered approach, the SENS structure focuses on all dimensions of PC as defined by the $\mathrm{WHO}{ }^{2}$ Healthcare professionals in the acute care setting confirmed that the SENS structure is suitable throughout all phases of the disease trajectory for patients with a life-limiting disease. The SENS structure showed to be useful in guiding patient-centered PC conversations covering the relevant issues for patients. It facilitated the EPC process in acute care settings. We demonstrated also its usefulness for planning, documentation, evaluation, and education from the perspective of professionals. 


\section{Timing and Impact of ACP as a relevant part of EPC on the quality of end of life care}

The critical appraisal of the existing literature on EPC and ACP as a relevant part, and the impact of EPC on the quality of care provided during EoL care (Chapter 3$)^{3}$ supported a timely integration of PC into the disease trajectory of patients diagnosed with all life-limiting or advanced diseases. The timeframe for EPC was found to encompass a wide range of times with a minimum of 3 up to 24 months prior to patients' estimated death. Early integrated PC including ACP was discussed ${ }^{3}$ as a broader approach supporting patients' coping mechanisms based on person-centered care principles.

\section{Patients' perception and experiences with the SENS-structured intervention}

The exploration of cancer patients' experiences (Chapter 4$)^{4}$ with the early PC integrated intervention ${ }^{1}$ showed that all the patient's needs correspond with themes discussed using the SENS structure ${ }^{1}$. It supports patients in engaging in conversations with healthcare professionals and their family about their concerns and issues, and future care decisions. Moreover, patients confirmed that healthcare professionals also offered support to their social network. Being confronted with the finiteness of life was challenging for some patients. For others it was a relief to be able to talk about their fears and expectations. Some patients stated that they lost their negative feeling towards receiving PC even though they still associated the term with end of life.

\section{Nurses' roles, responsibilities and educational requirements in the context of $A C P$}

As a relevant part of EPC, our scoping review (Chapter 5$)^{5}$ revealed core roles and responsibilities of RNs and APRNs specifically in ACP in the acute care setting. These included, but were not limited to facilitating ACP conversations, and advocating for patients' wishes. Themes related to ACP included information about disease and treatment, as well as patients' values and wishes (e.g., goals of care for the future and preferred place of care). We found that in order to perform their roles related to ACP, RNs and/or APRNs require appropriate education. Based on a foundation of PC knowledge, this education should include communication skills to engage in ACP conversations, problem-solving 
strategies and knowledge about regulatory issues around EoL care. In our publication it was not clear whether RNs currently have the skills or need further education to engage in ACP discussions. We concluded therefore that APRNs (due to their advanced knowledge) are in the best position to be involved in ACP and to guide patients towards legal documents such as an advance directive.

\section{Nursing care worktime for patients at the end-of-life in the acute care setting}

As part of the interprofessional team nurses play a pivotal role in caring for patients at the end of life by performing direct care activities through direct interaction with patients. Additionally, they execute indirect care activities by performing tasks on behalf of the patient. We compared direct and indirect nursing care time data as measured by $\operatorname{tacs}^{\circledR}$ for patients dying in a tertiary hospital (Chapter 6$)^{6}$ who received usual PC (UPC) and for patients who received in addition specialized PC (SPC) based on SENS in a complex EoL situation. ${ }^{1,7}$ In order to be able to compare the results to other studies in the acute care settings ${ }^{8-11} w^{6}$ used the internationally recognized Nursing Interventions Classification (NIC) ${ }^{12}$ to be able to differentiate between direct and indirect care activities that were documented by nurses within tacs ${ }^{\circledR}$. Results showed that patients who received UPC and SPC versus patients who received only UPC needed overall significantly more direct and indirect nursing care worktime than patients who received UPC alone. Furthermore, an increase in worktime for indirect care activities was documented on the day of the SPC.

\section{Discussion}

\section{Themes and structures relevant for PC conversations and patients' perception}

Based on the bio-psycho-social and spiritual dimensions of $\mathrm{PC}^{2,13}$, themes discussed in pivotal trials included: a) symptom management, b) psychological issues (e.g., helplessness and hopelessness), c) uncertainty in understanding the illness and its prognosis, d) issues around treatment decision-making, as well as e) support for patients' caregivers. ${ }^{14-21}$ This is in line with the SENS-structured intervention which we developed. ${ }^{1}$ It aimed at supporting patients' active participation, their problem-solving strategies, and self-efficacy in the four PC 
dimensions that they identified as important to them. The themes outlined in the SENS structure ${ }^{1}$ included the themes covered in the aforementioned studies but underlined also the inclusion of patients' main resources such as spirituality. The fact that the four themes in the SENS structure are considered as equally important and require a strong interprofessional collaboration ${ }^{1}$ is innovative because this was only marginally described in other EPC intervention studies. ${ }^{15,16,22}$

One identified theme within the SENS structure is EoL decision making, which includes ACP. This ensures a continual process of sharing patients' values and goals as well as discussing preferences of care and treatment. ${ }^{3}$ As confirmed by Montgomery et $\mathrm{a}^{23}$ this process should result in decisions that are based on patients' expectations and wishes. By this, escalation of medical / care situations may be avoided depending on factors such as: a) the personal characteristics of patients, b) the dynamics of their disease, or $c$ ) the setting of care. ${ }^{4}$

We discovered that the SENS-structured intervention helped cancer patients to take the lead in certain areas (e.g., involving their social network in actively discussing decisions regarding future care and treatment). ${ }^{4}$ This is comparable to the study by Maloney et $\mathrm{al}^{24}$ who found that patients' problem-solving strategies were enhanced by a PC intervention which was conducted by APRNs. Their intervention was based on the Chronic Care Model by Wagner ${ }^{25}$ and the WHO dimensions of $\mathrm{PC}^{13}$. Our study ${ }^{4}$ revealed that due to the SENS-structured intervention patients experience a more individualized symptom management approach, an improved preparation for their future care and a better support for their family caregiver(s). We found out that although the intervention can be confronting ${ }^{4}$, patients found it important to openly discuss the themes with the $P C$ team. This emotional but affirming impact on patients accentuated findings of an earlier study with cancer patients undergoing a similar EPC intervention. ${ }^{24}$

Our study ${ }^{4}$, like several other studies ${ }^{26,27}$, confirmed that the themes need to be tailored and prioritized to each individual patient's situation regardless of the timing within the life-limiting disease trajectory. Cancer patients in our study ${ }^{4}$ found the themes (especially personalized information related to future healthcare planning) within the SENS structure useful. It allowed them to plan ahead for their future treatment and care based on their disease progression and prognosis. Patients mentioned that they felt able to participate in the conversation most likely due to the support of a prompt sheet that outlined the themes that could or were discussed. This type of prompt sheet was also found 
to be helpful by patients in other studies. ${ }^{28,29}$ Patients in our study ${ }^{4}$ had the feeling that through the intervention they could regain control of their situation rather than mainly being steered by medical treatment activities. Patients suggested these themes be incorporated into usual oncology care because they had not yet been discussed in earlier conversations with their specialists. Our findings ${ }^{4}$, like those of Schulman-Green and colleagues ${ }^{30}$, demonstrated that the information provided about future care decisions could be emotional or overwhelming to some patients. However, other patients wanted even more detailed information (e.g., about their prognosis or the intention of the proposed treatment approach). In our study ${ }^{4}$ no patient felt overburdened by the themes discussed during the SENS-based intervention despite sometimes being hesitant about the need for it at the beginning. In a similar study ${ }^{31}$ cancer patients who received outpatient oncology care expressed being surprised to be asked to participate in a PC study. Healthcare professionals feared that if PC is integrated too early, patients might lose hope in medical treatment options. However, in this phase of a life-limiting disease hope might shift to a focus other than hope in a cure. ${ }^{32,33}$ Although some patients in our study experienced talking about PC as confronting, losing hope due to the EPC intervention was never mentioned by any participant. ${ }^{4}$

\section{Timing of EPC including ACP in the acute care setting}

In a recent publication it was stated that it is not yet common for patients with a life-limiting disease to engage in EPC conversations including ACP early in their disease trajectory ${ }^{34}$ with their general practitioner or treating specialist. However, this should ideally commence before any acute crisis arises. ${ }^{35,36}$ EPC focuses on a life-expectancy ranging between 3 to 24 months before anticipated death. ${ }^{3}$ This timeframe of initiating EPC is in line with a Cochrane Review ${ }^{37}$ which recommends EPC be concurrent to oncological treatment for patients with advanced cancer and limited prognosis for survival. Based on our qualitative study ${ }^{4}$ and other relevant publications ${ }^{38,39}$, it is recommended (even by patients themselves) that EPC should be integrated close to the diagnosis of a life-limiting disease no longer amenable to curative treatment. ${ }^{40-42}$ This approach is not yet routinely implemented into clinical cancer care. ${ }^{43,44}$ The lack of timely integration of EPC has been mentioned by healthcare professionals who believe that PC is mainly integrated in the care for patients close to death. ${ }^{45,46}$ 
We, therefore, suggest using the term 'concurrent' for patients with a life-limiting disease instead of 'early integrated $P C$ ' to describe the timing of integrating PC concurrently with disease-modifying treatment. This emphasizes the life-limiting factor of the disease. ${ }^{3}$ This terminology was also used in other publications s $^{24,40,47-49}$ and reflects the fact that PC should be offered at the same time or combined with ${ }^{50}$ any diagnosis-related treatment approach.

Research shows that if patients are willing to engage in EPC (and specifically ACP) they can benefit most from these conversations. ${ }^{38,45}$ For some patients, EPC may be too early and others expect EPC as early as possible. In this context, the prognosis is not the only factor that needs to be considered. Our qualitative study ${ }^{4}$ showed that patients expect that the initiation of EPC takes into consideration their current status with regard to their knowledge and emotionally dealing with the disease situation. Therefore, depending on the person and the disease entity with its dynamics, specific triggers (e.g., patients' performance status, anticipated time until death, or symptom burden) can initiate the early integration of PC. ${ }^{3}$ Evidence around these potential triggers is growing ${ }^{51,52}$ and will need to be evaluated for the acute care setting. Whether the onset of PC should be based on estimated prognosis, patients' specific needs or other triggers should be discussed.

\section{Nurses' role, competencies and educational requirements in ACP}

Nurses facilitate ACP conversations as part of EPC, document patients' decisions and provide education about medical information. ${ }^{53}$ Patients with a life-limiting disease ${ }^{45}$ and family caregivers ${ }^{54}$ acknowledge the role of nurses in the process but do not explicitly specify all the disciplines they think should be specifically involved in these conversations. ${ }^{18}$ Due to the nurses' mediator and advocate roles between specialists and the patient, they are in an optimal position to open doors for ACP conversations early within and throughout the patients' disease trajectory. ${ }^{55}$ Our scoping review underlined nurses' continued responsibility in the acute care setting as educator, mentor, advocate and supporter of decisions regarding future treatment and care for patients. ${ }^{5}$ Guidelines or position statements on nurses' roles and responsibilities in ACP are being developed to support our findings..$^{56-61}$ 
Several concepts or tools (e.g., "five wishes ${ }^{\circledR "}$ or "respecting patient choices ${ }^{\circledR \prime \prime}$ ) are used by RNs and/or APRNs for ACP conversations. ${ }^{62}$ However, the results of our review ${ }^{5}$ showed that some of these concepts are not suitable for the acute care setting because they were designed for a broad population regardless of age or health status (e.g., "five wishes ${ }^{\circledR \prime}$ ) or had a strong focus on physical care or medical decisions ${ }^{42}$. As with other publications ${ }^{55,63}$, our review of the literature ${ }^{5}$ revealed that RNs and APRNs do review the discussed and documented wishes together with patients with a life-limiting disease in the acute care setting and compare these with concerns regarding future treatment and care. This could contribute to the further development and expression of nursing's role in ACP practice ${ }^{64}$ and result in enhancing the quality of care ${ }^{65,66}$ as portrayed in our case study. ${ }^{67}$

Currently, general PC aspects are part of many undergraduate nursing curricula. ${ }^{5}$ The content of the respective curricula and the competencies might vary between countries and institutions based on the corresponding rules and legislation. ${ }^{68-70}$ Depending on the modules taught at the undergraduate level, not all RNs feel adequately prepared to engage in ACP conversations or have sufficient knowledge about legal issues.65,71-73 Better educational activities for the different levels of nursing and specialties as well as guiding policies and regulations for the undergraduate and postgraduate levels are required in the future. ${ }^{74,75}$ This supports the findings of our scoping review. ${ }^{5}$ We concluded that an appropriate educational level and clinical expertise needs to be determined to be able to take over or facilitate the responsibility of engaging in ACP.

For conversations about ACP ${ }^{4}$, effective communication skills are the basis for a trusting relationship and person-centered care. ${ }^{5}$ Several studies recognized APRNs' competencies of providing direct palliative and EoL patient care including taking a leading role in anticipatory guidance and counseling based on effective communication skills. ${ }^{76-78}$ Our review ${ }^{5}$ highlighted also the opportunity for RNs and APRNs to be more involved in ACP conversations with patients if their roles and responsibilities are clarified. Our findings ${ }^{5}$ were confirmed by a recent review ${ }^{69}$ in which a facilitating and leading role in ACP conversations was expected from specialized PC APRNs but not necessarily RNs. Ferrell and colleagues discussed that it is up to the interprofessional team to decide at what level nurses have the appropriate professional qualifications and training to facilitate and/or lead these conversations. ${ }^{41}$ 


\section{Effect of specialized PC on nursing care worktime in EoL care}

Until now it was not known how the support by a specialized PC team for patients in a complex and instable EoL situation affects nurses' worktime for direct (e.g., close interaction with patient and/or family such as performance of care procedures) and indirect (e.g., coordination of care on behalf of the patient) nursing care. Therefore, our study on how PC in the acute care setting affects nurses' worktime for direct and indirect nursing care activities for dying patients appears to be one of the first of its kind in the field of PC. ${ }^{6}$ This study did not consider whether patients received PC earlier in their disease trajectory.

Data and validated tools to identify nursing care activities such as the Nursing Activities Score (NAS) ${ }^{79}$ exist mainly in the field of intermediate or intensive care. $8,80,81$ These tools measure the worktime spent for direct patient care as well as administrative/managerial tasks. A validated German version did not exist at the time of our study. ${ }^{6}$ We therefore used the Swiss electronic controlling system $\operatorname{tacs}^{\circledR}$, which distinguishes between worktime for direct and indirect care activities. The descriptive study by Kakushi and Evora ${ }^{8}$ used the NAS for direct nursing activities and a technology-based estimate for indirect nursing care on an intensive care unit. They discovered that the majority of nurses' worktime is devoted to direct care. This finding is similar to our study ${ }^{6}$ but a comparison of the values between the two studies is not possible because of the different instruments used in different settings and populations.

Our study ${ }^{6}$ was unique because it utilized a comprehensive comparison between patients who received usual PC with or without the intervention by a specialized PC team until a patients' death. We saw that overall the worktime for direct and indirect care activities in the group who received specialized PC was significantly higher. Our study also included the analysis of the nursing care worktime on the day of a specialized PC intervention compared to the worktime until a patient's death before and after the intervention. New information was that the worktime for indirect care for patients who received specialized PC rose significantly on the day of the PC intervention and returned to the baseline value thereafter. No other literature was discovered with comparable results.

\section{Theoretical and methodological considerations}

A major strength of this thesis is the use of different research designs and the broader focus including both the patients' perspectives and the nurses' roles. 
We used the following methods: a) literature reviews ${ }^{3,5}, \mathrm{~b}$ ) a quality improvement project ${ }^{1}$ based on the Medical Research Council (MRC) framework ${ }^{82}$ including a quantitative evaluation of its clinical usefulness, c) a qualitative study ${ }^{4}$ and d) a quantitative study ${ }^{6}$.

Reviews ${ }^{3,5}$ provide an overview of current literature but exclusion criteria such as language or healthcare setting might limit the generalizability of the findings especially in the context of other cultures or professional policies. We included available literature in languages that were comprehended by our research team, namely English, German, Spanish and Dutch. One of our reviews provided insights into the roles and responsibilities of RNs and APRNs in EPC including ACP from an international (mainly Anglo-Saxon due to the absence of publications from other countries) perspective in the acute care setting. ${ }^{5}$ This could have led to missing studies or other relevant documents available in other languages. On the other hand, the systematic search approach with specified search terms offered accuracy of the findings and provided answers to our research aims.

To develop a clinically useful structure for PC conversations ${ }^{1}$, the phases of the MRC framework for a quality improvement project were followed. These involve an ongoing process because its clinical use and outcomes must be adapted to the demands of providers (healthcare professionals) and expectations of patients. For example, an action research approach ${ }^{83}$ would not have been easily transferable with the amount of patient records that eventually led to the SENS structure. The exploratory phase embedded in the MRC framework helped to refine the content of the SENS in a pragmatic way. However, whether it is useful in other countries or in different healthcare settings other than the acute care setting needs to be explored.

In the third phase of the MRC framework our qualitative study ${ }^{4}$ (which was part of an intervention study funded by the Swiss National Science Foundation ${ }^{84,85}$ ) made a relevant scientific contribution to the knowledge about patients' experience with the SENS-structured intervention. Most studies on the usefulness of EPC and how it affects patients are based on quantitative research methods. ${ }^{15-17,22,86-89}$ Not all EPC interventions tested in quantitative study designs reveal a statistically significant impact on patients' outcomes ${ }^{85}$ but still may be of clinical value to patients because they for instance appreciate being offered to talk about the issues offered in the intervention..$^{90}$ This could be addressed by a qualitative study approach ${ }^{91}$ to better understand the impact of 
the intervention on patients. Various Anglo-Saxon studies also used qualitative research methods to provide insights as to why and in what way EPC makes a difference to patients. ${ }^{14,16,24,31,92-95}$ That is why we designed our qualitative study ${ }^{4,96}$ using a single semi-structured interview with patients who underwent the SENSstructured intervention at different timepoints after their diagnosis of incurable cancer. ${ }^{84}$ We chose a single interview with patients at different timepoints along their disease trajectory after their cancer diagnosis which resulted in a variety of viewpoints of patients' perception of EPC. Several repeated interviews with the same patient population at predefined timepoints after their diagnosis could be conducted to get additional insights into the experience of EPC as a process. Patients who participated in our qualitative study ${ }^{4}$ were motivated to share their experience with the SENS structure, a potential positive selection bias.

We applied a quantitative study approach to assess the direct and indirect nursing care time ${ }^{6}$ in the acute care setting. In this study we used data from the tacs ${ }^{\circledR}$ system, a nurse staffing tool employed in the participating institution. At that time there were no comparable tools available in the field of PC which would differentiate between the direct and indirect nursing worktime for dying patients in the acute care setting. The data collected in the clinical process (which is still underutilized in PC research ${ }^{97}$ ) instead of data solely collected for research purposes provided an excellent opportunity to better understand actual clinical nursing worktime. Therefore, this method and tool used offer an innovative approach. Our study excluded an observation and selection bias because all data that met the inclusion criteria (e.g., adults who died in the acute care setting but not in the emergency room due to accidental causes or on the same day of admission) were used. Unfortunately, there is no current data to compare our results because we used $\operatorname{tacs}^{\circledR}$ (a Swiss tool) for which detailed reliability and validity data were not available. Because $\operatorname{tacs}^{\circledR}$ is not yet available internationally its value for institutions in other countries is limited. In the future, data of comparable Swiss institutions should be used for benchmarking if the intervention by the PC team is comparable.

\section{Implications for clinical practice, education and research in the acute care setting}

Based on the findings of this thesis recommendations are derived for the acute care setting. Furthermore, suggestions for future areas of research are outlined. 


\section{Implications for clinical practice and nursing education}

- Use of SENS in the acute care setting

Early integration of PC concurrent to disease modifying treatment approaches corresponds with patients' wishes ${ }^{4}$ if relevant themes are sensitively addressed by following a thematic structure such as SENS'1. This approach can result in positive patient experiences. ${ }^{4}$ SENS not only provides a clear structure for discussions during family meeting ${ }^{18}$ and discussions about patients' future treatment and care, but also facilitate patients' and their families' active involvement in decision making and care planning. ${ }^{4}$ Our qualitative study ${ }^{4}$ implies that EPC is helpful for cancer patients if they are ready to participate in discussing sensitive themes. To establish a person-centered care approach and to not overburden the patient these themes need to be tailored to the individual situation. Despite the fact that SENS can be considered as a complex intervention ${ }^{82,98}$, our study ${ }^{1}$ showed that it is accepted by healthcare professionals as an easy tool to use in clinical practice. SENS can also be applied by general PC clinicians ${ }^{1}$ to contribute to routine/usual PC care.

\section{- Timing of EPC including ACP}

The right timing of EPC including ACP needs to be considered carefully. Our review indicates that 'early' integration may mean offering a structured patientoriented palliative care approach 3 to 24 months before assumed death. ${ }^{3} \mathrm{~A}$ more narrow general definition of the best timing remains a challenge because several factors such as disease entity and/or treatment options need to be taken into consideration. Therefore, we recommend that PC should be offered starting concurrent (disregarding the assumed time until death) to the diagnosis of a lifelimiting disease by establishing a systematic integration in care pathways.

- Role of RNs/APRNs in ACP

Several healthcare professionals including RNS and APRNS are involved in the ACP process as part of EPC. In line with our study ${ }^{4}$, patients expect high competencies in symptom control and communication as well as empathy from healthcare professionals in whom they put their trust. ${ }^{4,93} \mathrm{~A}$ well trained team is therefore recommended to fulfil these expectations. Themes that can or should be discussed by RNs and APRNs should be defined within the interprofessional team keeping in mind that no specific competency is yet 'purely' directed by RNs / APRNs. 
Communicative skills such as how to engage with patients in ACP conversations need to be taught on undergraduate and postgraduate level. Another approach would be to educate the interprofessional team together with the intention to "learn together to work together". ${ }^{99}$ This may lead to a partnership within the team that is competency driven ${ }^{5}$ rather than professionbound. ${ }^{100-103}$

Basic and ongoing nursing education related to participating in and facilitating the early onset of the ACP process is recommended. ${ }^{5,53,55} \mathrm{RNs}$ and APRNs need to be well-trained in discussing issues such as a) treatment goals, b) management of symptoms, c) EoL decision making including ACP, d) assessment of patients' social/professional network and e) support needs of caregiver. These issues correspond with the SENS structure. ' Levels of competencies could be developed such as based on Benners' model "From novice to expert". 104-106 This model encourages nurses to identify up to which level they want to or can participate in ACP. In clinical practice, ACP conversations leading to e.g. an advance directive can best be initiated by RNs and APRNs who have the pathophysiological knowledge and are specifically trained in communication skills. ${ }^{5}$

- Support by specialized PC team in complex EoL situations

Finally, the support and advice by a specialized PC team in complex and unmanageable EoL patient situations might evoke an increase in devoted worktime for indirect nursing care activities such as coordinating care. ${ }^{6}$ At the same time, it is not known which nurses (RNs and/or APRNs) are best prepared to participate in or facilitate these tasks in EoL situations. It might be necessary to define whether RNs and/or APRNs should take over indirect care tasks such as coordination of care. A change in workforce allocation (e.g., support by APRNs) could also be considered. This supports the planning and allocation of appropriately trained nursing staff in favor of improving nursing care quality.

\section{Implications for further research}

We need to better understand how palliative care can effectively be integrated early in or concurrent to the course of the disease and in all healthcare settings using a structure such as SENS to determine patient preferences and wishes. This will help to define how EPC can be implemented (e.g., when to initiate EPC 
and which themes are relevant, who should be involved, how should EPC be embedded in care pathways) leading to improvement of quality of care.

- What themes and structures should be studied?

Mutual themes, such as structured by SENS1, that should be discussed during EPC including ACP still need to be clarified and defined for other PC services to allow benchmarking. It would be interesting to learn whether it is always necessary to include all four themes of SENS in one conversation or which themes are most helpful for patients. To further develop the SENS structure, it would be helpful to understand from the patient and family caregivers' point of view which component(s) of SENS is/are useful to them and in which phase of patients' life-limiting disease trajectory.

- $\quad$ For whom could EPC including ACP be helpful?

Many pivotal studies on EPC services ${ }^{15,16,18,27,107-110}$ focus on patients with cancer. Our qualitative study ${ }^{4}$ added knowledge to the perceptions of EPC including ACP on cancer patients. But the patient population in need of EPC is diverse and confounding factors can influence the outcomes of studies. Over the past years research in the field of EPC in disease trajectories of other life-limiting diseases has increased. Whether the benefits or experiences of using the SENS structure ${ }^{1}$ can be transferred to patients with a life-limiting disease other than cancer and within a different healthcare system than the Swiss system should be explored in future research.

Our study showed that a structured EPC approach impacts ACP conversations between patients and family caregiver(s). ${ }^{4}$ As a unit of care, family caregivers of patients with a life-limiting disease need just as much information, care and support. They should to be included throughout the process to also meet their needs in these often-challenging situations. Family caregivers often report to be more satisfied with patient care when they are assured that the wishes of the patient are addressed appropriately. ${ }^{111,112}$ Future research could focus on what it means to family caregivers to be included in EPC including ACP, how they can support the patient, what support they need and how they can continue their life despite being a family caregiver. ${ }^{113}$ 
- When should EPC including ACP be initiated?

To include EPC into chronic life-limiting disease trajectories future research should focus on the best timepoint to integrate EPC so patients benefit most from it. This needs to be defined based not only on the timespan prior to patients' estimated death ${ }^{3}$ but also on other specifically defined triggers such as patients' underlying life-limiting disease (e.g., cancer, heart failure, chronic lung diseases, chronic kidney diseases, multimorbidity, frailty and/or patients with a cognitive impairment including dementia).

- By whom should EPC including ACP be initiated?

The underlying healthcare systems as well as nurses' roles and responsibilities in ACP (often based on their level of education and expertise) may differ between countries, the education/training of an individual nurse and institutions. To understand how our findings relate to other countries that were not included in the review further research is recommended because every country has its unique healthcare system, legal requirements and educational systems. It will also be interesting to see how our results can specifically be transferred into other clinical settings such as homecare, hospice or long-term care facilities.

In this context we need to further understand by which profession ${ }^{114}$ themes (e.g., based on SENS) should best be addressed to meet patients' and families' needs. In the future it would be valuable to assess which themes within the SENS structure are or can be covered mainly by RNs and/or APRNs. Future studies could take a closer look at the roles and responsibilities of RNs and APRNs in ACP conversations throughout patients' disease trajectory. ${ }^{115-117}$ Perhaps the discussion of specific themes is not only bound to a certain profession within the interprofessional team but could rather be driven by their competencies, trust and quality of the relationship in the individual patient situation, requiring an innovative interprofessional approach in future research.

- What could the impact of specialized PC be on nurses EoL care?

Our study on nurses' worktime for care activities in EoL care ${ }^{6}$ should be replicated and continued in other acute care institutions with similar conditions (e.g., availability of a specialized PC team, use of a similar structure such as SENS) to allow benchmarking. We know that nurses who received support from the specialized PC team in complex EoL patient situations devote more worktime to indirect care activities at patients' EoL after the PC teams' involvement. ${ }^{6}$ 
Therefore, additional research needs to be conducted to get more insight into the impact of support by a specialized PC team on the worktime of nurses caring for patients with a life-limiting disease. It would also be interesting to understand what nurses actually do after a specialized team got involved. If and how the timely clarification of relevant decisions through a structured ACP process (which results e.g. in an advance directive) could influence the time for coordinative and other indirect care activities should be addressed. The results could justify additional education for nurses.

- Which methods could be used for further research in this area?

Interventional trials on the benefits of EPC interventions including ACP in larger populations are important to increase evidence but challenges remain in such vulnerable study populations. However, our recent experience with a qualitative study ${ }^{4}$ which included patients with a solid tumor from a randomized controlled trial showed that a combination of an intervention and a qualitative study design ${ }^{85}$ may provide meaningful results and a deeper insight into the defined outcomes.

Patient involvement ${ }^{118}$ in developing a structure such as SENS seemed to be essential. The SENS structure, developed in close partnership with patients and their family caregivers, resulted in a structure which is appreciated by both patients ${ }^{4}$ and healthcare professionals ${ }^{1}$ alike. A similar participatory approach may also be applicable when developing a clearer understanding of nurses' roles during $\mathrm{ACP}$, as well as gaining further knowledge regarding direct and indirect nursing activities in EoL care.

- Which potential outcomes of future research in EPC including ACP should be considered?

The way in which SENS was developed by clinicians ${ }^{1}$ and the interviews with patients during the SENS study ${ }^{4}$ may help to define outcomes, especially in the field of EPC ${ }^{119}$, and the nursing role in the ACP process that are relevant to patients as well as healthcare professionals. These outcomes need to be in the focus of research in the coming years. It is acknowledged that ACP as part of EPC is a potential nursing responsibility to optimize patient care if they are well trained. In what way patients benefit from nurses' contribution within EPC including ACP needs further studies. 
In the qualitative study ${ }^{4}$, patients shared their experience with our approach using SENS, as well as their view on being confronted with difficult themes such as end of life. Quality indicators such as an atmosphere in which patients feel stimulated in actively engaging in EPC and/or ACP could support a sustainable person-centered care approach. ${ }^{120}$

Future prospective studies using a systematically integrated EPC intervention such as based on SENS may contribute to clinically relevant findings such as improved patient reported outcome measures. ${ }^{121-123}$ Studies could be oriented for example towards what impact does EPC and/or ACP have on patients, or which outcomes do patients consider as relevant. A trusting relationship between the healthcare professional and the patient or a sense of security experienced by the unit of care could become additional key outcomes.

\section{Concluding remarks}

This thesis started with a case study in which issues of a patient with a lifelimiting disease and his wife on the one hand and issues for the involved nurses on the other hand were identified. At the end, this thesis concludes with a published cancer case report. ${ }^{67}$ This case report indicates how results generated in the context of this thesis ideally could be transferred into clinical practice in the acute care setting. These include the potential of the SENS structure in guiding treatment and care decisions together with the specialized PC team and concurrent to disease specific measures. In addition, the role of RNs and APRNs in EPC including ACP as well as EoL care is described. 


\section{References}

1. Fliedner MC, Mitchell G, Bueche D, Mettler M, Schols JMGA, Eychmueller S. Development and Use of the 'SENS'-Structure to Proactively Identify Care Needs in Early Palliative Care-An Innovative Approach. Healthcare (Basel). 2019;7(1). doi 10.3390/healthcare7010032.

2. World Health Organization (WHO). Definition Palliative Care World Health Organization; 2002 [Available from: http://www.who.int/cancer/palliative/definition/ en/. Accessed 16.02.2014.

3. Zambrano SC, Fliedner MC, Eychmuller S. The impact of early palliative care on the quality of care during the last days of life: what does the evidence say? Curr Opin Support Palliat Care. 2016;10(4):310-5. doi 10.1097/SPC.0000000000000240.

4. Fliedner M, Zambrano S, Schols JM, Bakitas M, Lohrmann C, Halfens RJ, et al. An early palliative care intervention can be confronting but reassuring: A qualitative study on the experiences of patients with advanced cancer. Palliat Med. 2019;33(7):783-92. doi 10.1177/0269216319847884.

5. Fliedner M, Halfens RJG, King CR, Eychmueller S, Lohrmann C, Schols JMGA. Roles and Responsibilities of Nurses in Advance Care Planning in Palliative Care in the Acute Care Setting: A Scoping Review. J Hosp Palliat Nurs. 2021;23(1):59-68. doi $10.1097 / \mathrm{NJH} .0000000000000715$.

6. Fliedner MC, Hagemann M, Eychmuller S, King C, Lohrmann C, Halfens RJG, et al. Does Time for (in)Direct Nursing Care Activities at the End of Life for Patients With or Without Specialized Palliative Care in a University Hospital Differ? A Retrospective Analysis. Am J Hosp Palliat Care. 2020;37(10):844-52. doi 10.1177/1049909120905779.

7. Hagemann M, Zambrano SC, Butikofer L, Bergmann A, Voigt K, Eychmuller S. Which Cost Components Influence the Cost of Palliative Care in the Last Hospitalization? A Retrospective Analysis of Palliative Care Versus Usual Care at a Swiss University Hospital. J Pain Symptom Manage. 2020;59(1):20-9 e9. doi 10.1016/j. jpainsymman.2019.08.026.

8. Kakushi LE, Evora YD. Direct and indirect nursing care time in an intensive care unit. Rev Lat Am Enfermagem. 2014;22(1):150-7. doi 10.1590/0104-1169.3032.2381.

9. Souza P, Cucolo DF, Perroca MG. Nursing workload: influence of indirect care interventions. Rev EsC Enferm USP. 2019;53:e03440. doi 10.1590/S1980$220 \times 2018006503440$.

10. Campos MS, Oliveira BA, Perroca MG. Workload of nurses: observational study of indirect care activities/interventions. Rev Bras Enferm. 2018;71(2):297-305. doi 10.1590/0034-7167-2016-0561.

11. Possari JF, Gaidzinski RR, Lima AF, Fugulin FM, Herdman TH. Use of the nursing intervention classification for identifying the workload of a nursing team in a surgical center. Rev Lat Am Enfermagem. 2015;23(5):781-8. doi 10.1590/01041169.0419.2615.

12. Butcher $H$, Bulechek $G$, Dochterman JM, Wagner C. Nursing Interventions Classification (NIC). 7th ed. St Louis (USA): Mosby (Elsevier - Health Sciences Division); 2018.

13. Sepulveda C, Marlin A, Yoshida T, Ullrich A. Palliative Care: the World Health Organization's global perspective. J Pain Symptom Manage. 2002;24(2):91-6. doi 
14. Boucher NA, Johnson KS, LeBlanc TW. Acute Leukemia Patients' Needs: Qualitative Findings and Opportunities for Early Palliative Care. J Pain Symptom Manage. 2018;55(2):433-9. doi 10.1016/j.jpainsymman.2017.09.014.

15. Temel JS, Greer JA, Muzikansky A, Gallagher ER, Admane S, Jackson VA, et al. Early palliative care for patients with metastatic non-small-cell lung cancer. $N$ Eng/J Med. 2010;363(8):733-42. doi 10.1056/NEJMoa1000678.

16. Zimmermann C, Swami N, Krzyzanowska M, Hannon B, Leighl N, Oza A, et al. Early palliative care for patients with advanced cancer: a cluster-randomised controlled trial. Lancet. 2014;383(9930):1721-30. doi 10.1016/S0140-6736(13)62416-2.

17. Franciosi V, Maglietta G, Degli Esposti C, Caruso G, Cavanna L, Berte R, et al. Early palliative care and quality of life of advanced cancer patients-a multicenter randomized clinical trial. Ann Palliat Med. 2019;8(4):381-9. doi 10.21037/ apm.2019.02.07.

18. Bakitas M, Lyons KD, Hegel MT, Balan S, Barnett KN, Brokaw FC, et al. The project ENABLE II randomized controlled trial to improve palliative care for rural patients with advanced cancer: baseline findings, methodological challenges, and solutions. Palliat Support Care. 2009;7(1):75-86. doi 10.1017/S1478951509000108.

19. Dougherty CM, Coats HL, Randall Curtis J, Doorenbos AZ. Development and testing of a goals of care intervention in advanced heart failure. Appl Nurs Res. 2017;38:99106. doi 10.1016/j.apnr.2017.09.017.

20. Hackett J, Bekker H, Bennett MI, Carder P, Gallagher J, Henry C, et al. Developing a complex intervention to support timely engagement with palliative care for patients with advanced cancer in primary and secondary care in the UK: a study protocol. BMJ Open. 2018;8(5):e022835. doi 10.1136/bmjopen-2018-022835.

21. Scheerens C, Chambaere K, Pardon K, Derom E, Van Belle S, Joos G, et al. Development of a complex intervention for early integration of palliative home care into standard care for end-stage COPD patients: A Phase 0-I study. PLoS One. 2018;13(9):e0203326. doi 10.1371/journal.pone.0203326.

22. Vanbutsele G, Van Belle S, De Laat M, Surmont V, Geboes K, Eecloo K, et al. The systematic early integration of palliative care into multidisciplinary oncology care in the hospital setting (IPAC), a randomized controlled trial: the study protocol. $B M C$ Health Serv Res. 2015;15:554. doi 10.1186/s12913-015-1207-3.

23. Montgomery C, Hickman SE, Wilkins C, Fromme EK, Anderson S. Response to Morrison, Advance Directives/Care Planning: Clear, Simple, and Wrong (DOI: 10.1089/jpm.2020.0272). J Palliat Med. 2020. doi 10.1089/jpm.2020.0523.

24. Maloney C, Lyons KD, Li Z, Hegel M, Ahles TA, Bakitas M. Patient perspectives on participation in the ENABLE II randomized controlled trial of a concurrent oncology palliative care intervention: benefits and burdens. Palliat Med. 2013;27(4):375-83. doi 10.1177/0269216312445188.

25. Wagner EH. Chronic disease management: what will it take to improve care for chronic illness? Eff Clin Pract. 1998;1(1):2-4.

26. Zwakman M, Jabbarian LJ, van Delden J, van der Heide A, Korfage IJ, Pollock K, et al. Advance care planning: A systematic review about experiences of patients with a life-threatening or life-limiting illness. Palliat Med. 2018;32(8):1305-21. doi $10.1177 / 0269216318784474$. 
27. Temel JS, Greer JA, Admane S, Gallagher ER, Jackson VA, Lynch TJ, et al. Longitudinal perceptions of prognosis and goals of therapy in patients with metastatic nonsmall-cell lung cancer: results of a randomized study of early palliative care. J Clin Oncol. 2011;29(17):2319-26. doi 10.1200/JCO.2010.32.4459.

28. Arthur J, Yennu S, Zapata KP, Cantu H, Wu J, Liu D, et al. Perception of Helpfulness of a Question Prompt Sheet Among Cancer Patients Attending Outpatient Palliative Care. J Pain Symptom Manage. 2017;53(1):124-30 e1. doi 10.1016/j. jpainsymman.2016.08.017.

29. odenbach RA, Brandes K, Fiscella K, Kravitz RL, Butow PN, Walczak A, et al. Promoting End-of-Life Discussions in Advanced Cancer: Effects of Patient Coaching and Question Prompt Lists. J Clin Oncol. 2017;35(8):842-51. doi 10.1200/JCO.2016.68.5651.

30. Schulman-Green D, Smith CB, Lin JJ, Feder S, Bickell NA. Oncologists' and Patients' Perceptions of Initial, Intermediate, and Final Goals of Care Conversations. J Pain Symptom Manage. 2018;55(3):890-6. doi 10.1016/j.jpainsymman.2017.09.024.

31. Hannon B, Swami N, Rodin G, Pope A, Zimmermann C. Experiences of patients and caregivers with early palliative care: A qualitative study. Palliat Med. 2017;31(1):7281. doi 10.1177/0269216316649126.

32. Kennedy V, Lloyd-Williams M. Maintaining hope: communication in palliative care. Recent Results Cancer Res. 2006;168:47-60. doi 10.1007/3-540-30758-3_5.

33. Mathews J, Hannon B, Zimmermann C. Models of Integration of Specialized Palliative Care with Oncology. Curr Treat Options Oncol. 2021;22(5):44. doi 10.1007/s11864021-00836-1.

34. Hausner D, Tricou C, Mathews J, Wadhwa D, Pope A, Swami N, et al. Timing of Palliative Care Referral Before and After Evidence from Trials Supporting Early Palliative Care. Oncologist. 2020. doi 10.1002/onco.13625.

35. Pearse W, Oprescu F, Endacott J, Goodman S, Hyde M, O'Neill M. Advance care planning in the context of clinical deterioration: a systematic review of the literature. Palliat Care. 2019;12:1178224218823509. doi 10.1177/1178224218823509.

36. Bernard C, Tan A, Slaven M, Elston D, Heyland DK, Howard M. Exploring patientreported barriers to advance care planning in family practice. BMC Fam Pract. 2020;21(1):94. doi 10.1186/s12875-020-01167-0.

37. Haun MW, Estel S, Rucker G, Friederich HC, Villalobos M, Thomas M, et al. Early palliative care for adults with advanced cancer. Cochrane Database Syst Rev. 2017;6:CD011129. doi 10.1002/14651858.CD011129.pub2.

38. Sudore RL, Lum HD, You JJ, Hanson LC, Meier DE, Pantilat SZ, et al. Defining Advance Care Planning for Adults: A Consensus Definition From a Multidisciplinary Delphi Panel. J Pain Symptom Manage. 2017;53(5):821-32 e1. doi 10.1016/j. jpainsymman.2016.12.331.

39. Gomez-Batiste X, Murray SA, Thomas K, Blay C, Boyd K, Moine S, et al. Comprehensive and Integrated Palliative Care for People With Advanced Chronic Conditions: An Update From Several European Initiatives and Recommendations for Policy. J Pain Symptom Manage. 2017;53(3):509-17. doi 10.1016/j.jpainsymman.2016.10.361.

40. Ferrell BR, Temel JS, Temin S, Alesi ER, Balboni TA, Basch EM, et al. Integration of Palliative Care Into Standard Oncology Care: American Society of Clinical Oncology Clinical Practice Guideline Update. J Clin Oncol. 2017;35(1):96-112. doi 10.1200/ JCO.2016.70.1474. 
41. Ferrell BR, Twaddle ML, Melnick A, Meier DE. National Consensus Project Clinical Practice Guidelines for Quality Palliative Care Guidelines, 4th Edition. J Palliat Med. 2018. doi 10.1089/.jpm.2018.0431.

42. Krones T, Budilivschi A, Karzig I, Otto T, Valeri F, Biller-Andorno N, et al. Advance care planning for the severely ill in the hospital: a randomized trial. BMJ Support Palliat Care. 2019. doi 10.1136/bmjspcare-2017-001489.

43. Webber C, Chan R, Scott M, Brown C, Spruin S, Hsu AT, et al. Delivery of Palliative Care in Acute Care Hospitals: A Population-Based Retrospective Cohort Study Describing the Level of Involvement and Timing of Inpatient Palliative Care in the Last Year of Life. J Palliat Med. 2020. doi 10.1089/jpm.2020.0056.

44. Vanbutsele G, Deliens L, Cocquyt V, Cohen J, Pardon K, Chambaere K. Use and timing of referral to specialized palliative care services for people with cancer: A mortality follow-back study among treating physicians in Belgium. PLoS One. 2019;14(1):e0210056. doi 10.1371/journal.pone.0210056.

45. Pini S, Hackett J, Taylor S, Bekker HL, Kite S, Bennett MI, et al. Patient and professional experiences of palliative care referral discussions from cancer services: A qualitative interview study. Eur J Cancer Care (Engl). 2021;30(1):e13340. doi 10.1111/ecc.13340.

46. Sorensen A, Wentlandt K, Le LW, Swami N, Hannon B, Rodin G, et al. Practices and opinions of specialized palliative care physicians regarding early palliative care in oncology. Support Care Cancer. 2019. doi 10.1007/s00520-019-04876-0.

47. Smith CB, Phillips T, Smith TJ. Using the New ASCO Clinical Practice Guideline for Palliative Care Concurrent With Oncology Care Using the TEAM Approach. Am Soc Clin Oncol Educ Book. 2017;37:714-23. doi 10.14694/EDBK_175474.

48. LeBlanc TW. Addressing End-of-Life Quality Gaps in Hematologic Cancers: The Importance of Early Concurrent Palliative Care. JAMA Intern Med. 2016;176(2):265-6. doi 10.1001/jamainternmed.2015.6994.

49. Bakitas MA, Tosteson TD, Li Z, Lyons KD, Hull JG, Li Z, et al. Early Versus Delayed Initiation of Concurrent Palliative Oncology Care: Patient Outcomes in the ENABLE III Randomized Controlled Trial. J Clin Oncol. 2015;33(13):1438-45. doi 10.1200/ JCO.2014.58.6362.

50. Barth C, Colombet I, Montheil V, Huillard O, Boudou-Rouquette P, Tlemsani C, et al. First referral to an integrated onco-palliative care program: a retrospective analysis of its timing. BMC Palliat Care. 2020;19(1):31. doi 10.1186/s12904-020-0539-x.

51. Gemmell R, Yousaf N, Droney J. "Triggers" for early palliative care referral in patients with cancer: a review of urgent unplanned admissions and outcomes. Support Care Cancer. 2019. doi 10.1007/s00520-019-05179-0.

52. Lunardi L, Hill K, Crail S, Esterman A, Le Leu R, Drummond C. 'Supportive and Palliative Care Indicators Tool (SPICT) improves renal nurses' confidence in recognising patients approaching end of life'. BMJ Support Palliat Care. 2020. doi 10.1136/bmjspcare-2020-002496.

53. Jackson GL, Padilla BI, Schneider SM, Kyte JJ. Optimizing Advanced Care Planning in Hospitalized Patients With Advanced Cancers: A Quality Improvement Initiative. J Dr Nurs Pract. 2019;12(2):239-45. doi 10.1891/2380-9418.12.2.239.

54. Hirschman KB, Corcoran AM, Straton JB, Kapo JM. Advance care planning and hospice enrollment: who really makes the decision to enroll? J Palliat Med. 2010;13(5):51923. doi 10.1089/jpm.2009.0370. 
55. Mohammed S, Savage P, Kevork N, Swami N, Rodin G, Zimmermann C. "I'm going to push this door open. You can close it": A qualitative study of the brokering work of oncology clinic nurses in introducing early palliative care. Palliat Med. 2019:269216319883980. doi 10.1177/0269216319883980.

56. Izumi S. Advance Care Planning: The Nurse's Role. Am J Nurs. 2017;117(6):56-61. doi 10.1097/01.NAJ.0000520255.65083.35.

57. Hospice and Palliative Nurses Association (HPNA). HPNA Position Statement Advance Care Planning. Journal of Hospice \& Palliative Nursing. 2018;20(5):E1-E3. doi

58. Head BA, Song MK, Wiencek C, Nevidjon B, Fraser D, Mazanec P. Palliative Nursing Summit: Nurses Leading Change and Transforming Care: The Nurse's Role in Communication and Advance Care Planning.J Hosp Palliat Nurs. 2018;20(1):23-9. doi 10.1097/NJH.0000000000000406.

59. Canadian Council of Cardiovascular Nursing (CCCN). Advance Care Planning and the Role of the Cardiovascular Nurse Position Statement. 2015.

60. Gabbard J, Pajewski NM, Callahan KE, Dharod A, Foley KL, Ferris K, et al. Effectiveness of a Nurse-Led Multidisciplinary Intervention vs Usual Care on Advance Care Planning for Vulnerable Older Adults in an Accountable Care Organization: A Randomized Clinical Trial. JAMA Intern Med. 2021. doi 10.1001/jamainternmed.2020.5950.

61. Institute of Medicine (IOM). Dying in America: Improving Quality and Honoring Individual Preferences Near the End of Life. Washington, D.C., USA: The National Academies Press; 2015.

62. MacKenzie MA, Smith-Howell E, Bomba PA, Meghani SH. Respecting Choices and Related Models of Advance Care Planning: A Systematic Review of Published Evidence. Am J Hosp Palliat Care. 2018;35(6):897-907. doi 10.1177/1049909117745789.

63. Rietze L, Heale R, Hill L, Roles S. Advance Care Planning in Nurse Practitioner Practice: A Cross-Sectional Descriptive Study. Nurs Leadersh (Tor Ont). 2016;29(3):106-19. doi 10.12927/cjnl.2016.24897.

64. Izumi S, Burt M, Smith J, McCord K, Fromme EK. Enhancing Advance Care Planning Conversations by Nurses in a Bone Marrow Transplantation Unit. Oncol Nurs Forum. 2019;46(3):288-97. doi 10.1188/19.ONF.288-297.

65. Carabez R, Scott M. 'Nurses don't deal with these issues': nurses' role in advance care planning for lesbian, gay, bisexual and transgender patients. J Clin Nurs. 2016;25(2324):3707-15. doi 10.1111/jocn.13336.

66. Goldsborough JL, Matzo M. Palliative Care in the Acute Care Setting. Am J Nurs. 2017;117(9):64-7. doi 10.1097/01.NAJ.0000524553.04309.8e.

67. Fliedner $M$, Willener R. A case study: Concurrent palliative care based on SENS $\square$ structure for patients with advanced prostate cancer. International Journal of Urological Nursing. 2020;14(2):92-5. doi 10.1111/ijun.12232.

68. Mastroianni C, Ramon Codina M, D'Angelo D, Petitti T, Latina R, Casale G, et al. Palliative Care Education in Undergraduate Nursing Curriculum in Italy. J Hosp Palliat Nurs. 2019;21(1):96-103. doi 10.1097/NJH.0000000000000515.

69. Hökkä M, Martins Pereira S, Polkki T, Kyngas H, Hernandez-Marrero P. Nursing competencies across different levels of palliative care provision: A systematic integrative review with thematic synthesis. Palliat Med. 2020;34(7):851-70. doi $10.1177 / 0269216320918798$. 
70. Hökkä M, Martins Pereira S, Hernández-Marrero P. The Blog of the European Association for Palliative Care [Internet]. (EAPC) EAfPC, editor2020. [cited 2020]. Available from: https://eapcnet.wordpress.com/2020/08/26/nursing-competenciesacross-different-levels-of-palliative-care-provision-highlighting-the-need-forfurther-research-and-international-collaboration/.

71. Buller H, Virani R, Malloy P, Paice J. End-of-Life Nursing and Education Consortium Communication Curriculum for Nurses. J Hosp Palliat Nurs. 2019;21(2):E5-E12. doi 10.1097/NJH.0000000000000540.

72. Lippe M, Volker D, Jones T, Carter P. Evaluating End-of-Life Care Education Within Nursing Programs: A Method for Targeted Curriculum Evaluation. Journal of Hospice \& Palliative Nursing. 2017;19(3):266-74. doi 10.1097/njh.0000000000000341.

73. Manning J, Creel A, Jones N. Effectiveness of an End-of-Life Nursing Education Consortium Training on Registered Nurses' Educational Needs in Providing Palliative and End-of-Life Patient Care. J Hosp Palliat Nurs. 2020. doi 10.1097/ $\mathrm{NJH} .0000000000000710$.

74. Ludwick R, Baughman KR, Jarjoura D, Kropp DJ. CE: Original Research: Advance Care Planning: An Exploration of the Beliefs, Self-Efficacy, Education, and Practices of RNs and LPNs. Am J Nurs. 2018;118(12):26-32. doi 10.1097/01.NAJ.0000549664.43827.ce.

75. Scheerens C, Pype P, Van Cauwenberg J, Vanbutsele G, Eecloo K, Derom E, et al. Early-Integrated Palliative home care and standard care for end-stage COPD (EPIC): A Phase II pilot RCT testing feasibility, acceptability and effectiveness.J Pain Symptom Manage. 2019. doi 10.1016/j.jpainsymman.2019.09.012.

76. Chan TE, Lockhart JS, Schreiber JB, Kronk R. Determining nurse practitioner core competencies using a Delphi approach. J Am Assoc Nurse Pract. 2020;32(3):200-17. doi 10.1097/JXX.0000000000000384.

77. Myers J, Cosby R, Gzik D, Harle I, Harrold D, Incardona N, et al. Provider Tools for Advance Care Planning and Goals of Care Discussions: A Systematic Review. Am J Hosp Palliat Care. 2018;35(8):1123-32. doi 10.1177/1049909118760303.

78. Rocque GB, Dionne-Odom JN, Sylvia Huang CH, Niranjan SJ, Williams CP, Jackson $\mathrm{BE}$, et al. Implementation and Impact of Patient Lay Navigator-Led Advance Care Planning Conversations. J Pain Symptom Manage. 2017;53(4):682-92. doi 10.1016/j. jpainsymman.2016.11.012.

79. Miranda DR, Nap R, de Rijk A, Schaufeli W, Iapichino G, System TWGTIS. Nursing activities score. Crit Care Med. 2003;31(2):374-82. doi 10.1097/01. CCM.0000045567.78801.CC.

80. Lachance J, Douville F, Dallaire C, Padilha KG, Gallani MC. The use of the Nursing Activities Score in clinical settings: an integrative review. Rev Esc Enferm USP. 2015;49 Spec No:147-56. doi 10.1590/S0080-623420150000700021.

81. Silva TCMS, Castro MCN, Popim RC. Adaptation of the Nursing Activities Score for oncologic care. Rev Bras Enferm. 2018;71(5):2383-91. doi 10.1590/0034-7167-20170015.

82. Medical Research Council (MRC). A Framework For Development and Evaluation of RCTs For Complex Interventions to Improve Health. London, UK2000.

83. Froggatt $\mathrm{K}$, Hockley J. Action research in palliative care: defining an evaluation methodology. Palliat Med. 2011;25(8):782-7. doi 10.1177/0269216311420483. 
84. Eychmueller S, Fliedner M. A structured early palliative care intervention for patients with advanced cancer - a randomized controlled trial with a nested qualitative study 2013 [Available from: http://www.nfp67.ch/en/projects/module-1-dying-processesprovision-care/project-eychmueller. Accessed 10.07.2018.

85. Eychmuller S, Zwahlen S, Fliedner MC, Juni P, Aebersold DM, Aujesky D, et al. Single early palliative care intervention added to usual oncology care for patients with advanced cancer: A randomized controlled trial (SENS Trial). Palliat Med. 2021;35(6):1108-17. doi 10.1177/02692163211005340.

86. Vanbutsele G, Van Belle S, Surmont V, De Laat M, Colman R, Eecloo K, et al. The effect of early and systematic integration of palliative care in oncology on quality of life and health care use near the end of life: A randomised controlled trial. Eur J Cancer. 2020;124:186-93. doi 10.1016/j.ejca.2019.11.009.

87. El-Jawahri A, LeBlanc T, VanDusen H, Traeger L, Greer JA, Pirl WF, et al. Effect of Inpatient Palliative Care on Quality of Life 2 Weeks After Hematopoietic Stem Cell Transplantation: A Randomized Clinical Trial. JAMA. 2016;316(20):2094-103. doi 10.1001/jama.2016.16786.

88. Scarpi E, Dall'Agata M, Zagonel V, Gamucci T, Berte R, Sansoni E, et al. Systematic vs. on-demand early palliative care in gastric cancer patients: a randomized clinical trial assessing patient and healthcare service outcomes. Support Care Cancer. 2019;27(7):2425-34. doi 10.1007/s00520-018-4517-2.

89. Groenvold M, Petersen MA, Damkier A, Neergaard MA, Nielsen JB, Pedersen L, et al. Randomised clinical trial of early specialist palliative care plus standard care versus standard care alone in patients with advanced cancer: The Danish Palliative Care Trial. Palliat Med. 2017;31(9):814-24. doi 10.1177/0269216317705100.

90. Wilkinson M. Distinguishing between statistical significance and practical/clinical meaningfulness using statistical inference. Sports Med. 2014;44(3):295-301. doi 10.1007/s40279-013-0125-y.

91. Gibson G, Timlin A, Curran S, Wattis J. The scope for qualitative methods in research and clinical trials in dementia. Age Ageing. 2004;33(4):422-6. doi 10.1093/ageing/ afh136.

92. Akyar I, Dionne-Odom JN, Bakitas MA. Using Patients and Their Caregivers Feedback to Develop ENABLE CHF-PC: An Early Palliative Care Intervention for Advanced Heart Failure. J Palliat Care. 2019;34(2):103-10. doi 10.1177/0825859718785231.

93. Hannon B, Swami N, Pope A, Leighl N, Rodin G, Krzyzanowska M, et al. Early Palliative Care and Its Role in Oncology: A Qualitative Study. Oncologist. 2016. doi 10.1634/ theoncologist.2016-0176.

94. Hannon B, Swami N, Pope A, Leighl NB, Krzyzanowska MK, Moore MJ, et al. Patients' and caregivers' views on the timing and benefits of early palliative care: A qualitative study. Journal of Clinical Oncology. 2013;31(31). doi

95. Lim CT, Tadmor A, Fujisawa D, MacDonald JJ, Gallagher ER, Eusebio J, et al. Qualitative Research in Palliative Care: Applications to Clinical Trials Work. J Palliat Med. 2017;20(8):857-61. doi 10.1089/jpm.2017.0061.

96. Fliedner M, Zambrano S, Lohrmann C, Schols J, Halfens R, Eychmueller S. Cancer patients' experiences with an early palliative care conversation: A qualitative study of an intervention based on the SENS-structure. Support Care Cancer 2018;26(Supplement 2):S63. doi 
97. Davies JM, Gao W, Sleeman KE, Lindsey K, Murtagh FE, Teno JM, et al. Using routine data to improve palliative and end of life care. BMJ Support Palliat Care. 2016;6(3):25762. doi 10.1136/bmjspcare-2015-000994.

98. Craig P, Dieppe P, Macintyre S, Michie S, Nazareth I, Petticrew M, et al. Developing and evaluating complex interventions: the new Medical Research Council guidance. BMJ. 2008;337:a1655. doi 10.1136/bmj.a1655.

99. World Health Organization (WHO), Study Group on Multiprofessional Education of Health Personnel: the Team Approach. Learning together to work together for health : report of a WHO Study Group on Multiprofessional Education of Health Personnel: the Team Approach [meeting held in Geneva from 12 to 16 October 1987]. Geneva: World Health Organization; 1988.

100. Bradway C, CotterVT, Darrah NJ, Gibbs VD, Hadley D, KimEH, etal. An Interprofessional Education Simulation Workshop: Health Professions Learning Palliative Care Communication. J Nurs Educ. 2018;57(8):493-7. doi 10.3928/01484834-2018072008.

101. Randall D, Garbutt D, Barnard M. Using simulation as a learning experience in clinical teams to learn about palliative and end-of-life care: A literature review. Death Studies. 2018;42(3):172-83. doi 10.1080/07481187.2017.1334006.

102. Saylor J, Vernoony S, Selekman J, Cowperthwait A. Interprofessional Education Using a Palliative Care Simulation. Nurse Educator. 2016;41(3):125-9. doi 10.1097/ nne.0000000000000228.

103. Prelock PA, Melvin C, Lemieux N, Melekis K, Velleman S, Favro MA. One TeamPatient, Family, and Health Care Providers: An Interprofessional Education Activity Providing Collaborative and Palliative Care. Semin Speech Lang. 2017;38(5):350-9. doi 10.1055/s-0037-1607071.

104. Benner P. From novice to expert: Excellence and Power in Clinical Nursing: Pearson Education (US); 1984.

105. Hayes C, So S, Mitchell A. By providing hospice/palliative care education to registered nurses does it improve their comfort level when communicating end of life choices, including hospice with patients and families? Hos Pal Med Int JnI. 2018;2(6):423-6. doi 10.15406/hpmij.2018.02.00138.

106. Khalil H, Byrne A, Ristevski E. The development and implementation of a clinical skills matrix to plan and monitor palliative care nurses' skills. Collegian. 2019;26(6):634-9. doi 10.1016/j.colegn.2019.05.002.

107. Zhang B, Wright AA, Huskamp HA, Nilsson ME, Maciejewski ML, Earle CC, et al. Health care costs in the last week of life: associations with end-of-life conversations. Archives of internal medicine. 2009;169(5):480-8. doi 10.1001/archinternmed.2008.587.

108. Bakitas M, Stevens M, Ahles T, Kirn M, Skalla K, Kane N, et al. Project ENABLE: a palliative care demonstration project for advanced cancer patients in three settings. J Palliat Med. 2004;7(2):363-72. doi 10.1089/109662104773709530.

109. Ichihara E, Matsuoka J, Kiura K. Early palliative care in non-small-cell lung cancer. $N$ Eng/J Med. 2010;363(23):2263; author reply 4-5. doi 10.1056/NEJMc1010529\#SA1.

110. Greer JA, Pirl WF, Jackson VA, Muzikansky A, Lennes IT, Heist RS, et al. Effect of early palliative care on chemotherapy use and end-of-life care in patients with metastatic non-small-cell lung cancer. J Clin Oncol. 2012;30(4):394-400. doi 10.1200/ JCO.2011.35.7996. 
111. Menon S, Kars MC, Malhotra C, Campbell AV, van Delden JJM. Advance Care Planning in a Multicultural Family Centric Community: A Qualitative Study of Health Care Professionals', Patients', and Caregivers' Perspectives. Journal of Pain and Symptom Management. 2018;56(2):213-21.e4. doi 10.1016/j.jpainsymman.2018.05.007.

112. Ng R, Chan S, Ng TW, Chiam AL, Lim S. An exploratory study of the knowledge, attitudes and perceptions of advance care planning in family caregivers of patients with advanced illness in Singapore. BMJ Supportive \&amp; Palliative Care. 2013;3(3):343-8. doi 10.1136/bmjspcare-2012-000243.

113. Tarberg AS, Kvangarsnes M, Hole T, Thronaes M, Madssen TS, Landstad BJ. Silent voices: Family caregivers' narratives of involvement in palliative care. Nurs Open. 2019;6(4):1446-54. doi 10.1002/nop2.344.

114. Tsuruwaka M, Ikeguchi $Y$, Nakamura M. When do Physicians and Nurses Start Communication about Advance Care Planning? A Qualitative Study at an Acute Care Hospital in Japan. Asian Bioethics Review. 2020;12(3):289-305. doi 10.1007/s41649020-00135-1.

115. Dahlin C, Coyne P. The palliative APRN leader. Ann Palliat Med. 2019;8(Suppl 1):S30-S8. doi 10.21037/apm.2018.06.03.

116. Christensen KL, Winters CA, Colclough Y, Oley E, Luparell S. Advance Care Planning in Rural Montana: Exploring the Nurse's Role. J Hosp Palliat Nurs. 2019;21(4):264-71. doi 10.1097/NJH.0000000000000556.

117. Miller H, Tan J, Clayton JM, Meller A, Hermiz O, Zwar N, et al. Patient experiences of nurse-facilitated advance care planning in a general practice setting: a qualitative study. BMC Palliat Care. 2019;18(1):25. doi 10.1186/s12904-019-0411-z.

118. Kroon LL, van Roij J, Korfage IJ, Reyners AKL, van den Beuken-van Everdingen $\mathrm{MHJ}$, den Boer $\mathrm{MO}$, et al. Perceptions of involvement in advance care planning and emotional functioning in patients with advanced cancer. J Cancer Surviv. 2021. doi 10.1007/s11764-021-01020-y.

119. Sudore RL, Heyland DK, Lum HD, Rietjens JAC, Korfage IJ, Ritchie CS, et al. Outcomes That Define Successful Advance Care Planning: A Delphi Panel Consensus. J Pain Symptom Manage. 2018;55(2):245-55 e8. doi 10.1016/j.jpainsymman.2017.08.025.

120. Santana MJ, Ahmed S, Lorenzetti D, Jolley RJ, Manalili K, Zelinsky S, et al. Measuring patient-centred system performance: a scoping review of patient-centred care quality indicators. BMJ Open. 2019;9(1):e023596. doi 10.1136/bmjopen-2018-023596.

121. Hoerger $M$, Greer JA, Jackson VA, Park ER, Pirl WF, El-Jawahri A, et al. Defining the Elements of Early Palliative Care That Are Associated With Patient-Reported Outcomes and the Delivery of End-of-Life Care. J Clin Oncol. 2018;36(11):1096-102. doi 10.1200/JCO.2017.75.6676.

122. Meier EA, Gallegos JV, Thomas LP, Depp CA, Irwin SA, Jeste DV. Defining a Good Death (Successful Dying): Literature Review and a Call for Research and Public Dialogue. Am J Geriatr Psychiatry. 2016;24(4):261-71. doi 10.1016/j.jagp.2016.01.135.

123. Dudgeon D. The Impact of Measuring Patient-Reported Outcome Measures on Quality of and Access to Palliative Care. J Palliat Med. 2018;21(S1):S76-S80. doi 10.1089/jpm.2017.0447. 


\section{Abbreviations}

- ACP: Advance Care Planning

- APRNs: Advanced Practice Registered Nurses (postgraduate level)

- EoL: End-of-Life

- EPC: Early integrated Palliative Care

- NAS: Nursing Activities Score

- PC: Palliative Care

- RNs: Registered Nurses (undergraduate level)

- SENS: Symptoms; End-of-life decisions and expectations; Network; and Support for the caregivers

- SPC: Specialized Palliative Care

- UPC: Usual Palliative Care 


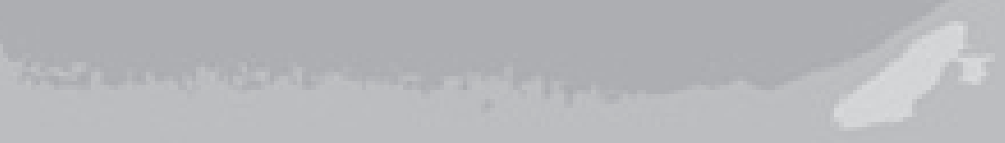

\section{Chas}
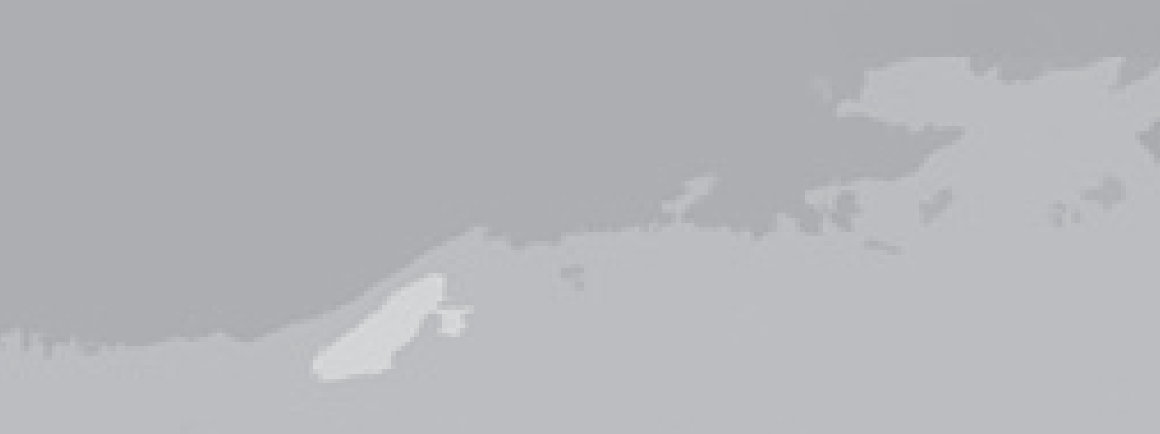

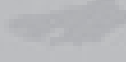

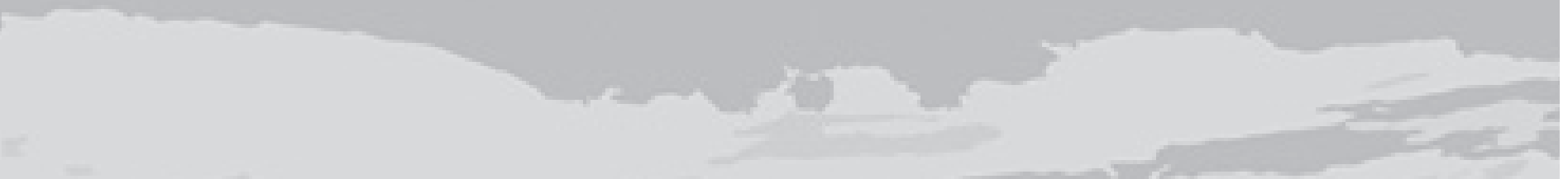

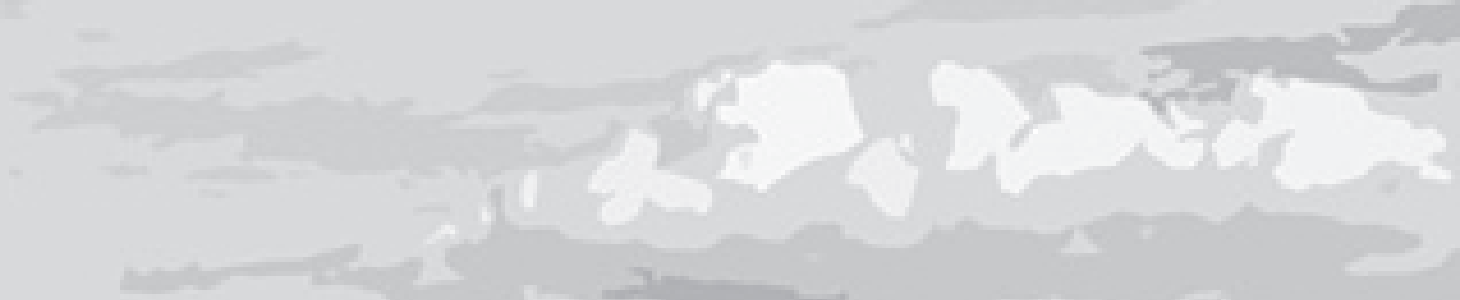

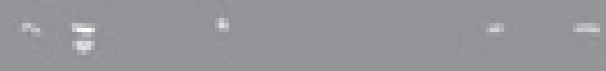

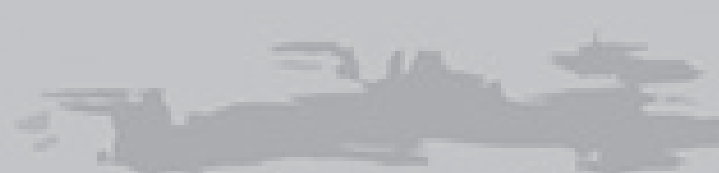

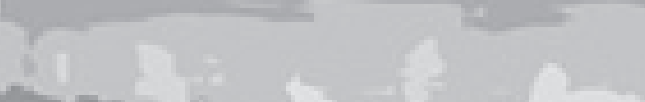

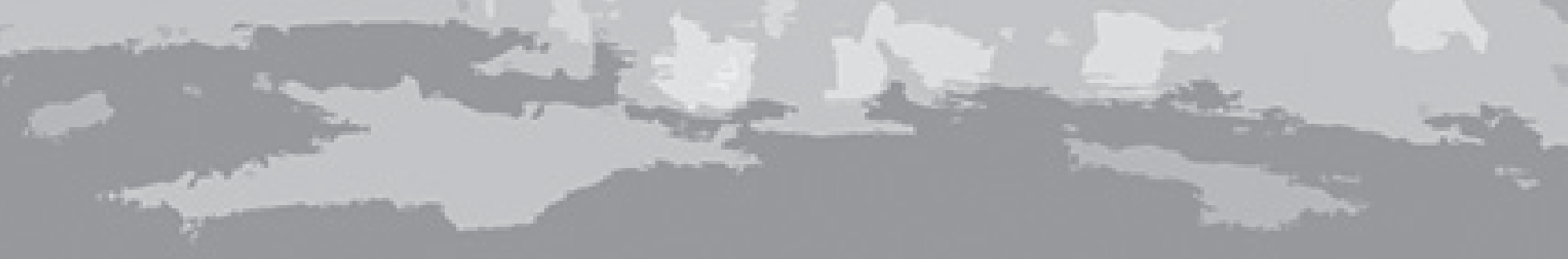


Chapter 9

Impact 
This chapter presents the social and scientific impact of the results of the studies included in this thesis.

The main aim of this thesis was to gain insight into patients' perception of early integrated palliative care (EPC) in the acute care setting and its potential benefits. Additionally, this thesis assessed the role and activities of undergraduate and postgraduate nurses specifically in advance care planning (ACP, a conversational process about treatment and care preferences and expectations) as part of early integrated palliative care and in end-of-life care. Palliative care $(P C)$ in general implicates the well-being in patients' physical, psychological, social and spiritual domains.

In a quality improvement project ${ }^{1}$ we developed a patient-oriented PC thematic assessment structure. The structure is called SENS which stands for the following themes:

- Symptom assessment and its management,

- End-of-life decisions and expectations which includes the process of decision making for the last phase of life (often referred to as advance care planning),

- Network assessment (private and professional),

- Support for the informal and professional caregivers

Additional information can also be found on the internet (www.sens-plan. com). This structure proved to be useful within the acute care setting (hospital) to identify and prioritize areas of concern of patients with a life-limiting disease in EPC. Healthcare professionals found this structure supportive in assessing and identifying needs of patients alongside a diagnosis-specific approach, which still is todays' clinical standard. Therefore, we can recommend professionals in the hospital to use the SENS structure in EPC interventions to support a concurrent care approach. ${ }^{2}$

We undertook also a qualitative study ${ }^{3}$ within a multicenter randomized controlled trial ${ }^{4}$ to explore how cancer patients perceived SENS-structured conversations. We included patients with a life-limiting disease who no longer had a curative treatment option. Patients noted that previous conversations with specialists were often based on medical diagnostic reasoning. SENS helped to create $a$ list of themes and action points that were equally important for patients and healthcare professionals. Patients considered all themes useful, because it not only helped them to understand what PC entails, but it also stimulated 
them to discuss their concerns and worries with their family. Some patients found talking about the SENS themes confronting but were relieved that they finally were able to speak about their fears and concerns in these areas. In a case report we demonstrated how SENS can be used in clinical practice. ${ }^{5}$ We concluded that patients and healthcare professionals value these structured conversations equally. Patients even encouraged the healthcare professionals to use the SENS structure concurrent with a diagnosis-driven approach and care planning whenever they were ready to talk about these themes. Healthcare professionals need to be sensitive about how individual patients are dealing with their disease and finiteness.

We reviewed the literature on the timing and impact of the early integration of PC in the hospital and the effect on patients' end-of-life care independent of the medical diagnosis. ${ }^{6}$ We found that conversations on PC issues should be started 3 to 24 months before the presumed death of patients. This might then have a positive impact on patients' quality of life and end-of-life care. We, therefore, recommend discussing PC issues (e.g., by SENS) with patients taking into consideration the anticipated time until presumed death to enable anticipatory planning.

Based on a literature search we identified roles, responsibilities and educational requirements of nurses involved in ACP conversations as one of the important parts of EPC. ${ }^{7}$ We concluded that with appropriate training on a postgraduate level and clinical experience, nurses are obviously capable to engage in and facilitate ACP conversations. Like treating physicians, nurses are able to inform patients about: a) the disease and potential treatment options, b) discuss patients' values and wishes (e.g., goals of care for the future and preferred place of care), and/or c) guide patients towards legal documents (e.g., advance directives).

In another study ${ }^{8}$ we retrospectively analyzed the time that nurses spent in direct and indirect care activities for patients dying in a hospital. Direct care activities were defined as close interaction with the patient and/or family (e.g., care procedures). Indirect care activities were defined as care on behalf of the patient such as coordination of care. We compared care activity times between patients who received usual PC and patients receiving additional specialized PC based on SENS. We saw that patients who received specialized PC needed overall notably more nursing care time than patients who received usual PC. Time for nursing care in general increased after starting specialized PC including 
time for symptom management and coordination of care. We concluded that patients receiving specialized PC require additional nursing care-time.

\section{Relevance}

\section{Contribution to nursing (science)}

This thesis provided relevant insights into the impact of EPC on patients' wellbeing. We also contributed to the understanding of patients' and healthcare professional's experiences when a patient-centered assessment structure such as SENS was used concurrently to the diagnosis-driven approach. SENS provides a common language between healthcare professionals and patients, supporting their active participation in the process. These are aspects of nursing which aim to translate medical reasoning into a pragmatic patient-centered approach. SENS is a structure that can be used in future clinical studies on EPC in other settings and with populations other than cancer patients.

This thesis also provided insight into the complementary nursing role within the interprofessional team in the ACP process in the hospital setting. SENS proved to be useful to all members of the interprofessional team. The knowledge about nurses' roles and their contribution within the ACP process provides a basis for future studies in this field. Based on our outcomes, direct and indirect care activities in PC need future attention to better understand their impact on care organization and patient related outcomes. This will enable nurse researchers to better evaluate the work of nurses and the effects of specialized PC.

To better understand effects of EPC (e.g., structured by SENS) on patients' well-being including the end-of-life phase, our results can target further studies on PC based on the perspectives of patients, their families and healthcare professionals. Our results may stimulate the scientific community to rethink outcomes to be measured in EPC research such as: a) which outcomes are relevant to professionals? b) which outcomes can be defined in close collaboration with patients and families?

It is known that tailored PC improves the well-being of patients with a life-limiting disease including their last phase of life. The studies of this thesis contribute to a better understanding of how these dimensions of well-being can be addressed with a pragmatic structure such as SENS. Our results showed that this problem-/patient-based care approach is more successful for improving 
patients' well-being than a diagnosis-based approach alone. Although it might be confronting to some patients, these themes become important and meaningful if $\mathrm{PC}$ is integrated early in patients' disease trajectory.

Healthcare professionals often still have a main focus on diagnosis-driven themes but these do not always correspond with the primary concerns of the patients. The SENS structure enables patients to keep control over a difficult phase in their life based on their concerns. This strengthens patient empowerment and a process of shared understanding and decision-making between patients and healthcare professionals. Consequently, the nature of these conversations might change. The results of this thesis also showed that nurses are able to be involved in or lead ACP conversations when trained appropriately.

\section{Challenges}

Similar to the general public ${ }^{9}$ in western societies, many patients still consider PC as connected to dying and consider it taboo to talk about the finiteness of life with healthcare professionals. Therefore, patients need information that the PC approach can be beneficial to them and their family when it has been addressed early in their disease trajectory and based on a structure such as SENS. Advance care planning supports patients and their families by giving them a sense of security about the future, knowing better what to expect realistically and what to decide for life-limiting situations. If patients are taught to discuss these issues openly it might be a start for changing the taboo into a more open issue within the social environment.

A competency-driven model of care defines who is best within the interprofessional care team in certain care aspects such as ACP. Through our work we have learned about the complementary role of nurses in ACP. We need to better understand the skills needed for conducting meaningful ACP conversations. However, it is clear that the role and responsibility of nurses in ACP need to be acknowledged. The same applies to the intensity of nursing care in the patients' last phase of life. 


\section{Relevance for target groups}

The results of this thesis are interesting and relevant for the following target groups:

- Patients in the palliative phase of their disease and their families might be interested in learning more about the themes structured by SENS in a PC approach, that can or should be discussed at their discretion. Being offered such a PC approach including ACP early in their disease trajectory routinely empowers patients to discuss concerns with their family. It strengthens a participatory approach with mutual understanding between healthcare professionals and patients with their family. This will ease the provision of continuity of care and enhance person-centeredness which will ultimately lead to a better quality of patients' well-being until death.

- The results of this thesis can be used by healthcare professionals in hospitals who wish to integrate a structured conversation based on SENS early on with patients with a life-limiting disease. Healthcare professionals can contribute to the further development and refinement by reflecting and discussing their experiences on using SENS.

- Nurses on undergraduate and post-graduate level working in the field of PC may be interested in understanding the background needed to engage in or lead ACP conversations and which topics patients want to discuss based on SENS. Additionally, nurses may understand how much time their work requires when caring for dying patients in the hospital.

- Based on the WHO recommendations, post-graduate PC education often promotes interprofessional learning opportunities. ${ }^{10}$ Based on the results of the thesis, educators in the field of PC could design a targeted competencydriven interprofessional training in which topics should be included such as a) when PC should be introduced; b) the use a joint structure (such as SENS) for PC conversations; c) how nurses can contribute to the ACP process; and d) patients' views on ECP including an early ACP conversation.

- The information generated on the role and responsibility of nurses as well as their direct and indirect care time for patients dying in the hospital is important for nursing and healthcare administrators because the results provide better insight into the work of nurses. This may help to define even better staffing levels with the appropriate mix of educational background. 


\section{Impact activities}

Next to the publications included in this thesis we presented the results of our studies at various national and international scientific conferences ${ }^{11-24}$ over the past years. Additionally, the results are now used as groundwork for the structure of interprofessional education in the field of PC in Switzerland. ${ }^{25}$ Specifically, nursing schools at undergraduate and post-graduate levels use our findings to educate nurses specifically in leading ACP conversations and contributing to clarifying the role of nurses within the interprofessional team.

To implement the newly developed concurrent model of $\operatorname{care}^{26}$ with a pragmatic problem-based structure parallel to diagnosis-driven care, healthcare professionals can use the SENS structure. ${ }^{1}$ SENS helps to develop triggers as to when the PC approach should be integrated to support the well-being of patients with a life-limiting disease in the hospital. Healthcare professionals in the Canton Bern developed already a document ${ }^{27}$ based on SENS for a more coordinated transition of patients between hospital and home in PC situations. This document is used by patients, families and healthcare professionals equally and provides a common understanding within PC.

An in-house project called "i-plan" is approved by the directorate of the University Hospital Bern, in which the author of this thesis is employed, to integrate palliative care early and in all medical specialties. This will enable patients, families and healthcare professionals to discuss PC issues based on SENS.

Additionally, SENS has been recognized as a structure within governmental documents outlining the PC strategy for Switzerland including ACP. ${ }^{28,29}$ Moreover, SENS has been acknowledged as an assessment instrument ("palliatives Basisassessment") within the SwissDRG system enabling the reimbursement of services provided by healthcare professionals in the context of palliative care (triggering the so called "palliative care complex code")..30,31 


\section{References}

1. Fliedner MC, Mitchell G, Bueche D, Mettler M, Schols JMGA, Eychmueller S. Development and Use of the 'SENS'-Structure to Proactively Identify Care Needs in Early Palliative Care-An Innovative Approach. Healthcare (Basel). 2019;7(1). doi 10.3390/healthcare7010032.

2. Ferrell BR, Temel JS, Temin S, Alesi ER, Balboni TA, Basch EM, et al. Integration of Palliative Care Into Standard Oncology Care: American Society of Clinical Oncology Clinical Practice Guideline Update. J Clin Oncol. 2017;35(1):96-112. doi 10.1200/ JCO.2016.70.1474.

3. Fliedner M, Zambrano S, Schols JM, Bakitas M, Lohrmann C, Halfens RJ, et al. An early palliative care intervention can be confronting but reassuring: A qualitative study on the experiences of patients with advanced cancer. Palliat Med. 2019;33(7):783-92. doi $10.1177 / 0269216319847884$.

4. Eychmüller S, Zwahlen S, Fliedner MC, Jüni $P$, Aebersold DM, Aujesky D, et al. Single early palliative care intervention added to usual oncology care for patients with advanced cancer: A randomized controlled trial (SENS Trial). Palliative Medicine. 2021;0(0):02692163211005340. doi 10.1177/02692163211005340.

5. Fliedner M, Willener R. A case study: Concurrent palliative care based on SENS structure for patients with advanced prostate cancer. International Journal of Urological Nursing. 2020;14(2):92-5. doi 10.1111/ijun.12232.

6. Zambrano SC, Fliedner MC, Eychmuller S. The impact of early palliative care on the quality of care during the last days of life: what does the evidence say? Curr Opin Support Palliat Care. 2016;10(4):310-5. doi 10.1097/SPC.0000000000000240.

7. Fliedner M, Halfens RJG, King CR, Eychmueller S, Lohrmann C, Schols JMGA. Roles and Responsibilities of Nurses in Advance Care Planning in Palliative Care in the Acute Care Setting: A Scoping Review. J Hosp Palliat Nurs. 2021;23(1):59-68. doi 10.1097/ $\mathrm{NJH} .0000000000000715$.

8. Fliedner MC, Hagemann M, Eychmuller S, King C, Lohrmann C, Halfens RJG, et al. Does Time for (in)Direct Nursing Care Activities at the End of Life for Patients With or Without Specialized Palliative Care in a University Hospital Differ? A Retrospective Analysis. Am J Hosp Palliat Care. 2020;37(10):844-52. doi 10.1177/1049909120905779.

9. Fliedner M, Zambrano S, Eychmueller S. Public Perception of Palliative Care: a Population-based Survey. Palliative Care and Social Practice. accepted for publication 22.04.2021. doi

10. World Health Organization (WHO), Study Group on Multiprofessional Education of Health Personnel: the Team Approach. Learning together to work together for health : report of a WHO Study Group on Multiprofessional Education of Health Personnel: the Team Approach [meeting held in Geneva from 12 to 16 October 1987]. Geneva: World Health Organization; 1988.

11. Willener R, Fliedner M. The SENS@ structure for assessment and management of uro oncological patients with severe acute symptoms who wish to die at home. Congress of the European Association of Urology Nurses; Barcelona 2019. 
12. Fliedner M, Zambrano S, Lohrmann C, Schols J, Halfens R, Eychmueller S, editors. Cancer patients' experiences with an early palliative care conversation: A qualitative study of an intervention based on the SENS-structure MASCC/ISOO Annual Meeting; 2018; Vienna.

13. Fliedner $M$, editor Palliative care challenges for urological patients at the end of life. 19th International Meeting of the European Association of Urology Nurses (EAUN); 2018; Copenhagen.

14. Fliedner M. Entscheidungen für das Lebensende. Bevölkerungsakademie; Bern, Biel: Palliative bern; 2018.

15. Fliedner M, Eychmueller S, Zambrano S, editors. How do people's expectations for their own end of life connect with their perceptions of palliative care? Learning opportunities for the promotion of early palliative care. EAPC; 2018; Bern.

16. Zwahlen S, Fliedner M, Eychmüller S. Overcoming Recruitment Challenges in a Randomized Clinical Trial of Early Palliative Care. 10th World Research Congress of the European Association for Palliative Care; Bern 2018.

17. Eychmüller S, Zwahlen S, Fliedner M, Trelle S, Maessen M, Aebersold D, et al., editors. A Structured Early Palliative Care Intervention for Patients with Advanced Cancer - A Randomized Controlled Trial EAPC; 2018; Bern.

18. Fliedner M. Die frühzeitige Einbindung von Palliative Care in den Patientenpfad macht Sinn - Was meint die Pflegeexpertin? 4 Symposium Palliativmedizin im Netzwerk der von der Deutschen Krebshilfe geförderten Comprehensive Cancer Center; Hamburg 2017.

19. Fliedner MC, Eychmüller S, Zambrano S, Lohrmann C, Schols JMGA, Halfens RJG, editors. How do cancer patients experience a structured early palliative care intervention? A qualitative study. EAPC; 2017; Madrid.

20. Fliedner M. Frühzeitiger Einbezug der Palliative Care bei PatientInnen mit Krebs verleiht das Sicherheit oder erzeugt es Angst? Internationales Seminar "Onkologische Pflege - Fortgeschrittene Praxis“; St.Gallen 2017.

21. Fliedner $M$, Eychmueller S. Recruitment of cancer patients into clinical trials on Advance Care Planning in Palliative Care - why is it so hard? ACPEL; München 2015.

22. Eychmueller S, Fliedner M. "SENS" framework to structure Advance Care Planning strengthening patient professionals partnership. ACPEL; München 2015.

23. Fliedner M, Eychmüller S, Lohrmann C, Schols JMGA, Halfens RJG. Inclusion of patients into clinical trials in Palliative Care - barriers and facilitating factors for successful recruitment/retention. EDCNS; Maastricht 2014.

24. Fliedner M. The SENS-structure in clinical practice - an alternative to nursing diagnosis? DESO; St.Gallen 2013.

25. Bundesamt für Gesundheit (BAG), Bundesamt für Berufsbildung und Technologie (BBT). Nationales Bildungskonzept «Palliative Care und Bildung» Strategisches Grundlagenpapier (Empfehlungen). Bern: Bundesamt für Gesundheit (BAG) und Bundesamt für Berufsbildung und Technologie (BBT); 2012. 
26. Smith CB, Phillips T, Smith TJ. Using the New ASCO Clinical Practice Guideline for Palliative Care Concurrent With Oncology Care Using the TEAM Approach. Am Soc Clin Oncol Educ Book. 2017;37:714-23. doi 10.14694/EDBK_175474.

27. palliative bern. Basisdokumentation Netzwerk Betreuungsplan Palliative Care. Bern, Switzerland2019.

28. Bundesamt für Gesundheit (BAG), palliative ch. Gesundheitliche Vorausplanung mit Schwerpunkt «Advance Care Planning». Nationales Rahmenkonzept für die Schweiz. Bern, Switzerland: Eidgenössisches Departement des Innern EDI, Bundesamt für Gesundheit BAG, Direktionsbereich Gesundheitspolitik; 2018.

29. Bundesamt für Gesundheit (BAG), Schweizerische Konferenz der kantonalen Gesundheitsdirektorinnen und -direktoren (GDK), palliative ch. Rahmenkonzept Palliative Care Schweiz. Eine definitorische Grundlage für die Umsetzung der «Nationalen Strategie Palliative Care». Bern 2014.

30. SwissDRG. Abbildung spezieller Leistungsbereiche in der Version 4.0. 2014.

31. Bundesamt für Statistik (BFS). Rundschreiben für Kodiererinnen und Kodierer: 2017 / Nr. 2. 2017. 


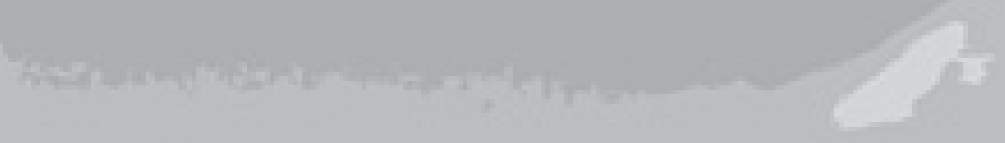

\section{Chas}
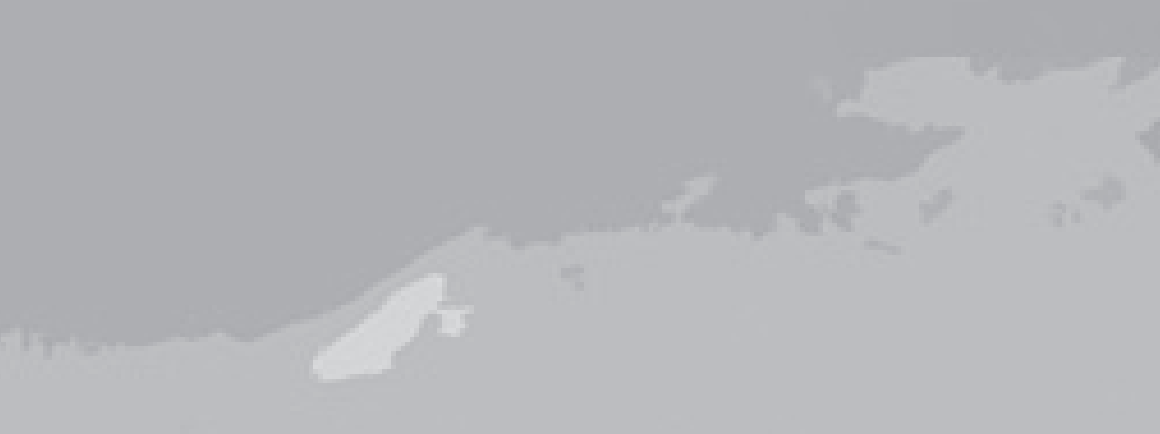

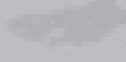

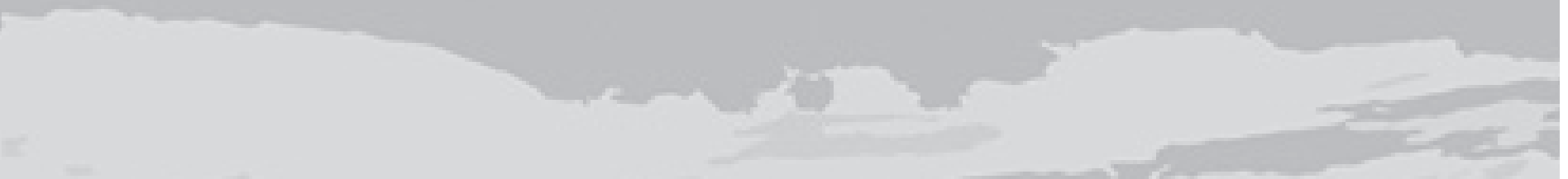

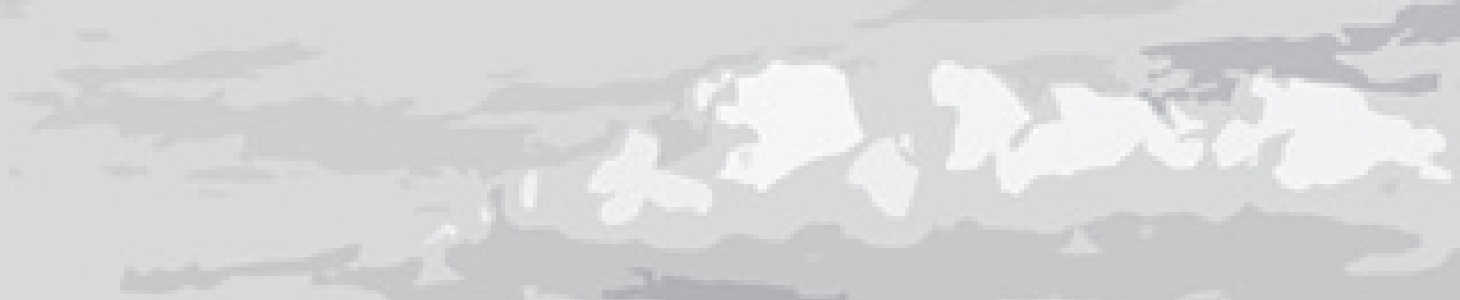

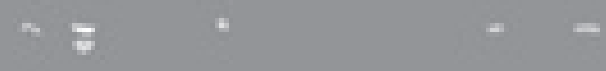

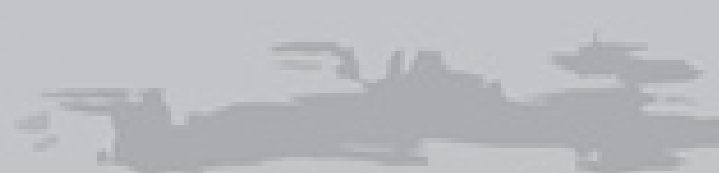

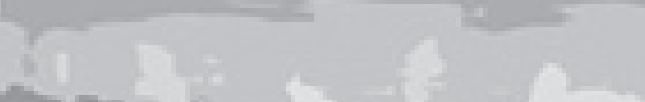

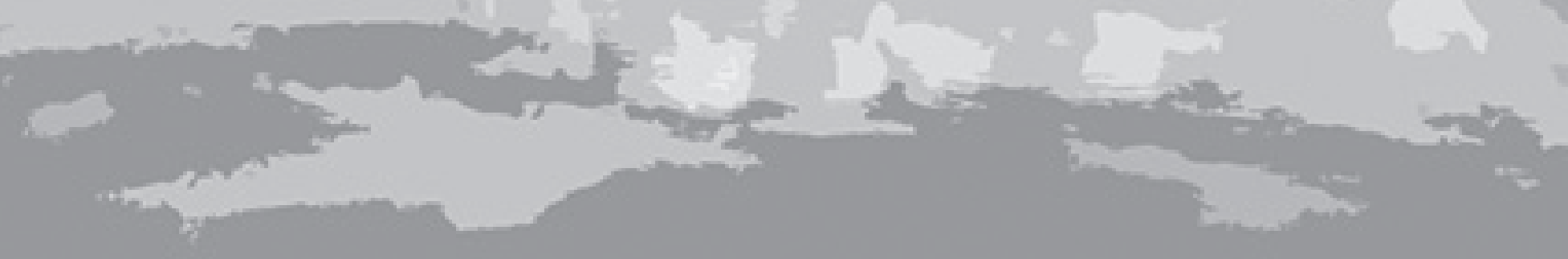


Summary 


\section{Summary}

Palliative care (PC) integrated early into the disease trajectory of adult patients with a life-limiting disease in the acute care setting is becoming state of the art. In the acute care setting the focus is often more on the disease and its physical aspects and medical strategies than on the quality of life and the worries and concerns of the individual patient. Early integrated PC tends to be a broader approach initiated early in the disease trajectory and includes supporting patients in dealing with the situation of the life-limiting disease. Based on current literature on $\mathrm{PC}^{1-6}$ it is proposed by several associations $\mathrm{s}^{7-9}$ to focus particularly on physical, psychological, social and spiritual needs of the person ${ }^{10}$. Nurses play an increasingly important role in facilitating early integration of the palliative care (EPC) approach and initiating the process of advance care planning ${ }^{11-14}(A C P)$ as one of its parts, for which nurses need adequate training.

The overall aim of this thesis was to provide and deepen knowledge regarding content and timing of EPC in the disease trajectory of patients with a life limiting disease in the acute care setting. In addition, the thesis expands knowledge on the role of nurses specifically in ACP as part of EPC. An exemplary clinical case report showed that patients need a structure to discuss the many issues of a life-limiting disease with the healthcare professionals. In addition, the case report revealed that nurses are uncertain regarding their role, responsibilities and about themes discussed in EPC. This thesis therefore deals with the following issues:

- Development of the so-called SENS-structure (symptoms, end-of-life decisions, network, and support) as a thematic structure for EPC and its clinical value from the perspective of professionals in the acute clinical setting (Chapter 2);

- Appraisal of the existing evidence on EPC, its relationship with ACP, and the impact of EPC on the quality of care provided during the last days of life (Chapter 3);

- Exploration of the perception and experiences of patients with advanced cancer undergoing a structured EPC conversational intervention based on SENS and its acceptability and impact on patients' lives (Chapter 4);

- Identification of specific roles and responsibilities of undergraduate nurses (RNs) and (post)graduate nurses (APRNs) involved in the ACP process in the acute care setting, including the themes related to ACP as discussed by 
RNs and/or APRNs and necessary skills and/or educational requirements (Chapter 5);

- Comparison of the overall time spent for direct / indirect nursing care activities for dying patients who received usual (general) PC compared to patients who received additional specialized PC based on SENS and to find out whether the time spent for direct / indirect care in the group of patients who received specialized PC changes before and after specialized PC (Chapter 6);

- Illustration of how the SENS-structure to support PC interventions can be applied in clinical practice in an exemplary case report of a cancer patient (Chapter 7).

The specific focus of this thesis is twofold, first on patients and families (Chapters 3 and 4) and secondly on RNs and APRNs (Chapters 5 and 6).

After an exemplary clinical case report, which points at the challenges of a patient with a life-limiting disease and nurses caring for similar patient populations Chapter 1 introduces the background to the thesis and the issues derived from the case report. A literature-based definition of EPC and ACP in relation to endof-life care provides a basis for the use of the terminology in the context of this thesis.

A lack of an effective but still easy-to-use thematic structure in the acute care setting to detect and prioritize areas of concern without overburdening patients and caregivers was identified in the literature. Chapter $\mathbf{2}^{15}$ describes the process of how an interprofessional PC team developed the SENS-structure, a thematic structure in the context of PC conversations between healthcare professionals and patients that can be useful early in the trajectory of a lifelimiting disease next to disease specific measures. The Medical Research Council's (MRC) framework ${ }^{16}$ was used for a hospital wide quality enhancement project. After identifying relevant PC structures in the literature and evaluating these for potential usefulness in the acute care setting, a preliminary structure was developed based on the Swiss National Strategy and national framework for $\mathrm{PC}^{17,18}$ and an analysis of more than 500 hospital-based interprofessional PC consultations. Thematic clusters formed the SENS-structure, which was tested by professionals in the acute care setting. The SENS-structure supports the focus on all aspects of $\mathrm{PC}$ as defined by the $\mathrm{WHO}^{10}$. A survey among healthcare professionals $(\mathrm{N}=57)$ using the SENS-structure in the hospital and outpatient 
acute care setting showed that SENS is an easy-to-use structure that is suitable throughout all phases of the disease trajectory of patients with a life-limiting disease. Healthcare professionals found some themes within SENS challenging to discuss, especially when patients hesitate talking about themes such as death and dying. By exploring the clinical value of the SENS-structure, the authors demonstrated its usefulness for planning, documentation, evaluation, and education primarily in the acute clinical setting from the perspective of healthcare professionals.

Chapter $\mathbf{3}^{19}$ provides a critical appraisal of the existing literature on early integrated palliative care, its relationship with ACP, and the impact of EPC on the quality of care provided during the last days of life. The aim was to find a timeframe for the early integration of PC, which was described as a minimum of three months prior to the assumed death of a patient with a life-limiting disease. In addition, a correlation between EPC and the ACP process was outlined. As part of EPC, ACP is seen as a process, in which the wishes and preferences of patients regarding their decisions and autonomy are continuously discussed and strived to be met irrespective of the timing and disease entity. Results support the early integration into the disease trajectory of patients with a life-limiting disease.

Despite a diversity of the investigated patient populations and healthcare systems and providers, the literature showed that EPC is commonly provided by a specialist PC team. Since not all acute care institutions have a specialized team at their disposal, general PC knowledge and skills should be available to be able to integrate PC into clinical practice. The specialized PC team can be consulted when the situation becomes complex. While the effective component of the EPC intervention is not yet well-defined, studies point at its positive effects on patients. These include but are not limited to improved symptoms and quality of life, including lower levels of depression and distress, higher satisfaction with communication and care, higher adherence with their preferred place of death and lower healthcare costs during the last days of life. If the themes of the EPC conversation are based on patients' agenda, EPC and the process of ACP could contribute to a perceived good death.

To better understand whether the use of the SENS-structure supports patients with a life-limiting disease in engaging in conversations about their concerns and issues, the authors explored in Chapter $4^{20}$ patients' perceptions and experiences of a SENS-structured EPC conversation and aimed to determine its acceptability and impact on patients' lives including influencing factors. For 
this study, the authors interviewed patients with various types of advanced cancer not amenable to curative treatment in the acute care setting. Findings were based on semi-structured, in-depth interviews with 20 patients who underwent the SENS-structured conversational intervention as a part of a larger randomized controlled trial. ${ }^{21}$ Some patients mentioned that it was the first time that healthcare professionals discussed not only physical issues, but also psychological, social or spiritual themes, end-of-life decisions, their professional and private network and support for their network. It showed that this kind of conversation could provoke emotions and could confront patients with the finiteness of life. For others it was a relief to be able to talk to a professional about their concerns and fears but also hopes and future care. Patients also stated that the themes of the SENS-structure covered their concerns. This facilitated conversations within the family about their future. Some patients lost their fear towards receiving "palliative care" even though they still associated the term with their end of life.

Patients appreciate proactive conversations with healthcare providers including RNs and APRNs about future healthcare decisions concurrent to diagnosis-related treatment approaches before they lose their decision-making capacity. Therefore, the question arose which specific roles and responsibilities RNs and/or APRNs have in this process, for which themes they are responsible and what educational background they require. The scoping review in Chapter $5^{22}$ revealed that RNs and/or APRNs in the acute care setting have a core role and specific responsibilities when involved in the ACP process. These include but are not limited to facilitating ACP conversations, advocating for patients' wishes and discussing specific themes. These themes include e.g. medical information about disease and treatment options, patients' personal view on life, treatment wishes and goals of care for the future including place of care, and how to communicate patients' values and wishes. In order to perform their roles and be able to engage in or facilitate ACP conversations, RNs' and/ or APRNs' need appropriate education and skills. This education should be based on a theoretical foundation of the PC approach and include topics such as communication competencies used to engage in ACP conversations, and knowledge about legal issues and regulations around end of life care. Based on their advanced training and knowledge, APRNs seem to be in the best position to not only be involved in these conversations but also to lead family meetings and guide patients towards advance directives. 
Based on nurses' training and knowledge of basic end-of-life care it can be assumed that nurses can handle most of these situations providing usual (general) PC (UPC). If the palliative/end-of-life situation becomes too complex and unmanageable (e.g., uncontrollable symptoms, multifaceted family situations, wish to hasten death), the care team may request support by a specialized palliative care (SPC) team. Chapter $\mathbf{6}^{23}$ investigated in a retrospective observational study how the SENS-structured intervention ${ }^{15}$ by a specialized PC team impacts the direct (e.g., performance of care procedures) and indirect (on behalf of the patient e.g. coordination of care) nursing care time for patients at the end of life. The authors aimed to assess the direct and indirect care time of RNs caring for patients who died in a tertiary hospital in Switzerland and to compare the overall time spent for direct / indirect nursing care activities for dying patients who received UPC as compared to patients who received in addition SPC. The authors also wanted to find out whether the time spent for direct / indirect care in the SPC group of patients changed before and after SPC. Nurses document daily all their care activities in an electronic controlling system called $\operatorname{tacs}^{\circledR}$ (Task Analysis and Controlling System for staff resources) distinguishing between direct / indirect care activities in minutes covering the 24 hours of the day. Findings were based on $\operatorname{tacs}^{\circledR}$ data of 746 patients who died within one year in a tertiary care hospital of which 104 patients received an additional SPC intervention based on SENS. Results revealed that patients who received additional SPC needed overall significantly more direct / indirect nursing care time than patients who received UPC. Adjusted with the propensity score for specific parameters it was assumed that this was because SPC patients overall stayed longer in the hospital. When looking at the trajectory of patients who received SPC the authors learned that on the day of the SPC intervention nurses needed significantly more time for indirect nursing care activities (e.g. coordination of care). In addition, nurses spent more time for direct care activities after the intervention.

Chapter $\mathbf{7}^{24}$ describes - based on a second clinical case report - the impact of the SENS-based PC intervention ${ }^{15}$, in which the team discusses with a patient with prostate cancer and his family in an acute care setting the management of (current or potential) symptoms and expectations and end-of-life decisions including ACP, as well as assesses patients' social network and sources to support them. Concurrent to disease specific measures, the specialized PC team guided the care team in treatment and care decisions using the SENS-structure. 
The SENS-structure was useful in breaking down the concerns and issues of the patient into manageable parts as well as defining tasks and responsibilities of patients, family carers and the interprofessional team: The SENS-structure helped to set up an interprofessional care plan which takes into consideration patients' wishes, values and concerns.

Chapter 8 provides a summary of all findings generated by the studies included in this thesis. A discussion and interpretation of the findings is followed by an outline of the implications for practice in the acute care setting, nursing education such as themes relevant for PC in the acute care setting, the timing of EPC including ACP and the nurses' role and responsibilities in ACP. Theoretical and methodological issues as well as limitations and strengths are considered. Future research areas in the field of EPC including ACP such as a deeper insight into what themes, for whom, when, and by whom it should be offered and its respective outcomes are outlined.

Lastly, chapter 9 summarizes the scientific impact of the conducted research projects and its relevancy to the nursing profession in the acute care setting. It includes also the social implications as well as challenges relevant to patients, healthcare professionals, nursing education and nursing management. 


\section{References}

1. Hausner D, Tricou C, Mathews J, Wadhwa D, Pope A, Swami N, et al. Timing of Palliative Care Referral Before and After Evidence from Trials Supporting Early Palliative Care. Oncologist. 2020. doi 10.1002/onco.13625.

2. Gartner J, Daun M, Wolf J, von Bergwelt-Baildon M, Hallek M. Early Palliative Care: Pro, but Please Be Precise! Oncol Res Treat. 2019;42(1-2):11-8. doi 10.1159/000496184.

3. Radbruch $L$, Becher $U$, Hesse M. Early integration of palliative care for patients with chronic and progressiv cardiac insufficiency. MMW Fortschr Med. 2020;162(18):43-7. doi 10.1007/s15006-020-4374-z.

4. Scheerens C, Pype P, Van Cauwenberg J, Vanbutsele G, Eecloo K, Derom E, et al. Early Integrated Palliative Home Care and Standard Care for End-Stage COPD (EPIC): A Phase II Pilot RCT Testing Feasibility, Acceptability, and Effectiveness. J Pain Symptom Manage. 2020;59(2):206-24 e7. doi 10.1016/j.jpainsymman.2019.09.012.

5. Tilburgs B, Koopmans R, Schers H, Smits C, Vernooij-Dassen M, Perry M, et al. Advance care planning with people with dementia: a process evaluation of an educational intervention for general practitioners. BMC Fam Pract. 2020;21(1):199. doi 10.1186/ s12875-020-01265-z.

6. Janssens A, Teugels L, Kohl S, Michielsen T, Leysen B, van Meerbeeck JP. Practical tools for implementing early palliative care in advanced lung cancer. Eur Respir $\mathrm{J}$. 2016;47(3):1010-2. doi 10.1183/13993003.00382-2015.

7. Ferrell BR, Temel JS, Temin S, Alesi ER, Balboni TA, Basch EM, et al. Integration of Palliative Care Into Standard Oncology Care: American Society of Clinical Oncology Clinical Practice Guideline Update. J Clin Oncol. 2017;35(1):96-112. doi 10.1200/ JCO.2016.70.1474.

8. Hill L, Prager Geller T, Baruah R, Beattie JM, Boyne J, de Stoutz N, et al. Integration of a palliative approach into heart failure care: a European Society of Cardiology Heart Failure Association position paper. Eur J Heart Fail. 2020;22(12):2327-39. doi 10.1002/ ejhf.1994.

9. Canadian Council of Cardiovascular Nursing (CCCN). Advance Care Planning and the Role of the Cardiovascular Nurse Position Statement. 2015.

10. World Health Organization (WHO). Definition Palliative Care World Health Organization; 2002 [Available from: http://www.who.int/cancer/palliative/definition/ en/. Accessed 16.02.2014.

11. Miller H, Tan J, Clayton JM, Meller A, Hermiz O, Zwar N, et al. Patient experiences of nurse-facilitated advance care planning in a general practice setting: a qualitative study. BMC Palliat Care. 2019;18(1):25. doi 10.1186/s12904-019-0411-z.

12. Izumi S, Burt M, Smith J, McCord K, Fromme EK. Enhancing Advance Care Planning Conversations by Nurses in a Bone Marrow Transplantation Unit. Oncol Nurs Forum. 2019;46(3):288-97. doi 10.1188/19.ONF.288-297.

13. Houben CHM, Spruit MA, Luyten H, Pennings HJ, van den Boogaart VEM, Creemers $\mathrm{J}$, et al. Cluster-randomised trial of a nurse-led advance care planning session in patients with COPD and their loved ones. Thorax. 2019;74(4):328-36. doi 10.1136/ thoraxjnl-2018-211943. 
14. Hilgeman MM, Uphold CR, Collins AN, Davis LL, Olsen DP, Burgio KL, et al. Enabling Advance Directive Completion: Feasibility of a New Nurse-Supported Advance Care Planning Intervention. J Gerontol Nurs. 2018;44(7):31-42. doi 10.3928/0098913420180614-06.

15. Fliedner MC, Mitchell G, Bueche D, Mettler M, Schols JMGA, Eychmueller S. Development and Use of the 'SENS'-Structure to Proactively Identify Care Needs in Early Palliative Care-An Innovative Approach. Healthcare (Basel). 2019;7(1). doi 10.3390/healthcare7010032.

16. Medical Research Council (MRC). A Framework For Development and Evaluation of RCTs For Complex Interventions to Improve Health. London, UK 2000.

17. Bundesamt für Gesundheit (BAG), Schweizerische Konferenz der kantonalen Gesundheitsdirektorinnen und -direktoren (GDK). Nationale Strategie Palliative Care 2010-2012. Bern: Bundesamt für Gesundheit (BAG), Gesundheitspolitik D, Projekte AM; 2009. http://www.gdk-cds.ch/fileadmin/docs/public/gdk/themen/strategie_ bundkantone/palliativecare/bt_nationale_strategie_palliative_care_2010-2012_d. pdf.

18. Bundesamt für Gesundheit (BAG), Schweizerische Konferenz der kantonalen Gesundheitsdirektorinnen und -direktoren (GDK), palliative ch. Rahmenkonzept Palliative Care Schweiz. Eine definitorische Grundlage für die Umsetzung der «Nationalen Strategie Palliative Care». Bern2014.

19. Zambrano SC, Fliedner MC, Eychmuller S. The impact of early palliative care on the quality of care during the last days of life: what does the evidence say? Curr Opin Support Palliat Care. 2016;10(4):310-5. doi 10.1097/SPC.0000000000000240.

20. Fliedner M, Zambrano S, Schols JM, Bakitas M, Lohrmann C, Halfens RJ, et al. An early palliative care intervention can be confronting but reassuring: A qualitative study on the experiences of patients with advanced cancer. Palliat Med. 2019;33(7):783-92. doi $10.1177 / 0269216319847884$.

21. Eychmuller S, Zwahlen S, Fliedner MC, Juni P, Aebersold DM, Aujesky D, et al. Single early palliative care intervention added to usual oncology care for patients with advanced cancer: A randomized controlled trial (SENS Trial). Palliat Med. 2021;35(6):1108-17. doi 10.1177/02692163211005340.

22. Fliedner M, Halfens RJG, King CR, Eychmueller S, Lohrmann C, Schols JMGA. Roles and Responsibilities of Nurses in Advance Care Planning in Palliative Care in the Acute Care Setting: A Scoping Review. J Hosp Palliat Nurs. 2021;23(1):59-68. doi 10.1097/ $\mathrm{NJH} .0000000000000715$.

23. Fliedner MC, Hagemann M, Eychmuller S, King C, Lohrmann C, Halfens RJG, et al. Does Time for (in)Direct Nursing Care Activities at the End of Life for Patients With or Without Specialized Palliative Care in a University Hospital Differ? A Retrospective Analysis. Am J Hosp Palliat Care. 2020;37(10):844-52. doi 10.1177/1049909120905779.

24. Fliedner M, Willener R. A case study: Concurrent palliative care based on SENSstructure for patients with advanced prostate cancer. Int J Urol Nurs. 2020;14(2):92-5. doi 10.1111/ijun.12232. 
Samenvatting 


\section{Samenvatting}

Vroegtijdige integratievan PalliatieveZorg(PZ)in hetziektetrajectvanvolwassenen met een ongeneeslijke ziekte wordt binnen de acute zorg toenemend als de norm voor moderne zorgverlening gezien. In de acute zorgsector ligt de focus vaak meer op de ziekte, de fysische aspecten en medische strategieën dan op de levenskwaliteit en de zorgen of het welzijn van de persoon. Vroegtijdige integratie van PZ betekent het op een zo vroeg mogelijk moment initiëren van een bredere ondersteuning van ongeneeslijke zieke patiënten bij het omgaan met hun problemen en zorgen binnen hun ziektetraject. Op basis van de actuele PZ literatuur ${ }^{1-6}$ wordt door verschillende organisaties $^{7-9}$ geadviseerd om in het bijzonder te focussen op de fysieke, psychologische, sociale en spirituele behoeften van de persoon ${ }^{10}$.

Verpleegkundigen spelen een steeds belangrijker wordende, ondersteunende rol bij vroegtijdig geïntegreerde PZ (early integrated palliative care $=E P C$ ) en zo ook bij het initiëren van het proces van advance care planning ${ }^{11-14}$ (ACP) als onderdeel daarvan. Om deze rol goed uit te kunnen voeren hebben verpleegkundigen een adequate opleiding nodig om hiervoor de juiste competenties te verwerven.

De doelstelling van dit proefschrift was het weergeven en uitdiepen van kennis met betrekking tot de inhoud en het tijdstip van EPC in het ziektetraject van patiënten met een ongeneeslijke ziekte in de acute zorgsector. Bovendien voegt dit proefschrift specifieke kennis toe over de rol van verpleegkundigen in het ACP-proces als onderdeel van EPC. Een beschrijving van een klinische casus liet zien dat patiënten een gestructureerde gespreksleidraad nodig hebben om de vele kwesties die een ongeneeslijke ziekte met zich meebrengt met zorgprofessionals te bespreken. Bovendien bleek uit de klinische casus dat verpleegkundigen onzeker zijn over hun rol, verantwoordelijkheden en de onderwerpen, die binnen EPC besproken moeten worden. In dit proefschrift komen daarom de volgende onderwerpen aan de orde:

- Ontwikkeling van de zogenoemde SENS-structuur (Duits acroniem voor symptomen, beslissingen rondom het levenseinde, netwerk, en support) als een thematische structuur voor EPC en de klinische waarde ervan, gezien vanuit het perspectief van professionals in de acute zorgsetting (Hoofdstuk 2); 
- Beoordeling van de bestaande wetenschappelijke bewijzen over de werkzaamheid van EPC, het verband met ACP, en de invloed van EPC op de kwaliteit van de zorg tijdens de laatste levensdagen (Hoofdstuk 3);

- Onderzoek naar de perceptie en ervaringen van patiënten met kanker in een vergevorderd stadium die een gestructureerde gespreksinterventie gebaseerd op SENS ondergingen, de aanvaardbaarheid ervan en de invloed van deze interventie op hun leven (Hoofdstuk 4);

- Identificatie van specifieke rollen en verantwoordelijkheden van gediplomeerde verpleegkundigen (registered nurses $=R N s$ ) en verpleegkundig specialisten/nurse practitioners op post-Hbo-niveau (Advance Practice Registered Nurses $=$ APRNs) die betrokken zijn bij het ACP-proces in de acute zorgsetting. Dit betreft ook de onderwerpen met betrekking tot ACP zoals besproken door RNs en/of APRNs en de noodzakelijke vaardigheden en/of opleidingseisen daarvoor. (Hoofdstuk 5);

- Vergelijking van de totaal bestede tijd aan directe/indirecte reguliere verpleegkundige $\mathrm{PZ}$ zorg voor stervende patiënten met de tijd die besteed wordt aan patiënten die tevens gespecialiseerde PZ kregen op basis van SENS; inclusief onderzoek naar de verandering van de tijd besteed aan directe/indirecte zorg in de groep van patiënten voor en na gespecialiseerde PZ (Hoofdstuk 6);

- Een illustratie hoe de SENS-structuur ter ondersteuning van PZ-interventies kan worden toegepast in de klinische praktijk aan de hand van een klinische casus van een patiënt gediagnosticeerd met kanker (Hoofdstuk 7).

Deze thesis focust op zowel patiënten en hun families (Hoofdstuk 3 en 4) als op RNs en APRNs (Hoofdstuk 5 en 6).

$\mathrm{Na}$ een klinische casus, die wijst op de ervaringen van zowel een patiënt met een ongeneeslijke ziekte als van verpleegkundigen die voor vergelijkbare patiënten zorgen, introduceert Hoofdstuk $\mathbf{1}$ de achtergrond van deze thesis en de kwesties die uit de casus naar voren komen. Een op de literatuur gebaseerde definitie van EPC en ACP in relatie tot de zorg voor patiënten aan het levenseinde vormt de basis voor het gebruik van de terminologie in de context van dit proefschrift.

De literatuur toonde een gebrek aan een doeltreffende maar toch gemakkelijk te gebruiken thematische structuur in de acute zorgsetting om probleemgebieden op te sporen en prioriteiten te stellen zonder de patiënten 
en de zorgverleners te overbelasten. Hoofdstuk $\mathbf{2}^{15}$ beschrijft hoe een interprofessioneel PZ-team de SENS-structuur heeft ontwikkeld. Dit betreft een thematische structuur voor PZ-gesprekken tussen zorgverleners en patiënten, welke al vroeg in het traject van een ongeneeslijke ziekte gebruikt kan worden naast ziekte-specifieke maatregelen. Het Medical Research Council's (MRC) framework ${ }^{16}$ werd gebruikt voor een kwaliteitsverbeteringsproject in een ziekenhuis. $\mathrm{Na}$ het identificeren van relevante PZ-structuren in de literatuur en het evalueren daarvan op de potentiële bruikbaarheid in de acute zorgsetting, werd een voorlopige structuur ontwikkeld, gebaseerd op de Zwitserse Nationale Strategie voor $\mathrm{PZ}{ }^{17,18}$ en een analyse van meer dan 500 interprofessionele PZconsultaties in ziekenhuizen. Thematische clusteranalyse bepaalde de SENSstructuur die vervolgens door professionals in de acute zorg werd getest. De SENS-structuur waarborgt aandacht voor alle aspecten van PZ zoals gedefinieerd door de Wereldgezondheidsorganisatie ${ }^{10}$. Een onderzoek met een vragenlijst onder zorgverleners in een ziekenhuis of in de ambulante zorg $(\mathrm{N}=57)$ die de SENS-structuur gebruikten, toonde aan dat SENS een gemakkelijk te gebruiken structuur is, die geschikt is voor alle fasen van het ziektetraject van patiënten met een ongeneeslijke ziekte. Zorgverleners vonden bepaalde onderwerpen binnen SENS moeilijk om te bespreken, vooral wanneer patiënten aarzelden om over deze onderwerpen te spreken, zoals over de dood en het sterven. De auteurs toonden de bruikbaarheid van de SENS-structuur aan voor de planning, documentatie, evaluatie en het onderwijs, vanuit het perspectief van de zorgverleners en de acute klinische setting.

Hoofdstuk $3^{19}$ geeft een kritische beoordeling van de bestaande literatuur over vroegtijdig geïntegreerde $\mathrm{PZ}$, de relatie met ACP en de invloed van EPC op de kwaliteit van zorg die tijdens de laatste levensdagen wordt verleend. Het doel was om een ideaal markeringspunt te vinden voor de start van vroegtijdige integratie van PZ. Dit punt werd omschreven als ten minste drie maanden vóór het veronderstelde overlijden van een patiënt met een ongeneeslijke ziekte. Bovendien werd een correlatie gesuggereerd tussen EPC en het ACP-proces. Als onderdeel van EPC wordt ACP gezien als een proces waarin de wensen en voorkeuren van de patiënten met betrekking tot hun beslissingen en autonomie voortdurend worden besproken en ernaar wordt gestreefd dat hieraan wordt voldaan, ongeacht het tijdstip en de achterliggende ziekte. De resultaten ondersteunen de vroege integratie in het ziektetraject van patiënten met een ongeneeslijke ziekte. 
Ondanks de diversiteit van de onderzochte patiëntenpopulaties, de verschillende gezondheidssystemen en zorgverleners, toonde de literatuur aan dat EPC over het algemeen wordt toegepast door een gespecialiseerd PZteam. Aangezien niet alle acute zorginstellingen over een gespecialiseerd team beschikken, zou algemene kennis en vaardigheden over PZ beschikbaar moeten zijn om goede PZ in de klinische praktijk te kunnen integreren. Een gespecialiseerd PZ-team kan vervolgens worden geraadpleegd indien de situatie complex wordt. Hoewel de effectieve component van EPC nog niet goed is gedefinieerd, wijzen studies op de positieve effecten ervan op patiënten. Deze omvatten, maar zijn niet beperkt tot, de verbetering van de symptomen en levenskwaliteit zoals minder voorkomen van depressies en stresstoestanden, hogere tevredenheid met de communicatie en verzorging, hogere naleving van patiëntenvoorkeuren voor de plaats van overlijden en lagere kosten voor gezondheidszorg tijdens de laatste levensdagen. Als de onderwerpen van het EPC-gesprek gebaseerd zijn op de agenda van de patiënt zouden EPC en het ACP-proces kunnen bijdragen tot een als goed ervaren sterfproces.

Om beter te begrijpen of het gebruik van de SENS-structuur patiënten met een ongeneeslijke ziekte ondersteunt bij het voeren van gesprekken over hun zorgen en problemen exploreerden de auteurs in Hoofdstuk $4^{20}$ de perceptie en ervaringen van patiënten met een gesprek conform de SENS-structuur en de aanvaardbaarheid en het effect op hun leven, met inbegrip van het bepalen van beïnvloedende factoren. Voor deze studie interviewden de auteurs patiënten met verschillende soorten kanker in een gevorderd stadium die niet in aanmerking kwamen voor een curatieve behandeling in de acute zorgsetting. De resultaten waren uiteindelijk gebaseerd op semigestructureerde diepte-interviews met 20 patiënten die de SENS-gestructureerde gespreksinterventie ondergingen als onderdeel van een groter gerandomiseerd gecontroleerd onderzoek. ${ }^{21}$ Sommige patiënten vermeldden dat het de eerste keer was dat zorgverleners niet alleen over lichamelijke kwesties spraken, maar ook over psychologische, sociale of spirituele thema's, beslissingen rond het levenseinde, hun professionele en persoonlijke netwerk en de steun voor hun netwerk. Hieruit bleek dat een dergelijk gesprek emoties kan oproepen en patiënten kan confronteren met de eindigheid van het leven. Voor anderen was het een opluchting om met professionals te kunnen praten over hun zorgen en angsten maar ook over hun hoop en toekomstige zorg. Patiënten verklaarden ook dat onderwerpen van de SENS-structuur hun zorgen en behoeften dekten. Dit vergemakkelijkte ook de 
gesprekken binnen de familie over hun toekomst. Sommige patiënten verloren hun angst voor het krijgen van "palliatieve zorg" ook al associeerden ze dit begrip nog steeds met hun levenseinde.

Patiënten stellen proactieve gesprekken over toekomstige beslissingen op prijs die samenhangen met de zorg die ze krijgen en diagnosegerelateerde behandelingsbenaderingen. Ze waarderen deze anticiperende gesprekken met zorgverleners, waaronder RN's en APRN's, voordat zij zelf hun besluitvaardigheid verliezen. Daarom ontstond de vraag welke specifieke rollen en verantwoordelijkheden RNs en/of APRNs in dit proces hebben, voor welke onderwerpen zij verantwoordelijk zijn en welke opleiding ervoor nodig is. Uit de scoping review in hoofdstuk $\mathbf{5}^{22}$ is gebleken dat RNs en/of APRNs in de acute zorgsetting een centrale rol en specifieke verantwoordelijkheden hebben wanneer zij betrokken zijn in het ACP-proces. Deze omvatten, maar zijn niet beperkt tot, het faciliteren van ACP-gesprekken, het opkomen voor de wensen van patiënten en het bespreken van specifieke onderwerpen, zoals bijvoorbeeld medische informatie over de ziekte en behandelingsmogelijkheden, het persoonlijke zicht van de patiënt op zijn leven, behandelwensen en zorgdoelen voor de toekomst, met inbegrip van de plaats van zorg, en ook hoe de waarden en wensen van patiënten over te brengen. Om hun rol te kunnen vervullen en om in staat te zijn goede ACP-gesprekken te voeren of te faciliteren, hebben RNs' en/of APRNs een passende opleiding en vaardigheden nodig. Deze opleiding zou gebaseerd moeten zijn op een theoretische basis van de PZ-benadering en zou onderwerpen moeten omvatten zoals communicatievaardigheden die gebruikt worden om ACP-gesprekken te voeren en kennis over wettelijke gegevens en regels over de zorg rond het levenseinde. Op basis van hun geavanceerde opleiding en kennis hebben APRNs een goede basis om niet alleen bij deze gesprekken betrokken te zijn, maar ook om familiebijeenkomsten te leiden en patiënten te ondersteunen in het schrijven van een wilsverklaring (advance directive).

Op basis van de opleiding van verpleegkundigen en hun kennis van de zorg voor patiënten aan het levenseinde kan eveneens worden aangenomen dat verpleegkundigen over het algemeen met deze situatie kunnen omgaan en algemene PZ (UPC = usual palliative care) kunnen toepassen. Als de palliatieve situatie of de situatie rond het levenseinde van de patiënt te complex en onbeheersbaar wordt (bijvoorbeeld bij niet controleerbare symptomen, gezinssituaties met veelvoudige dimensies, wensen om de dood te bespoedigen) 
kan het zorgteam om ondersteuning vragen aan een gespecialiseerd PZ $(S P C=$ specialized palliative care $)$ team. Hoofdstuk $6^{23}$ onderzocht in een retrospectieve observationele studie hoe de SENS-gestructureerde interventie ${ }^{15}$ door een gespecialiseerd PZ-team de directe (bijvoorbeeld het uitvoeren van zorghandelingen) en indirecte (bijvoorbeeld coördinatie van zorg namens de patiënt) verpleegkundige zorgtijd voor patiënten aan het einde van hun leven beïnvloedt. De auteurs wilden de directe en indirecte zorgtijd evalueren van RNs die patiënten verzorgden die overleden in een tertiair ziekenhuis in Zwitserland en ook de totale tijd die besteed werd aan directe/indirecte verpleegkundige zorgactiviteiten vergelijken voor stervende patiënten die UPC ontvingen in vergelijking met patiënten die daarnaast SPC ontvingen. De auteurs wilden ook weten of de tijd besteed aan directe/indirecte zorg in de SPC-groep van patiënten veranderde voor en na SPC. Verpleegkundigen in Zwitserland documenteren dagelijks hun zorgactiviteiten in een elektronisch controlesysteem, het tacs $^{\circledR}$ system genaamd (Task Analysis and Controlling System for staff resources) waarbij onderscheid wordt gemaakt tussen directe en indirecte zorgactiviteiten in minuten per 24 uur. De resultaten waren gebaseerd op $\operatorname{tacs}^{\circledR}$ gegevens van 746 patiënten die binnen een jaar overleden in een tertiair zorgziekenhuis, waarvan 104 patiënten een aanvullende SPC kregen op basis van SENS. ${ }^{15}$ De resultaten toonden aan dat patiënten die extra SPC kregen over het algemeen significant meer directe/indirecte verpleegkundige zorgtijd nodig hadden dan patiënten die UPC kregen. Gecorrigeerd met de propensity score voor specifieke parameters werd aangenomen dat dit kwam doordat SPC-patiënten over het algemeen langer in het ziekenhuis verbleven. Wanneer gekeken werd naar het traject van patiënten die SPC kregen, leerden de auteurs dat verpleegkundigen op de dag van de SPC-interventie significant meer tijd nodig hadden voor indirecte verpleegkundige zorgactiviteiten (bv. coördinatie van zorg). Bovendien besteedden verpleegkundigen na de interventie meer tijd aan directe zorgactiviteiten.

Hoofdstuk $7^{24}$ beschrijft - op basis van een tweede casus - het effect van de op SENS gebaseerde PZ-interventie ${ }^{15}$ waarin het team met een patiënt met prostaatkanker en zijn familie in een acute zorgsetting de (be)handelingen van (huidige of potentiële) symptomen, verwachtingen en beslissingen rond het levenseinde, inclusief ACP, bespreekt en het sociale netwerk van de patiënt en de bronnen om hem te ondersteunen, evalueert. Gelijktijdig met de ziektespecifieke maatregelen begeleidde het gespecialiseerde PZ-team met behulp 
van de SENS-structuur het zorgteam bij beslissingen over behandeling en zorg. De SENS-structuur was nuttig om de zorgen en problemen van de patiënt in hanteerbare delen op te splitsen en om de taken en verantwoordelijkheden van patiënten, mantelzorgers en het interprofessionele team vast te leggen: De SENS-structuur hielp bij het opstellen van een interprofessioneel zorgplan dat rekening houdt met de wensen, waarden en zorgen van de patiënt.

Hoofdstuk 8 geeft een overzicht van alle bevindingen uit de studies die in dit proefschrift zijn opgenomen. Een discussie en interpretatie van de bevindingen wordt gevolgd door een schets van de implicaties voor de praktijk in de acute zorg, de verpleegkundige opleiding, de timing van EPC inclusief ACP en de rol en verantwoordelijkheden van de verpleegkundigen bij ACP. Theoretische en methodologische kwesties, alsook beperkingen en sterke punten worden besproken. Toekomstige onderzoeksgebieden op het gebied van EPC inclusief ACP worden geschetst.

Tenslotte geeft hoofdstuk 9 een samenvatting van de wetenschappelijke impact van de uitgevoerde onderzoeksprojecten en de relevantie ervan voor het verpleegkundig beroep in de acute zorgsetting. Het omvat ook de sociale implicaties en uitdagingen die relevant zijn voor patiënten, zorgprofessionals, verpleegkundigen in opleiding en het verpleegkundig management. 


\section{Referenties}

1. Hausner D, Tricou C, Mathews J, Wadhwa D, Pope A, Swami N, et al. Timing of Palliative Care Referral Before and After Evidence from Trials Supporting Early Palliative Care. Oncologist. 2020. doi 10.1002/onco.13625.

2. Gartner J, Daun M, Wolf J, von Bergwelt-Baildon M, Hallek M. Early Palliative Care: Pro, but Please Be Precise! Oncol Res Treat. 2019;42(1-2):11-8. doi 10.1159/000496184.

3. Radbruch $L$, Becher $U$, Hesse M. Early integration of palliative care for patients with chronic and progressiv cardiac insufficiency. MMW Fortschr Med. 2020;162(18):43-7. doi 10.1007/s15006-020-4374-z.

4. Scheerens C, Pype P, Van Cauwenberg J, Vanbutsele G, Eecloo K, Derom E, et al. Early Integrated Palliative Home Care and Standard Care for End-Stage COPD (EPIC): A Phase II Pilot RCT Testing Feasibility, Acceptability, and Effectiveness. J Pain Symptom Manage. 2020;59(2):206-24 e7. doi 10.1016/j.jpainsymman.2019.09.012.

5. Tilburgs B, Koopmans R, Schers H, Smits C, Vernooij-Dassen M, Perry $M$, et al. Advance care planning with people with dementia: a process evaluation of an educational intervention for general practitioners. BMC Fam Pract. 2020;21(1):199. doi 10.1186/s12875-020-01265-z.

6. Janssens A, Teugels L, Kohl S, Michielsen T, Leysen B, van Meerbeeck JP. Practical tools for implementing early palliative care in advanced lung cancer. Eur Respir J. 2016;47(3):1010-2. doi 10.1183/13993003.00382-2015.

7. Ferrell BR, Temel JS, Temin S, Alesi ER, Balboni TA, Basch EM, et al. Integration of Palliative Care Into Standard Oncology Care: American Society of Clinical Oncology Clinical Practice Guideline Update. J Clin Oncol. 2017;35(1):96-112. doi 10.1200/ JCO.2016.70.1474.

8. Hill L, Prager Geller T, Baruah R, Beattie JM, Boyne J, de Stoutz N, et al. Integration of a palliative approach into heart failure care: a European Society of Cardiology Heart Failure Association position paper. Eur J Heart Fail. 2020;22(12):2327-39. doi 10.1002/ejhf.1994.

9. Canadian Council of Cardiovascular Nursing (CCCN). Advance Care Planning and the Role of the Cardiovascular Nurse Position Statement. 2015.

10. World Health Organization (WHO). Definition Palliative Care World Health Organization; 2002 [Available from: http://www.who.int/cancer/palliative/definition/ en/. Accessed 16.02.2014.

11. Miller H, Tan J, Clayton JM, Meller A, Hermiz O, Zwar N, et al. Patient experiences of nurse-facilitated advance care planning in a general practice setting: a qualitative study. BMC Palliat Care. 2019;18(1):25. doi 10.1186/s12904-019-0411-z.

12. Izumi S, Burt M, Smith J, McCord K, Fromme EK. Enhancing Advance Care Planning Conversations by Nurses in a Bone Marrow Transplantation Unit. Oncol Nurs Forum. 2019;46(3):288-97. doi 10.1188/19.ONF.288-297.

13. Houben CHM, Spruit MA, Luyten H, Pennings HJ, van den Boogaart VEM, Creemers $J$, et al. Cluster-randomised trial of a nurse-led advance care planning session in patients with COPD and their loved ones. Thorax. 2019;74(4):328-36. doi 10.1136/ thoraxjnl-2018-211943.

14. Hilgeman MM, Uphold CR, Collins AN, Davis LL, Olsen DP, Burgio KL, et al. Enabling Advance Directive Completion: Feasibility of a New Nurse-Supported Advance Care Planning Intervention. J Gerontol Nurs. 2018;44(7):31-42. doi 10.3928/0098913420180614-06. 
15. Fliedner MC, Mitchell G, Bueche D, Mettler M, Schols JMGA, Eychmueller S. Development and Use of the 'SENS'-Structure to Proactively Identify Care Needs in Early Palliative Care-An Innovative Approach. Healthcare (Basel). 2019;7(1). doi 10.3390/healthcare7010032.

16. Medical Research Council (MRC). A Framework For Development and Evaluation of RCTs For Complex Interventions to Improve Health. London, UK 2000.

17. Bundesamt für Gesundheit (BAG), Schweizerische Konferenz der kantonalen Gesundheitsdirektorinnen und -direktoren (GDK). Nationale Strategie Palliative Care 2010-2012. Bern: Bundesamt für Gesundheit (BAG), Gesundheitspolitik D, Projekte AM; 2009. http://www.gdk-cds.ch/fileadmin/docs/public/gdk/themen/ strategie_bundkantone/palliativecare/bt_nationale_strategie_palliative_care_20102012_d.pdf.

18. Bundesamt für Gesundheit (BAG), Schweizerische Konferenz der kantonalen Gesundheitsdirektorinnen und -direktoren (GDK), palliative ch. Rahmenkonzept Palliative Care Schweiz. Eine definitorische Grundlage für die Umsetzung der «Nationalen Strategie Palliative Care». Bern2014.

19. Zambrano SC, Fliedner MC, Eychmuller S. The impact of early palliative care on the quality of care during the last days of life: what does the evidence say? Curr Opin Support Palliat Care. 2016;10(4):310-5. doi 10.1097/SPC.0000000000000240.

20. Fliedner M, Zambrano S, Schols JM, Bakitas M, Lohrmann C, Halfens RJ, et al. An early palliative care intervention can be confronting but reassuring: A qualitative study on the experiences of patients with advanced cancer. Palliat Med. 2019;33(7):783-92. doi 10.1177/0269216319847884.

21. Eychmuller S, Zwahlen S, Fliedner MC, Juni P, Aebersold DM, Aujesky D, et al. Single early palliative care intervention added to usual oncology care for patients with advanced cancer: A randomized controlled trial (SENS Trial). Palliat Med. 2021;35(6):1108-17. doi 10.1177/02692163211005340.

22. Fliedner M, Halfens RJG, King CR, Eychmueller S, Lohrmann C, Schols JMGA. Roles and Responsibilities of Nurses in Advance Care Planning in Palliative Care in the Acute Care Setting: A Scoping Review. J Hosp Palliat Nurs. 2021;23(1):59-68. doi $10.1097 / \mathrm{NJH} .0000000000000715$.

23. Fliedner MC, Hagemann M, Eychmuller S, King C, Lohrmann C, Halfens RJG, et al. Does Time for (in)Direct Nursing Care Activities at the End of Life for Patients With or Without Specialized Palliative Care in a University Hospital Differ? A Retrospective Analysis. Am J Hosp Palliat Care. 2020;37(10):844-52. doi 10.1177/1049909120905779.

24. Fliedner M, Willener R. A case study: Concurrent palliative care based on SENSstructure for patients with advanced prostate cancer. Int J Urol Nurs. 2020;14(2):92-5. doi 10.1111/ijun.12232. 
Acknowledgements 


\section{Acknowledgements}

"The truth is, once you learn how to die, you learn how to live." Mitch Albom, Tuesdays with Morrie (2006)

I am very grateful to all the people who supported me during my PhD-journey. Finally - after all these years and many joyful moments and obstacles - I can let go of that longstanding project and focus on further developing nurses' role and high quality of interprofessional palliative care. Countless people supported me throughout this journey but to some I would like to specifically express my deepest gratitude.

\section{At the University of Maastricht, Graz and Bern My PhD supervisors}

First - a big thank you to Jos (the fastest feedback-provider ever), Christa (the clear clinical viewpoint and creative teacher) and Ruud (the experienced researcher) for being so supportive and at times critical with a gentle but distinct push to finalize my PhD.

Steffen (the incredible ideologist and supporter of nursing and nurses) - I could not have a better "brother" than you supporting me during this journey. I learned a lot from you and I appreciate your never-ending creativity and drive to start changing the world to a palliative care mindset.

I appreciate that all promotors supported me in changing the topic from oral mucositis in cancer patients to palliative care - a topic where my heart and my focus of clinical work turned to. Together with my promotors, I also want to thank Suzanne Rijken for her fantastic support in getting my thesis to the assessment committee on time and preparing all papers and documents necessary - without her I would not have been able to get everything finalized.

\section{My PhD fellows}

Barbara, Birgit, Karin, Daniela, Donja, Fitri, Thomas, Gerhild, Silvia, Sandra, Gabriele and many more - I always valued the discussions we had over each of our projects, receiving supportive feedback and also the sharing of challenges 
and pleasures of the PhD journey and personal accomplishments. It was fun to travel with you once in a while or share a room - I will miss that!

\section{Assessment committee members}

My gratitude reaches out to Prof. Dr. S. Zwakhalen, chair of the assessment committee, as well as Dr. J.M.M. Meijers, Prof. Dr. M.H.J. van den Beuken - van Everdingen, Prof. Dr. N.J.A. van den Noortgate and Prof. Dr. P. Larkin for taking the time and effort to critically evaluate the thesis.

\section{At work}

In the hospital Inselspital, I would like to thank (in alphabetical order) Prof. Dr. Daniel Aebersold, Ueli von Allmen, Prof. Dr. Martin Berger, Luzia Herrmann, Prof. Dr. Jonas Marschall and Prof. Dr. Stüber for their supportive attitude and continued interest throughout these years. It is great to know that advanced clinical nursing practice and specifically nursing science can rely on your support. Thank you to Rouven Porz, who conducted some of the interviews in the qualitative study.

My working colleagues in research and clinics: Andy, Andreas, Annette, Barbara, Claudia, Corina, Friederike, Isabelle, Maud, Marina, Martina, Nora, Petra, Sandra, Sibylle, Tania, and many more - thank you for being my critical peer and for so often cheering me up in difficult times. I am also grateful to Anita, Ralph and Kaja for their administrative support.

\section{Co-authors (in alphabetical order)}

Marie Bakitas - thank you for being such an excellent role model for me - from hard core stem cell transplantation to palliative care was the way you took, and throughout the years and several publications we worked on together, I truly learned that work can be combined with fun (remember the baseball game we went to during ONS in Philadelphia?).

Daniel Büche and Mona Mettler - your inspiring collaboration in developing the SENS structure and your never-ending energy to set up the Certificate of Advanced Studies (CAS) for interprofessional Palliative Care Specialists based on the SENS structure is truly an example for younger clinicians to keep up with a dream. 
Monika Hagemann - it is inspiring to work with you on the data article - your ideas and knowledge always impressed me, specifically not being from a healthcare profession, but having an economic background. Having you on the team is a true asset and I am positive that new ideas for future research and projects will be accomplished.

Cyndy King - we have known each other now for more than 3 decades and you just came around the corner on time to support me in this last stretch of the PhD journey. Your professionalism but also friendship and incredible support during this journey is unique. I still can vividly remember the days we spent at your home with Mike and the dogs in North Carolina after the conference in Houston (I recall the severe thunderstorm at the airport) - Bernie and I felt so warmly welcomed!

Geoffrey Mitchell - the start of my palliative care career in Ipswich, after working in palliative care in the team in Utrecht many years ago, was the best I could have done. You gave me the opportunity to look beyond hospital borders and develop an eye for the connection of acute palliative care starting at the GPs office and reaching into the hospital and back - thank you for making this experience unforgettable.

Rita Willener - thank you Rita for your incredible support not only for me but also to many other young nurses who wanted to develop into an academic career - I will never forget our start during the APEF project! You are an asset to the nursing world specifically in Urology Nursing!

Sofia Zambrano - the first time we met over the phone was in Australia and I immediately heard that you are a brilliant scientist, teacher and human being. When you came to work with us in Bern, I knew that you were an asset to the team - thank you ever so much!

\section{My family and friends}

My deepest gratitude goes to my late father Ted and his wife Giko, who always believed that I can do it despite all the hurdles I had to take in my professional life. Dad - I wish you would have been able to celebrate this with me but I know deep down in my heart you are here with me on this special day of the thesis 
defense - thank you for shaping my life as you did and all the conversations and discussions we had throughout my life. I learned that we are all only human beings and as such vulnerable - but also that, if the $24 \mathrm{~h}$ of the day are not enough, then there is still the night to use to get things done - very true during this PhD adventure.

Thank you also to my mother Gisela, who was so brave to move back to her roots in Berlin - I admire your courage to start all over even though it is more difficult than you thought, especially in Corona-times.

My sisters and brother with their families, especially Karen - being my older sister we have gone through rough times but together we were always strong and without "us" I would not be me and not where I am now.

My Dutch family especially Ton, Leo, Miranda (my paranimf), Erna and Ans - a big thank you for being there throughout all these $30+$ years and providing me a home whenever I am there!

My Swiss family with mom, Hanspeter and Lily, Bruno and Dora, Hans and Annemarie, Gero and Anna. Thank you for your curiosity in my work, which inspired me, but also for taking me into your family circle. Thank you also to Marianne and Helena - the time that we now know each other is unbelievable.

Erika (my paranimf) - you are truly my Swiss sister and a night owl - we have a lot in common! Thank you for being there - day and night!

Catherine - our friendship goes back to 1986 when I first came to Basel. After so many years of close friendship - even with 10 years of the Netherlands in between with regular Fasnacht visits in Basel - and being my support, for whatever came along the road of my life, you always encouraged me to continue although at times I did not see an end. I will never forget the journeys we did throughout the years, sharing nature with special animal encounters - I am very very grateful for all you have done!

Bianca - sharing choir music, the love for animals especially dogs and American experiences was the foundation of our friendship - and in the end of the PhD journey, you improved pieces of text when I no longer saw the forest for the trees. 
Monica (the $1^{\text {st }}$ ) in Hamburg - thank you for this special connection in the past years! Stay healthy and I hope I will see you again soon!

And last but definitely not least Bernhard - you are very special to me. Without your support, friendship, never-ending discussions and patience I would not have been able to do this. Our time together is very precious to me and I value every single minute at home and around the world during our trips. You were so patient in giving me the backup I needed to finish this thesis. Discussing the issues I am occupied with, reading through the documents although the topic is not familiar to you, making dinner and forcing me to get out and breath some fresh air was truly helpful. I am looking forward to going traveling soon! Tatonka! 


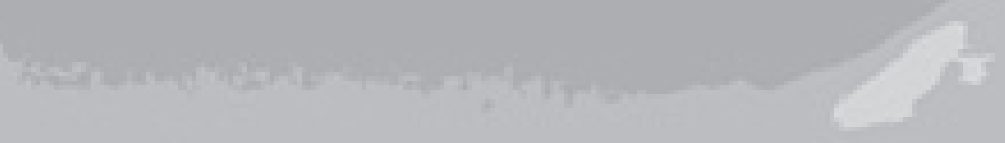

\section{Chas}
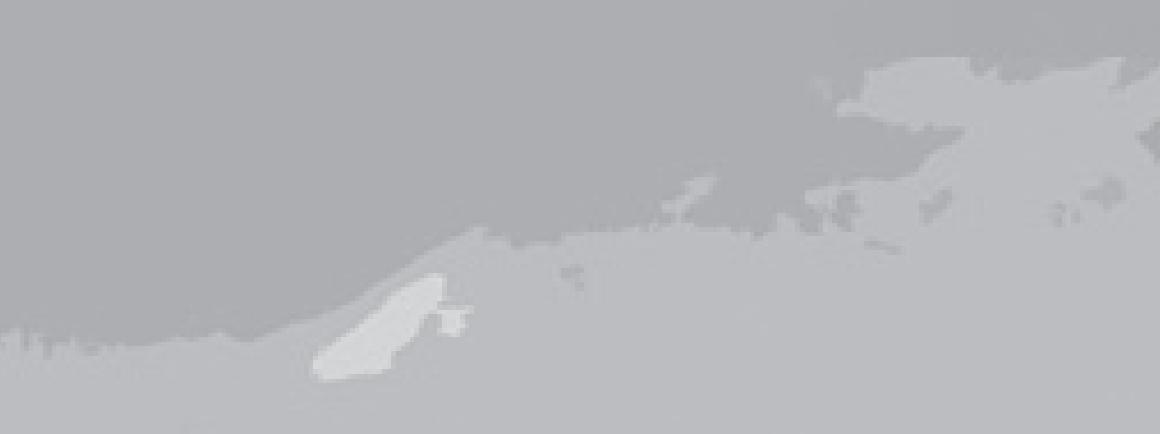

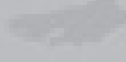

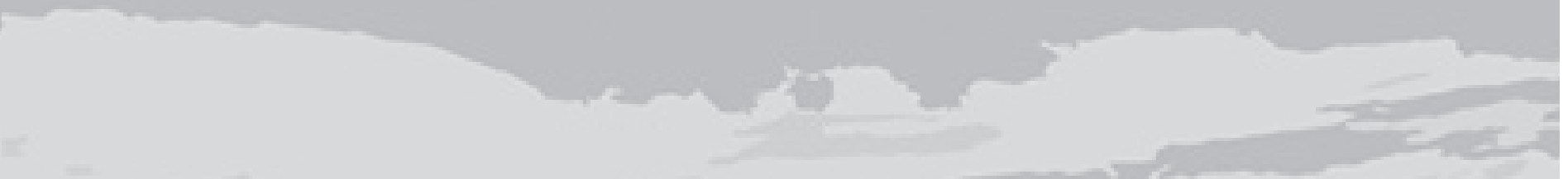

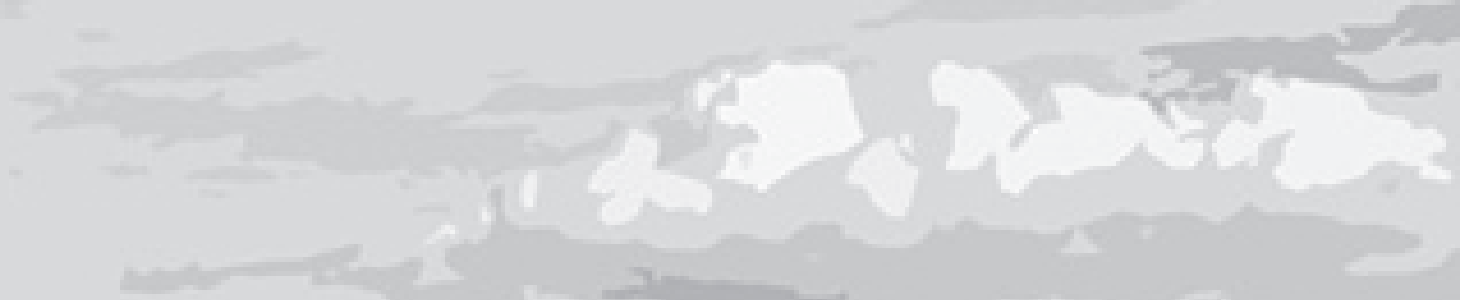

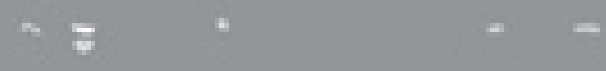

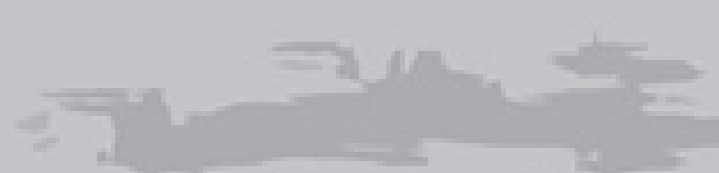

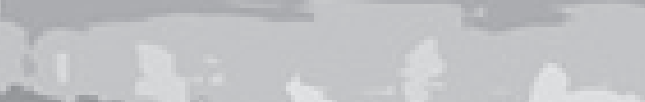

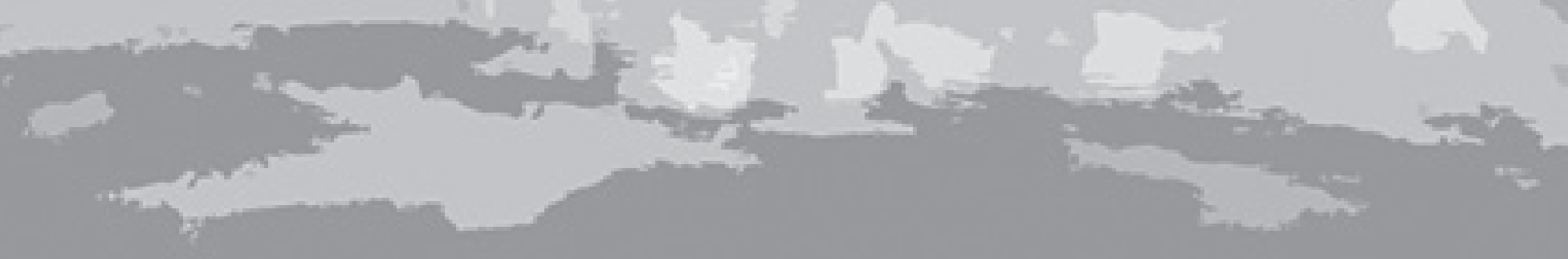


About the author 


\section{About the author}

Monika Caroline Fliedner was born in June 1963, in the USA. After her undergraduate nursing training in Heidelberg (Germany) she started her career as a junior nurse (1986 - 1990) on a general internal medicine unit before she changed to haemato-oncology/stem cell transplantation unit at the University hospital Basel (Switzerland). In 1990 she went to the Netherlands, first to work on the haemato-oncology/stem cell transplantation unit in Leiden for 2 years and then 8 years on the haemato-oncology/stem cell transplantation unit at the University Hospital in Utrecht. There - in the mid 1990s - palliative care was supported by the Dutch ministry for healthcare. Already then she was part of the interprofessional and interdisciplinary palliative care team while working on the haemato-oncology/stem cell transplantation unit. During these years she was initially treasurer and later president of the European Blood and Marrow Transplantation - Nurses Group (EBMT-NG) which enabled her to get insight into nursing care not only within many European countries but also in countries such as USA, Japan, South Korea, Saudi Arabia, Thailand and Australia. In 2014 she received the Distinguished Merrit Award for her services within the EBMTNG.

In 1993 she finished her training as Clinical Nurse Specialist from the Hoge School Midden Nederland and in 1995 she graduated from the University of Cardiff (Wales) with a Masters Degree in Nursing Science with her quantitative study on "Quality of life in patients undergoing allogeneic stem cell transplantation". During these years she worked as Clinical Nurse Specialist being responsible for the quality and developments of nursing in the field of hematology and stem cell transplantation. Her activities in the Dutch National Stem cell Transplant Nurses Group and with the Dutch stem cell transplantation patient organization gave her insight into nursing care from a patient angle.

In 2000 she moved back to Switzerland. First, she worked as research assistant at the Institute for Nursing Science in Basel where she coordinated a study on compliance to oral immunosuppressants in kidney transplantation patients. In December 2002 she started as Clinical Nurse Specialist for Oncology at the University Hospital Bern, Inselspital. When the University Center for Palliative Care was founded in February 2012 she took over the position as codirector together with Prof. Dr. Steffen Eychmüller. Starting in 2005 she also worked part time in the Directorate of Nursing to provide a bond between clinical practice and nursing development. In this part of her work she was responsible 
for organizing the annual symposium on behalf of the Director of Nursing on a changing variety of topics next to being responsible for nursing care guidelines used throughout the hospital.

She started her PhD in 2012 in the European Doctoral Program in Nursing Science, a collaboration between the University of Maastricht, the University of Graz and the Bern University of Applied Sciences. Supervised by Prof. Dr. Jos M.G.A. Schols (Maastricht University), and Dr. Ruud J.G. Halfens (Maastricht University), Prof. Christa Lohrmann (Medical University of Graz) and Prof. Steffen Eychmüller (Bern University) she worked towards her PhD in the field of palliative care. In clinical practice she is mostly involved in conducting consultancies together with a palliative care physician for patients in the hospital. In addition, she is responsible for the quality of (specialized) palliative nursing care throughout the hospital. Next to her clinical duties she is engaged in teaching in the interprofessional training towards a certificate of advanced studies that is led by Prof Eychmüller in collaboration with the palliative care specialists in St.Gallen. Her main focus of academic work was on early integrated palliative care and the role of nurses in this process. A quantitative with a nested qualitative study supported by the Swiss National Fund formed the basis of her doctoral thesis. She presented at numerous national and international conferences, chaired sessions and was part of organizing committees of several national and international interprofessional conferences in the field of nursing in oncology and palliative care. She is reviewer for numerous (inter)professional journals in the field of oncology and palliative care.

Since 2019 she is president of palliative bern, the Bernese section of the Swiss National Society for Palliative Care. In this position she is responsible for local / cantonal developments for lay people as well as professionals and experts in the field. In addition, she is member of the working group of Swiss palliative care nurses which aims at developing a positioning of nurses in palliative care including the national educational training structures.

Next to her clinical and academic work she is president of the Nursing Science Foundation Switzerland which was established in 2005. Prior to taking over the role as president in 2013 she was an active member of the scientific advisory board since its beginning. The Foundation aims to support young researchers to broaden the body of knowledge in excellent nursing practice and to support the implementation of research results into clinical practice. 
Publications 


\section{Publications}

\section{Peer reviewed journals}

- Bryant-Lukosius D, Spichiger E, Martin J, Stoll H, Kellerhals SD, Fliedner M, et al. Framework for Evaluating the Impact of Advanced Practice Nursing Roles. J Nurs Scholarsh. 2016;48(2):201-9. doi 10.1111/jnu.12199.

- Eychmuller S, Zwahlen S, Fliedner MC, Juni P, Aebersold DM, Aujesky D, et al. Single early palliative care intervention added to usual oncology care for patients with advanced cancer: A randomized controlled trial (SENS Trial). Palliat Med. 2021;35(6):1108-17. doi 10.1177/02692163211005340.

- Fliedner M, Halfens RJG, King CR, Eychmueller S, Lohrmann C, Schols JMGA. Roles and Responsibilities of Nurses in Advance Care Planning in Palliative Care in the Acute Care Setting: A Scoping Review. J Hosp Palliat Nurs. 2021;23(1):59-68. doi 10.1097/NJH.0000000000000715.

- Fliedner M, Willener R. A case study: Concurrent palliative care based on SENS $\square$ structure for patients with advanced prostate cancer. International Journal of Urological Nursing. 2020;14(2):92-5. doi 10.1111/ijun.12232.

- Fliedner M, Zambrano S, Lohrmann C, Schols J, Halfens R, Eychmueller S. Cancer patients' experiences with an early palliative care conversation: A qualitative study of an intervention based on the SENS-structure. Support Care Cancer 2018;26(Supplement 2):S63. doi

- Fliedner M, Zambrano S, Schols JM, Bakitas M, Lohrmann C, Halfens RJ, et al. An early palliative care intervention can be confronting but reassuring: A qualitative study on the experiences of patients with advanced cancer. Palliat Med. 2019;33(7):783-92. doi 10.1177/0269216319847884.

- Fliedner MC, Hagemann M, Eychmuller S, King C, Lohrmann C, Halfens RJG, et al. Does Time for (in)Direct Nursing Care Activities at the End of Life for Patients With or Without Specialized Palliative Care in a University Hospital Differ? A Retrospective Analysis. Am J Hosp Palliat Care. 2020;37(10):844-52. doi 10.1177/1049909120905779.

- Fliedner MC, Mitchell G, Bueche D, Mettler M, Schols JMGA, Eychmueller S. Development and use of the 'SENS'-structure to proactively identify care needs in early palliative care - an innovative approach. Healthcare. 2019;7(32):1-12. doi 10.3390/healthcare7010032. 
- Fliedner MC, Zambrano SC, Eychmueller S. Public perception of palliative care: a survey of the general population. Palliat Care Soc Pract. 2021;15:1-11. doi 10.1177/26323524211017546.

- Kobleder A, Raphaelis S, Glaus A, Fliedner M, Mueller MD, Gafner D, et al. Recommendations for symptom management in women with vulvar neoplasms after surgical treatment: An evidence-based guideline. Eur J Oncol Nurs. 2016;25:68-76. doi 10.1016/j.ejon.2016.10.003.

- Zambrano SC, Fliedner MC, Eychmuller S. The impact of early palliative care on the quality of care during the last days of life: what does the evidence say? Curr Opin Support Palliat Care. 2016;10(4):310-5. doi 10.1097/ SPC.0000000000000240

\section{Non-peer reviewed journals}

- Eychmueller S, Zwahlen D, Fliedner M. The oncological patient in the palliative situation. Recent Results Cancer Res. 2014;197:59-72. doi 10.1007/978-3-64240187-9_5.

- Eychmueller S, Zwahlen D, Fliedner M. The Oncological Patient in the Palliative Situation. Recent Results Cancer Res. 2018;210:67-85. doi 10.1007/978-3-31964310-6_5.

- Fitch MI, Fliedner MC, O'Connor M. Nursing perspectives on palliative care 2015. Ann Palliat Med. 2015;4(3):150-5. doi 10.3978/j.issn.22245820.2015.07.04.

- Fliedner MC, Eychmueller S. Ansprüche an die interprofessionelle Zusammenarbeit - Die anderen und ich. Der Onkologe. 2016;22:631-7. doi 10.1007/s00761-016-0070-0.

\section{National and international conferences}

- Eychmueller S, Fliedner M. "SENS" framework to structure Advance Care Planning - strengthening patient professionals partnership. ACPEL; München 2015.

- Eychmüller S, Zwahlen S, Fliedner M, Trelle S, Maessen M, Aebersold D, et al., editors. A Structured Early Palliative Care Intervention for Patients with Advanced Cancer - A Randomized Controlled Trial EAPC; 2018; Bern

- Fliedner M. The SENS-structure in clinical practice - an alternative to nursing diagnosis? DESO; St.Gallen 2013. 
- Fliedner M. Die frühzeitige Einbindung von Palliative Care in den Patientenpfad macht Sinn - Was meint die Pflegeexpertin? 4 Symposium Palliativmedizin im Netzwerk der von der Deutschen Krebshilfe geförderten Comprehensive Cancer Center; Hamburg 2017.

- Fliedner M. Frühzeitiger Einbezug der Palliative Care bei PatientInnen mit Krebs - verleiht das Sicherheit oder erzeugt es Angst? Internationales Seminar "Onkologische Pflege - Fortgeschrittene Praxis“; St.Gallen 2017.

- Fliedner M, Palliative care challenges for urological patients at the end of life. 19th International Meeting of the European Association of Urology Nurses (EAUN); 2018; Copenhagen.

- Fliedner M. Entscheidungen für das Lebensende. Bevölkerungsakademie; Bern, Biel: Palliative bern; 2018.

- Fliedner M, Eychmueller S. Recruitment of cancer patients into clinical trials on Advance Care Planning in Palliative Care - why is it so hard? ACPEL; München 2015.

- Fliedner M, Eychmueller S, Zambrano S, editors. How do people's expectations for their own end of life connect with their perceptions of palliative care? Learning opportunities for the promotion of early palliative care. EAPC; 2018; Bern.

- Fliedner M, Eychmüller S, Lohrmann C, Schols JMGA, Halfens RJG. Inclusion of patients into clinical trials in Palliative Care - barriers and facilitating factors for successful recruitment/retention. EDCNS; Maastricht 2014.

- Fliedner M, Zambrano S, Lohrmann C, Schols J, Halfens R, Eychmueller $S$, editors. Cancer patients' experiences with an early palliative care conversation: A qualitative study of an intervention based on the SENSstructure MASCC/ISOO Annual Meeting; 2018; Vienna.

- Fliedner MC, Eychmüller S, Zambrano S, Lohrmann C, Schols JMGA, Halfens RJG, editors. How do cancer patients experience a structured early palliative care intervention? A qualitative study. EAPC; 2017; Madrid.

- Willener R, Fliedner M. The SENS ${ }^{\odot}$ structure for assessment and management of uro oncological patients with severe acute symptoms who wish to die at home. Congress of the European Association of Urology Nurses; Barcelona 2019.

- Zwahlen S, Fliedner M, Eychmüller S. Overcoming Recruitment Challenges in a Randomized Clinical Trial of Early Palliative Care. 10th World Research Congress of the European Association for Palliative Care; Bern 2018. 


